\author{
Universidade de São Paulo \\ Escola de Engenharia de São Carlos \\ Departamento de Engenharia de Produção
}

Teresinha das Graças Coletta

\title{
Conhecimento de acesso livre na Internet para apoiar a inovação e o desenvolvimento de produtos: critérios de análise e sua aplicação
}

São Carlos

2007 


\section{Teresinha das Graças Coletta}

\section{Conhecimento de acesso livre na Internet para apoiar a inovação e o desenvolvimento de produtos: critérios de análise e sua aplicação}

Dissertação apresentada à Escola de Engenharia de São Carlos, da Universidade de São Paulo, para obtenção do título de mestre em Engenharia de Produção.

Área de concentração: Processos e gestão de operações Orientador: Prof. Dr. Henrique Rozenfeld

São Carlos 
AUTORIZO A REPRODUÇÃO E DIVULGAÇÃO TOTAL OU PARCIAL DESTE TRABALHO, POR QUALQUER MEIO CONVENCIONAL OU ELETRÔNICO, PARA FINS DE ESTUDO E PESQUISA, DESDE QUE CITADA A FONTE.

Ficha catalográfica preparada pela Seção de Tratamento da Informação do Serviço de Biblioteca - EESC/ USP

Coletta, Teresinha das Graças
Conhecimento de acesso livre na Internet para apoiar a
inovação e o desenvolvimento de produtos: critérios de
análise e sua aplicação / Teresinha das Graças Coletta ;
orientador Henrique Rozenfeld. -- São Carlos, 2007.
Dissertação (Mestrado-Programa de Pós-Graduação em
Engenharia de Produção e Área de Concentração em Processo
e Gestão de Operaços) -- Escola de Engenharia de São
Carlos da Universidade de São Paulo, 2007.
1. Conhecimento on-line. 2. Conhecimento de acesso
livre. 3. Portais web - avaliação. 4. Desenvolvimento de
produto. 5. Inovação. I. Título.


Ao meu pai Miguel (in memorian) pela oportunidade da vida.

À minha mãe Helia, que sempre sonhou com uma vida melhor a partir do conhecimento e nunca mediu esforços para prover os filhos dos recursos necessários para que conseguissem estudar... seu grande sonho abdicado... 


\section{Agradecimentos}

À Diretoria da Escola de Engenharia de São Carlos - USP pelo apoio e incentivo na realização do mestrado.

Ao professor Hernique Rozenfeld por acreditar no meu trabalho.

Aos funcionários da Biblioteca que se mantiveram firmes no trabalho e me deram tranqüilidade e apoio para realizar cada etapa dessa jornada. Eu tinha certeza que podia contar com vocês!

Aos professores do Departamento por propiciarem um aprendizado de excelência.

À Sayuri pela efetiva colaboração e em nome de quem agradeço toda equipe do NUMA pela atenção e respeito que sempre demonstraram.

Aos colegas de Departamento que, em nome do Charbel e da Simone Branício, agradeço o companheirismo.

Ao Zé Luiz, secretário do Programa de Pós em Engenharia de Produção.

À Isabel Santoro e Leila Lenk, mulheres, mães, profissionais... obrigada pelos ensinamentos e pelo carinho.

Aos meus amigos Ana Rita, Fernando, Grazieli, Hai, Eli, Helô, João, Marco, Paula, Rachel, Roseli, Sérgia, Sérgio, Tomaz ... É um risco nominá-los... alguém muito querido pode ficar fora da lista... por favor, sinta-se incluído.

Ao meu irmão Angelo Miguel, meus sobrinhos Emily, Hugo Junior, Katleen e as minhas sobrinhas-neta Julia e Rafaela por compreenderem a minha ausência em muitos momentos.

À Deus, que me ilumina e me dá sabedoria para ser feliz nessa vida.

Muito obrigada! 
Eu queria ter menos consciência da quantidade de conhecimento disponível...

$\mathrm{Eu}$ queria ter menos conhecimento de estratégias de busca...

Eu queria ter menos pontos de acesso aos recursos de informação...

Eu queria ter menos certeza de que o conhecimento aqui expresso não seria insuficiente por alguns instantes...

Teresinha, 2007 
COLETTA, T. G. (2007). Conhecimento de acesso livre na Internet para apoiar a inovação e o desenvolvimento de produtos: critérios de análise e sua aplicação. 161f. Dissertação (mestrado) - Escola de Engenharia de Sao Carlos, Universidade de São Paulo, São Carlos, 2007.

Definição de critérios de análise de sites e avaliação da disponibilidade de conhecimento de acesso livre como ferramenta de apoio à inovação e ao desenvolvimento de produto. O conhecimento encontra-se, entre outras formas, disponível em páginas web. Para a criação compartilhada de conhecimento de qualidade e de acesso livre, que atendam aos interesses específicos de pessoas e organizações, assim como sua recuperação, são fundamentais os recursos de Internet. Esse contexto justifica a definição de critérios de análise de sites para identificação da disponibilidade desses recursos. O objetivo desse trabalho é a identificacão e avaliação de sites na Internet, com características de compartilhamento, divulgação e produção de conhecimento de acesso livre, para apoiar a inovação e desenvolvimento de produto. Para atingir o objetivo, inicialmente sistematiza o conhecimento por meio de pesquisa exploratória e procedimentos de pesquisa bibliográfica e documental. Fundamentando-se nas pesquisas, lista portais que possam contemplar o objetivo. Define critérios para análise desses sites com base nas dimensões conteúdo, usabilidade e funcionalidade. Analisa, então, cada uma das dimensões por meio de características e atributos que geram indicadores parciais e um indicador geral por site e permite a análise comparativa entre eles. Dos vinte portais analisados; nenhum contempla todos os atributos; a dimensão conteúdo recebe a melhor pontuação enquanto a dimensão funcionalidade apresenta o desempenho mais negativo; os atributos menos contemplados são acessibilidade, criptografia e controle de versões. Com base nos resultados obtidos, conclui que existe uma disponibilidade limitada de conhecimento de acesso livre sobre inovação e desenvolvimento de produto; aponta a existência de comunidades de prática que propiciam o compartilhamento de conhecimento; e evidencia as razões pelas quais existem falhas na recuperação do conhecimento disponível on-line. Tais razões podem fornecer orientação aos interessados no assunto sobre onde é possível, necessário ou recomendável consultar. Também fornece subsídos para orientação aos provedores interessados na melhoria dos portais existentes ou na criação de novos.

Palavras-chave: Conhecimento on-line. Conhecimento de acesso livre. Portais web avaliação. Portais web - critérios de análise. Desenvolvimento de produto. Inovação. 
COLETTA, T. G. (2007). Knowledge of free access avaliable in Internet to support the innovation and product development: criteria for analysis and its application. 161f. Dissertação (mestrado) - Escola de Engenharia de São Carlos, Universidade de São Paulo, São Carlos, 2007.

Definition of criteria for site analysis and evaluation of the availability of knowledge of free access as a support tool to innovation and product development. The knowledge is found, among another feature, available in web pages. For the shared creation of good quality and free access knowledge, that will supply specific interests of people and organizations, as its recovering, the websites are fundamental resources. This context justifies the definition of the analysis requirements of web sites for the identification of availability of these resources. The purpose of this researche is the identification and evaluation of websites which presents characteristics such as sharing, spreading and producing free knowledge access, to support the innovation and development of the product. To reach the goal, it initially organizes the knowledge through the explorative research and bibliographic and documental research procedures. Based on the researches, it catalogues websites that contemplate the area innovation and product development with the mentioned characteristics. It defines the analysis requirements of these websites based on the content, usability and functionality dimensions. Then it analyzes each one of the dimensions through characteristics and attributes that produce partial indicators and a general indicator per website, and makes possible the comparative analysis among them. From the twenty websites that were analyzed, none contemplates every attribute; the content dimension receives the best punctuation while the functionality dimension shows the worst performance; the less contemplated attributes are accessibility, cryptography and version control. Based on the gotten results, concludes that there is a limited availability of free access knowledge about innovation and product development; points the existence of practice communities that propitiate in the best way the sharing of knowledge; and evidences the reasons why there are imperfections in the recovering of the knowledge available on line. These reasons could provide help to orientate the suppliers to improve the existent websites and the creation of new ones.

Keywords: Online knowledge. Free knowledge access. Websites - evaluation. Websites criteria for analysis. Product development. Innovation. 


\section{LISTA DE FIGURAS}

Figura 1 - Processo de inovação em uma organização

Figura 2 - Visão geral do modelo de referência para PDP

Figura 3 - Gráfico da dimensão conteúdo - característica propósito

Figura 4 - Gráfico da dimensão conteúdo - característica abrangência / cobertura

Figura 5- Gráfico da dimensão conteúdo - característica padrão de publicação

Figura 6 - Gráfico da dimensão conteúdo - característica atualidade

Figura 7 - Gráfico da dimensão conteúdo - característica correção

Figura 8 - Gráfico da dimensão conteúdo - característica autoridade / copirraite 75

Figura 9 - Gráfico da dimensão conteúdo - objetividade

Figura 10 - Gráfico da dimensão conteúdo - regras de publicação e acesso

Figura 11 - Gráfico da dimensão usabilidade - característica inteligibilidade

Figura 12 - Gráfico da dimensão usabilidade - característica apreensibilidade

Figura 13 - Gráfico da dimensão usabilidade - característica operacionalidade

Figura 14 - Gráfico da dimensão funcionalidade - característica adequação

Figura 15 - Gráfico da dimensão funcionalidade - característica acurácia

Figura 16 - Gráfico da dimensão funcionalidade - característica interoperabilidade ..... 88

Figura 17 - Gráfico da dimensão funcionalidade - característica conformidade $\quad \ldots . . . . \quad 89$

Figura 18 - Gráfico da dimensão funcionalidade - característica segurança de acesso .. 90

Figura 19 - Dimensões conteúdo, usabilidade e funcionalidade para todos os portais ... 92

Figura 20 - Indicador geral de cada portal 


\section{LISTA DE QUADROS}

Quadro 1 - Exemplos de falhas na recuperação de informação $\quad$................................ 30

Quadro 2 - Resumo dos métodos, classificações e instrumentos selecionados $\quad$ _...... $\quad 50$

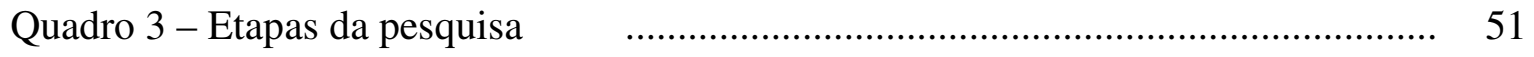

Quadro 4 - Tipos de conteúdo contemplados nos sites $\quad$.......................................... 62

Quadro 5 - Disponibilidade de tipos de conteúdo $\quad$..................................................... 65

Quadro 6 - Assuntos de interesse e pontuação $\quad$....................................................... 66

Quadro 7 - Mecanismos de busca $\quad$.................................................................... 66

Quadro 8 - Pontuação obtida pelos sites na dimensão conteúdo $\quad$ _............................... 68

Quadro 9 - Pontuação obtida pelos sites na dimensão usabilidade ............................... 78

Quadro 10 - Pontuação obtida pelos sites na dimensão funcionalidade $\quad$.................... 84

Quadro 11 - Média de cada dimensão e indicador geral de site $\quad$................................. 91 


\section{LISTA DE SIGLAS}

ABDI - Agência Brasileira de Desenvolvimento Industrial

ACRL - Association of College \& Research Libraries

CIS - Community Innovation Survey (Comunidade Européia de Pesquisa em Inovação)

$\mathrm{CNPq}$ - Conselho Nacional de Desenvolvimento Científico e Tecnológico

CoP - Comunidade de Prática

COPPE - Coordenação dos Programas de Pós-graduação de Engenharia, da UFRJ

CRIE - Centro de Referência em Inteligência Empresarial

FAPESP - Fundação de Amparo à Pesquisa no Estado de São Paulo

FINEP - Financiadora e Estudos e Projetos

FNQ - Fundação Nacional da Qualidade

FSF - Free Software Foundation

FTP - File Transfer Protocol

GEI2 - Grupo de Engenharia Integrada e Engenharia de Integração

GNU-GPL - General Public Licence

IBGE - Instituto Brasileiro de Geografia e Estatística

IBICT - Instituto Brasileiro de Informação em Ciência e Tecnologia

IFLA - The International Federation of Library Associations and Institutions

IFM - Instituto Fábrica do Milênio

INOVA - Agência de Inovação da Unicamp

INPI - Instituto Nacional de Propriedade Intelectual

ISO - International Organization for Standardization

MCT - Ministério da Ciência e Tecnologia

MDIC - Ministério do Desenvolvimento, Indústria e Comércio Exterior

MIT - Massachusetts Institute of Technology

MSL - Movimento do Software Livre

MSN - Microsoft Service Network

NUMA - Núcleo de Manufatura Avançada

OECD - Organization for Economic Co-operation and Development

ONU - Organização da Nações Unidas

OPHI - The Open Process Handbook Initiative

OSI - Open Source Initiative 
PBD - Programa Brasileiro do Design

PDP - Processo de Desenvolvimento de Produto

PDPNet - Product Development Process Network

PITCE - Política Industrial, Tecnológica e de Comércio Exterior

ProBE - Programa Biblioteca Eletrônica

PSGD - Programa SENAI de Gestão da Inovação e do Design

RNP - Rede Nacional de Pesquisa

SBPC - Sociedade Brasileira para o Progresso da Ciência

SBRT - Serviço Brasileiro de Respostas Técnicas

SCIENTi - Rede Internacional de Fontes de Informação e Conhecimento para a Gestão de Ciência, Tecnologia e Inovação

SEBRAE - Serviço Brasileiro de Apoio às Micro e Pequenas Empresas

SENAI - Serviço Nacional de Aprendizagem Industrial

UFRJ - Universidade Federal do Rio de Janeiro

USP - Universidade de São Paulo 


\section{SUMÁRIO}

1 INTRODUÇÃO

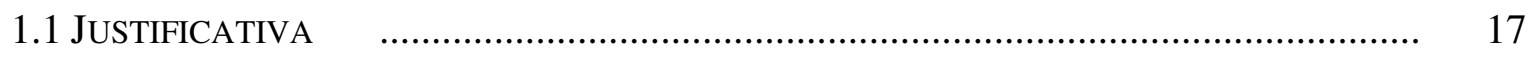

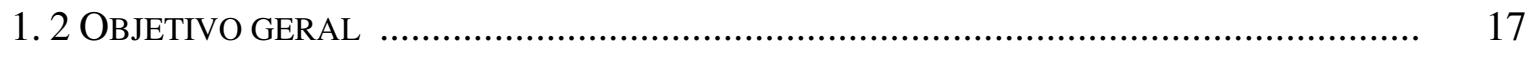

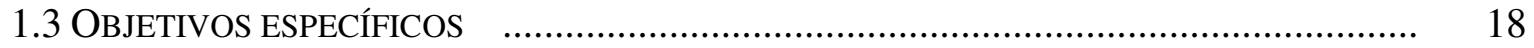

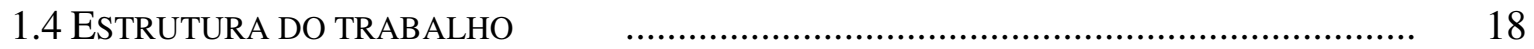

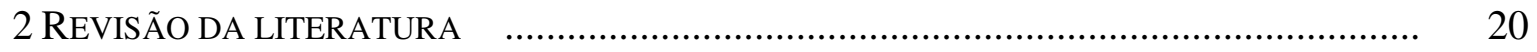

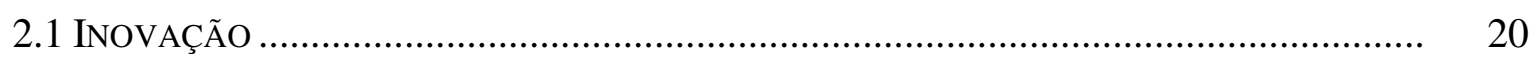

2.1.1 DEFINIÇÕES E ALGUMAS CONSIDERAÇÕES ....................................................... 20

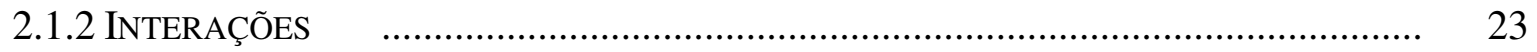

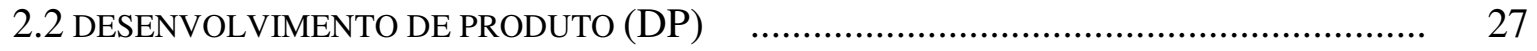

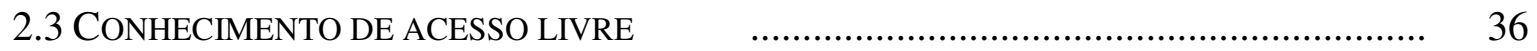

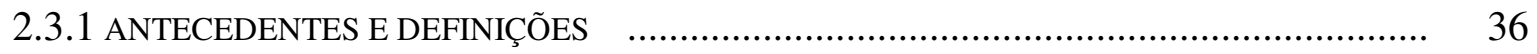

2.3.2 COMUNIDADES DE PRÁTICA .......................................................................... 43

2.3.3 CONHECIMENTO DE ACESSO LIVRE SOBRE INOVAÇÃO E DESENVOLVIMENTO DE

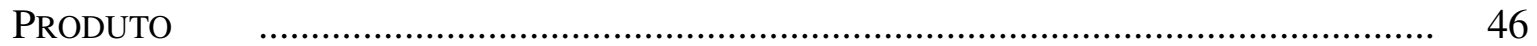

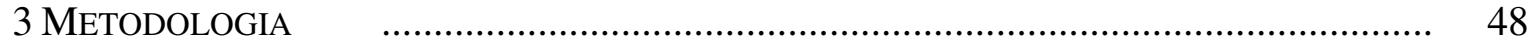

3.1 ABORDAGEM METODOLÓGICA

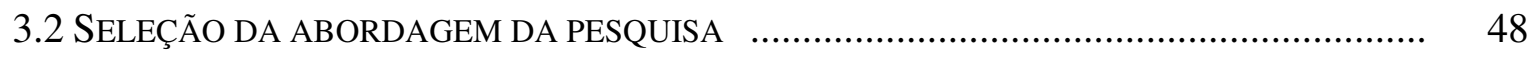

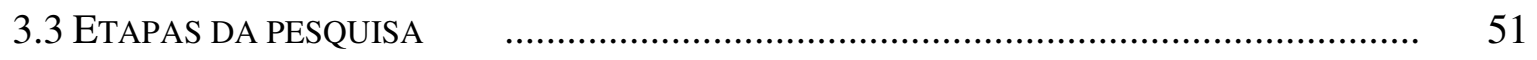

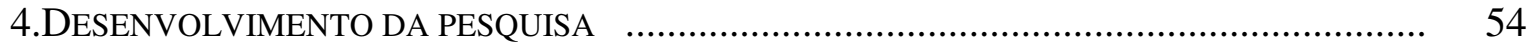

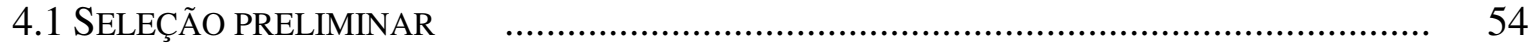

4.2 CRITÉRIOS DE AVALIAÇÃO DE SITES $\quad$.......................................................... 55

4.3 ANÁLISE DETALHADA DOS SITES E SELEÇÃO DA AMOSTRA $\quad$............................ 61

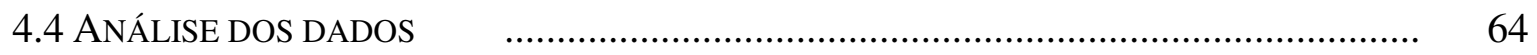

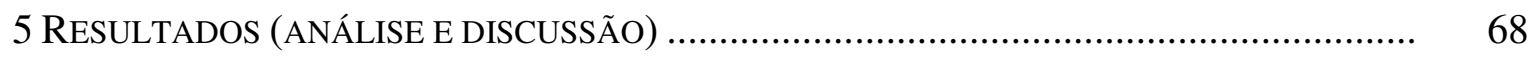

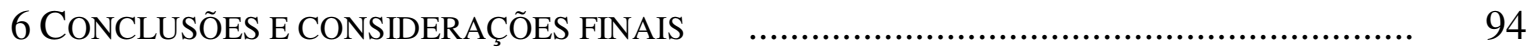

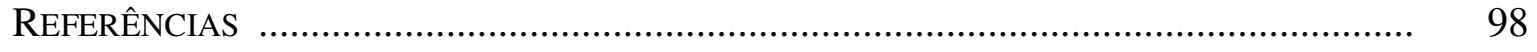

APÊNDICE A - INICIATIVAS GENÉRICAS $\quad$....................................................... 105

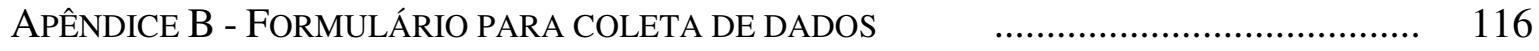


APÊNDICE C -LISTA DOS SITES QUE CONSTITUEM A AMOSTRA $\quad$............................... 118

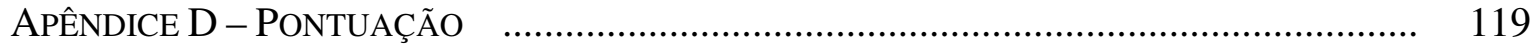

APÊNCIDE E - AMOSTRA - FORMULÁRIO DE ANÁLISE COM A PONTUAÇÃO DE CADA SITE 121 


\section{Introdução}

Essa pesquisa contempla o estudo do conhecimento de acesso livre sobre inovação e desenvolvimento de produto (DP), disponível na Internet. Nesse contexto, busca evidenciar o acesso, a criação, o compartilhamento, a sistematização e a recuperação de conhecimento, inclusive a participação e o fomento à criação de comunidades de prática.

Ressaltam-se o trabalho colaborativo e o acesso irrestrito ao conhecimento como dois fatores de relevância para a inovação e o desenvolvimento de produto e, portanto, dois alicerces de motivação dessa pesquisa. Dentre os trabalhos relevantes em função da forma de abordagem dos temas, dois são de Benkler (2002; 2006), que tratam respectivamente do desenvolvimento colaborativo de software livre (em especial o caso do Linux) e da riqueza das redes. Benkler (2002) aborda um novo modelo econômico contrário ao comportamento vigente, onde milhares de pessoas trabalham de forma colaborativa e compartilham conhecimento. Com base na experiência de software livre, o autor extrapola para outros campos do saber a possibilidade de produção de conhecimento em ambiente digital, pouco hierárquico, baseado em confiança. E ao reforçar a importância da informação como instrumento de autonomia, Benkler (2006) ressalta que a produção coletiva da informação através da comunicação on-line fortalece as relações sociais e possibilita que cada um seja um produtor daquilo que quer e precisa.

A oportunidade de acesso livre (ágil, fácil e gratuito) ao conhecimento por diferentes profissionais e para as mais diversas necessidades é o outro alicerce de motivação dessa pesquisa. Das áreas organizacionais, passando pela tecnologia da informação até a gestão de negócios, todas as pessoas podem, de forma colaborativa e gratuita, organizar, acessar e compartilhar o conhecimento em escala mundial (MALONE et al., (Ed.), 2003).

A globalização, por sua vez, provocou crises quanto ao acesso à informação aos novos mercados. Também mostrou que o conhecimento tem papel preponderante no crescimento econômico e na inovação, razões que fazem das interações inter e entre organizações fundamentais para o compartilhamento de conhecimento (MANUAL..., 2006).

Mais recentemente Tapscott e Williams (2007) tratam do poder da colaboração em massa como fator de mudança nos negócios e denominam de wikinomics essa nova arte e ciência da colaboração. Enfatizam que, definitivamente, isso rompe uma etapa e cria uma nova 
forma de colaboração e oportunidade de criação de conhecimento. Para tanto argumentam que

Para inovar e ter êxito, a nova colaboração em massa precisa se tornar parte do roteiro e do léxico de todos os líderes. Aprender como interagir e criar em conjunto com um grupo mutante de parceiros auto-organizados está se tornando uma habilidade essencial, tão importante como a elaboração de orçamentos, $\mathrm{P} \& \mathrm{D}$ e planejamento (p.31).

No Brasil existem iniciativas como, por exemplo, o Grupo de Engenharia Integrada e de Engenharia de Integração (GEI2) ${ }^{1}$, que ao longo de dez anos de atuação tem desenvolvido vários trabalhos de pesquisa que buscam sistematizar o conhecimento acumulado para servir de apoio e referencial para os interessados na inovação e no desenvolvimento de produto nas organizações. Dentre os trabalhos, destacam-se para efeito dessa pesquisa, a criação e implementação de uma comunidade de prática denominada PDPNet (SANTA EULÁLIA, 2003); a criação de um modelo de referência para o processo de desenvolvimento de produto - PDP (ROZENFELD et al., 2006); e a implementação do Portal de Conhecimentos (http://www.portaldeconhecimentos.org.br).

O contexto apresentado gera algumas questões que embasam a delimitação dessa pesquisa:

1. Qual o quadro atual de ambientes de compartilhamento, divulgação e produção de conhecimento na Internet, especialmente no Brasil, voltados para as áreas de interesse da inovação e do desenvolvimento de produto?

2. Como analisar esses ambientes para verificar se atendem total ou parcialmente as áreas de interesse e os requisitos de compartilhamento, divulgação e produção de conhecimento?

3. A forma como os sites estão estruturados facilita a rápida identificação e recuperação do conhecimento?

4. O acesso ao conhecimento nesses ambientes é livre ou restrito?

\footnotetext{
${ }^{1}$ GEI2 - Grupo de Engenharia Integrada e Engenharia de Integração (http://www.numa.org.br/ei) do Núcleo de Manufatura Avançada - Numa (http://www.numa.org.br), da Escola de Engenharia de São Carlos - USP (http://www.eesc.usp.br). O NUMA é uma das instituições parceiras do Instituto Fábrica do Milênio - IFM (http://www.ifm.org.br).
} 


\subsection{Justificativa}

A literatura ressalta a dificuldade de identificação e recuperação de informação sobre conteúdos de qualidade, disponíveis para uso, publicados em diferentes formatos e suportes, e nos dias atuais, especialmente no formato on-line. Isso se dá, entre outras razões, em função do crescimento da quantidade de informação eletrônica; da falta de estruturação dos sites e da inabilidade dos usuários na definição de estratégias de buscas e identificação da informação relevante (BAEZA-YATTES; RIBEIRO NETTO, 1999; FEITOSA, 2006; GOMES, 2006).

Em trabalho desenvolvido por Lopes (2002) sobre estratégia de busca na recuperação da informação, com base em resultados obtidos por outros estudos nas décadas de 70, 80 e 90, é reforçado o problema da dificuldade dos usuários nesse processo. Alerta ainda que as tecnologias disponíveis não a solucionam, embora a maioria dos estudos analisados trate das técnicas sem mencionar as linguagens de recuperação e a estrutura de informação nas bases de dados.

Nessa linha de pensamento Breitman (2005), que define a Internet atual como web sintática, ressalta que a recuperação da informação depende da interpretação das pessoas, o que dificulta o processo de avaliar, classificar e selecionar a informação de interesse. Mas acredita que a web semântica pode beneficiar a criação de representações do conhecimento para facilitar o compartilhamento mediante o uso de linguagem comum entre pessoas e computadores.

Esses problemas também são verificados quando se trata da recuperação da informação na web por engenheiros que trabalham com desenvolvimento de produto. Nesse caso a qualidade e quantidade de conteúdo, associadas à forma de estruturação dos sites foram percebidas como responsáveis pelas falhas ocorridas (KRAAJENBRINK, 2007).

Considerando a relevância do conhecimento para apoiar a inovação e o desenvolvimento de produto, especialmente quanto ao acesso de forma simples, didática, organizada, motivadora, intuitiva e a partir do próprio local de trabalho e acreditando que isso pode ser melhorado com a prática do compartilhamento, justifica-se a elaboração dessa pesquisa.

Mediante análise do contexto e da justificativa, são apresentados a seguir o objetivo geral e os objetivos específicos do trabalho. 


\subsection{Objetivo geral}

Identificar e avaliar sites na Internet, com características de compartilhamento, divulgação e produção de conhecimento de acesso livre, que se propõem a apoiar a inovação e desenvolvimento de produto.

\subsection{Objetivos específicos}

1. Selecionar uma amostra de sites que contemplem as áreas de inovação e desenvolvimento de produto e que tenham características de compartilhamento, divulgação e produção de conhecimento;

2. Definir critérios de análise desses sites, considerando as características indicadas e os benefícios para as pessoas e organizações interessadas no assunto;

3. Avaliar os sites com base nesses critérios para identificar quais melhor contemplam o compartilhamento, a divulgação e a produção de conhecimento de acesso livre em inovação e desenvolvimento de produto.

\subsection{Estrutura do trabalho}

O trabalho está estruturado em capítulos onde se destacam em cada um deles, os pontos relevantes do tema tratado.

No capítulo 1 é apresentado o contexto em que a pesquisa se desenvolve, a justificativa para o estudo, o objetivo geral e os objetivos específicos. O Capítulo 2 traz uma revisão da literatura, nacional e internacional, dividida em tópicos para facilitar o entendimento: inovação (definições e algumas considerações); desenvolvimento de produto (considerações gerais, o processo de desenvolvimento de produto - PDP, modelo de referência e aprendizado para o PDP); conhecimento de acesso livre (antecedentes e definições, comunidades de prática e uma breve apresentação sobre conhecimento de acesso livre sobre inovação e desenvolvimento de produto).

A metodologia é apresentada no Capítulo 3, onde é feita uma apresentação sobre a abordagem metodológica e a seleção da abordagem adotada bem como a descrição das etapas da pesquisa. Segue-se para o desenvolvimento da pesquisa descrito no Capítulo 4 onde é apresentada a forma de seleção preliminar dos sites e a definição de critérios de 
avaliação. É definido também o formulário para a coleta de dados e a atribuição de notas e pesos dos critérios.

No Capítulo 5 são apresentados os resultados, seguidos de análise e discussão, apoiados por quadros e gráficos para facilitar a visualização dos dados que levam às conclusões e às considerações finais no Capítulo 6.

Para finalizar, são apresentadas as referências que dão suporte teórico e os apêndices que complementam o trabalho. 


\section{Revisão da literatura}

\subsection{Inovação}

Com o "objetivo de orientar e padronizar conceitos, metodologias e construção de estatísticas e indicadores de pesquisa em P\&D de países industrializados", a terceira edição do Manual de Oslo (MANUAL..., 2006, p.9) é a base das definições desse trabalho. A sua adoção se dá em virtude da Agência Brasileira de Inovação utilizá-lo para o prêmio da Financiadora e Estudos e Projetos - FINEP de Inovação, além de ser referência para a Comunidade Européia de Pesquisa (survey) em Inovação (CIS - Community Innovation Survey).

\subsubsection{Definições e algumas considerações}

\section{- Inovação}

É a implementação de um produto (bem ou serviço) novo ou significativamente melhorado, ou um processo, ou um novo método de marketing, ou um novo método organizacional nas práticas de negócios, na organização do local de trabalho ou nas relações externas (p.56).

As atividades de inovação são constituídas de "etapas científicas, tecnológicas, organizacionais, financeiras e comerciais que conduzem, ou visam conduzir, à implementação de inovações" (p.56). Tanto a inovação de produtos e processos quanto o esforço de $\mathrm{P} \& \mathrm{D}$ representam um grande desafio aos dirigentes, pois estão diretamente relacionados à competitividade das empresas (VASCONCELOS; MILAGRES; NASCIMENTO, 2005).

\section{- Inovação de produto}

É a introdução de um bem ou serviço novo ou significativamente melhorado no que concerne a suas características ou usos previstos. Incluem-se melhoramentos significativos em especificações técnicas, componentes e materiais, softwares incorporados, facilidade de uso ou outras características funcionais. (p.57).

\section{- Inovação de processo}

É a implementação de um método de produção ou distribuição novo ou significativamente melhorado. Incluem-se mudanças significativas em técnicas, equipamentos e/ou softwares. (p.58). 


\section{- Inovação de marketing}

É a implementação de um novo método de marketing com mudanças significativas na concepção do produto ou em sua embalagem, no posicionamento do produto, em sua promoção ou na fixação de preços. (p.59).

\section{- Inovação organizacional}

É a implementação de um novo método organizacional nas práticas de negócios da empresa, na organização do seu local de trabalho ou em suas relações externas (p.61).

Segundo Schumpeter (1984), desde o início do século XIX, a inovação era vista como elemento para o desenvolvimento. Mas a decisão de inovar e de desenvolver novos produtos geralmente ocorre sob grande incerteza (CLARK; FUJIMOTO, 1991; CLARK; WHEELWRIGHT, 1993; ROGERS, 2003; ROSENBERG, 1994; ROZENFELD et al., 2006).

Para Rosenberg (1994) o nível de incerteza quanto aos futuros desenvolvimentos em conhecimento e demanda de produtos varia, principalmente, em função do setor e do ciclo de vida do produto. Associado a isso, ressalta que a recuperação de informações relevantes pode consumir muito tempo e dinheiro.

A inovação não é um processo isolado e está diretamente relacionada a objetivos econômicos, como o desenvolvimento de novos produtos; expansão de mercados; obtenção de maior eficiência; condições de aprendizado e de implementação de mudanças; entre outros. Por sua complexidade, e de acordo com o MANUAL... (2006) vários fatores podem prejudicar as atividades de inovação, como:

- Fatores econômicos: riscos percebidos como excessivos; custos altos; ausência de demanda; falta de fontes públicas de financiamento etc.;

- Fatores empresariais: potencial de inovação insuficiente; carência de pessoal qualificado; falta de conhecimento sobre tecnologias; resistência pessoal às mudanças; falta de parceiros apropriados para projetos conjuntos etc.;

- Fatores legais: regulações; regras tributárias etc.

Para Nelson e Winter (1982) o processo de inovação depende das interações entre conhecimento e tecnologia. Nessa linha de pensamento, está a visão da inovação como 
sistema feitas por Lundvall ${ }^{2}$ (1992 apud MANUAL..., 2006, p.41) e Nelson (1993), que estudam as interações externas como fatores significativos para a transferência e para a difusão de atividades inovadoras (idéias, experiências, conhecimentos etc.). Para eles e de acordo com o MANUAL... (2006, p.41), a inovação é um "processo dinâmico em que o conhecimento é acumulado por meio do aprendizado e da interação". Para Vasconcelos; Milagres e Nascimento (2005, p.394),

$\mathrm{Na}$ economia do aprendizado, o conhecimento é um ativo fundamental para o sucesso no processo competitivo, mas sua utilização, enquanto recurso estratégico, impõe às empresas a busca por novas formas de organização e interação entre si e os demais agentes - fornecedores, consumidores, distribuidores, clientes, instituições de pesquisa, governo, comunidade, etc.

Rogers (2003) divide o processo de inovação em duas fases: início e implementação (execução), separadas pela decisão (de implementação). E essas fases, em cinco estágios como podem ser observados na Figura 1:

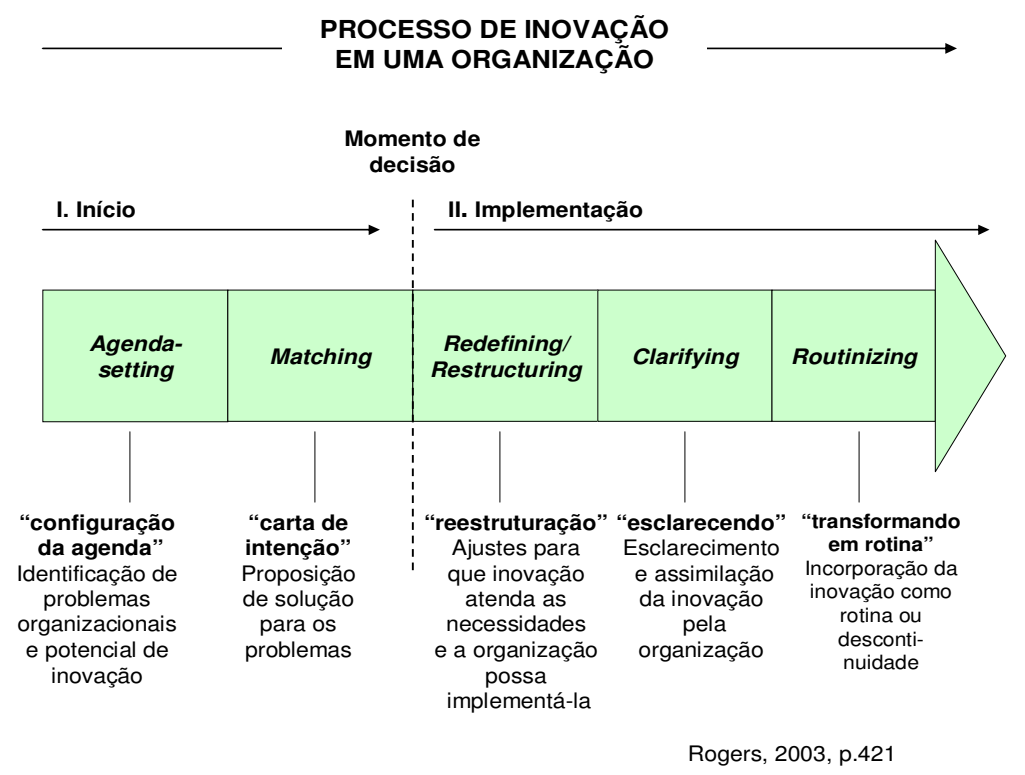

Figura 1 - Processo de inovação em uma organização

$$
\text { Fonte - Rogers (2003, p.241) }
$$

\footnotetext{
${ }^{2}$ LUNDVALL, B.A. (Ed.). (1992). National systems of innovation: towards a theory of innovation and interactive learning. London: Pinter.
} 
Na fase I - Início, dois estágios são fundamentais:

a) agenda setting - "definição da agenda": essa definição é feita a partir da identificação dos problemas e priorização das necessidades organizacionais. Verifica-se, no ambiente organizacional, onde há uma possibilidade de inovação para solucionar os problemas;

b) matching - "carta de intenção": é o momento de planejar a solução dos problemas. Este estágio marca a transição da fase inicial para a execução, feita a partir da tomada de decisão.

Com o planejamento em mãos e tomada a decisão, é iniciada a fase II - Implementação, constituída de três estágios:

a) redefining/restructuring - "reestruturação": estágio onde são feitos os ajustes necessários para que a inovação atenda às necessidades da organização e as mudanças estruturais para acomodar a inovação;

b) clarifying - "esclarecendo": estágio em que uma inovação é assimilada gradualmente até se tornar mais clara para a organização. Uma mudança radical provocada por uma inovação não assimilada pela organização pode provocar mais danos do que benefícios;

c) routinizing - "transformando em rotina": momento em que a inovação é incorporada pela organização e passa a ser rotina. Nesse momento completa-se o processo de inovação. É o momento também onde a inovação pode ser descontinuada.

Como pode ser observado, em todos os estágios está embutido o conhecimento, proveniente das decisões tomadas pela organização em função das diversas interações necessárias.

\subsubsection{Interações}

As interações envolvidas no processo de inovação, tanto internas quanto externas, são entendidas como fluxos de conhecimento que atravessam o valor das empresas. Para as interações internas ressalta-se a importância de se identificar quais partes da empresa são fontes relevantes de informação, pois isso viabiliza o entendimento de como se dá esse 
fluxo de conhecimentos dentro da empresa. (MANUAL..., 2006; VASCONCELOS; MILAGRES; NASCIMENTO, 2005).

As interações externas, por outro lado, podem ser de três tipos (MANUAL..., 2006):

\section{a) Fontes de informação abertas:}

Propiciam o acesso gratuito ao conhecimento. As informações provenientes de universidades, por exemplo, podem ser mais difíceis de serem utilizadas em função da qualificação do pessoal. Mas o desafio que se impõe é a localização das fontes de informação, ou seja, as empresas podem não ter conhecimentos suficientes sobre as fontes potenciais de informação. A troca de informações tecnológicas e comerciais é facilitada pelas redes de conhecimentos, tanto formais (organizações de negócios, associações, universidades, etc.) quanto informais (contatos pessoais, comunidades de prática, etc.).

\section{b) Compra ou aquisição de conhecimentos:}

Considera-se aqui a compra de tecnologias e conhecimentos externos, onde a fonte de fornecimento não está envolvida no processo. Os conhecimentos podem estar incorporados em máquinas ou equipamentos; em pessoal qualificado; contratação de pesquisas e de serviços de consultoria. Podem incluir também outras fontes, como: patentes, licenças, marcas registradas e softwares.

\section{c) Inovação cooperativa:}

Ao contrário da aquisição de conhecimento, a inovação cooperativa envolve a participação de diferentes organizações, de forma ativa em projetos de inovação. Esse tipo de inovação habilita as empresas, em conjunto, a acessar o conhecimento que sozinhas elas não estariam aptas a utilizar. Ou seja, aprendem umas com as outras potencializando as sinergias de cooperação de cada uma.

É importante considerar a inovação numa perspectiva ampla e nesse contexto, a visão baseada em conhecimento está concentrada

Nos processos interativos através dos quais o conhecimento é criado e trocado dentro das empresas e entre empresas e outras organizações. [...] Apesar de a P\&D atuar de forma vital no processo de inovação, muitas atividades inovadoras não são baseadas em $\mathrm{P} \& \mathrm{D}$, ainda que elas dependam de trabalhadores altamente capacitados, interações com outras empresas e instituições públicas de pesquisa e uma estrutura organizacional que conduz ao aprendizado e à exploração do conhecimento (MANUAL..., 2006, p.35). 
No contexto das organizações, um dos investimentos intangíveis mais relevantes é o gerenciamento do conhecimento, que compreende as "atividades relacionadas à apreensão, uso, e compartilhamento do conhecimento pela organização. Essa é uma importante parte do processo de inovação” (MANUAL..., 2006, p.32).

As interações inter e entre organizações propiciam o acesso ao conhecimento tácito, disponível somente na cabeça das pessoas e nas rotinas das organizações. Diferentemente do conhecimento codificado, que

Podem ser acessados e usados sem a interação direta com a fonte. As transferências de conhecimentos codificados compreendem um grande compartilhamento de difusão de tecnologia e os esforços para promover a codificação do conhecimento podem ter impactos importantes na produtividade, no crescimento e na inovação. Um exemplo é o trabalho para o estabelecimento de padrões tecnológicos. Mesmo para a informação disponível e aberta, encontrá-la pode ser um grande desafio, sobretudo quando buscar novas informações é custoso demais (MANUAL..., 2006, p.40).

A obtenção de conhecimento depende da intensidade das interações realizadas, das fontes disponíveis e dos custos praticados. O custo, por exemplo, varia muito quando se trata do acesso às patentes e do acesso a consultores para obtenção do conhecimento desejado. Mas já estão disponíveis para acesso livre bases de dados de patentes ${ }^{3}$, referencial ou com texto completo, um recurso ainda pouco conhecido. Independente da forma de interação que viabiliza a obtenção do conhecimento, só haverá benefícios se o conhecimento for compartilhado no contexto do desenvolvimento de novos produtos e da inovação.

As visões sociológicas e econômicas da difusão ressaltam diferentes atributos das empresas quanto à decisão de adotar novos conhecimentos e tecnologias. Enquanto a primeira foca a vantagem relativa de uma nova tecnologia, sua compatibilidade com os procedimentos existentes, sua complexidade e a forma como a empresa avalia essa tecnologia, a segunda foca nos custos e benefícios de sua adoção (ROGERS, 2003).

Diante dessas colocações, fica claro que a inovação, ao mesmo tempo em que requer conhecimento, também é fonte de criação de conhecimento. Mas de acordo com o MANUAL... (2006, p.46), a inovação está condicionada aos aspectos setoriais e regionais, que podem variar muito quanto ao "desenvolvimento, taxa de mudança tecnológica,

\footnotetext{
${ }^{3}$ Bases de dados de patentes com tutorial disponível para acesso em http://www.sibi.usp.br/patentes.
} 
interações e acesso ao conhecimento, assim como em termos de estruturas organizacionais e fatores institucionais".

Stefanovitz (2006, p.153) estuda a criação de conhecimento e inovação em projetos de uma empresa de alta tecnologia na região de São Carlos, SP e verifica que qualquer tipo de projeto faz uso intensivo de conhecimentos explícitos e tácitos. Mas quando se trata de projetos onde a inovação é mais radical, prevalece o uso de conhecimento tácito. Observa, ainda, que em projetos mais radicais, há maior envolvimento pessoal e trabalho coletivo em função da "inexistência de fontes consolidadas do conhecimento requerido, a elevada incerteza e a necessidade por 'descobertas' sucessivas, de maior ou menor grau”.

Segundo o MANUAL... (2006, p.100-101), a empresa constitui-se essencialmente dos conhecimentos sobre os processos, produtos e mercados. Nesse contexto, a competitividade e a capacidade inovadora de uma empresa podem ser melhoradas a partir de um sistema adequado de gestão do conhecimento, que envolve:

- as atividades relativas à apreensão, ao uso e ao compartilhamento de conhecimentos pela organização;

- a gestão das interações externas e dos fluxos de conhecimento no interior da empresa, incluindo métodos e procedimentos de busca de conhecimento externo e o estabelecimento de relacionamentos mais estreitos com outras empresas (fornecedores, concorrentes), consumidores ou instituições de pesquisa;

- métodos para o compartilhamento e o uso dos conhecimentos, incluindo a implantação de sistemas de valores para o compartilhamento do conhecimento e práticas para a codificação de rotinas.

Alguns exemplos práticos de gestão do conhecimento voltados para a melhoria do fluxo interno e do uso das informações podem ser citados: a) "as bases de dados sobre as 'melhores práticas' dos trabalhadores"; b) "a educação regular ou os programas de treinamento"; c) "os grupos de trabalho formais e informais para promover a comunicação entre os trabalhadores e sua interação"; d) "as atividades de integração, que promovem a interação entre os empregados de diferentes áreas, por exemplo, engenheiros e operários da produção" (MANUAL..., 2006, p.101).

Segundo Stal et al. (2006), para o Brasil melhorar a sua condição de inovação, dentre outras ações, estão as relacionadas ao conhecimento: utilização, pelas empresas, de variadas fontes de informação interna e externa, inclusive institutos de pesquisa e universidades; adequada gestão do conhecimento; definição conjunta de políticas de propriedade intelectual bem 
como licenciamento para comercialização, considerando parâmetros de disseminação do conhecimento. Esses aspectos são também tratados pelo Instituto Brasileiro de Geografia e Estatística - IBGE (2007), por meio da pesquisa de inovação tecnológica junto às empresas, denominada PINTEC.

\subsection{Desenvolvimento de produto - DP}

O desenvolvimento de produto pode ser entendido como "processo pelo qual a empresa transforma dados sobre oportunidades de mercado e possibilidades técnicas em bens e informações para a fabricação de produtos comercias" (CLARK; FUJIMOTO, 1991). Isso inclui a criação e seleção de idéias, o projeto em si, a preparação dos meios de manufatura e o lançamento do produto. Envolve também o processo de transformação de informação, e não simplesmente como fluxo de materiais, forma convencional de mapeamento $\mathrm{e}$ entendimento dos processos industriais

Rozenfeld et al. (2006, p.3), ao tratarem da gestão do desenvolvimento de produto, atualizam o conceito ao dizerem que o desenvolvimento de produtos,

Consiste no conjunto de atividades por meio das quais busca-se, a partir das necessidades do mercado e das possibilidades e restrições tecnológicas, e considerando as estratégias competitivas e de produto da empresa, se chegar às especificações de projeto de um produto e seu processo de produção, para que a manufatura seja capaz de produzi-lo.

O desenvolvimento de produto envolve também as atividades de acompanhamento do produto após o lançamento. Esse acompanhamento viabiliza a realização de eventuais mudanças nas especificações, o planejamento da descontinuidade do produto no mercado e a incorporação, "no processo de desenvolvimento, das lições aprendidas ao longo do ciclo de vida do produto" (ROZENFELD et al., 2006, p.4).

Para Clark e Fujimoto (1991), o desenvolvimento mais rapido e de produtos melhores é o ponto central da agenda competitiva dos gerentes em qualquer parte do mundo e está no bojo da competição industrial. Isso é corroborado por Rozenfeld et al. (2006, p.4), quando afirmam que

O desenvolvimento de produtos é considerado um processo de negócio cada vez mais crítico para a competitividade das empresas, principalmente com a crescente internacionalização dos mercados, aumento da diversidade e variedade de produtos e redução do ciclo de vida dos produtos no mercado [...] Ou seja, é por meio desse processo que a empresa pode criar novos produtos mais competitivos e em menor tempo para atender 
à constante evolução do mercado, da tecnologia e dos requisitos do ambiente institucional (principalmente quanto à sua saúde, meio ambiente e segurança).

Para os autores (p.40), processo de negócio (BP) compreende "um conjunto de atividades organizadas entre si visando produzir um bem ou um serviço para um tipo específico de cliente (interno ou externo à empresa)". Esse conceito representa uma evolução de conceitos consagrados anteriormente como, por exemplo, Davenport (1994, p.7), que entendia processo de negócio como "uma ordenação específica das atividades de trabalho no tempo e no espaço, com um começo, um fim, e inputs e outputs claramente identificados: uma estrutura para a ação".

Outro ponto que merece destaque é a abrangência do escopo do processo de desenvolvimento de produto (PDP), que vai desde o lançamento ou a melhoria de um produto até a sua retirada do mercado, ou seja, todo o ciclo de vida do produto. Isso requer a integração desse processo com todas as funções industriais e, nesse contexto, a informação é fator de relevância (ROZENFELD et al., 2006).

Clark e Wheelwright (1993) afirmam que o principal problema para o sucesso de um projeto é a falha dos executivos em não planejar o portfólio de produtos para que sejam providenciadas as fontes de recursos e as habilidades necessárias, bem como para a integração desse processo com outras estratégias da organização. Para os autores, o que ocorre antes do início do projeto é fundamental para o seu sucesso e afirmam, ainda, que esse sucesso depende do momento em que alta gerência efetivamente dá atenção ao projeto e o grau de influência sobre ele. Depende também da sinergia entre o planejamento de negócios e o processo estratégico, e a variedade de projetos em desenvolvimento na empresa. Se não houver conexão entre as duas áreas, o resultado pode não refletir a direção e a intenção do negócio.

Por esta razão, é essencial a constituição de equipes de especialistas, mas com visão geral do PDP (CLAUSING, 1994). E para Pugh (1996), o PDP na prática requer a integração entre as várias técnicas da organização e dos fatores operacionais, o que não ocorre na formação profissional. Isso gera um conflito entre o que o PDP requer e o que efetivamente os profissionais têm capacitação para fazer. 
Ressalta-se, ainda, outros fatores gerenciais que afetam o desempenho do PDP, devidamente elencados e explicitados por Rozenfeld et al. (2006): integração do PDP com as estratégias de mercado, produto e de desenvolvimento tecnológico; planejamento integrado do conjunto de projetos; desenvolvimento; papel dos líderes e gerentes do projeto; envolvimento da cadeia de fornecedores e de clientes; integração das áreas funcionais da empresa; e estruturação das etapas e atividades do processo.

Diante da complexidade do PDP, é essencial a definição e adoção de um modelo de referência para eficiência e eficácia de sua gestão.

Existem duas características do PDP que o diferencia dos outros processos de negócio. São características de natureza cíclica de resolução de problemas e de consistência de detalhes. Geralmente o desenvolvimento de um produto envolve profissionais de diversas especialidades que realizam diferentes atividades simultâneas, o que pressupõe a existência de uma harmonia e uma consistência entre os detalhes (CLARK; FUJIMOTO, 1991).

Essas características são sumarizadas por Rozenfeld et al. (2006, p.6), a saber:

- o elevado grau de incertezas e riscos das atividades e resultados;

- decisões importantes devem ser tomadas no início do processo, quando as incertezas são ainda maiores;

- dificuldade de mudar as decisões iniciais;

- as atividades básicas seguem um ciclo iterativo do tipo: Projetar (gerar alternativas)Construir-Testar-Otimizar;

- manipulação e geração de alto volume de informações;

- as informações e atividades provêm de diversas fontes e áreas da empresa e da cadeia de suprimentos; e

- multiplicidade de requisitos a serem atendidos pelo processo, considerando todas as fases do ciclo de vida do produto e seus clientes.

Para essa pesquisa, as informações, e mais especificamente o conhecimento, é de especial interesse. E, de acordo com Kraaijenbrink e Groen (2006), na última década, a Internet se tornou uma fonte importante e crescente de informação para engenheiros. Mas com isso surgiram os novos desafios: a grande quantidade de informação disponível e como avaliar a 
qualidade da informação recuperada (CHOO, DETLOR e TURNBULL ${ }^{4}, 2000$ apud KRAAIJENBRINK, 2007, p.1368).

Em estudo desenvolvido na Holanda sobre as falhas na busca de informação na web, Kraaijenbrink (2007) analisa o comportamento de uso da informação na web por 17 (dezessete) engenheiros de pequenas e médias empresas de alta tecnologia, envolvidos no processo de desenvolvimento de novos produtos. No estudo foram identificados 65 (sessenta e cinco) exemplos de processos de uso da informação, divididos em 05 (cinco) tipos de necessidades em cada uma das etapas do processo de recuperação da informação: identificação, aquisição e utilização (Quadro 1). Esse resultado é significativo, pois demonstra claramente a existência de um problema no acesso ao conhecimento.

\begin{tabular}{|c|c|c|}
\hline Dimensões & $\begin{array}{c}\text { Tipo de } \\
\text { necessidade }\end{array}$ & Falhas \\
\hline \multirow{5}{*}{$\begin{array}{l}\text { Da identificação } \\
\text { da informação - } \\
\text { fora da empresa } \\
\text { (p.1373-1375) }\end{array}$} & $\begin{array}{l}\text { Quanto à } \\
\text { necessidade de } \\
\text { informação }\end{array}$ & $\begin{array}{l}\text { a) Falta de informação para orientação e inspiração; } \\
\text { os resultados levam a fatos consumados; } \\
\text { b) A necessidade inicial dos engenheiros é diferente } \\
\text { da necessidade final; etc. }\end{array}$ \\
\hline & $\begin{array}{l}\text { Quanto à } \\
\text { disponibilidade de } \\
\text { informação }\end{array}$ & $\begin{array}{l}\text { a) Falta de adequação da quantidade e diversidade da } \\
\text { informação obtida: demasiada ou insuficiente; } \\
\text { b) Falta de informação nova: os engenheiros querem } \\
\text { informação que não existe, ou que não foi publicada; } \\
\text { etc. }\end{array}$ \\
\hline & $\begin{array}{l}\text { Quanto à } \\
\text { categorização da } \\
\text { informação }\end{array}$ & $\begin{array}{l}\text { a) Falta de categorização múltipla; } \\
\text { b) Os engenheiros querem uma categorização } \\
\text { inequívoca; etc. }\end{array}$ \\
\hline & $\begin{array}{l}\text { Quanto as opções de } \\
\text { navegação }\end{array}$ & $\begin{array}{l}\text { a) Falta de links ou indicação inadequada; } \\
\text { b) Falta de dispositivo de busca simultânea; } \\
\text { c) Falta de múltiplas formas de navegação; etc. }\end{array}$ \\
\hline & $\begin{array}{l}\text { Quanto à linguagem } \\
\text { utilizada }\end{array}$ & $\begin{array}{l}\text { a) Falta de uniformização de nomes (termos técnicos e } \\
\text { nomes comuns); } \\
\text { b) Falta de sinônimos, qualificadores, etc. }\end{array}$ \\
\hline
\end{tabular}

\section{Continua}

\footnotetext{
${ }^{4}$ CHOO, C.V.; DETLOR, B.; TURNBULL, D. (2000). Web work: information seeking and knowledge work on the world wide web. Dordrecht: Kluwer Academic.
} 


\section{Conclusão}

\begin{tabular}{|c|c|c|}
\hline \multirow{5}{*}{$\begin{array}{l}\text { Da aquisição da } \\
\text { informação - } \\
\text { transferência da } \\
\text { informação da } \\
\text { fonte para o usuário } \\
\text { (p.1375-1377) }\end{array}$} & $\begin{array}{l}\text { Quanto ao suporte } \\
\text { de informação }\end{array}$ & $\begin{array}{l}\text { a) Falta de múltiplos formatos de documentos; } \\
\text { b) Falta de representação física dos objetos; etc. }\end{array}$ \\
\hline & $\begin{array}{l}\text { Quanto à } \\
\text { propriedade } \\
\text { intelectual }\end{array}$ & $\begin{array}{l}\text { a) Falta de permissão para uso da informação } \\
\text { necessária; } \\
\text { b) Falta de informação completa (texto). A } \\
\text { recuperação, muitas vezes, é somente dos metadados; } \\
\text { etc. }\end{array}$ \\
\hline & $\begin{array}{l}\text { Quanto à função e a } \\
\text { "competição" entre } \\
\text { os atores }\end{array}$ & $\begin{array}{l}\text { a) Falta de uniformização entre os níveis de expertise, } \\
\text { plataformas tecnológicas; etc. }\end{array}$ \\
\hline & Quanto ao tempo & $\begin{array}{l}\text { a) Falta de agilidade nas respostas; } \\
\text { b) Falta de facilidade para obtenção da informação } \\
\text { específica (múltiplas interações); etc. }\end{array}$ \\
\hline & $\begin{array}{l}\text { Quanto aos recursos } \\
\text { financeiros }\end{array}$ & $\begin{array}{l}\text { a) Falta de informação a custo acessível; } \\
\text { b) Falta de acordo entre as fontes e os pesquisadores } \\
\text { sobre as formas de pagamento pela informação } \\
\text { (pagamento por uso, por assinatura, etc.); } \\
\text { c) As fontes e os pesquisadores dão valor diferente } \\
\text { para a informação. }\end{array}$ \\
\hline \multirow{5}{*}{$\begin{array}{l}\text { Da utilização da } \\
\text { informação - se a } \\
\text { informação obtida } \\
\text { refere-se à } \\
\text { procurada para } \\
\text { resolver os } \\
\text { problemas do } \\
\text { desenvolvimento } \\
\text { de novos produtos } \\
\text { (para apoiar o DP) } \\
\text { (p.1377-1378) }\end{array}$} & $\begin{array}{l}\text { Quanto à área de } \\
\text { conhecimento } \\
\text { requerida }\end{array}$ & $\begin{array}{l}\text { a) Divergência quanto as áreas de conhecimento } \\
\text { fornecidas pelas fontes e as que interessam aos } \\
\text { pesquisadores; } \\
\text { b) Falta de informação para o futuro (disponibilidade } \\
\text { de informação para a situação atual); } \\
\text { c) Falta de informação para uso operacional } \\
\text { (oferecimento de informação estratégica); etc. }\end{array}$ \\
\hline & $\begin{array}{l}\text { Quanto ao nível de } \\
\text { agregação da } \\
\text { informação }\end{array}$ & $\begin{array}{l}\text { a) Falta de informação para diferentes níveis } \\
\text { (componentes, produtos, etc.); }\end{array}$ \\
\hline & $\begin{array}{l}\text { Quanto ao nível de } \\
\text { abstração da } \\
\text { informação }\end{array}$ & $\begin{array}{l}\text { a) Falta de informação fundamental (maior } \\
\text { disponibilidade de informação aplicada); } \\
\text { b) Falta de informação em diferentes níveis: } \\
\text { problemas, sintomas, soluções; } \\
\text { c) Falta de informação sobre variáveis (há mais } \\
\text { informação sobre indicadores). }\end{array}$ \\
\hline & $\begin{array}{l}\text { Quanto à qualidade } \\
\text { da informação }\end{array}$ & $\begin{array}{l}\text { a) Falta de acordo entre o que é especificidade, } \\
\text { completeza, profundidade etc. da informação } \\
\text { requerida. }\end{array}$ \\
\hline & $\begin{array}{l}\text { Quanto a ausência } \\
\text { de informação e } \\
\text { informação } \\
\text { incomparável }\end{array}$ & $\begin{array}{l}\text { a) Falta de informação sobre componentes padrão; } \\
\text { Dificuldade de comparar as informações obtidas de } \\
\text { diferentes produtos para aplicação específica; etc. }\end{array}$ \\
\hline
\end{tabular}

Quadro 1 - Exemplos de falhas na recuperação de informação

Fonte - Kraaijenbrink (2007) 
Para Kraaijenbrink (2007), das falhas levantadas, algumas reforçam estudos anteriores e outras surgem agora. Muitas das novas falhas estão relacionadas à usabilidade e à funcionalidade dos sites, o que poderia ser aproveitado pelos desenvolvedores para buscar solucioná-las.

Os engenheiros que trabalham com desenvolvimento de novos produtos são considerados fundamentais para a inovação. Naquele contexto precisam de muita informação externa, e a Internet pode ser considerada uma fonte relevante, desde que utilizada com sabedoria.

Com base na literatura nacional e internacional, somada às experiências e melhores práticas, foi possível propor um "modelo de referência" teórico e prescritivo que pode ser adotado integralmente ou adaptado às necessidades de cada organização (em consonância com suas estratégias) para avaliar e propor melhorias no PDP - um modelo unificado de desenvolvimento de produto. Para os autores o modelo de referência genérico é um modelo de processo de negócio que é utilizado para derivar (criar) modelos de referência específicos. Modelo de referência específico é a "adaptação de um modelo de referência genérico para uma empresa" (ROZENFELD et al., 2006, p.535). Esse modelo de referência genérico pode ser visto também na Comunidade do Livro (http://numa.sc.usp.br/forum), estabelecida para ser um espaço de compartilhamento de conhecimento entre seus leitores.

De acordo com Rozenfeld et al. (2006) o modelo é voltado principalmente para empresas de manufatura de bens de consumo duráveis e de capital. É composto de três macrofases denominadas: pré-desenvolvimento, desenvolvimento e pós-desenvolvimento. Estas fases estão representadas na Figura 2 (p.33), seguidas de breve comentário sobre cada uma delas.

As fases são determinadas pelos deliverables (entrega). Cada fase tem seus resultados avaliados pelos gates (transição de fase), devidamente formalizados. As fases do PDP, conforme o modelo, nem sempre são seqüenciais; elas podem se apresentar sobrepostas.

A macrofase de pré-desenvolvimento, de acordo com o modelo apresentado na Figura 2, possui duas grandes fases:

a) planejamento estratégico de produtos: "composta pelo conjunto de atividades que transformam as informações contidas nas Estratégias Corporativas e da Unidade de Negócio no Plano Estratégico de Produtos, o 
qual contém a descrição do portfólio de produtos" (ROZENFELD et al., 2006, p 59);

b) planejamento de projeto: constitui-se "pelas atividades de determinação do escopo e planejamento macro do projeto". Inicia-se próximo à "data prevista da realização de um dos projetos do Plano Estratégico de Produtos" e "finaliza no momento em que um projeto específico, depois de planejado, é considerado viável e aprovado no gate" (ROZENFELD et al., 2006, p 59).

Ou seja, para o PDP o planejamento estratégico feito na macrofase de pré-desenvolvimento é fundamental. Nesta fase são consideradas as estratégias de mercado e as estratégias tecnológicas que, via de regra, definem o portfólio de produtos. A principal importância desta fase está no fato dela ser a ponte entre o objetivo da empresa e os produtos que ela desenvolve, além de ser a fonte de informações necessárias à próxima macrofase: o desenvolvimento (ROZENFELD et al., 2006).

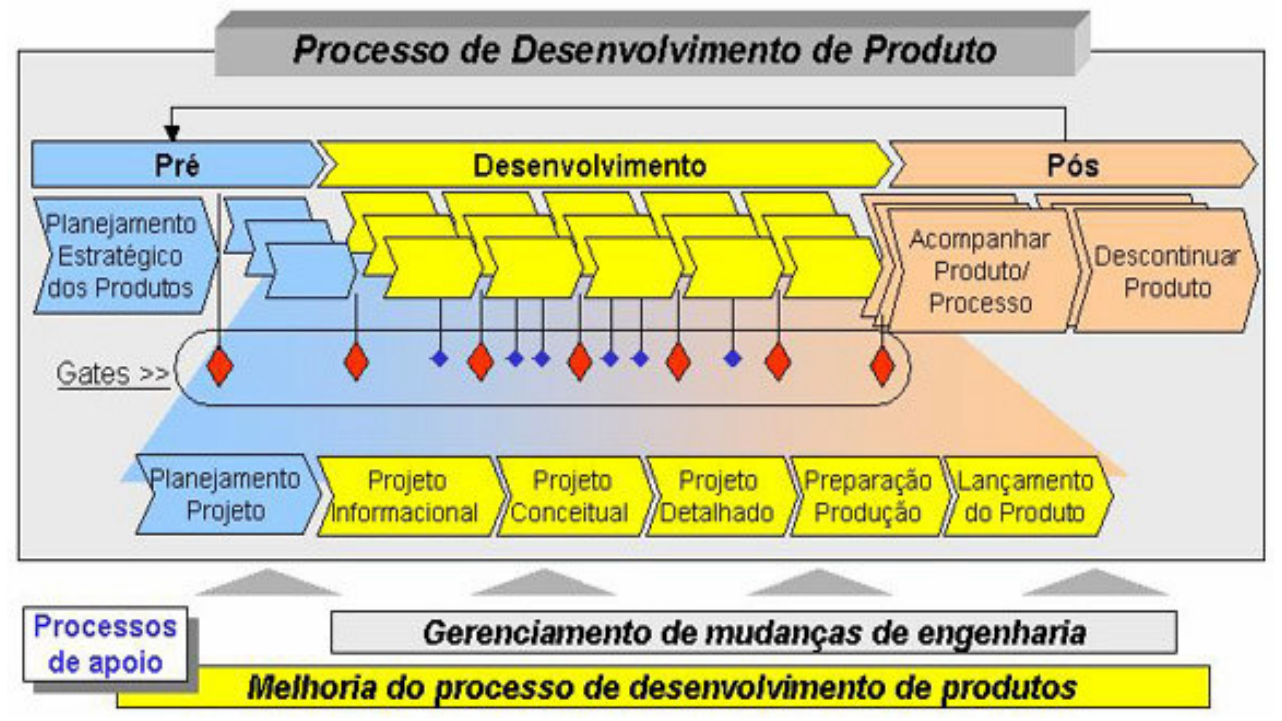

Figura 2: Visão geral do modelo de referência

Fonte - Rozenfeld et al. (2006, p.44)

A macrofase do desenvolvimento, de acordo com o modelo, é constituída de cinco fases: projeto informacional; projeto conceitual; projeto detalhado; preparação da produção; lançamento do produto. Ao longo desta macrofase podem ocorrer modificações de produto em função do grau de incertezas inicial, o que gera custos. O custo de mudança é mais elevado à medida que as fases do desenvolvimento avançam, razão pela qual as 
informações geradas no pré-desenvolvimento são fundamentais para o time de desenvolvimento.

O time de desenvolvimento varia de tamanho e tipo de membro de acordo com cada projeto e fase, sendo maior e mais abrangente no início. Mas há um time central multidisciplinar permanente que participa de todas as fases para garantir a continuidade do conhecimento ao longo dessa macrofase. O time só é dissolvido algum tempo após o lançamento e acompanhamento do produto, principalmente se este for inovador. E assim como na macrofase anterior, são produzidas informações técnicas detalhadas de produção e comerciais, quando é considerado o fim do PDP para muitas metodologias de projeto.

Mas o modelo em questão trata de uma terceira macrofase, denominada pósdesenvolvimento, considerada de importância similar às anteriores. Esta macrofase vai até a descontinuidade do produto (ROZENFELD et al., 2006).

A macrofase de pós-desenvolvimento é a mais longa e mesmo com os ciclos de vida mais curtos, os produtos podem permanecer por vários anos no mercado. Inicia-se após o lançamento do produto no mercado, quando se desfaz o time de desenvolvimento e cria-se o time de acompanhamento, constituído por pessoas que participaram do desenvolvimento e por outras responsáveis pela produção e assistência técnica do produto. O time, embora com características diferentes, pois ficam alocados em outras atividades paralelas, reúne informações sobre todos os processos referentes ao produto e fazem "avaliação da satisfação do cliente e o monitoramento do desempenho técnico do produto”. O acompanhamento ocorre até o final do ciclo de vida do produto, quando são reunidas todas as informações pertinentes para utilização futura (ROZENFELD et al., 2006, p.68).

Assim como no processo de inovação, em todas as fases do modelo observa-se que o conhecimento está presente, o que reforça a importância do aprendizado para o PDP. O conhecimento tem sido considerado um componente crítico para obtenção e manutenção de vantagem competitiva nas organizações (DRUCKER, 1993; QUIN; ANDERSON; FINKELSTEIN, 1996; STAL et al., 2006). E, segundo Ulrich (Org.) (2000), o fato de uma empresa conseguir vantagem competitiva baseada no conhecimento, propicia a manutenção de sua liderança e dificulta o acompanhamento pelos seus concorrentes. 
O PDP utiliza-se do conhecimento dos requisitos do mercado para criar novos produtos e a estratégia de produto/mercado é composta de quatro questões importantes (CLARK; WHEELWRIGHT, 1993):

- quais produtos serão oferecidos;

- quem é o público alvo;

- como os produtos vão chegar até os clientes;

- porque os clientes vão preferir o produto - atributos e valores do produto.

Associado a isso, grande parte do conhecimento necessário para o desenvolvimento de produtos é resultante do aprendizado com projetos anteriores, razão pela qual a transferência de conhecimento entre projetos no PPD é essencial. Ressalta-se que quanto melhor o conhecimento de projetos anteriores, maior a eficiência de projetos atuais (DAVENPORT; PRUSAK, 1998).

O PDP é um ambiente dinâmico onde os requisitos dos clientes podem mudar e segundo Verganti; MacCormack e Iansiti (1998), as empresas enfrentam dois grandes desafios: o de continuar a aprender durante o desenvolvimento, e o outro que é a necessidade de "incorporar novas informações no projeto do produto até os últimos estágios de desenvolvimento".

Aprender durante o desenvolvimento de um produto requer além da transferência do conhecimento adquirido com outros projetos, a intensa experimentação, o que é essencial em um ambiente onde o conhecimento deprecia-se rapidamente (MUNDIN, 2001). Para a autora, a aprendizagem individual deve estar associada à aprendizagem organizacional, onde a organização necessita incorporar e criar conhecimentos mais rápido que os seus concorrentes.

Dois outros trabalhos (SILVA, 2002; SILVA; ROZENFELD, 2003) tratam da proposição de um modelo para caracterização das conversões do conhecimento no PDP por meio das quatro dimensões da conversão: a socialização, a externalização, a combinação e a internalização. Nestes trabalhos os autores demonstram que através da aplicação do modelo é possível verificar que a gestão do conhecimento sobre DP tem de ser considerada como 
"dependente" das conversões e entendem que somente a ação conjunta do conhecimento explícito e tácito viabiliza o apendizado prático do trabalho.

Ao pesquisar os fatores que influenciam a geração de conhecimento no processo de desenvolvimento de produto em empresas como IBM, Microsoft, Sony entre outras, Song; Van Der Bij e Weggeman (2006) observam que o investimento em P\&D, a rotação de cargo, as tecnologias de informação, o compromisso individual e a crise organizacional tem influência positiva nesse processo.

Considerados os pontos levantados em relação ao PDP, especialmente quanto à importância do conhecimento, apresenta-se a seguir uma breve revisão sobre conhecimento, mais especificamente sobre conhecimento de acesso livre.

\subsection{Conhecimento de acesso livre}

\subsubsection{Antecedentes e definições}

Como é de conhecimento público, a Internet surgiu na década de 1960, junto ao Departamento de Defesa dos Estados Unidos, por necessidade militar, com nome de ARPANET. Posteriormente foi liberado o uso em pesquisas científicas e conversas pessoais e em 1995, foi privatizada e passou a ser utilizada comercialmente.

Para dar suporte a Internet no Brasil, foi criada em 1995 a Rede Nacional de Pesquisa RNP, junto à Fundação de Amparo à Pesquisa no Estado de São Paulo - FAPESP. A RNP envidou esforços para esclarecer e orientar essa "nova comunidade" quanto ao uso dos recursos disponíveis. E, dentre eles, a tradução de um guia elaborado para atender inicialmente a necessidade do Computer Science Department da Widmer University, E.U.A., onde é ressaltada que a essência das redes está nos desejos de se comunicar, congregar e compartilhar, "algo" inerente ao ser humano que, ao longo do tempo, tem buscado formas cada vez mais ágeis de se corresponder. Naquela época o autor já destaca o uso correio eletrônico, o que no Brasil era praticamente uma novidade. Outro ponto abordado é o uso das listas de discussão, onde as pessoas podem compartilhar interesses comuns, assim como o File Transfer Protocol - FTP (KEHOE, 1993, p.10). Nesse contexto, as palavras "cooperativa" e "compartilhamento" são citados com freqüência além, ainda, do "acesso público" e do "acesso aberto e gratuito" quando se refere, por exemplo, a bibliotecas, sistemas de computação comunitários, diretórios e bases de dados. Outros 
pontos que merecem atenção no trabalho de Kehoe (1993) é a menção às conversas on-line, como o Microsoft Service Network - MSN de hoje e aos serviços comerciais que viabilizam o acesso às revistas eletrônicas. No Brasil o acesso a revistas eletrônicas foi institucionalizado (exceto algumas ações isoladas) somente em 1999, com a criação do Programa Biblioteca Eletrônica - ProBE (http://www.probe.br). Com isso as instituições participantes (sete inicialmente) constituem uma rede de conhecimento científico para apoiar a pesquisa e o ensino.

Para Castells (2006, p. 40), "as redes interativas de computadores estão crescendo exponencialmente, criando novas formas e canais de comunicação, moldando a vida e, ao mesmo tempo, sendo moldadas por ela". Isso leva à organização de redes específicas onde as pessoas são conectadas e desconectadas o tempo todo. E, ao estudar o surgimento de uma nova estrutura social, dentre vários assuntos abordados, Castells (2006) trata do conhecimento e da informação como elementos cruciais do desenvolvimento. Para ele a produtividade está atrelada ao conhecimento e ao processamento da informação. E, de certa forma, compara a revolução tecnológica à Revolução Industrial do século XVIII, apoiada no uso da informação e na promoção da inovação.

Zook (2001) já falava da existência de milhões de usuários de redes no mundo inteiro, em todos os ramos da comunicação humana (política, religião, sexo, pesquisa), mas tendo o comércio eletrônico como principal atração. Segundo Castells (2006), a capacidade da Internet permite que parte considerável das comunicações aconteça de forma espontânea, não-organizada e pelas mais diversificadas finalidades.

Quando se trata de redes e mais especificamente de difusão gratuita pela Rede, o exemplo mais significativo que existe é o do software Linux (BENKLER, 2002; CASTELLS, 2006), um software livre que tem seu modelo de desenvolvimento essencialmente colaborativo.

Por ser um fenômeno não totalmente conhecido, o desenvolvimento de software livre ainda gera dúvidas. Trata-se de um fenômeno social e econômico, que envolve o voluntariado em massa e ainda requer estudos mais aprofundados para melhor entendê-lo. Exemplos como o projeto Gutenberg (http://www.gutenberg.org), a Wikipedia (http://www.wikipedia.org), o YouTube (http://www.youtube.com), o MySpace (http://www.myspace.com), o Flickr (http://www.flickr.com) entre outros, mostram a capacidade do processo de colaboração 
altruística. E como cita Taurion (2004), esses "projetos têm fascinado milhões de pessoas no mundo inteiro e tiveram o mérito de chamar a atenção para a viabilidade do modelo de computação filantrópica, com a utilização maciça dos ciclos ociosos de computadores pessoais".

As teorias de software livre são discutidas por Raymond (2001) quanto aos dois estilos de desenvolvimento fundamentalmente diferentes: o modelo Catedral, mais comum no mundo comercial versus o modelo Bazar, ligado ao mundo Linux. O Catedral é escrito por um grupo pequeno de pessoas, pagas para isso, e acessível somente a elas enquanto está em desenvolvimento. É liberado para uso após atingir um certo grau de confiabilidade. Por outro lado, o Bazar é escrito por grande número de pessoas, que se comunicam pela Internet, de maneira informal, em trabalho voluntário. Independente do estilo, são exemplos de um forte trabalho colaborativo.

Humes (2004) ao fazer um estudo sobre a adoção de software livre na Universidade de São Paulo ressalta que a disposição de colaborar é, dentre outros parâmetros pessoais, um fator que move as pessoas que lideram um projeto e enfatiza que

O desafio em uma iniciativa open source é como unir participantes em torno de uma meta comum [...] um projeto open source tem como propriedade a flexibilidade de poder ser alterado por qualquer pessoa, mas as decisões para a versão estável de um produto não são democráticas, pois são tomadas por um grupo seleto de pessoas.

Além de tratar de software livre de forma genérica, é necessário apresentar alguns conceitos a ele relacionados e ao acesso livre, temas que ainda podem ser considerados recentes na literatura:

- "Free access" - "acesso livre": acesso livre e gratuito ao conteúdo através da Internet para qualquer usuário ler, copiar, imprimir ou fazer um link para os textos completos. A reprodução e distribuição são limitadas em função dos direitos autorais e do direito de citação adequada (BUDAPEST Open Access Initiative, 2001); 
- "Free content" - "conteúdo gratuito": "é uma licença que tem o mesmo estatuto para o conteúdo livre (textos, imagens, música) que a GNU-GPL ${ }^{5}$ tem para o software" (WIKIPEDIA..., 2006);

- "free software" - "software livre": segundo a Free Software Foundation é "qualquer programa de computador que pode ser usado, copiado, estudado, modificado e redistribuído com algumas restrições". Esta liberdade refere-se ao conceito, oposto ao conceito de software proprietário e ao mesmo tempo, diferente de software que é vendido com o objetivo de lucro (software comercial). A distribuição de software livre normalmente é feita mediante uma licença que disponibiliza o código fonte do programa (WIKIPEDIA..., 2006);

- "open access" - "acesso aberto": licença que permite o uso irrestrito, distribuição e reprodução em qualquer meio, desde que citada a fonte original (CREATIVE COMMONS, 2007). Para Reitz (2007), trata-se de conteúdo informacional feito livremente e universalmente disponível pela Internet, em formato de fácil leitura. É um novo modelo de publicação. Open access é diferente de free access (WILLINSKY, 2006);

- "open content" - "conteúdo aberto ou conteúdo livre": termo criado por analogia ao 'open source', descreve qualquer tipo de trabalho criativo inclusive artigos, pinturas, audio e video, publicados em formato que permite a cópia e a modificação, sem restriçoes, por todos os interessados. (OPEN..., 2007);

- "free knowledge" - "conhecimento livre e gratuito": conhecimento acessível livremente, que pode ser distribuído e modificado, como o software 'open source' (THE OPEN..., 2007);

- "open knowledge" - "conhecimento de acesso livre": acesso livre vem do inglês open access (OA), e "é a forma abreviada como no mundo dos sistemas de informação e documentação científica se refere ao acesso livre ao conhecimento. Acesso livre significa a livre disponibilização na Internet, permitindo a qualquer

\footnotetext{
${ }^{5}$ GNU - General Public Licence: Licença pública da Free Software Foundation (FSF), uma entidade estabelecida em 1985, com o objetivo de promover o direito de usuários de computador quanto ao uso, estudo, cópia, modificação e redistribuição de programas de computador.
} 
utilizador pesquisar, consultar, descarregar, imprimir, copiar e distribuir, o texto integral de artigos e outras fontes de informação científica (WIKIPEDIA... 2006);

- "open source" - "fonte aberta": Programa de computador para o qual o código fonte é disponibilizado sem cobrança, geralmente através da Internet, para encorajar o rápido desenvolvimento. A prática permite que o produto seja personalizado de acordo com as necessidades locais. Para ser certificado pela Open Source Initiative (OSI), o software não pode, por exemplo, ter restrições de acesso (REITZ, 2007);

Também merece destaque o trabalho colaborativo onde Benkler (2002) extrapola a idéia do desenvolvimento colaborativo de software para a possibilidade de criação de conhecimento e trata de "commons-based peer production", expressão que pode ser entendida por “produção compartilhada em comum". Ou seja, uma nova modalidade de produção (de conhecimento) possível somente a partir da evolução da Internet. Trata, na verdade, de uma comunidade aberta que coopera de forma voluntária e espontânea, mas com alguma coordenação. O tamanho da comunidade é variável (pequena ou imensa - pode atingir milhares de pessoas) para produzirem um bem ou um serviço. A essência da atividade está na motivação que leva à colaboração, não relacionada à recompensa financeira e sim ao reconhecimento pela produção do conhecimento a partir da complexidade das relações sociais e da tecnologia envolvida.

Para Morigi e Santin (2007)

O software livre como um movimento social tem a capacidade de mobilizar e articular grupos sociais a questionarem o processo de desenvolvimento das tecnologias de informação e o uso livre do conhecimento, possibilitando a transformação das instituições sociais em torno dos seus valores.

Questionam a necessidade da não interferência dos direitos de propriedade intelectual sob controle dos interesses das corporações e reforçam que

O direito de acesso à informação e o uso livre do conhecimento são considerados direitos sociais básicos na construção da cidadania, pois o seu exercício pleno pressupõe o acesso às informações e aos saberes produzidos e distribuidos socialmente (MORIGI; SANTIN, 2007).

Outro estudo de relevância é apresentado por Malone et al. (Ed.) (2003) que, ao organizar o MIT Process Handbook, tratam da definição de uma visão: o acesso ao conhecimento de qualidade, de forma rápida e organizada, que pode atender aos mais variados objetivos. Ou 
seja, um homem de negócios, um profissional da área de computação ou da informação, um gerente ou consultor, pode ter em mãos:

- o conhecimento organizado;

- a rápida recuperação do conhecimento;

- o compartilhamento eletrônico do conhecimento;

- a possibilidade de customização para uso específico;

- a geração de novas idéias organizacionais;

- acesso às melhores práticas, exemplos de casos e softwares;

- diferentes versões de uma mesma base de conhecimento.

Esta é a visão que guia há mais de dez anos o projeto do MIT Process Handbook e segundo Malone et al. (Ed.) (2003) continua a guiá-los. Ressaltam que ainda há muito a ser feito para concretizar a promessa completa, mas acreditam que se trata de uma visão desejável e factível; convidam os interessados a se juntarem a eles para torná-la realidade.

O que se verifica, é o que se pode chamar de transposição do Movimento do Software Livre - MSL para a criação de novos movimentos informacionais e de acesso ao conhecimento livre. Nesse contexto, Morigi e Santin (2007) afirmam que o MSL influenciou o surgimento de outros movimentos, como o Cultura Livre, criado por Lessig e suportado pelo Creative Commons (http://creativecommons.org, com versão brasileira em http://creativecommons.org.br). O cultura livre discute os efeitos da substituição de uma sociedade livre por uma sociedade de permissão, considerando a questão da propriedade intelectual que, como na história da criação da radio FM em 1935, precisa ser ajustada às necessidades do século XXI (Lessig, 2005). Na mesma linha de influência, surge o Open Access, instituido em 2002 pela Budapest Open Access Initiative (http://www.soros.org/openaccess). Para Morigi e Santin (2007) o Open Access surge

Para modificar a realidade da distribuição do saber científico e do patrimônio cultural, com base no uso livre dos meios de comunicação como mecanismos de divulgação do conhecimento e das instituições científicas, dos financiadores, das bibliotecas, dos arquivos e museus do mundo. 
Dessas iniciativas pioneiras, desdobraram-se outras além de declarações de apoio ao acesso aberto no mundo e também no Brasil, a saber:

- Association of College \& Research Libraries (ACRL). Principles and Strategies for the Reform of Scholarly Communication, August 28, 2003 (http://www.ala.org);

- Bethesda Statement on Open Access Publishing, June 20, 2003 (http://www.earlham.edu/ peters);

- Berlin Declaration on Open Access to Knowledge in the Sciences and Humanities, October 22, 2003 (http://www.zim.mpg.de/openaccess-berlin);

- Organization for Economic Co-operation and Development (OECD). Declaration on Access to Research Data From Public Funding, January 30, 2004 (http://www.oecd.org);

- The International Federation of Library Associations and Institutions (IFLA) released the IFLA Statement on Open Access to Scholarly Literature and Research Documentation, February 24, 2004 (http://www.ifla.org);

- Declaração de Salvador sobre Acesso Aberto: a perspectiva dos países em $\begin{array}{lllll}\text { desenvolvimento, } & 23 & \text { de } & \text { setembro } & \text { de }\end{array}$ (http://www.icml9.org/public/documents/pdf/pt/Dcl-Salvador-AcessoAberto-pt.pdf);

- Acesso Aberto Brasil (http://www.acessoaberto.org), responsáveis pela "Carta de São Paulo" - Declaração de apoio ao acesso aberto à literatura científica, de 23 de dezembro de 2005;

- Compromisso do Minho: compromisso sobre o acesso livre à informação científica em países lusófonos, 2006 (http://www.ibict.br/anexos_seções/compromissoDoMinho.doc)

- Livre acesso à informação científica: carta aberta à Sociedade Brasileira para o Progresso da Ciência - SBPC, de 18 de junho de 2006 (http://www.ancib.org.br/content.php?codpg=98).

Considerando o MSL como um "importante movimento social transnacional de luta em defesa por maior inclusão tecnocientífica", Guesser (2007, p.47) destaca a forma 
colaborativa de trabalho e a estrutura descentralizada e não-hierárquica, "como elementos inovadores e promotores de maior participação social e de luta contra-hegemônica".

A colaboração interativa dos diferentes atores dos campos universitário, empresarial, privado e governamental foi fundamental para existência do software livre (GUESSER, 2007). Esse tipo de trabalho colaborativo também é fundamental para a criação do conhecimento de acesso livre.

Para Willinsky $\left(2005^{6}\right.$; 2006) o acesso à informação deve se dar de forma diversa como meio para aumentar o acesso ao conhecimento. O acesso aberto (open access) é uma força nesse sentido, lembrando que isso não significa que seja gratuito (free access). Defende o acesso aberto ao público geral e não restrito aos acadêmicos, o que entende ser um aspecto crítico. Ressalta a importância da decisão compartilhada (share decision), viabilizada de forma mais efetiva com os recursos da Internet e reporta-se ao acesso aberto na área de saúde, onde os pacientes já podem discutir com os médicos os seus diagnósticos, o que deveria ser ampliado a todas as áreas do conhecimento. Mas lembra que muitos pesquisadores desconhecem essa possibilidade e, em alguns casos, se recusam a compartilhar seus documentos. Outro fato que inviabiliza o acesso ao conhecimento é que muitas instituições sequer têm um repositório para arquivo e disposição dos documentos. Associado a existência dos repositórios, deve existir uma boa indexação para que o acesso aos documentos seja facilitado. Caso contrário, muitos trabalhos não serão localizados.

Uma das formas de agilizar e facilitar o compartilhamento de conhecimento é participação em comunidades de prática, a seguir comentadas.

\subsubsection{Comunidades de prática}

Apesar de não ser um assunto novo, a literatura sobre comunidades de prática pode ser considerada escassa. O termo comunidade de prática foi cunhado por Lave e Wenger (1991) quando estudavam o aprendizado como modelo de aprendizagem, um processo mais amplo onde o estudante e o mestre são vistos como aprendizes.

\footnotetext{
${ }^{6}$ WILLINSKY, J. (2005). The Access principle: the new economics of knowledge as a public good. Palesta proferida no 3. Simpósio Internacional de Bibliotecas Digitais, realizado em São Paulo, de 28 de novembro a 01 de dezembro de 2005.
} 
Logo depois, Rheingold (1993) trata de comunidades de prática como comunidades virtuais, que conceitua como uma rede eletrônica auto definida de comunicação interativa e organizada em torno de interesses ou fins em comum. É uma nova forma de comunidade que reúne as pessoas on-line, definição essa compartilhada por Teixeira Filho (2002, p.162), que entende a comunidade de prática como um "grupo de pessoas ligadas primariamente por interesses em comum, que compartilham conhecimentos e experiências adquiridas em sua prática de trabalho e/ou pessoal".

Para Snyder (1997) a comunidade de prática é um veículo perfeito de transferência de conhecimento e desenvolvimento de competência e serve de "ponte entre as teorias de aprendizagem organizacional e o desempenho organizacional”.

Mais recentemente esse conceito começa ser melhor entendido e discutido no âmbito das organizações. Na verdade há uma evolução do conceito de comunidade de prática que, segundo Wenger (2004), pode ser entendida, de forma resumida, como "grupos de pessoas que compartilham algo que sabem como fazer, e que interagem regularmente para aprender como fazer melhor".

Para que uma comunidade de prática exista, é preciso que haja "um grupo de pessoas que mantenham interesse comum sobre um determinado tema" e embora não trabalhem necessariamente juntas, "comunicam-se informalmente para aprender ou criar conhecimentos para si mesmas, e às vezes para a organização" (SANTA EULÁLIA, 2003, p.31-32). E as organizações, por sua vez, entendem que o trabalho colaborativo merece destaque e atribuem a ele um papel cada vez mais central, com base na idéia de que o conhecimento é um ato de participação e que deve ser gerido por quem o produz (WENGER, 1998; WENGER; SNYDER, 2000).

A sustentação de comunidades de prática se dá mediante a combinação de três características estruturais (WENGER; McDERMATT; SNYDER, 2002):

- Domínio - "você precisa saber o que quer": a área do conhecimento que une a comunidade lhe dá identidade e define os assuntos principais a serem tratados. Uma comunidade de prática não é somente uma rede pessoal. A sua identidade é definida não somente por uma tarefa, como em uma equipe, mas "por uma área" de conhecimento que tem de ser explorada e desenvolvida; 
- Comunidade - "você precisa de pessoas que tenham conhecimento": grupo de pessoas para as quais o assunto é relevante e o aprendizado se dá de forma aberta. Uma comunidade de prática não é somente um site ou uma biblioteca; envolve as pessoas que interagem e que desenvolvem as relações que lhes permitem gerenciar os problemas e compartilhar o conhecimento.

- Prática - "você precisa de experiência para produzir conhecimento útil”: conjunto de conhecimento (métodos, idéias, instrumentos, histórias, casos, documentos) que os membros desenvolvem, compartilham e mantêm em conjunto. Uma comunidade de prática não é simplesmente uma comunidade de interesse. Ela une pessoas que estão envolvidas na realização de algo. Depois de algum tempo, há acúmulo de conhecimento em um tema, o que diferencia os seus integrantes quanto à capacidade de atuar individualmente e coletivamente.

Wenger (2004) argumenta sobre a importância da gestão do conhecimento enquanto fator de relevância para a vantagem competitiva da organização. Retrata a ação das comunidades de prática como uma forma de gerir e atualizar conhecimento, algo muito comum no âmbito da comunidade médica que, via de regra, interage em função do estímulo à aprendizagem e porque o conhecimento é demasiado complexo em qualquer dos campos de atuação. Naquele campo do conhecimento, a noção de comunidade de prática desempenha um papel crítico.

Ao ressaltar que "nenhuma comunidade pode dirigir totalmente a aprendizagem do outro, mas nenhuma comunidade pode dirigir totalmente a sua própria aprendizagem”, Wenger (2004) afirma que isso pode ser considerado tanto um alívio como um desafio. Um alívio porque a responsabilidade de gerenciar o conhecimento pode ser compartilhada e um desafio porque não é fácil criar um ambiente capaz de fazer isso bem.

Quando se fala de comunidades de prática, é importante frisar a necessidade de facilitar a comunicação entre os participantes. E ao tratar da construção de uma ontologia para comunidades de prática em empresas de alta tecnologia, Biscozzo; Corallo; Elia (2005) reforçam que uma linguagem apropriada é uma forma de criar um compartilhamento compreensível e capturar aspectos do conhecimento tácito. Inclusive apresentam uma metodologia para essa finalidade, que requer o uso de instrumentos que capacitam os 
participantes a propor modificações, informar sobre as mudanças feitas por outros e facilitar as discussões sobre as mudanças propostas. Reforçam que a construção coletiva de ontologias a partir das bases (bottom-up) funciona melhor do que se imposta (top-down). Em função dessas considerações, para pesquisadora o conhecimento de acesso livre pode ser entendido como o conhecimento científico ou não, independente do formato, cujo acesso gratuito é permitido para uso apropriado aos interessados em conhecer, compartilhar e/ou criar conhecimento.

\subsubsection{Conhecimento de acesso livre sobre inovação e desenvolvimento de produto}

Tendo em vista a importância do conhecimento para o DP e o movimento de acesso livre em discussão no mundo, é relevante pensar na possibilidade de acesso livre ao conhecimento sobre inovação e DP. Isso pode agilizar o DP em nível global e viabilizar o desenvolvimento eqüitativo das nações.

Impulsionados pelo mercado, os cientistas que trabalham com $\mathrm{P} \& \mathrm{D}$ nas organizações estão cada vez mais envolvidos com redes de conhecimento que propiciam trabalhos colaborativos entre universidades e empresas. Isso abre uma forte discussão sobre o público e o privado, conforme demonstra um estudo de Lam (2005).

No Brasil uma iniciativa de relevância para o compartilhamento de conhecimento sobre DP foi a criação da comunidade de prática PDPNet, em 2001, uma rede de conhecimentos sobre PDP (Product Development Process Network), apresentada por SANTA EULÁLIA (2003). Segundo a autora, a iniciativa surgiu a partir do estabelecimento de um objetivo comum de "desenvolver um modelo para a gestão de conhecimento em DP entre as instituições de pesquisa" (p.65).

O compartilhamento de conhecimento propiciado pela PDPNet gerou uma massa de conhecimento que viabilizou a criação de um portal de conhecimentos sobre DP e inovação. O portal tem como objetivo "registrar e organizar conhecimentos sobre o processo de desenvolvimento de produto de forma que esses conhecimentos sejam compartilhados pela comunidade interessada no assunto" (PORTAL..., 2007).

No Brasil foram criadas também CoPs junto às empresas, como é o caso da Petrobrás (MELO; SATTAMINI, 2007), mas com acesso restrito à empresa e seus colaboradores. 
A partir das iniciativas nacionais, busca-se na literatura outros exemplos, inclusive internacionais, de CoPs e de portais voltados para a divulgação, compartilhamento e produção de conhecimento sobre inovação e DP. Algumas delas são analisadas por meio de seus sites e constituem a amostra (Apêndice C) do trabalho. 


\section{Metodologia}

\subsection{Abordagem metodológica}

Vários autores buscam explicar o significado da pesquisa científica, que Silva e Menezes (2005, p.20) sintetizam como o "conjunto de ações, propostas para encontrar a solução para um problema, que têm por base procedimentos racionais sistemáticos”. Castro (1977, p.33) afirma que a "metodologia é um ponto de encontro e de convergência entre pesquisadores e filósofos", razão pela qual seu objetivo é convidar a ciência a especular e a filosofia a se interessar por problemas práticos. A partir disto resume que o objetivo da metodologia é ajudar a compreender, de forma ampla, "não os produtos da pesquisa, mas o próprio processo". Para Thiollent (2002) é papel da metodologia conduzir a pesquisa de acordo com as exigências acadêmicas para garantir confiabilidade e a possibilidade de replicação dos procedimentos utilizados na busca de solução de problemas de pesquisa. Para tanto, é necessário entender os métodos de pesquisa descritos na literatura e selecionar o mais adequado à pesquisa em questão.

\subsection{Seleção da abordagem da pesquisa}

A escolha do método está diretamente relacionada à natureza do objeto de pesquisa. Ela é feita, também, em função dos objetivos, associados aos recursos disponíveis (GIL, 1999; LAKATOS; MARCONI, 1992; SILVA; MENEZES, 2005).

Da análise dos métodos e das características desta pesquisa, associada aos objetivos, o método indicado é o indutivo.

Para Cervo e Bervian (1996, p.30) “os propósitos básicos dos argumentos, sejam eles dedutivos ou indutivos, são obter conclusões verdadeiras a partir de premissas verdadeiras". Mas nos argumentos indutivos não é muito simples, embora quando as premissas são verdadeiras, pode-se afirmar que estas sustentam ou atribuem certa semelhança à sua conclusão. A indução tem um caráter provável e não necessário (VARGAS, 1985).

Parte-se do princípio que o conhecimento é fundamental para a inovação e o desenvolvimento de produto e que o acesso irrestrito ao conhecimento pode agilizar ou promover a melhoria dos produtos existentes; gerar inovação; e garantir vantagem competitiva. Outra premissa do trabalho é a dificuldade de recuperação da informação em 
função da falta de conhecimento sobre a sua disponibilidade; da falta de habilidade dos usuários; e de recursos de tecnologia suficientemente adequados para a efetiva recuperação. Ao efetuar a pesquisa com base no pensamento indutivo, busca-se verificar se as premissas são confirmadas ou identificadas na literatura.

Do ponto de vista dos fins (da utilização dos resultados), a pesquisa pode ser classificada como aplicada, pois na busca de esclarecer melhor a questão do conhecimento de acesso livre, parte da análise da literatura e aplica os conhecimentos na avaliação de sites. Isso possibilita conhecer a realidade de alguns ambientes colaborativos de compartilhamento, divulgação e produção de conhecimento sobre inovação e desenvolvimento de produto na Internet.

Mediante análise das abordagens de pesquisa e das características da pesquisa, adota-se a abordagem qualitativa, pois se vale da interpretação dos fenômenos e da atribuição de significados subjetivos. Aliado a isto, a abordagem qualitativa é a mais indicada para estudos exploratórios (ROESCH, 1999).

Para Minayo (Org.) (1996, p.21-22), a pesquisa qualitativa "trabalha com o universo de significados, motivos, aspirações, crenças, valores e atitudes”, que não podem ser quantificados. Preocupa-se com as relações entre os processos e os fenômenos, que "não podem ser reduzidos à operacionalização de variáveis". Ou seja, a pesquisa qualitativa busca se aprofundar nos significados, o que é difícil de ser percebido e captado pelas equações, médias e estatísticas.

Do ponto de vista dos objetivos e considerando os métodos, a pesquisa pode ser classificada como exploratória. A pesquisa exploratória visa, essencialmente, tornar claros conceitos e idéias para a melhor formulação de problemas e hipóteses para estudos posteriores, através de pesquisa bibliográfica, análise de exemplos etc. (GIL, 1999; SILVA; MENEZES, 2005). Para Cervo e Bervian (1996), um estudo exploratório é uma forma de pesquisa descritiva.

Justifica-se a escolha deste tipo de pesquisa devido ao grau de conhecimento sobre o problema de pesquisa. E por ter um caráter exploratório, ao se definir os objetivos procurou-se indicar ações que buscassem maior familiarização com o assunto para que os resultados pudessem apoiar outros trabalhos sobre inovação e DP. 
Quanto aos procedimentos técnicos, optou-se pela elaboração de pesquisa bibliográfica e pesquisa documental. A pesquisa bibliográfica, conduzida durante todo o trabalho, propicia um melhor entendimento e atualização do tema para, a partir de sua evolução, viabilizar o embasamento teórico da pesquisa como um todo. A pesquisa documental é utilizada para identificar e analisar ambientes com características de acesso livre, de divulgação e de compartilhamento de conhecimento. Quanto ao instrumento de coleta de dados, optou-se pelo formulário que, segundo Marconi e Lakatos (1986) e Cervo e Bervian (1996), facilita o registro dos dados feito pelo próprio pesquisador, possibilita a obtenção de um número representativo de itens a serem avaliados e propicia uma uniformidade nos símbolos (ou notas) estabelecidos pelo pesquisador.

Para facilitar a visualização das escolhas, apresenta-se a seguir um quadro resumo dos métodos, classificações e instrumentos selecionados:

\begin{tabular}{|c|c|}
\hline \multicolumn{2}{|c|}{ Métodos de pesquisa } \\
\hline $\begin{array}{l}\text { • indutivo } \\
\text { dedutivo } \\
\text { hipotético-dedutivo } \\
\text { dialético } \\
\text { fenomenológico } \\
\text { histórico }\end{array}$ & \\
\hline \multicolumn{2}{|c|}{ Classificações da pesquisa } \\
\hline Dos fins (utilização dos resultados) & $\begin{array}{l}\text { básica (pura) } \\
\bullet \quad \text { aplicada }\end{array}$ \\
\hline Forma de abordagem do problema & $\begin{array}{r}\text { quantitativa } \\
\bullet \quad \text { qualitativa }\end{array}$ \\
\hline Quanto aos objetivos & $\begin{array}{l}\text { descritiva } \\
\text { explicativa } \\
\bullet \quad \text { exploratória } \\
\text { pesquisa-ação } \\
\text { "preditiva" }\end{array}$ \\
\hline Procedimentos técnicos & $\begin{array}{l}\bullet \quad \text { bibliográfica } \\
\bullet \quad \text { documental } \\
\text { experimental } \\
\text { ex post facto } \\
\text { levantamento (survey) } \\
\text { estudo de caso } \\
\text { pesquisa participante } \\
\text { pesquisa-ação }\end{array}$ \\
\hline \multicolumn{2}{|c|}{ Instrumentos de coleta de dados } \\
\hline $\begin{array}{l}\text { entrevista } \\
\text { questionário } \\
\quad \text { formulário } \\
\text { observação } \\
\text { pesquisa de mercado } \\
\text { teste e outros }\end{array}$ & \\
\hline
\end{tabular}

Quadro 2 - Resumo dos métodos, classificações e instrumentos selecionados 
São apresentadas a seguir as etapas da pesquisa.

\subsection{Etapas da pesquisa}

A pesquisa é um procedimento reflexivo e crítico que requer um planejamento e execução sistematizada (SILVA; MENEZES, 2005).

Para esta pesquisa foram definidas seis etapas apresentadas no Quadro 3:

\begin{tabular}{|c|c|}
\hline Etapas da Pesquisa & Descrição \\
\hline Escolha do tema & $\begin{array}{l}\text { A primeira etapa da pesquisa foi definida basicamente em função } \\
\text { de: } \\
\text { - } \\
\text { - } \text { necessidade de aprofundamento do conhecimento para } \\
\text { - } \text { afinidade da pesquisadora com o tema, especialmente } \\
\text { quanto ao acesso e uso do conhecimento; } \\
\text { - grau de novidade do conhecimento de acesso livre: } \\
\text { produção e compartilhamento; } \\
\text { - } \\
\text { tema em desenvolvimento pelo GEI2, grupo de pesquisa } \\
\text { coordenado pelo orientador do trabalho. }\end{array}$ \\
\hline Revisão da literatura & $\begin{array}{l}\text { Consiste de busca na literatura do que já foi publicado sobre um } \\
\text { assunto. E, para efeito desta pesquisa, recorre-se à literatura } \\
\text { nacional e internacional para identificar o há que de relevante e mais } \\
\text { apropriado sobre conhecimento de acesso livre para apoiar a } \\
\text { inovação e desenvolvimento de produto. A partir da revisão } \\
\text { bibliográfica inicial, a bibliografia foi atualizada ao longo de toda a } \\
\text { pesquisa, com base nos termos/expressões de busca indicados: } \\
\text { - Acesso gratuito ao conhecimento; } \\
\text { - Aprendizagem organizacional; } \\
\text { - Comunidade de prática; } \\
\text { - Compartilhamento de conhecimento; } \\
\text { - Conhecimento livre; } \\
\text { - Desenvolvimento de produto; } \\
\text { - Inovação; } \\
\text { - Metodologia de pesquisa; } \\
\text { - Portais corporativos; } \\
\text { - Portais web - avaliação e requisitos; } \\
\text { - Recuperação da informação; } \\
\text { - Recursos abertos; } \\
\text { - Trabalho colaborativo. } \\
\text { Não foi delimitado o período de busca. Priorizou-se as publicações } \\
\text { mais recentes, além da indicação de trabalhos clássicos e/ou mais } \\
\text { antigos, agrupados em: inovacao; desenvolvimento de produto; e } \\
\text { conhecimento de acesso livre. }\end{array}$ \\
\hline
\end{tabular}

\section{Continua}


Continua

\begin{tabular}{|c|c|}
\hline Definição da metodologia & $\begin{array}{l}\text { Foi realizada uma revisão da literatura sobre método científico, } \\
\text { tipos de pesquisa, procedimentos técnicos bem como sobre os } \\
\text { instrumentos utilizados para coleta e análise dos dados. Isso } \\
\text { possibilitou uma explanação sobre as opiniões de diversos autores, } \\
\text { conforme apresentado no item } 3.2 \text { - Seleção da abordagem da } \\
\text { pesquisa. } \\
\text { O conhecimento obtido sobre metodologia associado ao tema de } \\
\text { estudo levam a uma forma de raciocínio indutivo. E, pelas suas } \\
\text { características, esta é uma pesquisa básica (pura). O problema é } \\
\text { abordado de forma qualitativa e de caráter exploratório. É } \\
\text { fundamentada através de pesquisa bibliográfica e documental, } \\
\text { além de contar com a coleta de dados mediante o uso de } \\
\text { formulário criado especificamente para o registro dos dados. }\end{array}$ \\
\hline Pesquisa documental & $\begin{array}{l}\text { Associada à pesquisa bibliográfica, os dados foram levantados } \\
\text { através de pesquisa documental, onde o tipo de documento é o } \\
\text { site (portal). A estratégia de busca para identificação dos sites } \\
\text { constou de: } \\
\text { - Definição das expressões de busca a partir dos temas } \\
\text { indicados para a revisão da literatura; } \\
\text { - Definição das fontes de busca: em sites gerais (Google); } \\
\text { em sites de instituições de ensino / pesquisa; sites de } \\
\text { governo e empresas; em bases de dados; } \\
\text { - Busca propriamente dita; } \\
\text { - Seleção preliminar com base no foco da pesquisa, que } \\
\text { gerou as iniciativas genéricas (Apêndice A); }\end{array}$ \\
\hline Coleta de dados & $\begin{array}{l}\text { A coleta de dados exige dois cuidados fundamentais: paciência e } \\
\text { persistência (SILVA; MENEZES, 2005). } \\
\text { Para esta pesquisa, a coleta de dados foi feita através da análise } \\
\text { das iniciativas genéricas. Foram analisados um a um através do } \\
\text { formulário de coleta de dados (Apêndice B), testado e ajustado } \\
\text { antes da coleta propriamente dita (pré-teste). } \\
\text { O registro dos dados foi feito pelo próprio pesquisador, para todos } \\
\text { os sites, o que contribui para minimizar possíveis divergências de } \\
\text { interpretação ou juízo de valor. } \\
\text { A coleta foi repetida em dias e horários diferentes para cada site } \\
\text { (no mínimo três vezes) para verificar a disponibilidade e para } \\
\text { complementar os dados. Isso também se fez necessário em função } \\
\text { da diversidade de interfaces, da divergência da terminologia } \\
\text { utilizada e da obtenção de novos conhecimentos. Raramente } \\
\text { houve problemas de acesso (não disponibilidade). } \\
\text { A partir da coleta de dados, foi estabelecida uma lista que } \\
\text { constitui a amostra (Apêndice C) para a análise dos dados. Ou } \\
\text { seja, é utilizada uma amostra acidental que segundo Selltiz; } \\
\text { Wrightsman; Cook (1987, p.85), é pegar o que aparece e "apenas } \\
\text { esperar que não esteja redondamente enganado". }\end{array}$ \\
\hline
\end{tabular}

Continua 


\section{Conclusão}

\begin{tabular}{|l|l|}
\hline $\begin{array}{l}\text { Análise dos dados, discussão } \\
\text { dos resultados e conclusões }\end{array}$ & $\begin{array}{l}\text { Para a análise de dados qualitativos recomenda-se codificá-los em } \\
\text { categorias e atribuir-lhes um código ou valor para facilitar a } \\
\text { tabulação e a comunicação dos dados. Sugere-se também a } \\
\text { elaboração de representações visuais, como gráficos, esquemas, } \\
\text { figuras entre outros (OLIVEIRA NETTO, 2005; PEREIRA, 2001; } \\
\text { VERGARA, 2000; VILELLA, 2003). } \\
\text { O estabelecimento de premissas para a definição da representação } \\
\text { simbólica ou numérica dos atributos avaliados é fundamental } \\
\text { (PEREIRA, 2001). Segundo o autor, propicia maior fidedignidade } \\
\text { dos dados obtidos pelo investigador, que toma por base o } \\
\text { conhecimento do objeto de estudo. Assim, mesmo partindo de } \\
\text { juízo de valor, os resultados podem ser considerados adequados. } \\
\text { É feita também a atribuição de pesos e notas, o que pode ser } \\
\text { observado no Apêndice D. } \\
\text { A partir dos dados obtidos, é feita a discussão dos resultados que } \\
\text { levam às conclusões e considerações finais. }\end{array}$ \\
\hline
\end{tabular}

Quadro 3 - Etapas da pesquisa 


\section{Desenvolvimento da pesquisa}

\subsection{Seleção preliminar}

Através de pesquisa bibliográfica e documental foi possível identificar na literatura e na prática a existência de ambientes com possibilidades de atender total ou parcialmente ao interesse da pesquisa: sites com características de compartilhamento, divulgação e produção de conhecimento sobre inovação e desenvolvimento de produto.

Uma análise preliminar resultou na lista identificada como iniciativas genéricas, apresentada no Apêndice A. A análise se deu com base no foco da pesquisa e a partir de buscas na Internet e também de citações da literatura.

Devem ser ressaltadas as iniciativas institucionais das universidades brasileiras, especialmente as públicas, que mantêm suas agências de inovação (núcleos de inovação, núcleo de gestão tecnológica ou outra denominação), mas com a mesma finalidade. Estas iniciativas são consideradas de consulta indispensável, principalmente para os membros das comunidades universitárias que estudam o assunto. Algumas das iniciativas são listadas a seguir:

- Agência USP de Inovação (http://www.inovacao.usp.br);

- Agência de Inovação da Unicamp - Inova (http://www.inova.unicamp.br);

- Agência de Inovação da Universidade Tecnológica Federal do Paraná (http://www.utfpr.edu.br/prorec/index.php?selecao=agencia.php), inaugurada no dia 30.08.2007;

- Núcleo de Inovação Tecnológica da Universidade Federal da Bahia (http://www.npi.ufba.br);

- Coordenadoria de Transferência e Inovação Tecnológica da Universidade Federal de Minas Gerais (http://www.ufmg.br/ctit);

- Agência de Inovação da Universidade Estadual de Londrina - inauguração prevista para o segundo semestre de 2007.

São ressaltadas também as iniciativas de governo e agências de fomento, que pelas mesmas razões das universidades, são consideradas de consulta obrigatória. Dentre elas, cita-se: 
- Portal do Ministério do Desenvolvimento, Indústria e Comércio Exterior (http://www.desenvolvimento.gov.br);

- Portal da Incubadora de conteúdos digitais da FAFESP - Fundação de Amparo à Pesquisa no Estado de São Paulo (http://incubadora.fapesp.br);

- Portal do Programa de Informação para Gestão de Ciência, Tecnologia e Inovação do IBICT - Instituto Brasileiro de Informação em Ciência e Tecnologia (http://www.prossiga.br).

\subsection{Critérios de avaliação de sites}

A avaliação de portais, segundo a literatura, pode ser feita a partir da análise de várias dimensões. Segundo Serafeimidis ${ }^{7}$ (1997 apud VILELLA, 2003) todo processo de avaliação é complexo, precisa ser feito com base em critérios bem definidos e seu resultado é sempre relativo, posição essa corroborada por Pereira (2001) e Vilella (2003). Verifica-se, também, que avaliação de páginas web tem sido feita, principalmente, por bibliotecários e educadores (MOSTAFA; TERRA, 1998), embora haja trabalhos como o de Eschenfelder (1997) que ao tratar do crescimento dos sites governamentais, apresenta as principais características da avaliação a partir das perspectivas da ciência da informação, dos negócios, da ciência da computação e da K-12 (referente à educação americana).

Para esse estudo, em função de suas características, optou-se pela análise com base em Vilella (2003) quando estudou os sites de governo. A metodologia é definida a partir das dimensões conteúdo, usabilidade e funcionalidade, bastante discutidas na literatura (ALMEIDA; BAX, 2003; BREITMAN, 2005; CHOU et al., 2005; COELHO, 2007; INTERNATIONAL ORGANIZATION FOR STANDARDIZATION - ISO, 2001; MORETTI; LIMA; AMARAL, 2005; NIELSEN, 2000; ROBERTSON, 2002; TERRA; BAX, 2003; TERRA; GORDON, 2002).

Cada dimensão (característica) a ser analisada, é contemplada por subcaracterísticas que estão divididas em itens de análise (VILELLA, 2003).

\footnotetext{
${ }^{7}$ SERAFEIMIDIS, V. (1997). Interpreting the evaluation of information systems investments: conceptual and operational explorations. Unpublished Doctoral dissertation, London School of Economics and Political Science. Disponível em:<http://www.lse.ac.uk/collections/informationSystems/pdf/theses/serafeimidis.pdf>.
} 
Para a obtenção da lista de critérios para uso nessa pesquisa, foram necessários os seguintes passos:

Passo 1

Adoção da listagem de parâmetros e critérios estabelecidos por Vilella (2003)

Passo 2

Comparação com outros autores da literatura nacional e internacional

Passo 3

Adaptação da descrição, inclusão e exclusão de critérios

Passo 4

Definição da lista de critérios para uso nesse estudo

Finalizados os três passos, obteve-se a lista de critérios que contempla as dimensões, as características (subscaracterísticas para VILELLA, 2003) e seus desdobramentos, aqui denominados atributos (itens de análise para VILELLA, 2003).

Lista de critérios para avalição de sites, definida para uso nesse estudo:

\section{DA DIMENSÃO CONTEÚDO}

- Característica Propósito (VILELLA, 2003)

○ Atributo 1: "Uma visão geral do portal é oferecida: propósito/missão do portal, apropriados à missão geral da entidade/órgão";

○ Atributo 2: "O escopo do portal está claramente colocado: tipo e origem da informação, público, datas de cobertura, etc.”;

○ Atributo 3: "Os serviços e informações oferecidos estão descritos no portal";

○ Atributo 4: Os assuntos abordados são complementados com a indicação de links para outras fontes de informação;

- Característica Abrangência/Cobertura (MORETTI; LIMA; AMARAL, 2005; TERRA; GORDON, 2002; VILELLA, 2003)

○ Atributo 1: Tipo de conteúdo (do autor); 
- Atributo 2: Tipo de assunto abordado (do autor);

- Atributo 3: Conteúdo está disponível em vários idiomas;

- Atributo 4: Mantém a publicação de diferentes versões de um mesmo documento, ou seja, tem controle de versões;

- Característica Padrão de publicação de conteúdo (ALMEIDA; BAX, 2003; BREITMAN, 2005; MORETTI ; LIMA; AMARAL, 2005; TERRA; GORDON, 2002)

- Atributo 1: Utiliza taxonomias; está claro o uso de ontologia; utiliza um sistema básico de classificação / organização; ou não é identificado nenhum padrão;

- Característica Atualidade (CHOU et al., 2005; VILELLA; 2003)

- Atributo 1: Conteúdo está atualizado, como pode ser observado nas datas de última atualização das páginas e também pela recuperação de informação disponibilizada recentemente;

- Atributo 2: Nas páginas de conteúdo mais significativo está indicada a última atualização;

- Característica Correção (VILELLA, 2003)

- Atributo 1: A responsabilidade pela precisão da informação está claramente indicada;

- Atributo 2: As fontes de informação são referenciadas de forma precisa;

- Atributo 3: Não há incidência de inconsistências, como erros de digitação, grafia e gramática.

- CaracterísticaAutoridade/copirraite (CHOU et al., 2005; VILELLA, 2003)

- Atributo 1: "Informações sobre copyright são fornecidas: identifica a propriedade intelectual do site e condições para estabelecimento de links, por exemplo";

- Atributo 2: "A menção das fontes de informação apresentada é um procedimento padrão";

- Atributo 3: "O responsável pela página está claramente identificado";

- Atributo 4: Há dados como endereço postal, telefone, etc., além de e.mail, que permitem verificar a legitimidade da página; 
- Característica Objetividade (CHOU et al., 2005; VILELLA, 2003)

- Atributo 1: "O conteúdo da página inicial (homepage) está de acordo com o propósito/ missão";

- Atributo 2: O conteúdo é adequado às necessidades e está acessível ao público-alvo;

○ Atributo 3: "O conteúdo é escrito em estilo de linguagem clara e consistente que está de acordo com o público-alvo";

- Atributo 4: "A informação está livre de publicidade";

○ Atributo 5: Os dados são úteis e propicia vantagens de uso;

- Característica Regras de publicação e acesso (COELHO, 2007; MORETTI; LIMA; AMARAL, 2005)

○ Atributo 1: Possui regras claras para publicação;

○ Atributo 2: $\mathrm{O}$ acesso é livre;

- Atributo 3: O acesso é condicionado, com pagamento de alguns conteúdos;

- Atributo 4: O acesso é restrito. Algumas categorias de usuários podem acessar, com ou sem pagamento, e outras não podem (mesmo pagando).

\section{DA DIMENSÃO USABILIDADE}

- Característica Inteligibilidade (CHOU et al., 2005; ISO, 2001; NIELSEN, 2000; VILELLA, 2003)

- Atributo 1: Utiliza estilos de fonte e atributos de formatação de texto adequados (ex.: tamanhos, cores, contrastes etc.);

○ Atributo 2: "Os links são claramente diferenciados, de forma a tornar fácil a compreensão de seu conteúdo";

○ Atributo 3: "Componentes da interface com o usuário como, por exemplo, menus, caixas de texto ou listas de seleção são utilizados respeitando-se as suas características funcionais".

- Característica Apreensibilidade (ISO, 2001; NIELSEN, 2000; VILELLA, 2003)

- Atributo 1: "Recursos para facilitar a navegação como, por exemplo, mapas do site, indicadores de novas informações disponíveis, ferramentas de busca etc., estão disponíveis e são facilmente identificáveis"; 
- Atributo 2: "Recursos para facilitar a apreensão do funcionamento da aplicação como, por exemplo, seções de ajuda e FAQ's estão disponíveis e são facilmente identificáveis";

○ Atributo 3: "Instruções de uso são fornecidas: instrução sobre necessidade de uso de browser específico, por exemplo";

- Atributo 4: "Existe indicação da existência de uma interface humana disponível para dar suporte à utilização, caso necessário".

- Característica Operacionalidade (CHOU et al., 2005; ISO, 2001; NIELSEN, 2000; VILELLA, 2003)

- Atributo 1: Não é necessária a rolagem horizontal e vertical para visualizar os elementos mais críticos da página;

- Atributo 2: O leiaute "permite o ajustamento do tamanho da homepage a diversas resoluções de tela";

- Atributo 3: "Itens estão agrupados na área de navegação, de modo que as categorias semelhantes ou relacionadas estão próximas entre si”;

- Atributo 4: "O acesso direto às tarefas de alta prioridade é oferecido na homepage";

○ Atributo 5: "A URL é clara ou não apresenta dificuldade de digitação para o usuário";

- Atributo 6: O portal está acessível na maior parte do tempo (aspecto analisado a partir de buscas eventuais, em dias e horários alternados);

- Atributo 7: "O conteúdo do portal pode ser acessado através de outras mídias, como celulares ou palm-tops" e informa aos usuários;

○ Atributo 8: Oferece recursos para acessibilidade.

\section{DA DIMENSÃO FUNCIONALIDADE}

- Característica Adequação (CHOU et al., 2005; ISO, 2001; MORETTI; LIMA; AMARAL, 2005; ROBERTSON, 2002; TERRA; GORDON, 2002; VILELLA, 2003)

- Atributo 1: Viabiliza um ambiente de promoção da comunicação em dois sentidos, ou seja, possibilita um diálogo real entre o site e o usuário; 
○ Atributo 2: Há “espaços de cooperação, a exemplo de salas de discussão e chats";

- Atributo 3: É incentivada a criação de comunidades de prática;

○ Atributo 4: Estão disponíveis aplicações (ferramentas) que possibilitam a implementação de compartilhamento de conhecimento e/ou comunidades de prática;

- Atributo 5: É possível "criar uma versão personalizada do conteúdo do portal";

○ Atributo 6: Possibilita a aquisição de conhecimento interna e externamente;

○ Atributo 7: Há espaço para a disseminação de notícias;

○ Atributo 8: A velocidade de acesso é adequada para a realização das buscas e interações.

- Característica Acurácia (CHOU et al., 2005; ISO, 2001; MORETTI; LIMA; AMARAL, 2005; ROBERTSON, 2002; VILELLA, 2003)

○ Atributo 1: Oferece informações, templates e formulários on-line adequados;

○ Atributo 2: Possibilita a elaboração de pesquisas em bases de dados locais e/ou externas;

- Atributo 3: Dispõe de mecanismo para "avisar ao usuário quando um novo conteúdo de seu interesse foi inserido";

○ Atributo 4: "Provê uma interface unificada para oferta de informações e serviços";

○ Atributo 5: Oferece mecanismo de gerenciamento de eventos;

○ Atributo 6: Disponibiliza estatísticas de uso.

- Característica Interoperabilidade (ISO, 2001; MORETTI; LIMA; AMARAL, 2005; TERRA; BAX, 2003; TERRA; GORDON, 2002; VILELLA, 2003)

○ Atributo 1: "Congrega informações de diferentes sites, não se configurando como um catálogo de links";

○ Atributo 2: "Provê acesso a fontes de dados heterogêneas, de forma transparente para o usuário";

○ Atributo 3: Possui mecanismos de acesso a perfis de usuários; 
○ Atributo 4: Dispõe de mecanismos de busca de $1^{\mathrm{a}}$. geração; $2^{\mathrm{a}}$. geração ou de $3^{\text {a }}$. Geração;

○ Atributo 5: Apresenta resultados de busca em formato estruturado (por assunto, por título, outro).

- Característica Conformidade (VILELLA, 2003)

- Atributo 1: "Está estruturado de acordo com uma política de desenvolvimento estabelecida pela entidade responsável";

- Característica Segurança de acesso (CHOU et al., 2005; ISO, 2001; TERRA; GORDON, 2002; VILELLA, 2003)

○ Atributo 1: "Especifica uma política de privacidade e segurança dos dados fornecidos pelos usuários";

○ Atributo 2: "Utiliza recursos de criptografia e site seguro".

A partir do detalhamento dos critérios, foi elaborado o formulário para a coleta de dados (Apêndice B) onde aparece a coluna 'pontuação', que será definida posteriormente para a análise dos dados.

4.3 Análise detalhada dos sites e seleção da amostra

Os sites utilizados para a análise (coleta de dados) são os indicados em iniciativas genéricas (Apêndice A).

Como o foco da pesquisa é inovação e desenvolvimento de produto, os dois assuntos são considerados o ponto de partida para a análise. Ou seja, os sites que não os contemplam, são automaticamente eliminados. Tendo em vista a importância do assunto, e para subsidiar a análise, além dos dois específicos "inovação" e "desenvolvimento de produtos", foram identificados os considerados como "áreas de interesse", extraídos dos sites analisados, a saber:

- Assunto específico: Inovação e Desenvolvimento de produto (DP);

- Áreas de interesse: cadeias produtivas, comunidades de prática, cultura corporativa, desenvolvimento industrial, empreendedorismo, gestão do conhecimento, gestão de empresas, informação tecnológica, inteligência competitiva, interação empresa e comunidade de CT\&I, marcas e patentes, manufatura e logística, marketing, 
organizações de aprendizagem, parcerias, planejamento estratégico, políticas públicas, processos de negócio, propriedade intelectual, qualidade.

É considerada também a importância dos tipos de conteúdos contemplados, pois através deles é possível verificar a diversidade e a abrangência dos documentos disponíveis. Os tipos de conteúdos apresentados no Quadro 4 também foram extraídos dos sites analisados, em especial do Portal de Conhecimentos (http://www.portaldeconhecimentos.org.br). De certa forma, essa lista atualiza e complementa a apresentada por Santa Eulália (2003, p.103), quando estudou a PDPNet - Comunidade de Prática sobre Desenvolvimento de Produto.

\begin{tabular}{|l|l|}
\hline \multicolumn{2}{|c|}{ Tipos de conteúdo } \\
\hline 1. Apresentações & Apresentações, imagens, vídeo \\
\hline 2. Artigos & De congressos, de periódicos, de divulgação \\
\hline 3. Caso & Casos, exemplos, lições aprendidas \\
\hline 4. Curso & Curso, disciplina, treinamento, programa de ensino \\
\hline 5. Empresa ou instituição & $\begin{array}{l}\text { Associações, consultoria, empresas, inst. de ensino, } \\
\text { ongs, fornecedores, grupos de pesquisa, redes de } \\
\text { cooperação }\end{array}$ \\
\hline 6. Estatística & Dados estatísticos, indicadores \\
\hline 7. Evento & Congresso, simpósios, workshop, reuniões, seminários \\
\hline 8. Glossário & Glossário, palavras-chave \\
\hline 9. Livro & Livros no todo e capítulos de livros \\
\hline 10. Melhores práticas & $\begin{array}{l}\text { Aplicativos, conceitos e aplicações, ferramentas e } \\
\text { métodos, sistemas e soluções, respostas técnicas, } \\
\text { software }\end{array}$ \\
\hline 11. Templates ou modelo de documento & Formulários, modelos de documentos \\
\hline 12. Pessoas & $\begin{array}{l}\text { Assessores, consultores, especialistas, pesquisadores, } \\
\text { professores, profissionais }\end{array}$ \\
\hline 13. Procedimentos & $\begin{array}{l}\text { Folhetos de equipamentos e de sistemas, guias, } \\
\text { manuais de uso, planilhas de instruções, roteiros, } \\
\text { tutoriais }\end{array}$ \\
\hline 14. Processo ou modelo de referência & $\begin{array}{l}\text { Modelos de referência, processo padrão, processos de } \\
\text { referência }\end{array}$ \\
\hline 15. Produto ou serviço & Produtos, serviços \\
\hline & ing \\
\hline
\end{tabular}

\section{Continua}




\section{Conclusão}

\begin{tabular}{|l|l|}
\hline 16. Projeto ou pesquisa & $\begin{array}{l}\text { Pesquisa, plano de pesquisa, projetos, trabalhos em } \\
\text { andamento, trabalhos futuros }\end{array}$ \\
\hline 17. Publicação geral & $\begin{array}{l}\text { Apostilas, boletins, clipping, depoimentos, editais, } \\
\text { entrevistas, legislação, newsletter, normas, notícias, } \\
\text { relatórios institucionais, reportagens, resenhas, white } \\
\text { papers, outros textos }\end{array}$ \\
\hline 18. Revista & Periódicos, revistas \\
\hline 19. Site & Blog, comunidades, grupos de discussão, site \\
\hline 20. Trabalho acadêmico & $\begin{array}{l}\text { Bibliografia comentada, dissertações e teses, listas de } \\
\text { referências, monografias, relatórios de viagens ou de } \\
\text { pesquisa, TCCs }\end{array}$ \\
\hline
\end{tabular}

Quadro 4 - Tipos de conteúdo contemplados nos sites

Segundo Terra e Gordon (2002) para que os portais aumentem sua eficiência e produtividade, é necessário que tenham características avançadas de personalização, o que permite a cada usuário acessar informações relevantes. E ao tratarem da avaliação de desempenho de portais de pequenas e médias empresas industriais de Taiwan, Chou et al. (2005) apresentam proposta de uma infra-estrutura integrada de avaliação. A infra-estrutura parte de critérios diversos como qualidade de dados, distribuição de conhecimento e aceitação de tecnologia. Da análise feita, verificou-se que qualidade dos dados foi considerada o principal atributo para aquelas empresas.

Para efeito da pesquisa atual, é estabelecido pelo pesquisador:

\section{Atributo principal}

- tipo de assunto

- acesso livre

- incentivo a criação de CoP

\section{Atributo secundário}

- tipo de conteúdo

- recursos para acessibilidade

- ferramentas para compartilhamento e CoP

\section{Atributo terciário}

- todos os demais atributos. 
Definidos os pontos-chave, foi elaborada a análise (coleta de dados) dos sites do Apêndice A, o que gerou uma nova lista (Apêndice C), com 20 (vinte) sites, que constitui a amostra para a análise dos dados.

\subsection{Análise dos dados}

Segundo Pereira (2001, p.29), a "imaterialidade da qualidade tende a falsamente sugerir sua imponderabilidade, ou seja, sua impossibilidade de ser medida". Mas "tudo na natureza é passível de mensuração, basta identificar qual numerus é adequado a essa tarefa". E retoma a afirmação atribuída a Galileu de que "se deve medir o mensurável e transformar em mensurável o que, à primeira vista, não for”.

Na análise qualitativa o pesquisador deve ter em mente que "a mensuração é uma estratégia de análise e não um objeto de análise”, razão pela qual é necessário “ajuizar qual o valor de expressão qualitativa de suas mensurações" (PEREIRA, 2001, p.29).

Para a análise dos dados, são definidos os seguintes passos:

Passo 1

Seleção da metodologia

Passo 2

Atribuição de pesos e notas

Passo 3

Atribuição de notas a cada um dos atributos a partir da análise dos sites (coleta de dados)

Passo 4

Definição da forma de calcular

Passo 5

Transposição dos dados (pesos e notas) para o formulário de análise de cada site

Passo 6

Geração dos gráficos de apoio à análise 
Para a seleção da metodologia de análise dos dados (passo 1), a literatura traz alguns trabalhos, mas nenhum deles apresenta um modelo para adoção integral. $\mathrm{O}$ trabalho de Vilella (2003), embora trate da avaliação de portais de governo eletrônico, é o que mais se aproxima do que se pretende fazer. Portanto é utilizado como base e adaptado para atender aos objetivos dessa pesquisa.

O estabelecimento de pesos e notas (passo 2) para cada atributo de todas as subcaracterísticas nas três dimensões (conteúdo, usabilidade e funcionalidade), é feito por Vilella (2003) mediante busca na literatura e consulta aos especialistas. Para esse estudo, a atribuição de pesos é feita pelo pesquisador, somente para os atributos, de acordo com categorização apresentada a seguir:

Atributo principal $\rightarrow$ peso 3

Atributo secundário $\rightarrow$ peso 2

Atributo terciário $\rightarrow$ peso 1

As notas vão de zero a dez, em duas variações de pontuação:

1. Variação de zero ou 10 (dez), onde:

○ Item válido $=10(\mathrm{dez})$;

○ Item inválido (não existente, parcial, não indica ou não se aplica) = zero.

\section{Variação 0/3/6/10}

Na dimensão USABILIDADE todos os atributos recebem pontuação zero ou 10 (dez). Nas dimensões CONTEÚDO e FUNCIONALIDADE aparecem também a variação 0/3/6/10, a saber:

a) Dimensão CONTEÚDO - característica ABRANGÊNCIA - atributo tipo de conteúdo É atribuída pontuação para o percentual de disponibilidade, a saber:

\begin{tabular}{|c|c|}
\hline \% de tipos de conteúdo disponível & Pontuação \\
\hline De 80 a 100\% (de 16 a 20 tipos) & 10 \\
\hline De 60 a 70\% (de 11 a 15 tipos) & 6 \\
\hline De 40 a 50\% (de 6 a 10 tipos) & 3 \\
\hline Até de 30\% (até 5 tipos) & Zero \\
\hline
\end{tabular}

Quadro 5 - Disponibilidade de tipos de conteúdo 
b) Dimensão CONTEÚDO -característica ABRANGÊNCIA - atributo tipo de assunto

Na mesma linha de raciocínio foi estabelecida a pontuação para "tipo de assunto", onde:

\begin{tabular}{|c|c|}
\hline Tipo de assunto & Pontuação \\
\hline Inovação e desenvolvimento de produto (DP) & 10 \\
\hline DP ou Inovação + assuntos relacionados & 6 \\
\hline Assuntos relacionados & 3 \\
\hline Todas as áreas do conhecimento, inclusive inovação e DP & 0 \\
\hline
\end{tabular}

Quadro 6 - Assuntos de interesse e pontuação

c) Dimensão CONTEÚDO - característica PADRÃO DE PUBLICAÇÃO DE CONTEÚDO - atributo taxonomia..., onde:

- Uso de taxonomia $=\mathrm{dez}$

- Uso de ontologia $=6$ (seis)

- Sistema básico de classificação = 3 (três)

- $\quad$ Não identificado $=$ zero

d) Dimensão FUNCIONALIDADE - característica INTEROPERABILIDADE - atributo mecanismo de busca, onde:

\begin{tabular}{|c|c|}
\hline Mecanismo de busca & Pontuação \\
\hline $\begin{array}{c}3^{\text {a }} \text {. Geração }=\text { busca por contexto, } \\
\text { linguagem natural, afinfidades }\end{array}$ & $10(\mathrm{dez})$ \\
\hline $2^{\mathrm{a}}$. Geração = busca por conceitos & $6($ seis $)$ \\
\hline $\begin{array}{c}1^{\mathrm{a}} \text {. Geração = palavras-chave, frase } \\
\text { exata, operadores booleanos }\end{array}$ & $3($ três $)$ \\
\hline Não dispõe de mecanismo de busca & zero \\
\hline
\end{tabular}

Quadro 7 - Mecanismos de busca

A atribuição de notas (passo 3) se deu a partir da análise de cada site. Com base nas notas e pesos pré definidos, é atribuída a pontuação para cada atributo.

Decidiu-se utilizar medidas simples (passo 4), tendo em vista o objetivo da pontuação. 
Todas as notas são transpostas para uma planilha de análise (passo 5), quando são gerados indicadores parciais para cada dimensão (e suas características) e um indicador geral para cada site. Os indicadores são levados em consideração para o estabelecimento de uma “classificação" dos sites, sem o intuito de indicar o melhor ou o pior. Servem de orientação para os interessados em conhecer quais são os ambientes prioritários de divulgação, compartilhamento e produção de conteúdo para apoiar a inovação e o desenvolvimento de produto.

Finalmente foram gerados os gráficos (passo 6) para facilitar a visualização dos dados obtidos. Esses gráficos são apresentados no próximo capítulo, seguidos de análise e discussão. 


\section{Resultados (análise e discussão)}

Os resultados são apresentados e analisados inicialmente a partir de cada uma das dimensões. No final é apresentada uma análise conjunta.

Ressalta-se que os dados obtidos estão detalhados no Apêndice E (p.121), que traz os formulários dos portais analisados.

\section{- Da dimensão Conteúdo}

Do ponto de vista da dimensão conteúdo, foram analisados 27 (vinte e sete) atributos das 08 (oito) características: a) propósito; b) abrangência; c) padrão de publicação; d) atualidade; e) correção; f) autoridade; g) objetividade; h) regras de publicação, detalhados nos critérios de análise dos sites (p.56).

Para facilitar a visualização dos dados obtidos é apresentado o Quadro 8 com a pontuação dos portais nessa dimensão:

\begin{tabular}{|c|c|c|c|c|c|c|c|c|c|}
\hline \multirow{2}{*}{ Site } & \multicolumn{8}{|c|}{ Conteúdo } & \multirow{2}{*}{$\begin{array}{l}\text { Média da } \\
\text { Dimensão } \\
\text { Conteúdo }\end{array}$} \\
\hline & Propósito & $\begin{array}{l}\text { Abran- } \\
\text { gência }\end{array}$ & $\begin{array}{l}\text { Padrão } \\
\text { de publ. }\end{array}$ & $\begin{array}{l}\text { Atuali- } \\
\text { dade }\end{array}$ & Correção & $\begin{array}{l}\text { Autori- } \\
\text { dade }\end{array}$ & $\begin{array}{c}\text { Objetivi- } \\
\text { dade }\end{array}$ & $\begin{array}{l}\text { Regras de } \\
\text { publ. }\end{array}$ & \\
\hline abdi & 10 & 6 & 3 & 0 & 10 & 7,5 & 10 & 12,5 & 7,37 \\
\hline $\operatorname{ccs}$ & 10 & 3,75 & 3 & 5 & 10 & 10 & 10 & 12,5 & 8,03 \\
\hline crie & 10 & 6 & 3 & 5 & 10 & 7,5 & 10 & 12,5 & 8 \\
\hline design & 10 & 8,5 & 3 & 10 & 10 & 10 & 10 & 10 & 8,93 \\
\hline inovar & 7,5 & 6 & 6 & 10 & 10 & 7,5 & 10 & 15 & 9 \\
\hline inpi & 10 & 8,5 & 6 & 10 & 10 & 7,5 & 10 & 12,5 & 9,31 \\
\hline $\mathrm{kmol}$ & 10 & 3,75 & 0 & 10 & 6,66 & 7,5 & 10 & 12,5 & 7,55 \\
\hline terraforum & 10 & 6 & 6 & 10 & 10 & 10 & 8 & 12,5 & 9,06 \\
\hline numaforum & 7,5 & 7 & 0 & 10 & 10 & 5 & 10 & 15 & 8,06 \\
\hline ocw & 10 & 4 & 3 & 10 & 10 & 10 & 10 & 15 & 9 \\
\hline patentnet & 5 & 3,75 & 0 & 0 & 3,33 & 2,5 & 8 & 12,5 & 4,38 \\
\hline conhece & 10 & 13 & 6 & 10 & 10 & 5 & 10 & 15 & 9,87 \\
\hline inovação & 10 & 7,5 & 3 & 0 & 6,66 & 10 & 10 & 12,5 & 7,45 \\
\hline bvinova & 10 & 6 & 3 & 0 & 10 & 10 & 10 & 12,5 & 7,68 \\
\hline sbrt & 7,5 & 0 & 0 & 5 & 10 & 7,5 & 10 & 15 & 6,87 \\
\hline score & 7,5 & 5,25 & 6 & 5 & 10 & 10 & 8 & 12,5 & 8,03 \\
\hline sebrae & 7,5 & 5,25 & 3 & 5 & 10 & 5 & 10 & 12,5 & 7,28 \\
\hline empreende & 10 & 2,25 & 3 & 5 & 6,66 & 0 & 2 & 12,5 & 5,17 \\
\hline scienti & 10 & 2,5 & 0 & 5 & 10 & 7,5 & 10 & 7,5 & 7,18 \\
\hline universia & 10 & 3 & 3 & 10 & 10 & 10 & 10 & 15 & 8,87 \\
\hline
\end{tabular}

Quadro 8 - Pontuação obtida pelos sites na dimensão conteúdo 
Ao observar os resultados verifica-se que a maior média é a do conhece, que obteve 9,87 pontos mas outros 4 (quatro) portais também atingiram a média 9 (nove). Além desses, 4 (quatro) atingiram média 8 (oito) e outros 06 (seis) ficaram entre 6,5 e 7,68 de média. Somente um obteve média 4,38, valor inferior a $50 \%$ da pontuação possível para essa dimensão, que é 11,85 .

Esses dados mostram, em primeira instância, que a maioria dos portais atende a maior parte dos critérios selecionados para análise de conteúdo, mas também que há espaço para melhoria de todos.

São apresentados a seguir os gráficos de cada característica para o conjunto de portais e no final, uma síntese da análise da dimensão conteúdo.

\section{Propósito}

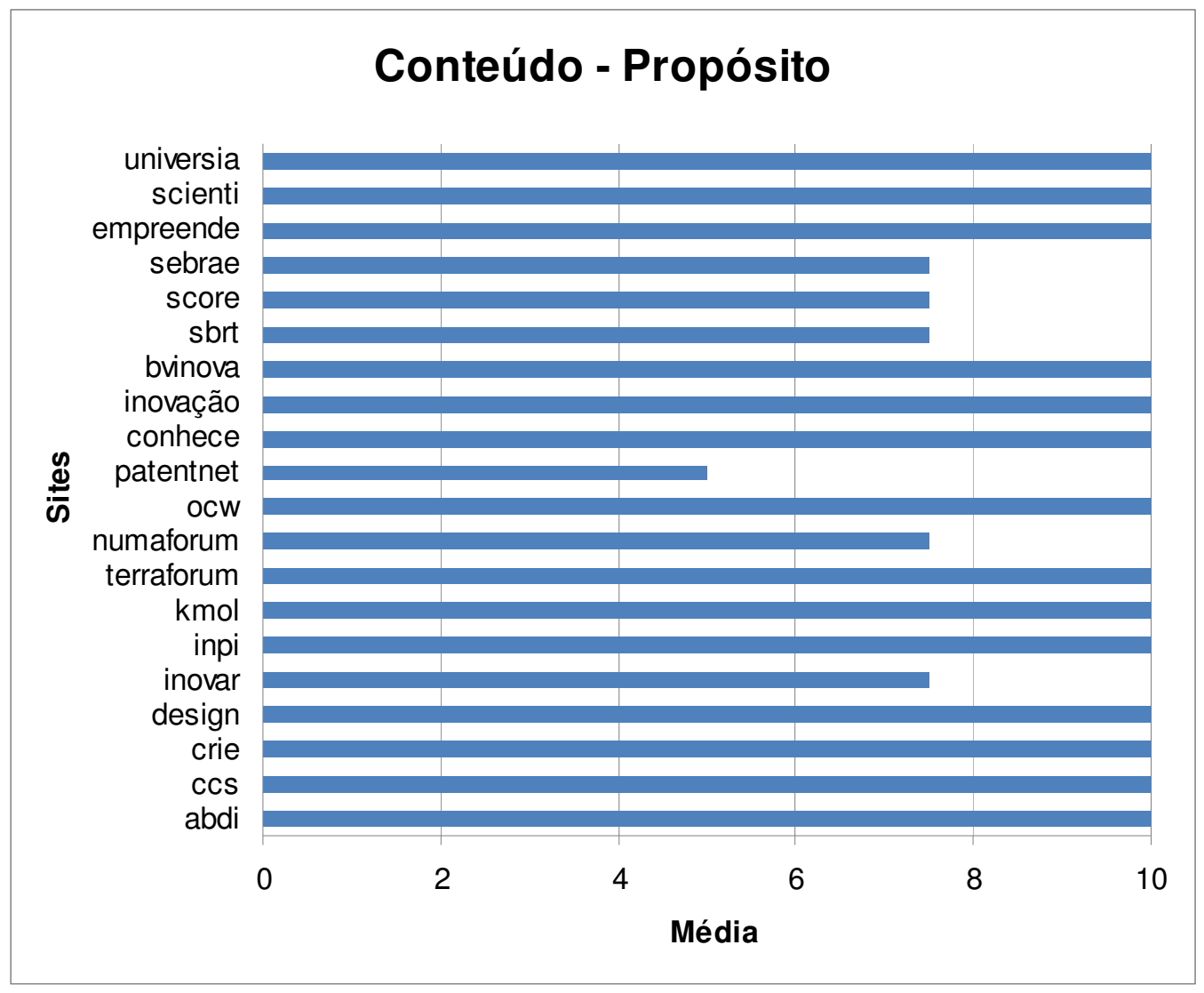

Figura 3 - Gráfico da dimensão conteúdo - característica propósito

Como pode ser observado, a maioria dos portais (catorze) obteve a pontuação máxima nessa característica, que inclui 4 (quatro) atributos: a) visão geral do site; b) definição de 
escopo; c) descrição dos serviços / informações; d) links complementares. As falhas verificadas referem-se à definição de escopo (inovar, patentenet, score e sebrae) e à falta de links complementares (numaforum, patentenet e sbrt). Com isso fica clara a razão da menor pontuação do patentenet (cinco) pois não contempla dois dos atributos analisados.

2. Abrangência / cobertura

Essa característica também é detalhada a partir de 4 (quatro) atributos: a) tipo de conteúdo; b) tipo de assunto; c) conteúdo em outros idiomas; d) controle de versões. Como pode ser observado no gráfico (Figura 4), os dados são mais divergentes do que para a característica propósito.

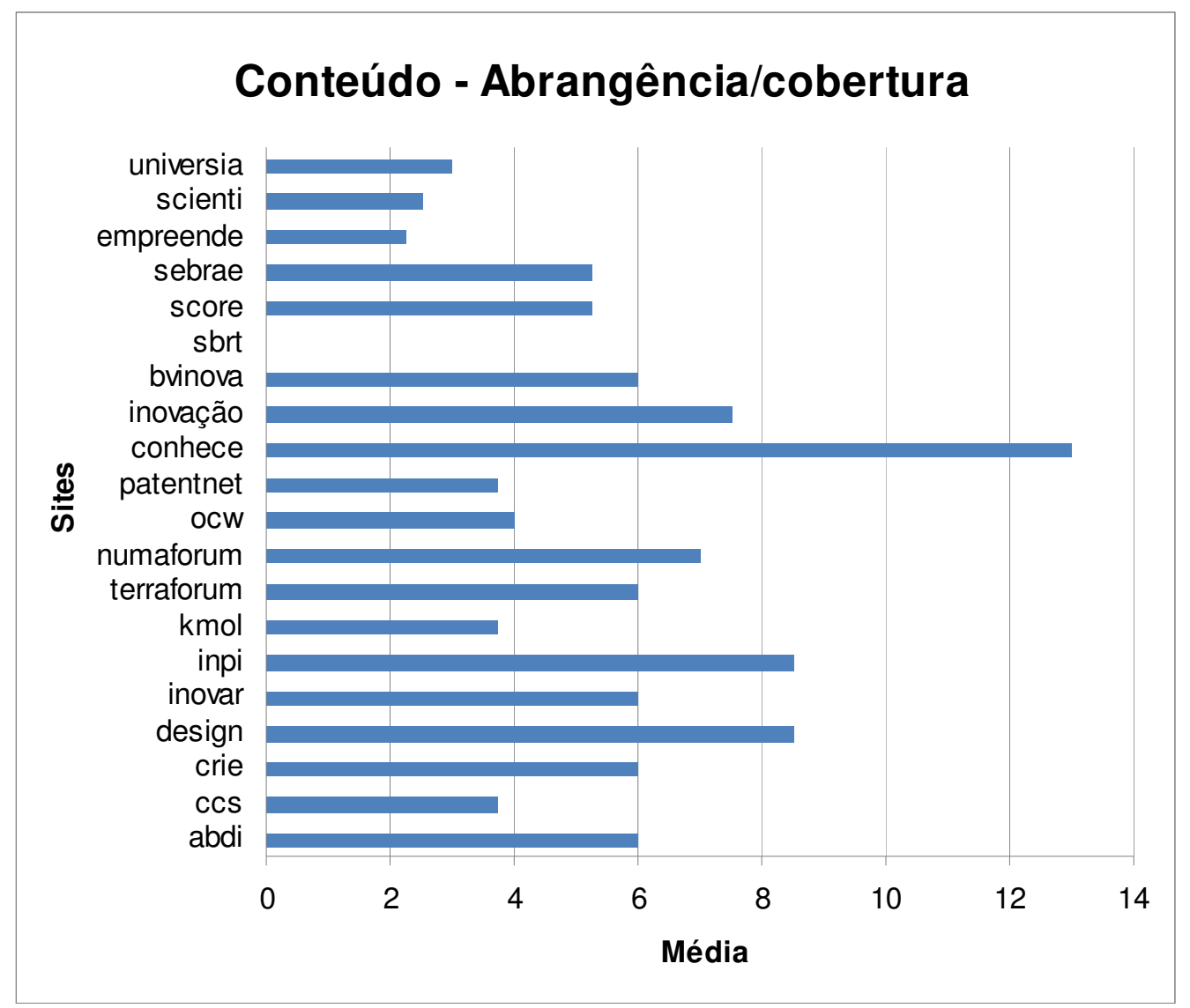

Figura 4 - Gráfico da dimensão conteúdo - característica abrangência / cobertura

Os dois maiores destaques dessa característica são observados para o conhece e para o sbrt, mas em situações opostas. O conhece obteve 13 (treze) pontos, valor bem maior que os demais portais. Isso ocorreu, principalmente, em função do atributo 'tipo de assunto', pois tem seu foco no desenvolvimento de produto e inovação, considerados de maior 
relevância para o estudo como indicado no Quadro 6 (p.51). O sbrt, por outro lado, teve a menor pontuação (zero), pois disponibiliza poucos tipos de conteúdo, atende a todas as áreas do conhecimento, não produz documentos em diferentes idiomas e também não mantém controle de versões dos conteúdos fornecidos, ou seja, não contempla nenhum dos quatro atributos analisados.

O 'tipo de conteúdo' está melhor contemplado (12 pontos) no conhece, no inovação, no score e no sebrae. Mas, como ocorre com o sbrt, que disponibiliza poucos tipos de conteúdo, também ficaram com a pontuação zero os seguintes portais: empreende, numaforum e scienti. Esse resultado, entretanto, deve ser observado em função do escopo de cada portal, como por exemplo o sbrt que disponibiliza dossiês e respostas técnicas elaborados, em sua maioria, sob demanda. Ou seja, oferece os tipos de conteúdos que atendem ao seu propósito.

Quanto à disponibilidade de conteúdos em outros idiomas, aqui entendido como o mesmo conteúdo em mais de idioma, somente é verificada no design (espanhol e inglês), no ocw (é o propósito do portal criar versões dos cursos em vários idiomas, inclusive em chinês) e no scienti (para atender às necessidades dos representantes dos países membros da Rede).

O atributo 'controle de versões' está contemplado no inpi (especialemente para legislação), no numaforum (onde são indicadas as atualizações a serem feitas) e no conhece.

3. Padrão de publicação de conteúdo

Essa característica tem um único atributo, que é o uso de taxonomia, ontologia ou algum tipo de classificação.

Ao observar o gráfico (Figura 5) verifica-se que nenhum portal obteve a pontuação máxima, ou seja, nenhum demonstrou o uso de taxonomia. Cinco utilizam recursos que podem ser considerados como uma ontologia (conhece, inovar, inpi, score e terraforum) e a maioria (dez) utiliza um sistema básico de classificação / organização. Nos outros cinco portais não é identificado nenhum padrão de publicação, razão pela qual receberam a pontuação zero e não aparecem representados no gráfico (kmol, numaforum, patentenet, sbrt e scienti). Esse resultado corrobora com outros encontrados na literatura, embora seja considerada importante a adoção de padrões para propiciar uma melhor recuperação da 
informação (FEITOSA, 2006; LOPES, 2002; KRAAIJENBRINK, 2007; BISCOZZO; CORALLO; ELIA, 2005).

O gráfico apresentado a seguir demonstra, de forma clara, a baixa média obtida pelos portais nessa característica:

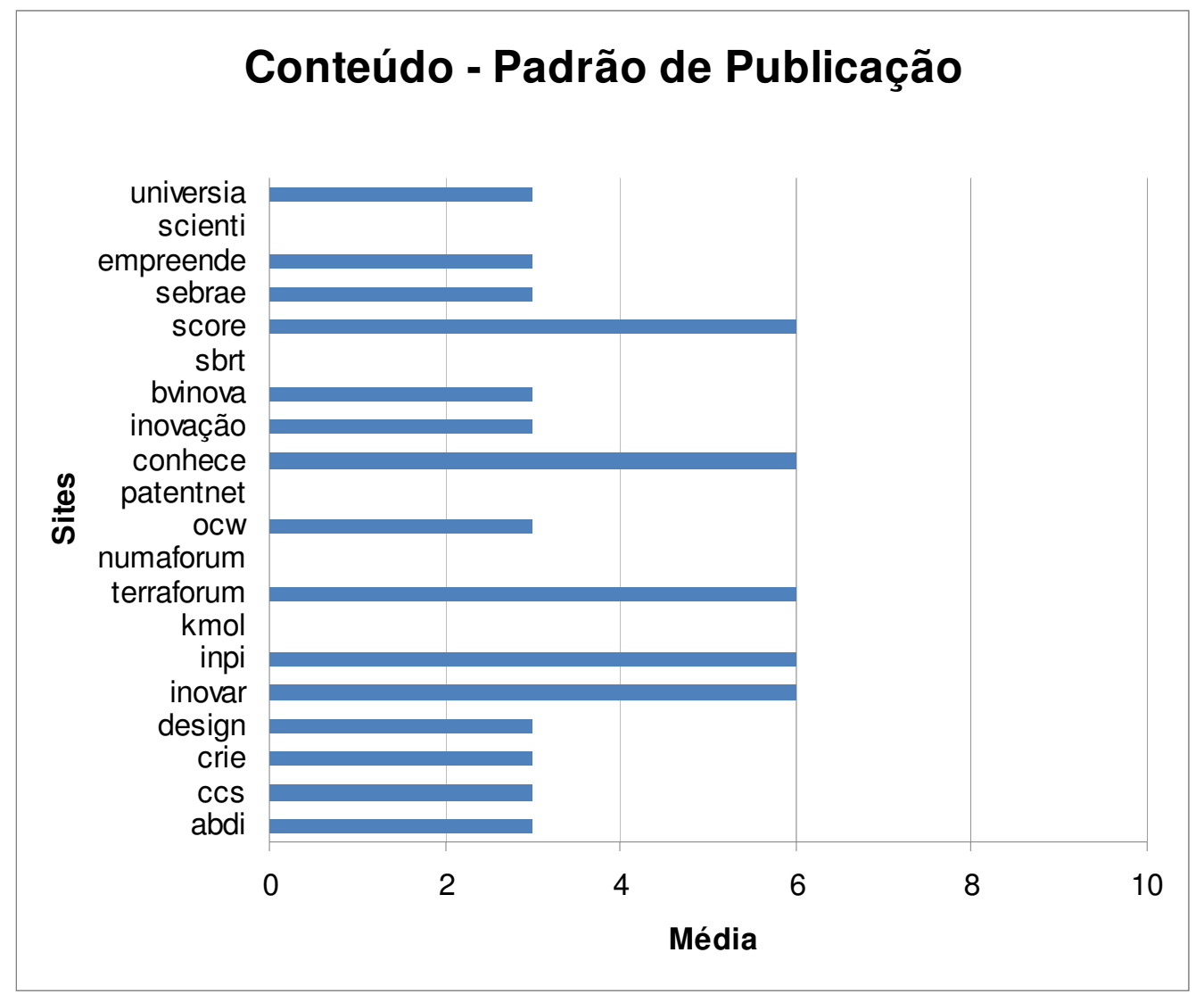

Figura 5 - Gráfico da dimensão conteúdo - característica padrão de publicação

\section{Atualidade}

A característica atualidade é analisada por meio de 2 (dois) atributos: a) conteúdo atualizado (de forma geral), com a identificação da data de atualização; b) data de atualização nos conteúdos mais significativos.

Menos da metade dos portais (nove) estão atualizados e indicam datas tanto na página inicial quanto nos conteúdos mais significativos. Alguns indicam a data em um ou outro local, independente da atualização (sete). Dois não indicam data em nenhum local embora estejam atualizados (abdi e inovação). O patentenet também não indica mas está 
desatualizado. Há ainda o scienti, que indica data de atualização na página inicial mas não é possível avaliar se está ou não atualizado.

Um atributo fundamental para decisão de uso é negligenciado pela maioria dos portais, ou seja, há um claro descaso quanto à orientação ao usuário sobre a atualidade do conteúdo. Aparentemente simples, a análise desses dois atributos demandou esforço e tempo além do necessário, segundo entedimento dessa pesaquisadora.

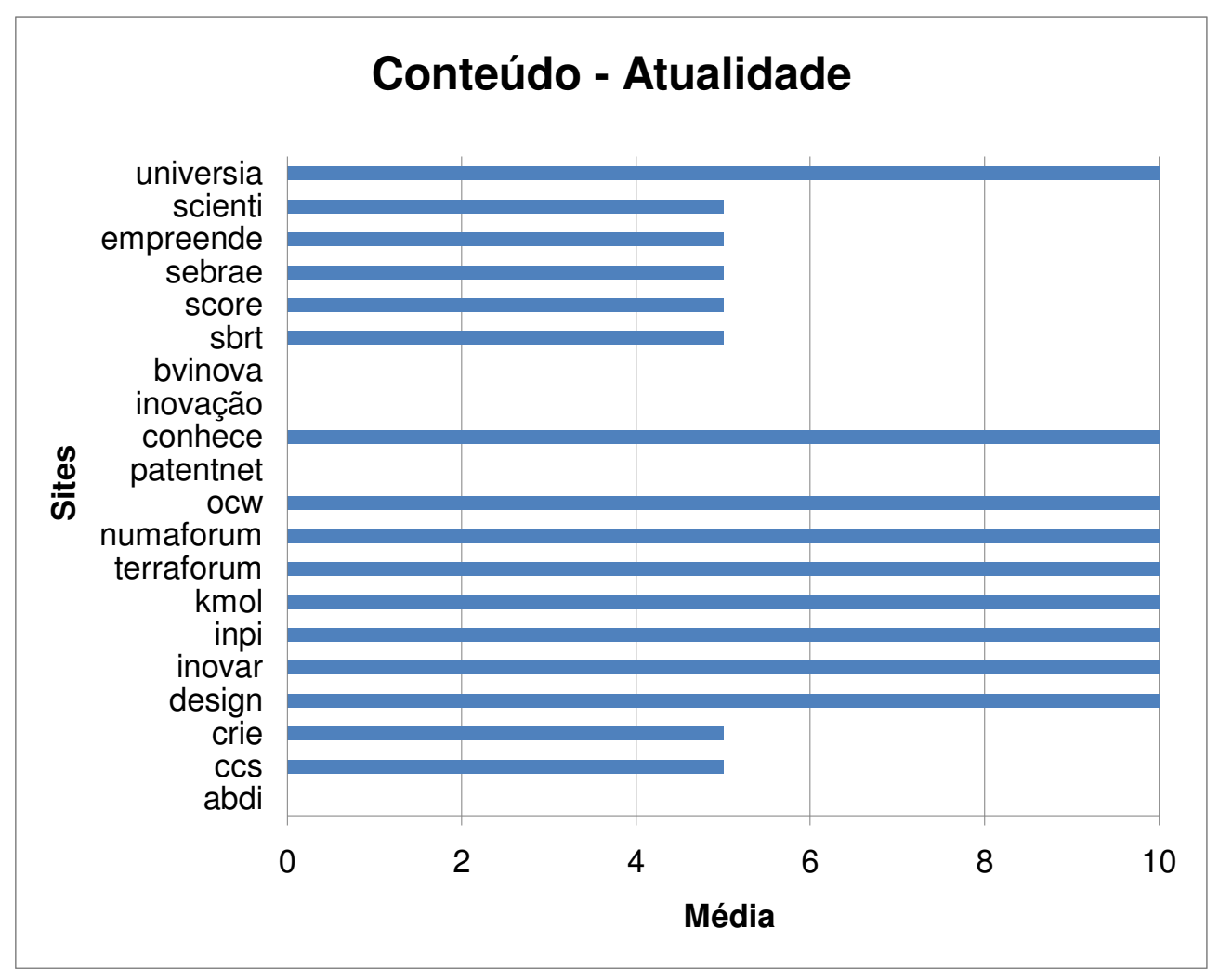

Figura 6 - Gráfico da dimensão conteúdo - característica atualidade

\section{Correção}

Três atributos são considerados para a análise da característica correção: a) responsabilidade da precisão; b) referenciação correta; c) inconsistências (erros de digitação, grafia e gramática). E a maioria dos portais (16) contempla os três atributos, o que pode ser considerado um resultado positivo, embora o ideal é que todos, no mínimo, evitem as inconsistências. 
Dos 3 (três) com pontução próxima a 7 (sete), empreende e kmol apresentam inconsistências de digitação, grafia e gramática enquanto o inovação não indica a responsabilidade pela precisão da informação. $\mathrm{O}$ patentenet recebe a menor pontuação por apresentar tanto problemas na referenciação das fontes de informação como inconsistências de grafia e digitação.

Os dados da característica correção podem ser melhor visualizados na Figura 7:

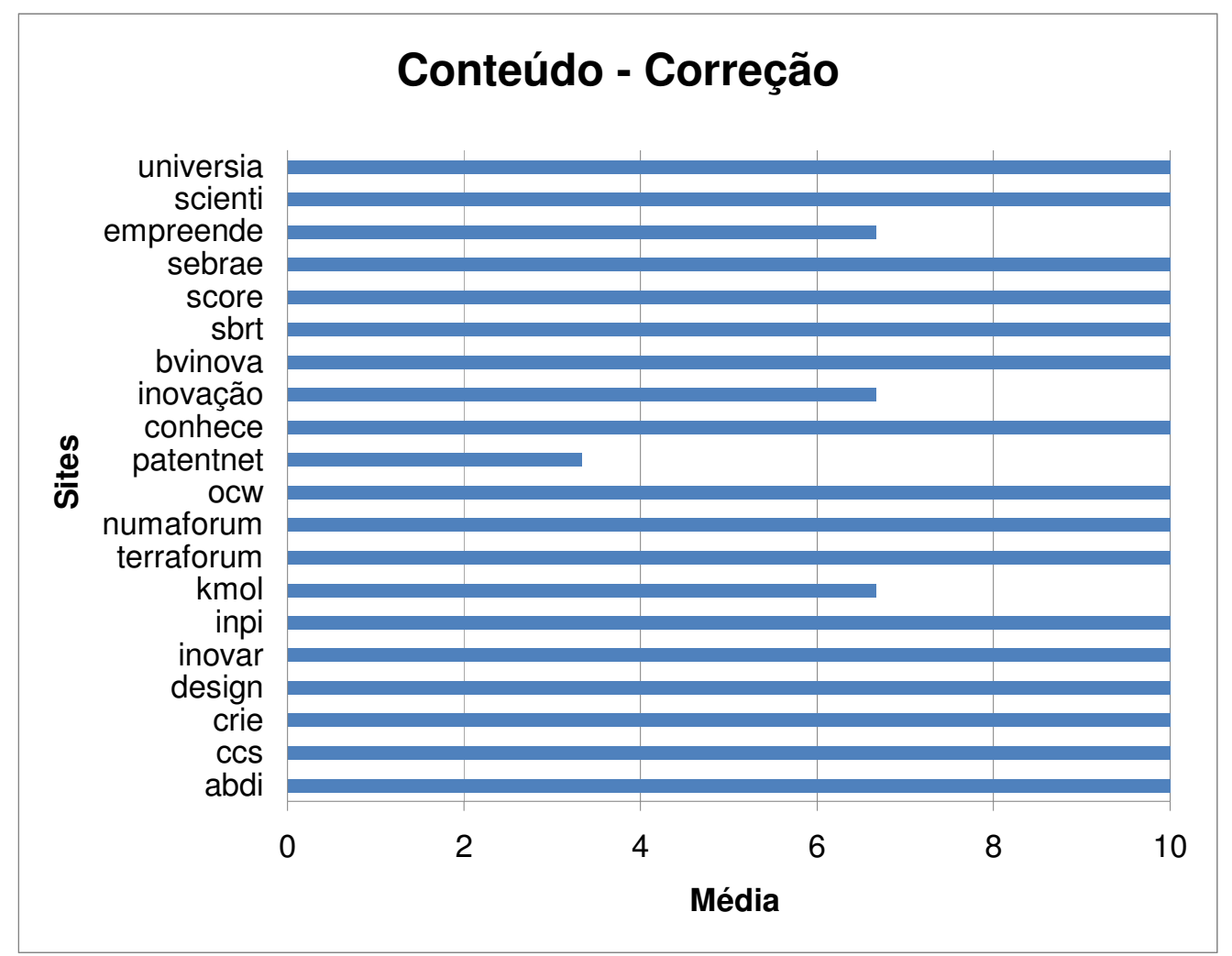

Figura 7 - Gráfico da dimensão conteúdo - característica correção

\section{Autoridade / copirraite}

A pontuação dos 4 (quatro) atributos da característica autoridade/copirraite é mais variada do que para a característica correção. Nesse caso, menos da metade (oito) dos portais contemplam todos os atributos: a) informação sobre copirraite; b) menção às fontes de informação; c) identificação de responsabilidade; d) legitimidade.

A maior incidência de falha refere-se ao atributo copirraite, pois 11 (onze) portais não fazem menção a ele. $O$ conhece, além de não mencinar o copirraite, não indica os dados 
que permitem verificar a sua legitimidade, o que também é observado no sbrt. O baixo desempenho do patentenet ocorre porque ele contempla apenas um atributo. E o desempenho efetivamente crítico é do empreende, que não contempla nenhum dos atributos dessa característica e, por essa razão, recebe pontuação zero, como mostra o gráfico (Figura 8):

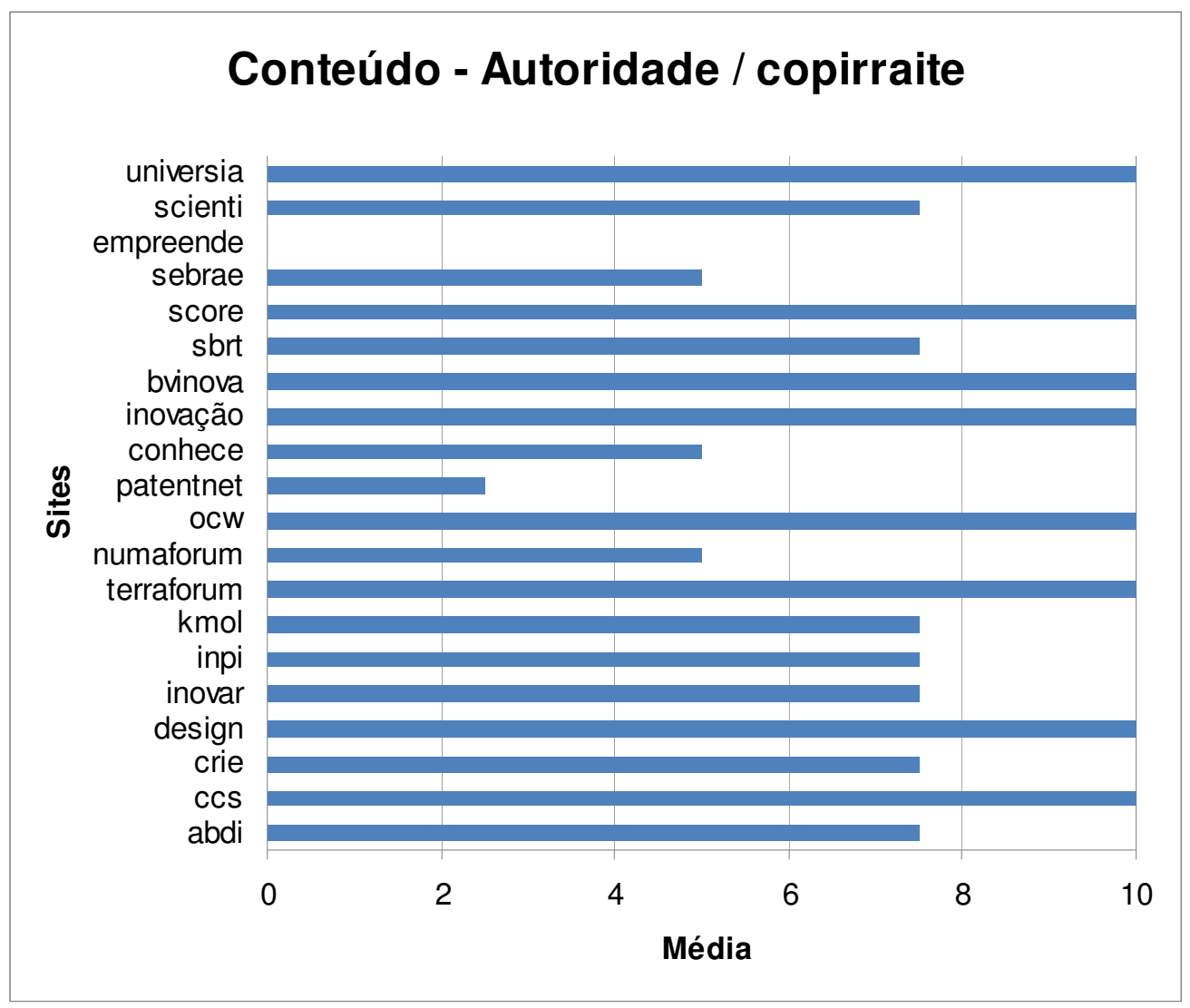

Figura 8 - Gráfico da dimensão conteúdo - característica autoridade / copirraite

7. Objetividade

A objetividade é avaliada a partir de 05 (cinco) atributos: a) conteúdo inicial de acordo com propósito/missão; b) adequação ao público alvo; c) estilo de linguagem de acordo; d) publicidade; e) utilidade e vantagem de uso.

Essa característica apresenta uma baixa variação de pontuação, exceto para o empreende. Dos 20 (vinte) portais, 16 (dezesseis) contemplam todos os atributos e dois (score e terraforum) não estão livres de publicidade. O empreende mais uma vez 
aparece em situação desfavorável em relação aos demais, pois contempla apenas um atributo que é a adequação do conteúdo inicial em relação ao propósito/missão.

Assim como para as demais caracteríticas, os dados são apresentados em formato de gráfico (Figura 9):

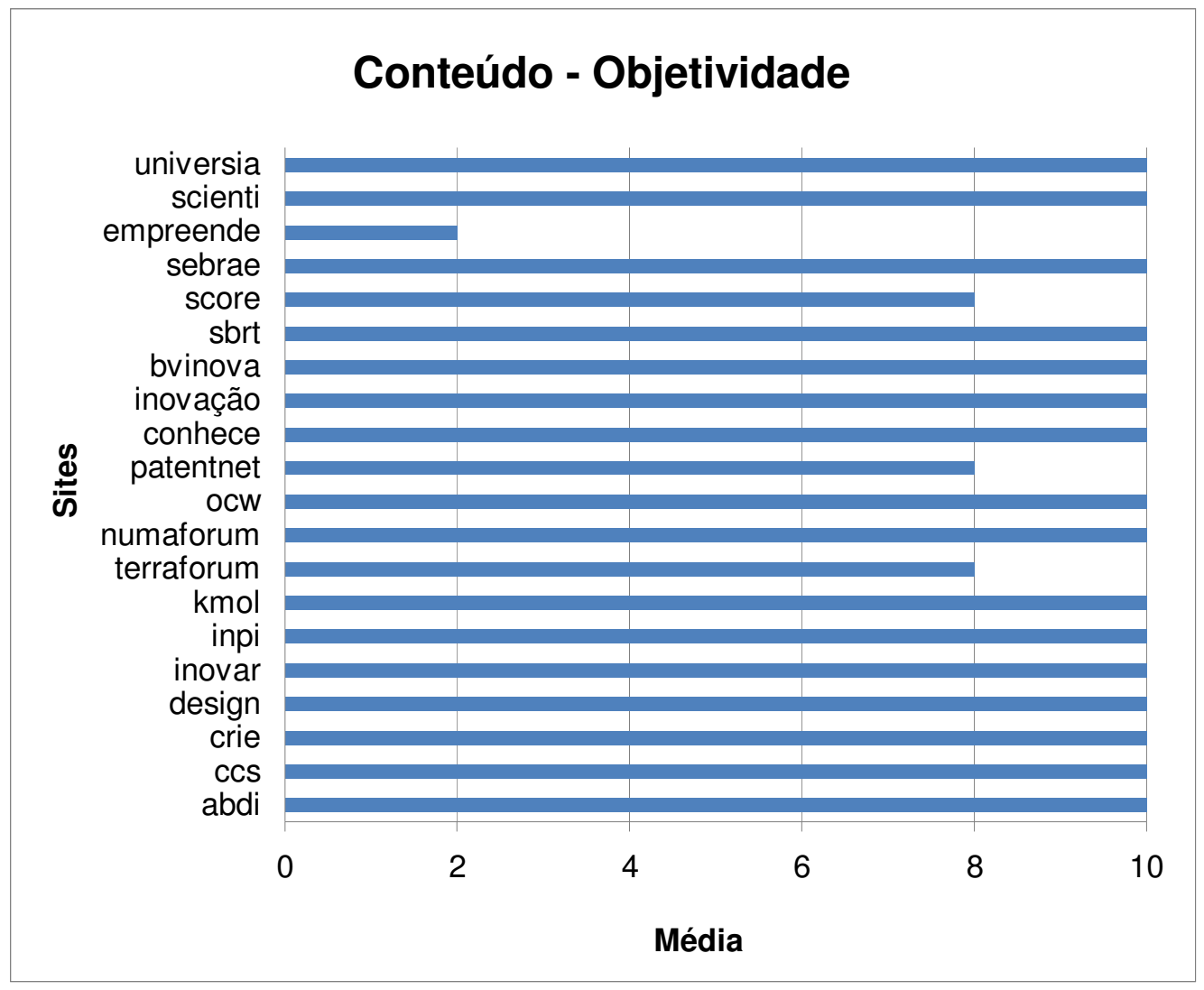

Figura 9 - Gráfico da dimensão conteúdo - objetividade

8. Regras de publicação e acesso

A última característica analisada da dimensão conteúdo contempla 4 (quatro) atributos: a) regras de publicação e acesso; b) acesso livre; c) acesso condicionado; d) acesso restrito.

Essa característica apresenta maior uniformidade de dados, onde o design obtém a menor pontuação por condicionar o acesso ao pagamento de parte do conteúdo e restringir o acesso a diferentes categorias, pois disponibiliza conteúdos específicos, por exemplo, para empresas e estudantes. 
Seis portais contemplam todos os atributos e o atributo com a menor incidência (sete) é a disponibilidade de regras de publicação e acesso. Outra falha observada em 5 (cinco) portais é o acesso condicionado, feito para alguns tipos de conteúdos, como livro no todo e revistas.

Confirmando a descrição dessa característica, é apresentado o gráfico (Figura 10), que facilita a visualização da referida uniformidade:

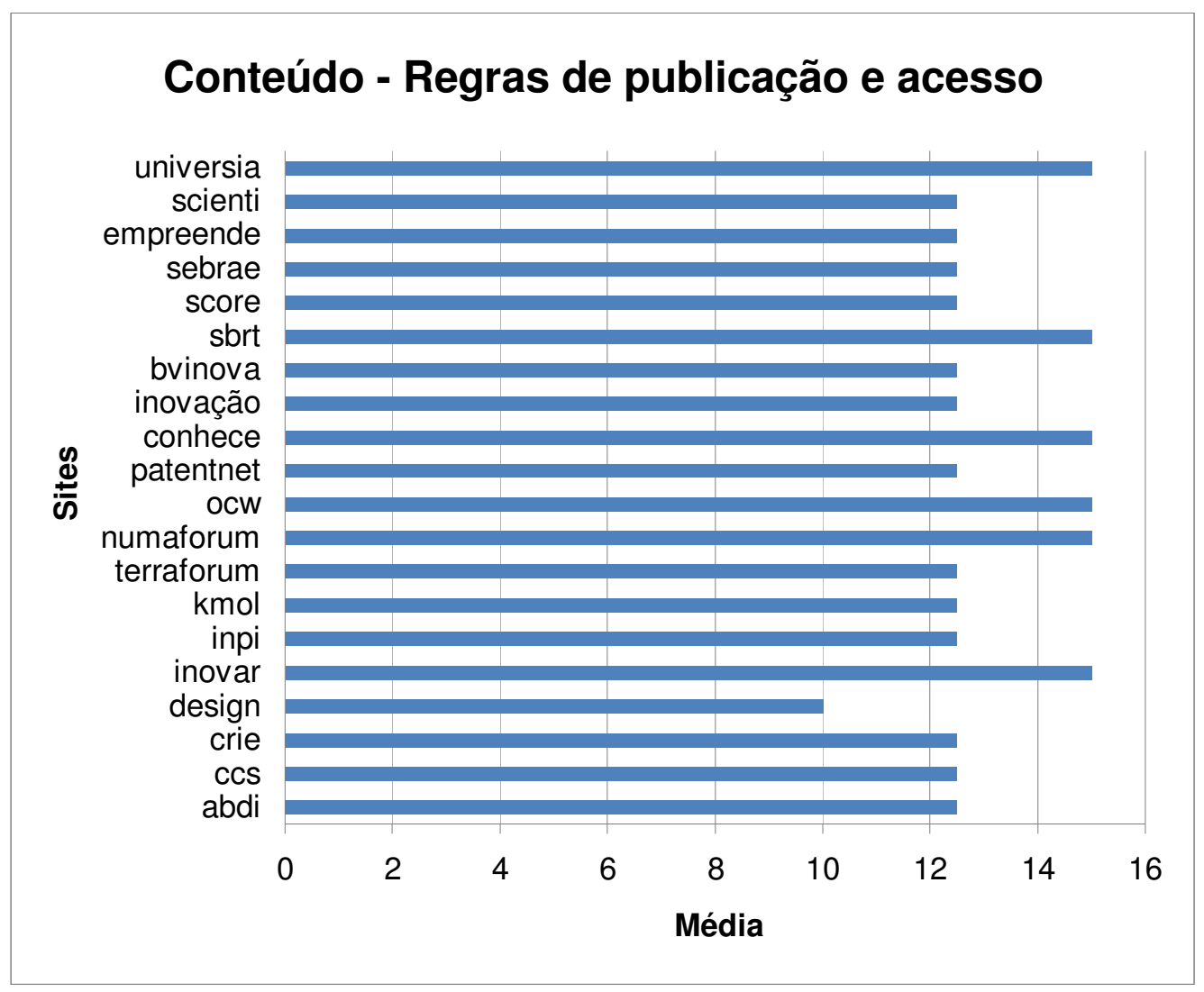

Figura 10 - Gráfico da dimensão conteúdo - regras de publicação e acesso

Analisadas todas as características e atributos, obseva-se que nenhum portal obteve a pontuação máxima possível para a dimensão conteúdo, que é de 11,63. Mas vale ressaltar que 5 (cinco) portais atingiram a média entre 9,0 e 9,87, o que pode ser considerado um bom resultado. Também merece destaque outros 06 (seis) portais com médias entre 8,0 e 8,93. Por outro lado, dois portais tiveram desempenho bastante negativo, com média inferior a metade da pontuação possível $(4,38$ e 5,17). É preciso considerar, ainda, que os portais, exceto o inpi, disponibilizam quantidade pequena de conteúdo, questão abordada 
pela característica abrangência, especialmente quanto aos atributos 'tipo de conteúdo' e 'tipo de assunto'. Isso, de certa forma, vai de encontro aos resultados de Kraaijenbrink (2007), utilizado como base para comparação nessa pesquisa porque trata especificamente de falhas de recuperação da informação na web por engenheiros envolvidos com o processo de desenvolvimento de produto. Naquele estudo são indicadas falhas relativas à necessidade, disponibilidade, área de conhecimento, nível de abstração e ausência de informação comparável.

\section{- Da dimensão Usabilidade}

A dimensão usabilidade foi avaliada com base em três características: inteligibilidade, apreensibilidade e operacionalidade, consideradas de relevância para esse estudo, e detalhadas em 15 (quinze) atributos, definidos nos critérios de análise (p.56).

Os dados estão sintetizadas no Quadro 9, que traz a pontuação obtida pelos portais na dimensão usabilidade:

\begin{tabular}{|c|c|c|c|c|}
\hline \multirow{2}{*}{ Site } & \multicolumn{3}{|c|}{ Usabilidade } & \multirow{2}{*}{$\begin{array}{l}\text { Média da } \\
\text { Dimensão } \\
\text { Usabilidade }\end{array}$} \\
\hline & Inteligibilidade & Apreensibilidade & Operacionalidade & \\
\hline abdi & 10 & 5 & 6,25 & 7,08 \\
\hline $\operatorname{ccs}$ & 6,66 & 0 & 1,25 & 2,63 \\
\hline crie & 10 & 5 & 5 & 6,66 \\
\hline design & 10 & 2,5 & 6,25 & 6,25 \\
\hline inovar & 10 & 5 & 6,25 & 7,08 \\
\hline inpi & 10 & 5 & 6,25 & 7,08 \\
\hline $\mathrm{kmol}$ & 10 & 2,5 & 7,5 & 6,66 \\
\hline terraforum & 10 & 0 & 5 & 5 \\
\hline numaforum & 10 & 7,5 & 6,25 & 7,91 \\
\hline ocw & 10 & 7,5 & 6,25 & 7,91 \\
\hline patentnet & 10 & 0 & 6,25 & 5,41 \\
\hline conhece & 10 & 7,5 & 6,25 & 7,91 \\
\hline inovação & 10 & 5 & 6,25 & 7,08 \\
\hline bvinova & 6,66 & 2,5 & 3,75 & 4,30 \\
\hline sbrt & 10 & 0 & 6,25 & 5,41 \\
\hline score & 10 & 10 & 8,75 & 9,58 \\
\hline sebrae & 6,66 & 7,5 & 6,25 & 6,80 \\
\hline empreende & 10 & 0 & 5 & 5 \\
\hline scienti & 3,33 & 0 & 5 & 2,77 \\
\hline universia & 10 & 7,5 & 7,5 & 8,33 \\
\hline
\end{tabular}

Quadro 9 - Pontuação obtida pelos sites na dimensão usabilidade 
Como pode ser observado o melhor desempenho é do portal score, com a média de 9,58 (do total possível de 10,66) e o único a atingir o nível nove de pontuação. O score é uma organização sem fins lucrativos, que trabalha desde 1964 com o aconselhamento livre e confidencial à pequena empresa e ao empresário americano.

Com média 8,33 aparece um segundo lugar o universia, voltado para o oferecimento de conteúdos de cursos. Mas as maiores concentrações de pontuação estão nas médias 7 (sete) e 5 (cinco), o que pode ser considerado um resultado negativo, especialmente para os portais com média abaixo de $50 \%$ do valor possível para essa dimensão $(5,33)$, além de outros 2 (dois) com pontuação um pouco superior $(5,41)$, também considerada crítica.

A visualização da pontuação obtida pelas diferentes características é apresentada, a seguir, em formato de gráfico.

1. Inteligibilidade

Característica contemplada por 3 (três) atributos: a) fontes e atributos de formatação; b) links claros; c) componentes de interface.

Como pode ser observado na Figura 11, a maioria dos portais (dezesseis) atende aos três atributos. Dos demais, o ccs, o bvinova e o sebrae apresentam problemas com os componentes da interface. E com a avaliação mais desfavorárel aparece scienti, que além da interface com problemas, não diferencia claramente os links, ou seja, deixa de contemplar dois dos atributos avaliados. Essas falhas, de certa forma, dificultam o acesso. 


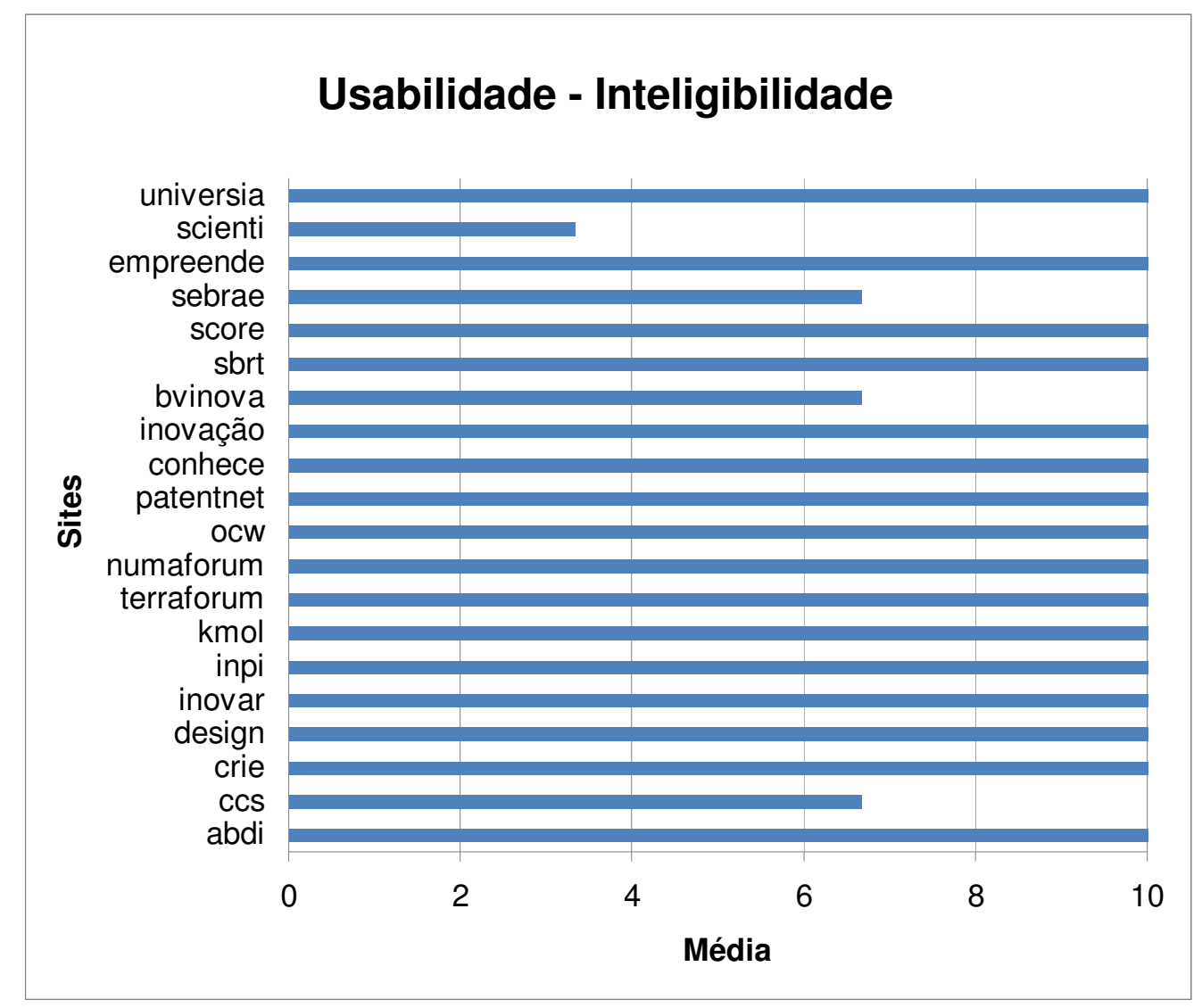

Figura 11 - Gráfico da dimensão usabilidade - característica inteligibilidade

\section{Apreensibilidade}

A avaliação da característica apreensibilidade é feita a partir da análise dos seguintes atributos: a) recursos de navegação; b) facilidade de apreensão; c) instruções de uso; d) interface humana para suporte.

A pontuação obtida pelos portais pode ser melhor vizualizada na Figura 12 (p.79).

O único portal a contemplar todos os atributos dessa caracaterística é o score que, inclusive, indica a disponibilidade de um especialista para atender às consultas. Além do score, o crie contempla o atributo interface humana. A falta desse atributo é responsável pela pontuação imediatamente inferior do conhece, do numaforum, do ocw, do sebrae e do universia.

Além da falta de interface humana, o atributo 'instruções de uso' não aparece em 4 (quatro) portais: crie (embora disponha de interace humana), inovar, inpi e inovação. Por outro lado, 3 (três) portais contemplam somente o atributo 'recursos de navegação' 
(bvinova, kmol e design). E, finalmente, o que mais chama a atenção nessa característica é a quantidade de portais (seis) que não contempla nenhum dos atributos, razão pela qual não estão representados visualmente no gráfico (ccs, terrafoum, patentenet, sbrt, empreende e scienti).

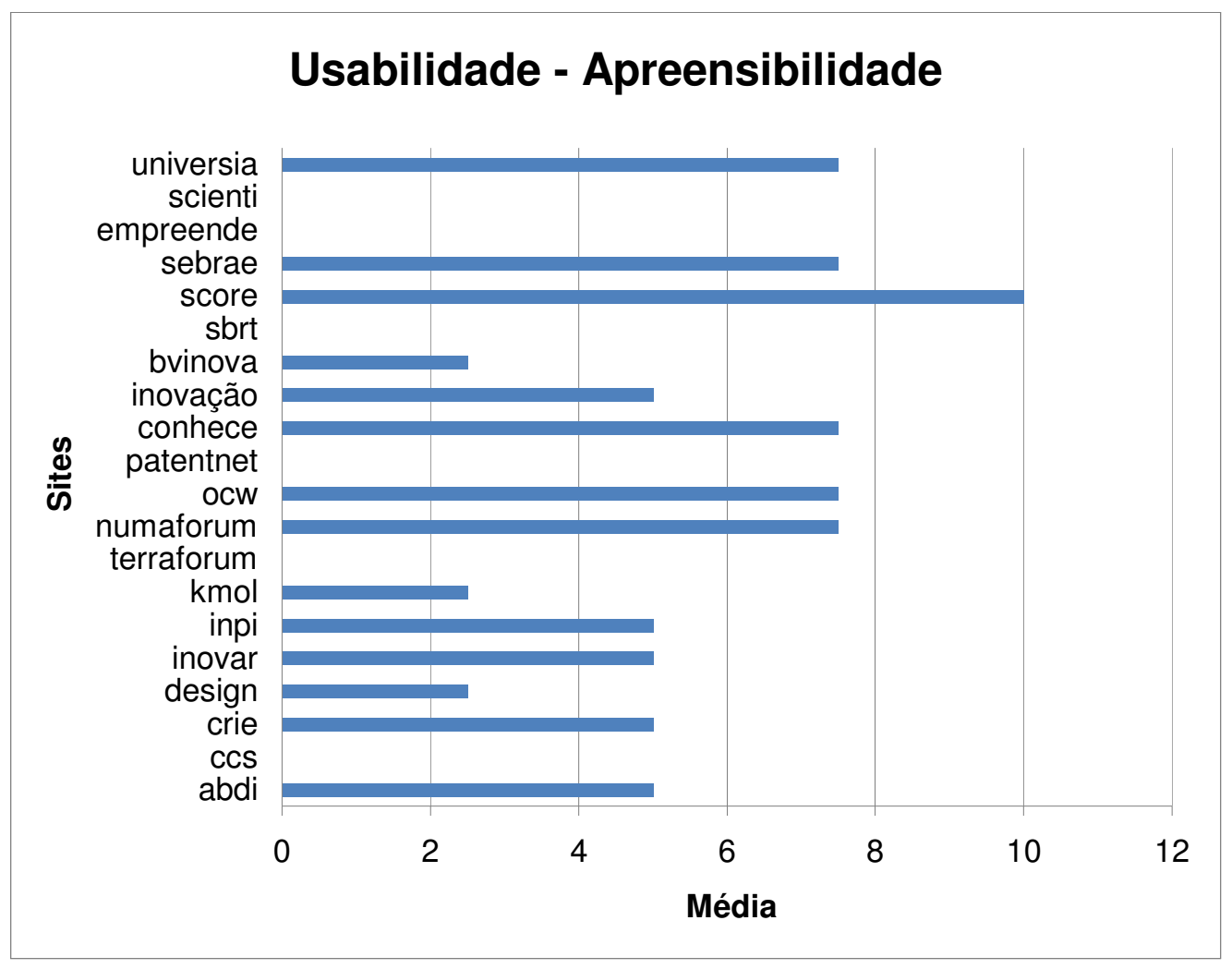

Figura 12 - Gráfico da dimensão usabilidade - característica apreensibilidade

Vale ressaltar que alguns portais embora apresentem alguns dos atributos analisados, eles são de dificil identificação e/ou localização, razão pela qual foram desconsiderados.

\section{Operacionalidade}

É a característica da dimensão usabilidade que oferece mais detalhes de análise (08 atributos), a saber: a) rolagem da página; b) ajuste de leiaute; c) agrupamento de itens; d) tarefas prioritárias na página inicial; e) clareza da URL; f) disponibilidade do portal; g) acesso através de outras mídias e h) acessibilidade. 
A Figura 13 mostra graficamente a média dessa característica para os portais analisados:

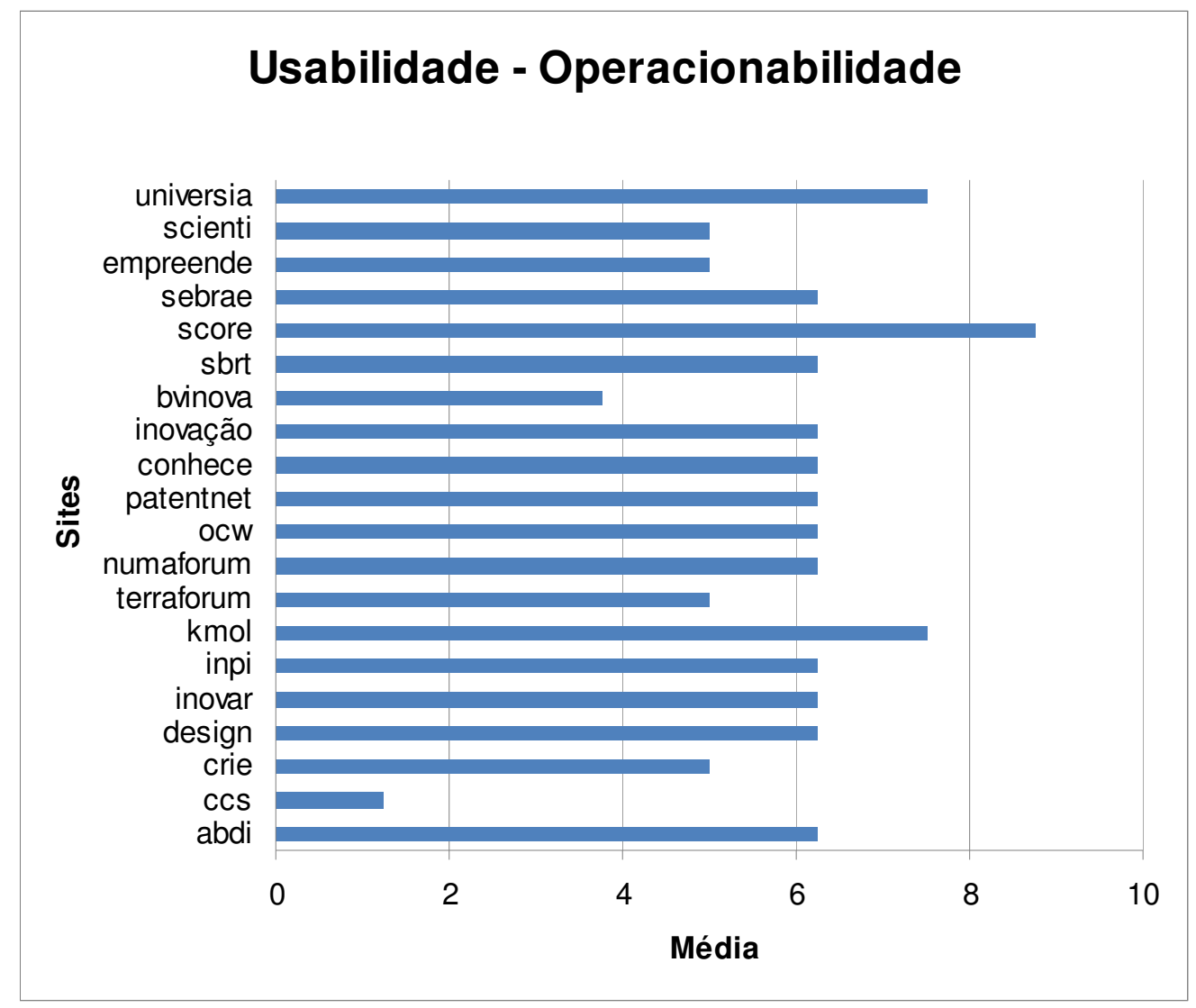

Figura 13 - Gráfico da dimensão usabilidade - característica operacionalidade

Como pode ser observado, o score recebe a maior pontuação nessa característica, embora deixe de contemplar dois atributos: ajuste de leiaute e outras mídias. A principal falha do score, e de praticamente todos portais (19), é não dispor de recursos para acesso através de outras mídias, o que é indicado no kmol. O mesmo ocorre com o atributo acessibilidade, contemplado apenas pelo score, que dispõe de recursos para acesso em Braille e por meio de texto falado (talking forms).

Embora nenhum dos portais contemple todos os atributos, o ccs é o único que contempla apenas um atributo (disponibilidade). Esse atributo foi avaliado em diferentes dias e horários, para todos os portais e houve problemas com o scienti no que se refere ao acesso aos links de segundo nível, que estão parcialmente corrompidos e os de terceiro que, em sua maioria, não funcionam. 
Finalizada a análise detalhada de cada uma das características da dimensão usabilidade, destacam-se:

- Apenas dois portais obtiveram boas médias: score $(9,58)$ e universia $(8,33)$;

- A maioria dos portais (onze) obteve médias entre 6,25 e 7,91, valores que podem ser considerados apenas razoáveis para usabilidade;

- A baixa pontuação de 6 (seis) portais, com variação de média entre entre 2,63 e 5,41. Dentre os resultados, destacam-se as médias obtidas pelo ccs $(2,63)$ e pelo scienti $(2,77)$, consideradas muito aquém do valor possível para essa dimensão, que é de 10,66. Especialmente para o scienti, por se tratar de uma rede pública de fontes de informação e conhecimento voltado à gestão da atividade científica, tecnológica e de inovação. Também se propõe a promover um espaço público e cooperativo de interação sobre ciência, tecnologia e inovação entre os países membros.

O maior comprometimento da dimensão usabilidade refere-se às características apreensibilidade e operacionalidade, mas a inteligibilidade também pode ser melhorada em todos os portais. Ou seja, embora os portais tenham a intenção de propiciar o acesso ao conhecimento, ainda é necessário investir na usabilidade para que isso, efetivamente, ocorra.

Esses resultados obtidos a partir da análise dos sites também corroboram os de Kraaijenbrink (2007), que considera que muitas das falhas na recuperação da informação na $w e b$ são decorrentes da usabilidade e da funcionalidade dos portais.

\section{- Da dimensão funcionalidade}

Assim como para conteúdo e usabilidade, a dimensão funcionalidade é analisada a partir de suas características e atributos, especificados nos critérios de análise (p.56).

O Quadro 10 (p.84) mostra a síntese dos resultados da dimensão funcionalidade, analisada a partir de 5 (cinco) características e 22 (vinte e dois) atributos. 


\begin{tabular}{|c|c|c|c|c|c|c|}
\hline \multirow{2}{*}{ Site } & \multicolumn{5}{|c|}{ Funcionalidade } & \multicolumn{2}{c|}{\begin{tabular}{c} 
Média da \\
dimensão \\
\cline { 2 - 7 }
\end{tabular}} & Adequação & Acurácia & $\begin{array}{c}\text { Interopera- } \\
\text { bilidade }\end{array}$ & $\begin{array}{c}\text { Conformi- } \\
\text { dade }\end{array}$ & Segurança & Funcionalidade \\
\hline abdi & 3,75 & 3,33 & 3,81 & 10 & 0 & 4,17 \\
\hline ccs & 3,75 & 1,66 & 4,06 & 10 & 5 & 4,89 \\
\hline crie & 12,5 & 5 & 9,07 & 10 & 0 & 7,31 \\
\hline design & 2,5 & 5 & 4,30 & 10 & 10 & 6,36 \\
\hline inovar & 3,75 & 3,33 & 4,28 & 10 & 5 & 5,27 \\
\hline inpi & 3,75 & 6,66 & 5,73 & 0 & 0 & 3,23 \\
\hline kmol & 11,25 & 5 & 7,58 & 10 & 0 & 6,76 \\
\hline terraforum & 6,25 & 1,66 & 4,18 & 10 & 5 & 5,42 \\
\hline numaforum & 10 & 3,33 & 5,87 & 10 & 0 & 5,84 \\
\hline ocw & 5 & 6,66 & 5,93 & 10 & 5 & 6,52 \\
\hline patentnet & 3,75 & 6,66 & 4,78 & 10 & 0 & 5,03 \\
\hline conhece & 7,5 & 6,66 & 7,15 & 10 & 0 & 6,26 \\
\hline inovação & 6,25 & 6,66 & 6,47 & 10 & 5 & 6,87 \\
\hline bvinova & 3,75 & 5 & 4,36 & 10 & 0 & 4,62 \\
\hline sbrt & 3,75 & 5 & 3,89 & 10 & 0 & 4,52 \\
\hline score & 5 & 6,66 & 5,93 & 10 & 10 & 7,52 \\
\hline sebrae & 10 & 3,33 & 6,96 & 10 & 0 & 6,06 \\
\hline empreende & 2,5 & 3,33 & 3,75 & 0 & 0 & 1,91 \\
\hline scienti & 7,5 & 5 & 6,59 & 10 & 0 & 5,81 \\
\hline universia & 5 & 3,33 & 4,82 & 10 & 5 & 5,63 \\
\hline & & & & & & 0 \\
\hline
\end{tabular}

Quadro 10 - Pontuação obtida pelos sites na dimensão funcionalidade

O quadro demonstra de forma evidente que a dimensão funcionalidade tem desempenho inferior ao do conteúdo e da usabilidade. A pontuação máxima foi obtida pelo score $(7,52)$, seguido do crie $(7,32)$, médias que podem ser consideradas baixas em relação ao total de pontos possíveis para essa dimensão $(11,36)$.

Os demais resultados reforçam a necessidade de atenção dos provedores. Oito portais obtém média entre 5,81 e 6,87 além de outros 10 (dez) que estão com menos de 50\% da pontuação possível, o que pode ser considerado um resultado muito aquém do necessário para o provimento do acesso, compartilhamento, divulgação e produção do conhecimento livre. Dentre esses, o desempenho extremamente crítico é do empreende, cuja média é 1,91 seguido do inpi, com 3,23.

A seguir são apresentados os gráficos que facilitam a visualização do desempenho de cada portal para as cinco características analisadas. 


\section{Adequação}

A média da característica está concentrada nos valores mais baixos, como pode ser observado no gráfico que segue:

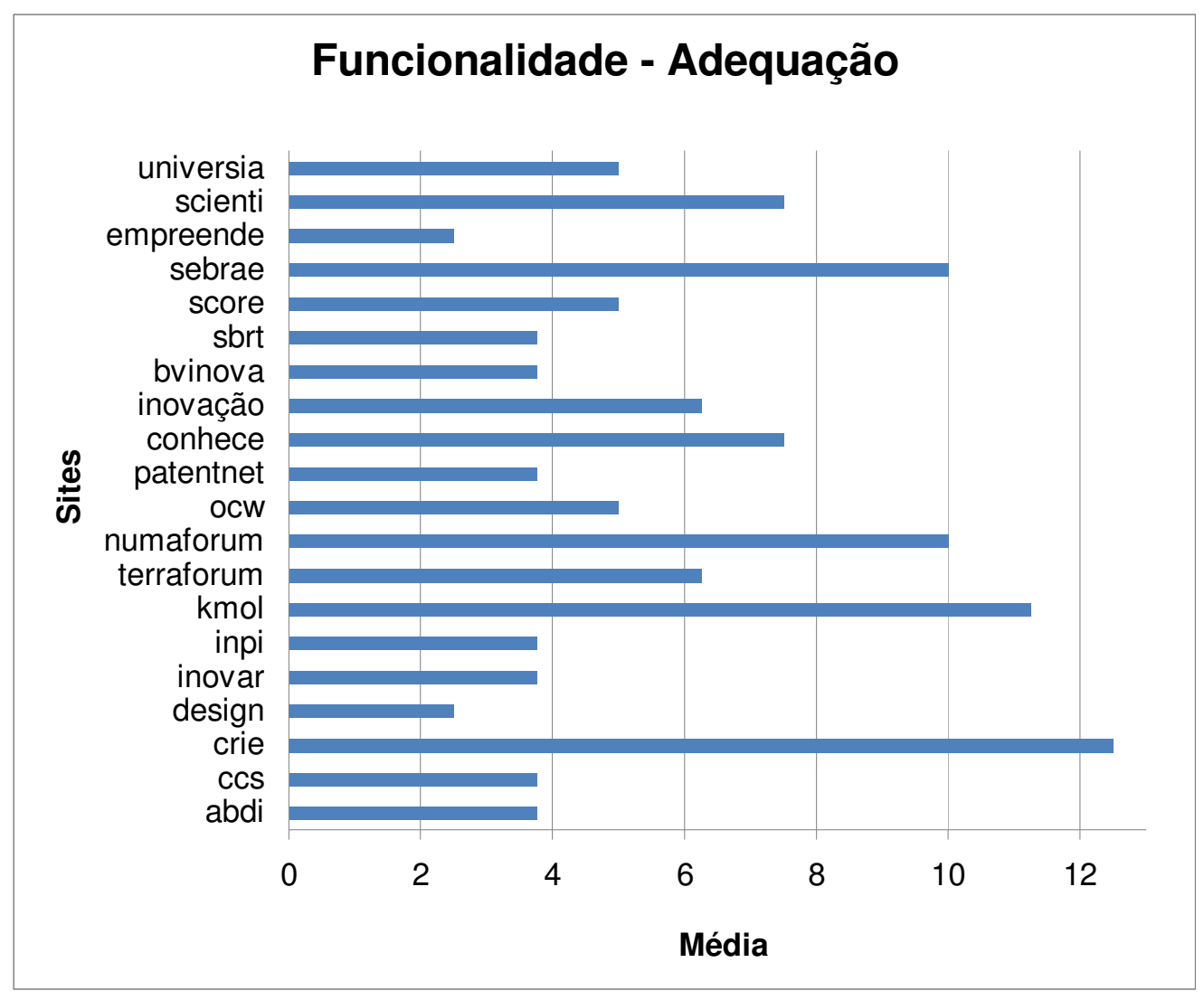

Figura 14 - Gráfico da dimensão funcionalidade - característica adequação

Para essa característica são analisados 8 (oito) atributos: a) diálogo site/usuário; b) espaços de cooperação; c) incentivo à criação de $\mathrm{CoP}$; d) ferramentas de $\mathrm{CoP}$; e) personalização de conteúdo; f) aquisição de conhecimento; g) espaço para notícias; h) velocidade de acesso. Desses, o único presente em todos os portais é a possibilidade de aquisição de conhecimento interna e externamente embora, como identificado na dimensão usabilidade característica inteligibilidade, nem sempre os links estejam claros. Em segundo lugar está a velocidade de acesso, que precisa ser melhorada no design e no empreende. A maioria (17) contempla espaços para disseminação de notícias.

Como compartilhamento e produção de conhecimento são focos do estudo e uma das formas mais propícias para isso é através das comunidades de prática, são analisados dois 
atributos: incentivo à criação e disponibilidade de ferramentas para implementá-las. Mas somente 7 (sete) portais incentivam claramente a criação e 2 (dois) disponibilizam ferramenta: crie e kmol. Ressata-se que ambos utilizam e disponibilizam o ICOX, um software brasileiro, livre, gratuito e de código aberto para gerenciar comunidades em rede.

\section{Acurácia}

Característica constituída de 6 (seis) atributos: a) disponibilidade de formulários; b) pesquisa em bases de dados; c) alerta personalizado; d) interface unificada; e) gerenciamento de eventos; f) estatística de uso.

Nenhum dos portais contempla todos os atributos. A maior pontuação obtida por 6 (seis) portais é 6,66. Pode ser considerado crítico o desempenho do ces e do terraforum, cuja média é de 1,66 .

Os atributos bases de dados e interface unificada são os mais contemplados. Por outro lado, o gerenciamento de eventos não é identificado em nenhum dos portais. Ressalta-se que vários apenas divulgam eventos. Outro atributo pouco contemplado é o alerta personalizado, presente somente em 3 (três) portais (kmol, ocw e patentenet). As estatísticas de uso também só aparecem em 6 (seis) portais, com destaque para o ocw e para o inpi, que apresentam vários tipos. Quanto aos formulários/templates, presentes na metade dos portais, não foi possível acessar os indicados pelo scienti, embora checados 5 (cinco) vezes em dias e horários diferentes, o que confirma o resultado indicado na dimensão usabilidade - característica operacionalidade.

O desempenho dos portais para a funcionalidade acurácia é demonstrado no gráfico que segue (Figura 15): 


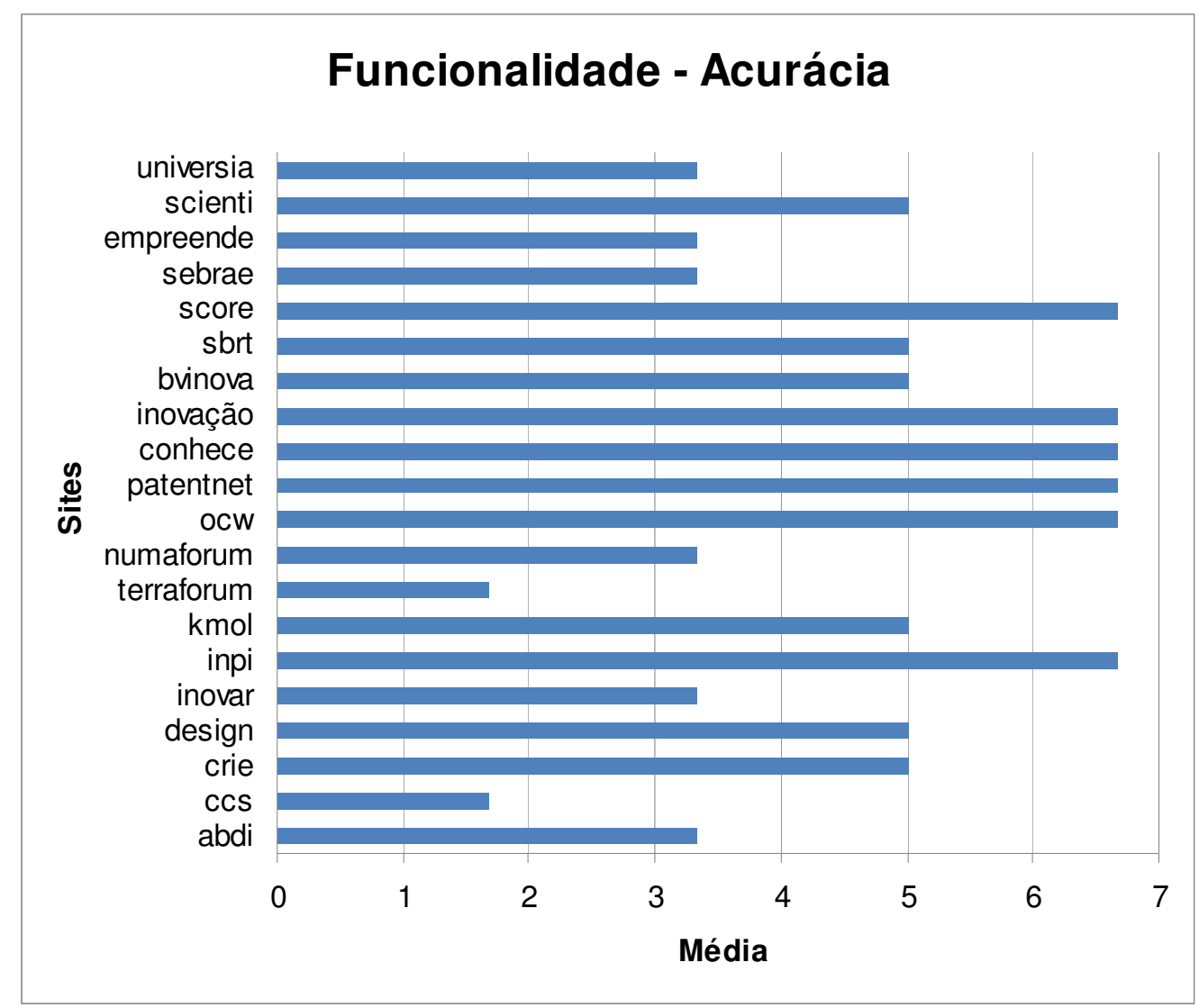

Figura 15 - Gráfico da dimensão funcionalidade - característica acurácia

3. Interoperabilidade

Os atributos avaliados na característica interoperabilidade são: a) fontes múltiplas sem se configurar como catálogo de links; b) transparência de acesso às fontes; c) acesso a perfis de usuários; d) mecanismo de busca; e) resultado de busca.

O acesso a perfis de usuários é permitido apenas em dois portais (crie e numaforum) e alguns informam que a restrição faz parte da política de privacidade. O numaforum, o patentenet e o terraforum não contemplam o atributo mecanismo de busca, que se apresenta de forma variada nos demais portais. A maioria (13) dispõe de mecanismo de $1^{a}$ geração, ou seja, a busca é feita a partir de palavras-chave ou frase exata, além da possibilidade de uso de operadores booleanos. No conhece e no scienti a busca pode ser feita a partir de conceitos ( $2^{\mathrm{a}}$ geração), enquanto o ccs e o inpi viabilizam as buscas com base no contexto além de se utilizarem de linguagem natural e afinidades $\left(3^{\mathrm{a}}\right.$ geração). 
Os atributos que contemplam o uso de fontes múltiplas com acesso transparente são identificados na maioria dos portais, mas o bvinova pode ser caracterizado como um catálogo de links e dados complementares.

Feitas estas considerações, apresenta-se a seguir o gráfico (Figura 16) que facilita a visualização do desempenho dos portais para a característica interoperabilidade:

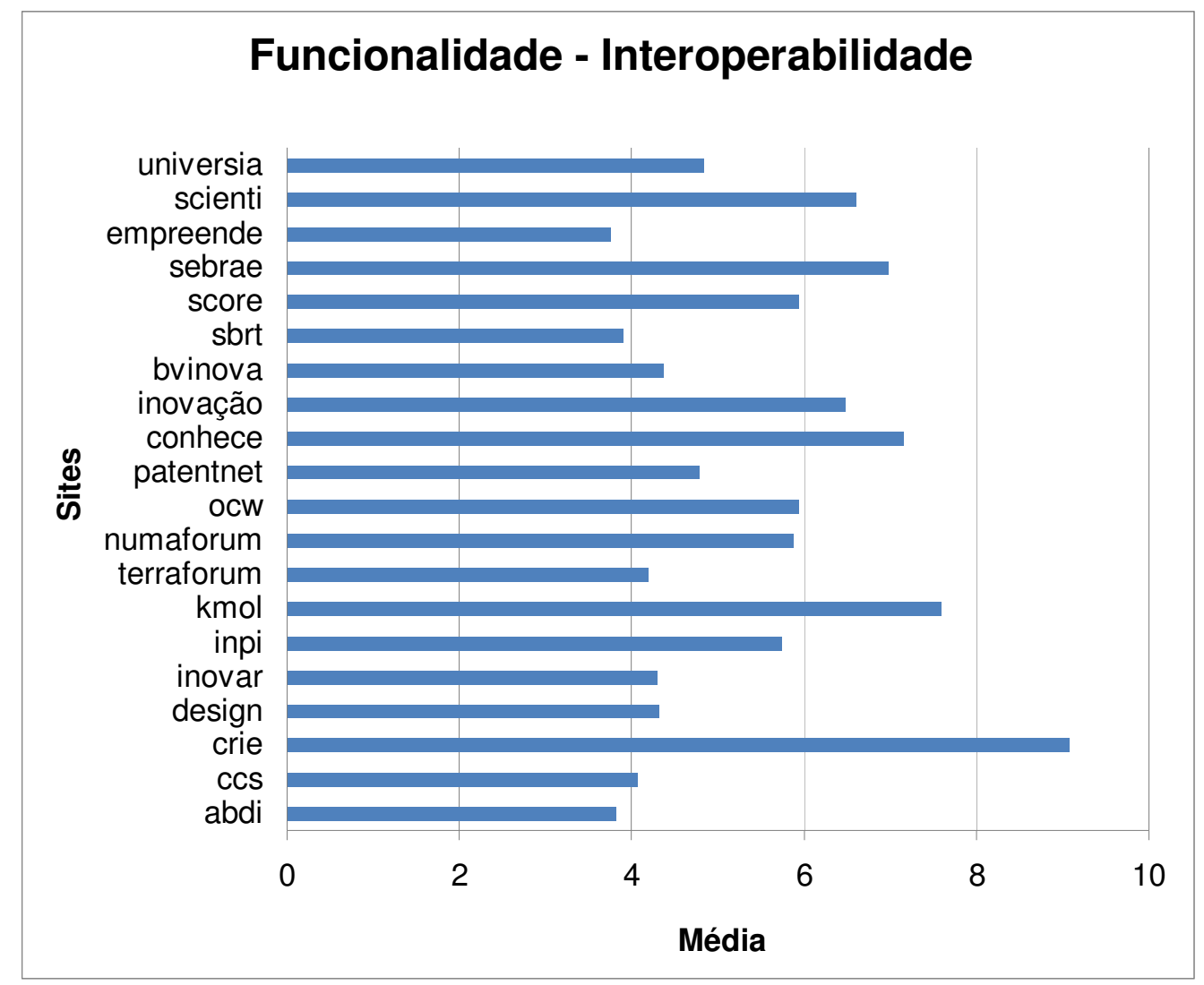

Figura 16 - Gráfico da dimensão funcionalidade - característica interoperabilidade

4. Conformidade

Nessa característica o atributo básico é verificar se o portal está efetivamente estruturado conforme a política de desenvolvimento. E como pode ser observado no gráfico (Figura 17), somente dois portais (empreende e inpi) não recebem pontuação. Isso se deve ao fato de não ter sido localizada a política estabelecida pela entidade responsável pelo desenvolvimento. 


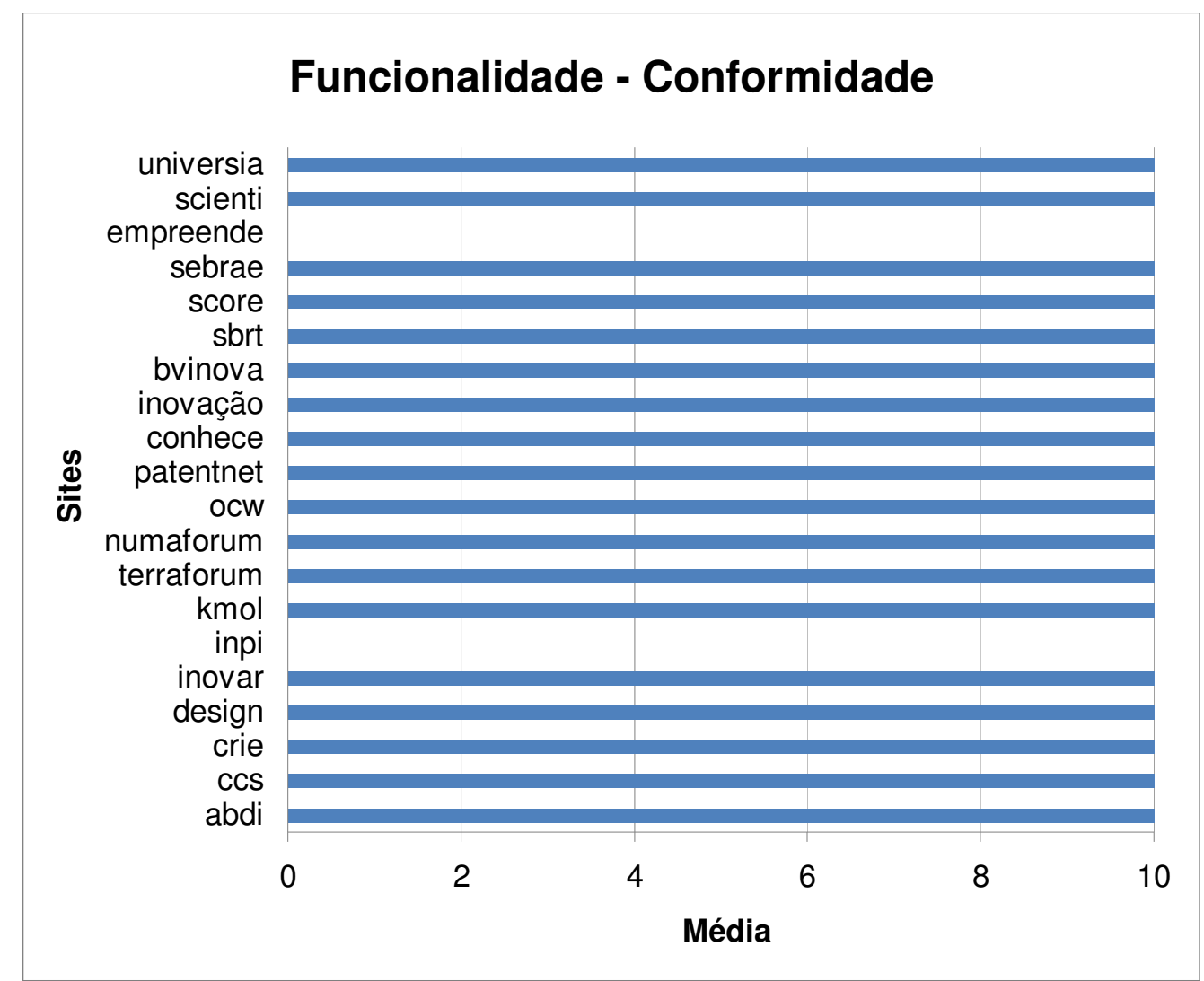

Figura 17 - Gráfico da dimensão funcionalidade - característica conformidade

5. Segurança de acesso

Para análise dessa característica são levados em consideração dois atributos: a) especificação de política de privacidade; b) uso de recursos de criptografia.

É a característica menos privilegiada pelos portais, pois na maioria (12) não foi identificado nenhum dos atributos. Em 8 (oito) há indicação e política de privacidade e apenas o design e o score indicam o uso de recursos de criptografia.

Considerando a necessidade de segurança de dados, deveria haver mais atenção dos provedores em relação a essa característica. Isso, de certa forma, explica a restrição de acesso aos perfis de usuários.

Segue o gráfico (Figura 18, p. 89) que representa os resultados obtidos para essa característica: 


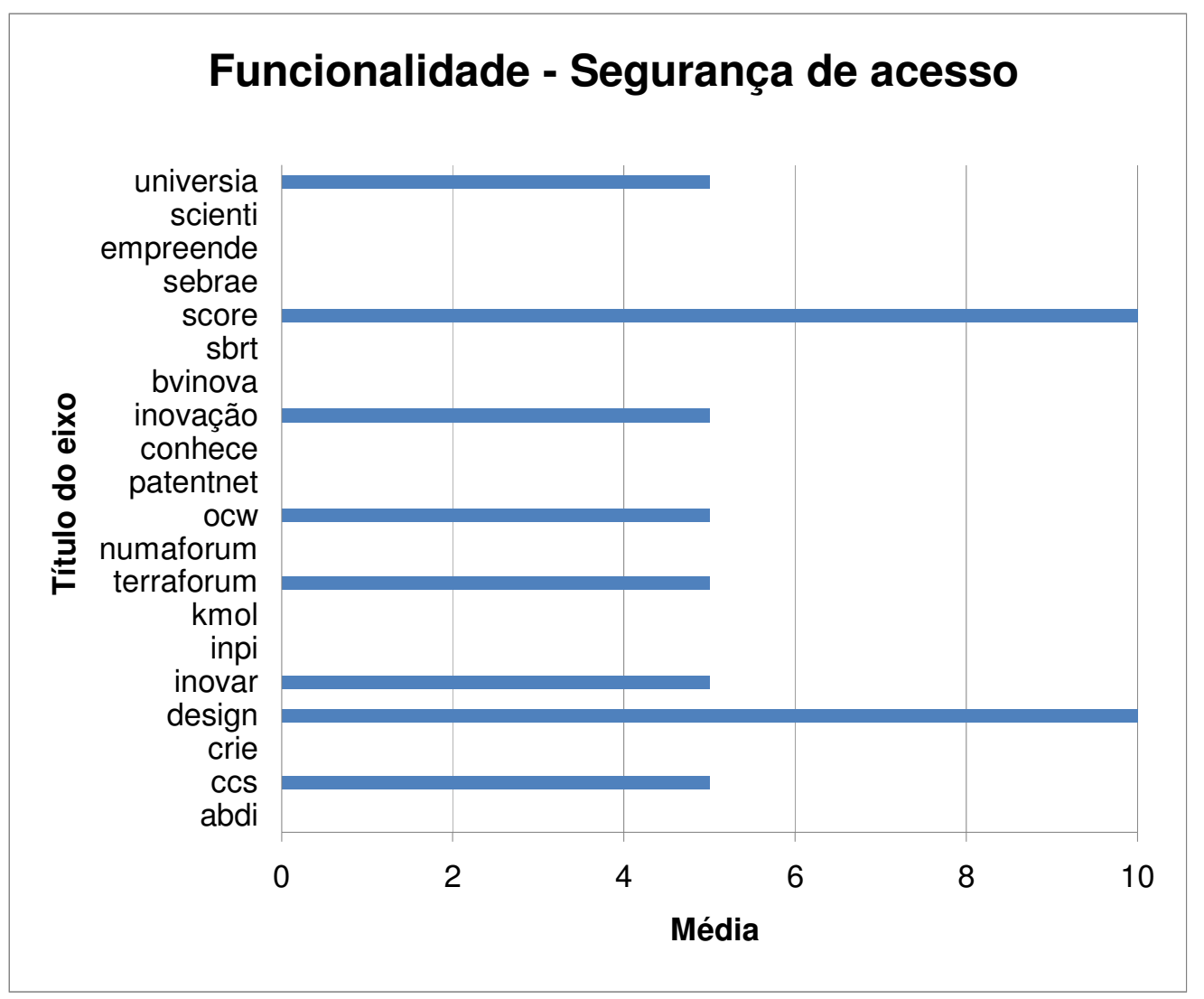

Figura 18 - Gráfico da dimensão funcionalidade - característica segurança de acesso

Dos dados obtidos verifica-se que a dimensão funcionalidade tem desempenho inferior em relação às dimensões conteúdo e usabilidade, onde apenas dois portais atingem média 7 (sete). Há significativa concentração de pontuação entre 4,17 e 5,81 além de situações consideradas muito críticas (médias 1,91 e 3,23).

- Do conteúdo / usabilidade / funcionalidade

Analisadas as três dimensões tem-se um panorama geral dos portais, com a geração de um indicador que serve de apoio à decisão aos interessados no compartilhamento, divulgação e produção do conhecimento de acesso livre. Nesse contexto é apresentada a posição de Tapscott e Williams (2007, p.53) que dizem:

Navegue um pouco hoje e ficará claro que essa nova cultura da participação permeia a web. Ninguém gasta mais tempo com a Internet do tipo "publique e navegue". Cada vez mais as pessoas preferem participar de uma nova geração de comunidades fabricadas por usuários nas quais esses mesmos usuários interagem e criam junto com seus colaboracdores (peers). 
Tomando por base essa idéia, observa-se os resultados da avaliação dos portais, cujos dados são apresentados no Quadro 11 e graficamente através da Figura 19 (p.92) e da Figura 20 (p.93):

\begin{tabular}{|c|c|c|c|c|}
\hline Site & $\begin{array}{l}\text { Média da Dimensão } \\
\text { Conteúdo }\end{array}$ & $\begin{array}{c}\text { Média da Dimensão } \\
\text { Usabilidade }\end{array}$ & $\begin{array}{l}\text { Média da Dimensão } \\
\text { Funcionalidade }\end{array}$ & Indicador \\
\hline abdi & 7,37 & 7,08 & 4,17 & 6,21 \\
\hline $\operatorname{ccs}$ & 8,03 & 2,63 & 4,89 & 5,18 \\
\hline crie & 8 & 6,66 & 7,31 & 7,32 \\
\hline design & 8,93 & 6,25 & 6,36 & 7,18 \\
\hline inovar & 9 & 7,08 & 5,27 & 7,11 \\
\hline inpi & 9,31 & 7,08 & 3,23 & 6,54 \\
\hline $\mathrm{kmol}$ & 7,55 & 6,66 & 6,76 & 6,99 \\
\hline terraforum & 9,06 & 5 & 5,42 & 6,49 \\
\hline numaforum & 8,06 & 7,91 & 5,84 & 7,27 \\
\hline OCW & 9 & 7,91 & 6,52 & 7,81 \\
\hline patentnet & 4,38 & 5,41 & 5,03 & 4,94 \\
\hline conhece & 9,87 & 7,91 & 6,26 & 8,01 \\
\hline inovação & 7,45 & 7,08 & 6,87 & 7,13 \\
\hline bvinova & 7,68 & 4,30 & 4,62 & 5,53 \\
\hline sbrt & 6,87 & 5,41 & 4,52 & 5,60 \\
\hline score & 8,03 & 9,58 & 7,52 & 8,37 \\
\hline sebrae & 7,28 & 6,80 & 6,06 & 6,71 \\
\hline empreende & 5,17 & 5 & 1,91 & 4,03 \\
\hline scienti & 7,18 & 2,77 & 5,81 & 5,26 \\
\hline universia & 8,87 & 8,33 & 5,63 & 7,61 \\
\hline
\end{tabular}

Quadro 11 - Média de cada dimensão e indicador geral de site

Os dados obtidos demonstram que os sites analisados estão aquém da expectativa demonstrada por Tapscott e Williams (2007, p.53), pois os indicadores podem ser considerados baixos em relação ao valor possível de 11,29 (média das três dimensões). Deve-se considerar, principalmente, as dimensões funcionalidade (pior desempenho) e usabilidade, fatores de sucesso para a colaboração, palavra-chave da web atual.

São destacados quatro portais no quadro: os dois melhores $(8,01$ e 8,37) e os dois piores $(4,03$ e 4,94) desempenhos. O melhor desempenho do score $(8,37)$, ao contrário dos demais portais, está na usabilidade que, do ponto de vista dos critérios de avaliação adotados nessa pesquisa, pode alcançar a pontuação máxima se atender a mais dois atributos: ajuste de leiaute e acesso através de outras mídias. O desempenho do conhece (8,01), cofirmando os resultados gerais dessa pesquisa, está comprometido principalmente pela funcionalidade. 
Nesse caso, o portal deixa de contemplar 09 (nove) atributos dos 22 (vinte e dois) analisados.

Quanto aos piores desempenhos, o patentenet tem comportamento similar nas três dimensões. O empreende, por outro lado, tem seu desempenho mais comprometido na funcionalidade, onde estão contemplados somente 7 (sete) atributos.

Através do gráfico (Figura 19) que segue pode-se melhor obeservar de forma comparativa, os dados das três dimensões de todos os portais:

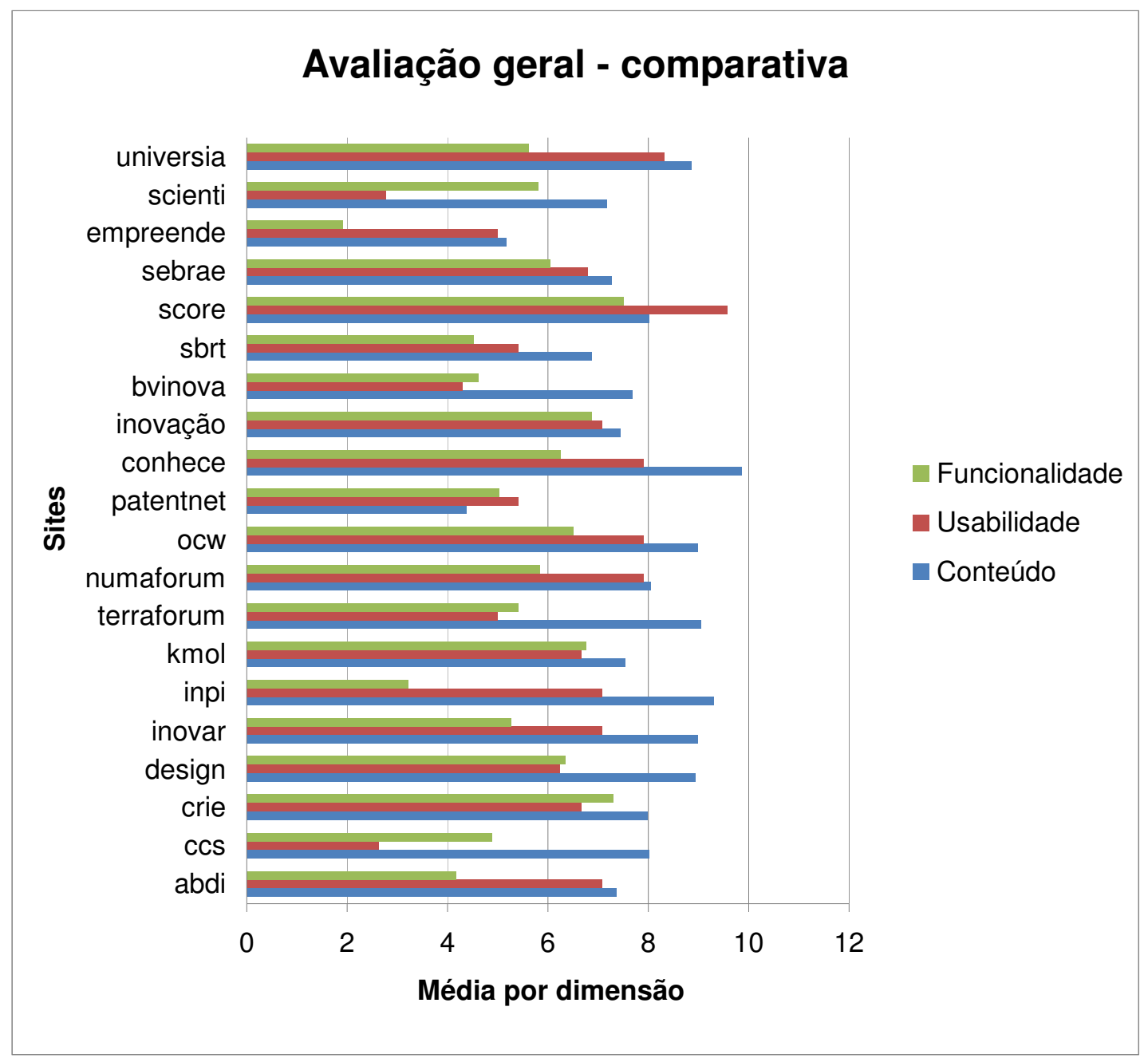

Figura 19 - Dimensões conteúdo, usabilidade e funcionalidade para todos os portais

Da mesma forma, o indicador de cada portal pode ser melhor visualizado em formato de gráfico (Figura 20, p.93) onde se verifica, de forma clara, que todos os portais analisados 
podem e precisam melhorar o seu desempenho para atender aos critérios de avaliação adotados nessa pesquisa:

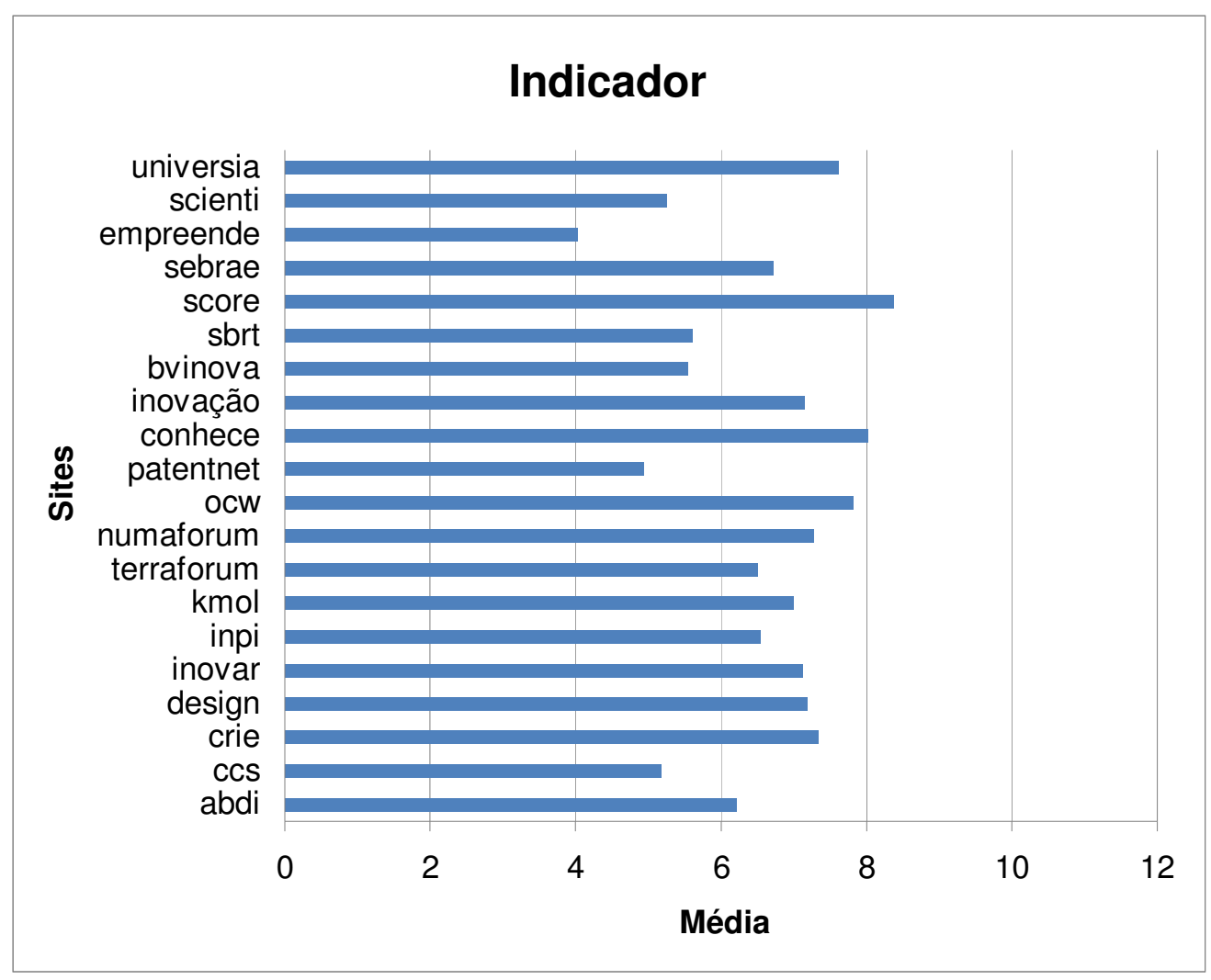

Figura 20 - Indicador geral de cada portal 


\section{Conclusões e Considerações finais}

O conhecimento está presente em todas as etapas do processo de inovação e do processo de desenvolvimento de produto descritos na literatura. Isso demonstra a relevância do assunto para todos os que estão envolvidos com o tema, tanto para a pesquisa na universidade quanto para aplicação na empresa.

A literatura também ressalta as falhas na recuperação da informação na $w e b$ provocadas por vários fatores como a estruturação dos sites, a forma de organização da informação, as dificuldades dos usuários entre outros. Mas destaca também o papel das comunidades de prática enquanto possibilidade de produção compartilhada de conhecimento entre pessoas interessadas em um assunto em comum, o que leva a um melhor aprendizado.

Esse contexto da literatura foi confrontado por meio de pesquisa documental, que teve como foco portais na web previamente selecionados e analisados detalhadamente. Para a análise foram estabelecidos critérios que pudessem ser considerados suficientes para atender ao objetivo geral do trabalho, que é a identificação e avaliação de sites na Internet, com características de compartilhamento, divulgação e produção de conhecimento de acesso livre, para apoiar a inovação e desenvolvimento de produto.

Definido o objetivo geral, partiu-se para a seleção de uma amostra de sites que tivessem características de compartilhamento, divulgação e produção de conhecimento e, ao mesmo tempo, contemplassem as áreas de interesse desse estudo. Inicialmente pretendia-se identificar somente os sites brasileiros, mas considerando a quantidade de experiências no país, alguns internacionais foram incluídos. Gerou-se uma lista (Apêndice A) para posterior análise detalhada, quando foram selecionados os 20 (vinte) que constituem a amostra para análise dos dados. Com isso considera-se que o primeiro objetivo específico foi atingido.

A definição dos critérios de análise teve por base a literatura e o foco da pesquisa. Dentre as dimensões identificadas para essa finalidade, três foram selecionadas: conteúdo, usabilidade e funcionalidade. Cada uma delas foi detalhada por características e atributos considerados de relevância para esse estudo. A definição dos critérios teve como base critérios de análise de portais de governo eletrônico, mas a partir dos ajustes feitos, eles podem ser considerados adequados para análise de qualquer tipo de site. Assim a nova lista 
de critérios é uma contribuição significativa do trabalho e garante o cumprimento do segundo objetivo específico.

Conforme definido no terceiro objetivo específico procedeu-se a avaliação dos sites por meio da aplicação dos critérios de análise, sintetizados em um formulário de coleta de dados. A coleta foi refeita em dias e horários diferentes para todos os sites (mínimo três vezes) para garantir a possibilidade de acesso e a completeza dos dados. Paralelamente foi estabelecida a forma de análise dos dados, com a definição de notas e pesos para todos os atributos. Esses dados foram transpostos para uma planilha para o cálculo das médias que geraram indicadores por característica, por dimensão e por site. Utilizou-se média simples porque o indicador é utilizado como um meio de estabelecer uma comparação sem, no entanto, ter a pretensão de se fazer uma indicação rigorosa de qual é o melhor ou o pior site. $\mathrm{O}$ que se pretende é indicar quais sites atendem ao propósito do trabalho e podem ser utilizados como ferramenta de apoio às pessoas e organizações.

A partir da geração dos indicadores parciais e do indicador geral, conclui-se:

- Nenhum site obteve a pontuação máxima possível estabelecida, mas todos contemplam a disponibilidade de conhecimento de acesso livre. O site que obteve a melhor pontuação $(8,37)$ é o portal do score, uma associação americana que há mais de quarenta anos dá apoio à pequena empresa. Sua atuação pode ser comparada parcialmente ao trabalho realizado no Brasil pelo sebrae $(6,71)$, através do empreende $(4,03)$, que obteve o pior desempenho geral;

- A dimensão funcionalidade obteve o pior indicador parcial e isso se confirma para o score e para o empreende, embora a pontuação desse último possa ser considerada crítica;

- Ao observar mais detalhadamente a dimensão funcionalidade, verifica-se que três características contribuem decisivamente para o seu baixo desempenho: segurança de acesso seguida da acurácia e da adequação;

- No nível dos atributos, confirmam-se os piores desempenhos da característica funcionalidade para: recursos de criptografia, condições de acessibilidade, 
disponibilidade de ferramentas para implementação de CoP, controle de versões, indicação de política de privacidade entre outros.

As conclusões podem ser observadas detalhadamente para todas as dimensões, características e atributos que constituem a lista de critérios de análise a partir da pontuação de cada um. Por outro lado, embora não tenha sido objeto de análise mais criteriosa a avaliação da quantidade de conteúdo disponibilzado, observa-se que de maneira geral os portais ainda disponibilizam uma pequena quantidade.

Diante dos dados é possível concluir que os sites analisados têm em mãos subsídios que propiciam a possibilidade de melhoria radical das dimensões conteúdo, usabilidade e funcionalidade. Se entenderem isso como oportunidade, podem ser transformados em ambientes adequados de compartilhamento, divulgação e produção de conhecimento de acesso livre. Mas essas conclusões, no entanto, devem ser consideradas em função das limitações da pesquisa, onde foi utilizada a pesquisa documental associada à pesquisa bibliográfica. A esses dois procedimentos técnicos poderiam ter sido associados uma pesquisa participante e um survey, por exemplo, que permitiriam obter mais dados e observar o comportamento dos envolvidos no momento da ação.

Há que se considerar também que a lista de critérios gerada é bastante abrangente, o que dificulta a aplicação no momento da análise dos sites. Embora não tenha sido possível definir o tempo médio de análise, que varia muito em função da estruturação de cada site, o tempo de análise pode ser considerado alto. Por essa razão, em trabalhos futuros sugere-se:

- Rever a necessidade de todos os atributos utilizados;

- Explorar outros atributos e características dos critérios de avaliação, com a possível adequação da terminologia;

- Definir os atributos indispensáveis para cada dimensão de análise.

Sugere-se, também, efetuar uma pesquisa mais explicativa, com a combinação da pesquisa documental com a pesquisa participante, e até mesmo, uma pesquisa-ação, em empresas voltadas para a inovação e desenvolvimento de produto;

Para finalizar, é indispensável ressaltar que em função do dinamismo da gestão de páginas web, os atributos dos portais analisados podem ter sido modificados após a análise. Isso 
significa que ao checar os dados aqui apresentados, muitos deles podem estar diferentes, especialmente os mais falhos. Na verdade espera-se que tenham sido efetivamente ajustados ou modificados para propiciar melhor qualidade no acesso, compartilhamento, produção e recuperação do conhecimento de acesso livre disponível on-line. 


\section{Referências}

ALMEIDA,M.B.; BAX, M.P. (2003). Uma visão geral sobre ontologias: pesquisa sobre definições, tipos, aplicações, métodos de avaliação e de construção. Ciência da Informação, Rio de Janeiro,v.32, n.3, p.7-20.

BAEZA-YATTES, R.; RIBEIRO NETO, B. (1999). Modern information retrieval. New York: Addison-Wesley.

BENKLER, Y. (2002). Coase's penguin, or, linux and the nature of the firm. The Yale Law Journal, New Haven, v.112, p.369-446, Oct.

(2006). The Wealth of netorws: how social production transforms markets and freedom. New Haven: Yale University Press.

BISCOZZO, M.; CORALLO, A.; ELIA, G. (2005). Building bottom-up ontologies for communities of practice in high-tehc firms. Berlin: Springer Berlin. p.142-148. (Lecture Notes in Computer Science, 3681).

BREITMAN, K.K. (2005). Web semântica: a Internet do futuro. Rio de Janeiro: LTC.

BUDAPEST open access initiative. (2001). Disponível

em:<http://www.soros.org/openaccess>. Acesso em: 15 Aug. 2006.

CASTELlS, M. (2006). A Sociedade em rede. 9.ed. São Paulo: Paz \& Terra.

CASTRO, C.M. (1977). A Prática da pesquisa. São Paulo: McGraw-Hill do Brasil.

CERVO, A.L.; BERVIAN, P.A. (1996). Metodologia científica. 4.ed. São Paulo: Makron Books.

CHOU, T.C. et al. (2005). Towards a framework of the performance evaluation of SMEs'industry portals. Industrial Management \& Data Systems, Bengley, v.105, n.4, p.527-544.

CLARK, K.B.; FUJIMOTO, T. (1991). Product development performance: strategy, organization and management in the world auto industry. Boston: Harvard Bussiness Schoool Press.

CLARK, K.B.; WHEELWRIGHT, S.C. (1993). Managing new product and process development: text and cases. New York: Free.

CLAUSING, D. (1994). Total quality development: a step-by-step guide to world class concurrent engineering. New York: ASME.

COELHO, R.A. (2007). Portais municipais na internet: estrutura e tipologia dos portais 
das cidades médias do Estado de São Paulo. São Carlos: EESC/Departamento de Arquitetura/Grupo de pesquisas e-urb. (Relatório de pesquisa).

CREATIVE COMMONS (2007). Licence your work. Disponível em:<http://creativecommons.org/licenses>. Acesso em: 10 Jan. 2007.

DAVENPORT, T.H. (1994). Reengenharia de processos. Rio de Janeiro: Campus.

DAVENPORT, T.H.; PRUSAK, L. (1998). Conhecimento empresarial: como as organizações gerenciam o seu capital intelectual. 3.ed. Rio de Janeiro: Campus.

DRUCKER, P.F. (1993). Sociedade pós-capitalista. São Paulo: Pioneira.

ESCHENFELDER, K.R. (1997). Assessing U.S. federal government websites.

Government Information Quarterly, Amsterdam, v.13, n.2, p.173-189.

FEITOSA, A. (2006). Organização da informação na web: das tags à web semântica. Brasília: Thesaurus.

GIL, A.C. (1999). Métodos e técnicas de pesquisa social. São Paulo: Atlas.

GOMES, S.L.R. (2006). O Acesso à informação em bibliotecas virtuais: princípios e valores. In: MIRANDA, A.; SIMEÃO, E. (Org.). Alfabetização digital e acesso ao conhecimento. Brasília: UNB. p.109-128. (Série Comunicação da Informação Digital, 4).

GUESSER, A.H. (2007). A Construção de um paradigma colaborativo: a experiência do Movimento Software Live e a luta por maior inclusão na sociedade da informação.

Inclusão Social, Brasília, v.2, n.1, p.47-59, out./mar.

HUMES, L.L. (2004). A Adoção de software livre na USP: um estudo de caso.

Dissertação (Mestrado) - Faculdade de Economia e Administração, Universidade de São Paulo, São Paulo, 2004.

INSTITUTO BRASILEIRO DE GEOGRAFIA E ESTATÍSTICA (2007). Pesquisa de inovação tecnológica 2005. Brasília: IBGE. Disponível

em:<http://www.ibge.gov.br/home/estatística/economia/industria/pintec/2005/defaut.shtm> . Acesso em: 1 ago. 2007.

INTERNATIONAL ORGANIZATION FOR STANDARDIZATION (2001). ISO/IEC 9126-1:200(E) - Software engineering - product quality. Part 1: quality model. Geneva.

KEHOE, B.P. (1993). Zen e a arte da internet: um guia introdutório à internet. São Paulo: Rede Nacional de Pesquisa. Versão preliminar em português.

KRAAIJENBRINK, J. (2007). Engineers and the Web: an analysis of real lige gaps in information usage. Information Processing and Management, New York, v.43, n.5, p.1368-1382, Sept. 
KRAAIJENBRINK, J.; GROEN, A.J. (2006). Small companies seeking information on the internet: any changes for online intermediaries?. Industry \& High Education, Oxford, v.20, n.3, p.195-205, June.

LAKATOS, E.M.; MARCONI, M.A. (1992). Metodologia científica. 2.ed. São Paulo: Atlas.

LAM, A. (2005). Work roles and careers of R\&D scientists in network organizations. Industrial Relations, Berkeley, v.44, n.2, p.242-275, Apr.

LAVE, J.; WENGER, E. (1991). Situated learning: legitimate peripheral participation. New York: Cambridge University Press.

LESSIG, L. (2005). Cultura livre: como a grande mídia usa a tecnologia e a lei para bloquear a cultura e controlar a criatividade. São Paulo: Trama.

LOPES, I.L. (2002). Estratégia de busca na recuperação da informação: revisão da literatura. Ciência da Informação, Rio de Janeiro, v.31, n.2, p.60-71.

MANUAL de Oslo: proposta de diretrizes para coleta e interpretação de dados sobre inovação tecnológica. [2006]. 3.ed. Brasília: OECD; EUROCAST; FINEP.

MALONE, T.W. et al. (Ed.). (2003). Organizing business knowledge: the MIT process handbook. Cambridge: MIT.

MARCONI, M.A.; LAKATOS, E.M. (1986). Técnicas de pesquisa. São Paulo: Atlas.

MELO, M.P.; SATTAMINI, S.R. (2007). A Criação de comunidades virtuais na Petrobrás. Disponível em:<http://www.abed.org.br/antiga/htdocs/paper_visem/marcelo_pereira_melo/ marcelo_pereira_melo.htm>. Acesso em: 14 set. 2007.

MINAYO, M.C.S. (Org.). (1996). Pesquisa social: teoria, método e criatividade. 5.ed. Petrópolis: Vozes.

MORETTI, D.; LIMA, K.K.; AMARAL, D.C. (2005). Critérios para avaliação de sistemas de apoio à gestão do conhecimento. In: ENCONTRO NACIONAL DE ENGENHARIA DE PRODUÇÃO, 25., 2005, Porto Alegre. Anais... Porto Alegre: ABEPRO. p.48374844.

MORIGI, V.; SANTIN, D.M. (2007). Reflexões sobre os valores do movimento software livre na criação de novos movimentos informacionais. Informação \& Informação, Londrina, v.12, n.1, jan./jun. Disponível em<http://www.uel.br/revistas/informacao $>$. Acesso em: 10 set. 2007.

MOSTAFA, S.P.; TERRA, M. (1998). As Fontes eletrônicas de informação: novas formas de comunicação e produção de conhecimento. São Paulo em Perpectiva, São Paulo, v.12, 
n.4, p.54-59, out./dez.

MUNDIN, A.P. (2001). Cenário de integração do processo de desenvolvimento de produtos: uma ferramenta educacional para capacitação profissional. Tese (Doutorado) Escola de Engenharia de São Carlos, Universidade de São Paulo, São Carlos, 2001.

NELSON, R. (1993). National innovation systems. Oxford: Oxford UP.

NELSON, R.; WINTER, S. (1982). An Evolutionary theory of economic change. Camridge: Belknap Press of Harvard University Press.

NIELSEN, J. (2000). Projetando websites. Rio de Janeio: Campus.

OLIVEIRA NETTO, A.A. (2005). Metodologia da pesquisa científica: guia prático para a apresentação de trabalhos acadêmicos. Florianópolis: VisualBooks.

OPEN knowledge definition v1.0. (2007). Disponível

em:<http://www.opendefinition.org/1.0>. Acesso em: 10 Jan. 2007.

THE OPEN knowledge foundation: protecting and promoting open knowledge in a digital age. Disponível em:<http://www.openknowledgefoundation.org/projects $>$. Acesso em: 10 Jan. 2007.

PEREIRA, J.C.R. (2001). Análise de dados qualitativos: estratégias medodológicas para as ciências da saúde, humanas e sociais. São Paulo: EDUSP.

PORTAL do conhecimento. (2007). Disponível em:<http://www.portaldeconhecimentos.org.br>. Acesso em: 10 ago.2007.

PUGH, S. (1996). Total design, partial design: a reconciliation. In:___ Criating innovative products using total design. Massachusetts: Addison-Wesley. Cap.7, p.79-86.

QUIN, J.B.; ANDERSON, P.; FINKELSTEIN, S. (1996). Managing professional intellect: making the most of best. Harvard Business Review, New York, v.74, n.2, p.71-80, Mar./Apr.

RAYMOND, E.S. (2001). The Cathedral and the bazaar: musings on Linux and Open Source by an accidental revolutionary. Beijing: O'Reilly.

REITZ, J.M. (2007). ODLIS: online dictionary for library and information center. Disponível em<http://lu.com/odlis/odlis_u.cfm>. Acesso em: 24 Mar. 2007.

RHEINGOLD, H. (1993). The virtual community: homesteading at the eletronic frontier. Reading: Addisson-Wesley. Disponível em:<http://www.rheingold.com/vc/book>. Acesso em: 24 Mar. 2007.

ROBERTSON, J. (2002). How to evaluate a content of management system. KM Column, 
Jan. Disponível em:<www.steptwo.com.au/papers/Kmc_evaluate/pdf/KMC_ EvaluateCMS.pdf>. Acesso em: 26 Mar. 2007.

ROESCH, S.M.A. (1999). Projetos de estágio e de pesquisa em administração. 2.ed. São Paulo: Atlas.

ROGERS, E.M. (2003). Diffusion of innovations. 5.ed. New York: Free.

ROSENBERG, N. (1994). Exploring the black box: technology, economics, and history. Cambridge: Cambridge University Press.

ROZENFELD, H. et al. (2006). Gestão de desenvolvimento de produtos: uma referência para a melhoria do processo. São Paulo: Saraiva.

SALZ, P.A. (2005). People powered: content and collaboration combine forces. EContent, Wilton, v.28, n.11, p.24-29, Nov.

SANTA EULÁLIA, E.P.M. (2003). Experiências de uma comunidade de prática sobre desenvolvimento de produtos: iniciativas e tecnologia promovendo aprendizagem e criação de conhecimentos. Dissertação (Mestrado) - Escola de Engenharia de São Carlos, Universidade de São Paulo, SãoCarlos, 2003.

SCHUMPETER, J. (1984). Capitalismo, socialismo e democracia. Rio de Janeiro: Zahar.

SELLTIZ, C.; WRIGHTSMAN, L.S.; COOK, S.W. (1987). Métodos de pesquisa nas relações sociais. São Paulo: EPU. v. 1.

SILVA, E.; MENEZES, E.M. (2005). Metodologia da pesquisa e elaboração de dissertação. 4.ed. Florianópolis: UFSC. Disponível EM:<http://www.ufsc.br>. Acesso em: 17 ago. 2006.

SILVA, S.L. (2002). Proposição de um modelo para caracterização das conversões do conhecimento no processo de desenvolvimento de produtos. Tese (Doutorado) - Escola de Engenharia de São Carlos, Universidade de São Paulo, São Carlos, 2002.

SILVA, S.L.; ROZENFELD, H. (2003). Modelo de avaliação da gestão do conhecimento no processo de desenvolvimento de produto: aplicação em um estudo de caso. Produção, São Paulo, v.13, n.2, p.6-20.

SNYDER, W.M. (1997). Communities of practice: combining organizational learning and strategy insights to create a bridge to the 21 st century. Disponível em: $<$ http://www.co-i1.com/coil/knowledge-garden/cop/cols.shtml>. Acesso em: 14 Nov. 2006.

SONG, M.; VAN DER BIJ, H.; WEGGEMAN, M. 2006). Factors for improving the level of knowledge generation in new product development. $R \& D$ Management, Oxford, v.36, n.2, p.173-187, Mar. 
STAL, E. et al. (2006). Inovação: como vencer esse desafio. São Paulo: Clio.

STEFANOVITZ, J.P. (2006). Criação do conhecimento e inovação na indústria de alta teconologia: estudo e análise de casos em uma empresa do setor de automação industrial. Dissertação (Mestrado) - Escola de Engenharia de São Carlos, Universidade de São Paulo, São Carlos, 2006.

TAPSCOTT, D.; WILLIAMS, A.D. (2007). Wikinomics: como a colaboração em massa pode mudar o seu negócio. Rio de Janeiro: Nova Fronteira.

TAURION, C. (2004). Software livre: potencialidades e modelos de negócio. Rio de Janeiro: Brasport.

TEIXEIRA FILHO, J. (2002). Comunidades virtuais: como as comunidades de práticas na internet estão mudando os negócios. Rio de Janeiro: SENAC.

TERRA, J.C.C.; BAX, M.P. (2003). Portais corporativos: instrumento de gestão da informação e de conhecimento. In: PAIM, I. (Org.). A Gestão da informação e do conhecimento. Belo Horizonte. p.33-53. Disponível em:<http://www.bax.com.br/publications>. Acesso em: 24 Jan. 2007.

TERRA, J.C.C.; GORDON, C. (2002). Portais corporativos: a revolução na gestão do conhecimento. São Paulo: Negócio.

THIOLlENT, M. (2002). Metodologia da pesquisa-ação. 10.ed. São Paulo: Cortez.

ULRICH, D. (Org.). (2000). Recursos humanos estratégico. São Paulo: Futura.

VARGAS, M. (1985). Metodologia da pesquisa tecnológica. Rio de Janeiro: Globo.

VASCONCELOS, M.C.R.L.; MILAGRES, R.; NASCIMENTO, E. (2005). Estratégia de relacionamento entre os membros da cadeia produtiva no Brasil: reflexões sobre o tema. Gestão \& Produção, São Carlos, v.12, n.3, p.393-404, set./dez.

VERGANTI, R.; MacCORMACK, A.; IANSITI, M. (1998). Rapid learning and adaptation in product development: an empirical study of the internet software industry. In: INTERNATIONAL PRODUCT DEVELOPMENT MANAGEMENT CONFERENCE, 5., 1998, Como, Italy. Proceedings... [S.1.:s.n.]. p.1063-1079.

VERGARA, S.C. (2000). Projetos e relatórios de pesquisa em administração. 3.ed. São Paulo: Atlas.

VILELLA, R.M. (2003). Conteúdo, usabilidade e funcionalidade: três dimensões para a avaliação de portais estaduais de Governo eletrônico na Web. Dissertação (Mestrado) Universidade Federal de Minas Gerais, Belo Horizonte, 2003.

WENGER, E. (1998). Communities of practice: learning, meaning, and identity. New 
York: Cambridge Press University.

(2004). Knowledge managemnt as a doughnut: shaping your knowledge strategy through communities of practice. Ivey Business Journal Online, London, v.68, n.3, Jan./Feb. Disponível em:<http://www.iveybusinessjournal.com/archives/defaut.asp?intYear=2004>. Acesso em: 26 Set. 2006.

WENGER, E.; McDERMOTT, R.; SNYDER, W. (2002). Cultivating communities of practice: a guide to managing knowledge. Boston: Harvard Business School Press.

WENGER, E.; SNYDER, W. (2000). Communities of practice: the organizational frontier. Harvard Business Review, New York, v.78, n.1, p.139-145, Jan./Feb.

WIKIPEDIA: a encyclopedia livre. (2006). Disponível em:<http://pt.wikipedia.org/wiki $>$. Acesso em: 25 set. 2006.

WILLINSKY, J. (2006). The Access principle: the case for open access to research and scholarship. Massachussetts: MIT. Disponível em:<http://mitpress.mit.edu/0262232421>. Acesso em: 9 Oct. 2007.

ZOOK, M. (2001). Old hierarchies or new networks of centrality: the global geography of the Internet content market. American Behavioral Scientist, Princeton, v.4, n.10, p.16791696, June. 


\section{APÊNDICE A -Iniciativas genéricas (sites selecionados para análise detalhada)}

Lista dos sites selecionados previamente, com indicação do endereço e breve descrição.

1 http://ccs.mit.edu/ph - conteúdo on-line sobre negócio

Envolve um grupo pessoas e organizações empenhadas no desenvolvimento de um espaço aberto na Internet para disponibilizar conhecimento sobre processos de negócio (uma biblioteca virtual), de acesso gratuito ao público em geral, com o uso de licenças open source. Um trabalho iniciado em 1991, já conta com mais de 5000 entradas de assunto além de um conjunto de ferramentas de software para gerenciar o conhecimento. Um dos produtos desta iniciativa é o livro MIT Process Handbook, que está à venda no site do MIT e pela Amazon. Na versão pública estão disponíveis o sumário, a introdução, os capítulos 1 , 8 e o índice.

2 PLoS (http://www.plos.org/): biblioteca pública de ciências Plos - Public Library of Science é uma organização não lucrativa de cientistas e médicos com o objetivo de tornar disponível gratuitamente a literatura científica mundial da área médica. Tem como princípios o open access; a cooperação; o atendimento aos interesses da comunidade de cientistas, medicos, educadores e o público (pacientes); o fornecimento de informação de editores científicos geograficamente dispersos (internacionalização); e a construção de uma biblioteca pública de acesso irrestrito a resultados de pesquisas científicas e descobertas, instrumentos e materiais para despertar o interesse, imaginação e o gosto do público pelo conhecimento científico.

3 Connexions (http://cnx.org/): compartilhamento de material didático e ferramentas de software free para ensino a distância.

Acreditam que o compartilhamento do conhecimento propicia a oportunidade de criar novos conhecimentos a partir daqueles que as pessoas já possuem. E nesse caso, a criação de novos materiais de aprendizagem.

Tem como princípio a troca mais livre de idéias. Todas as ferramentas são free e open source e o material produzido está livemente disponível através de licença open content. 


\section{Projeto Gutenberg (http://www.gutenberg.org)}

Criação, por voluntários, de uma biblioteca digitalizada e de livre acesso, de livros de domínio público. O Projeto Gutenberg é a primeira e a maior coleção de livros eletrônicos (eBooks) gratuitos. Iniciado em 1971, por Michael Hart, que acreditava que o maior valor do computador não estava na capacidade de cálculo e sim no armazenamento, recuperação, e busca de documentos em bibliotecas.

A filosofia é que todos os documentos estejam disponíveis de forma gratuita e cada um possa usá-los da forma que quiser: em sala de aula, em website literário ou até mesmo para fazer uma adaptação do texto para publicação. A maior parte dos documentos dos ebooks do Projeto Gutenberg é acesso gratuito e livre. O foco do Projeto é romper as barreiras da ignorância e do analfabetismo.

5 http://www.openknowledge.net/: comunidade de desenvolvimento e intercambio de conteúdos.

É uma iniciativa para apoiar a criação e o intercâmbio de conteúdos comunitários em idiomas locais pelo Hemisfério Sul, com o uso de variadas tecnologias de informação e comunicação. Disponível em vários idiomas, inclusive em português (http://www.openknowledge.net/portugues/);

6 Incubadora (http://incubadora.fapesp.br)

É uma incubadora virtual de conteúdos digitais, que tem como objetivo "promover e facilitar o desenvolvimento colaborativo de conteúdo digital aberto de qualidade, de viés acadêmico, tecnológico ou social”. Tem como foco a produção de conteúdo e para tanto disponibiliza infra-estrutura computacional e técnica. É constituída de usuários e projetos. Toma por base os conceitos de Benkler (2006) e a experiência da Wikipedia.

7 Wikipedia (http://wikipedia.org)

Enciclopédia livre, produzida de forma compartilhada por quem quiser participar. Abrange todas as áreas do conhecimento, em mais de 50 línguas. Projeto iniciado em 15 de Janeiro 
de 2001, em língua inglesa, atingiu quase 10.000 artigos em apenas um ano. Utiliza licença GNU e mantem os créditos aos colaboradores.

\section{8 http://www.dgroups.org/}

É um espaço de hospedagem de grupos e comunidades interessadas em desenvolvimento internacional;

9 http://www.score.org

Portal do Counselors to America's Small Business (SCORE), cuja proposta se assemelha ao SEBRAE, embora bem mais abrangente. É a primeira iniciativa americana voltada para o aconselhamento livre e confidencial à pequena empresa e ao empresário. Sem fins lucrativos dedica-se à formação e desenvolvimento de pequenas empresas.

Instituído em 1964, o SCORE já apoiou mais de 7.5 milhões de pequenas empresas, através do atendimento on-line, por e.mail e através de aproximadamente 400 (quatrocentos) escritórios nos diferentes Estados americanos. Para tanto conta com mais de 10,500 conselheiros voluntários, que atendem a mais de 600 habilidades empresariais. Esses conselheiros são executivos procedentes das 500 empresas top da Fortune, uma das principais revistas de negócios do mundo.

10 http://www.sebrae.og.br

"O Sebrae, Serviço Brasileiro de Apoio às Micro e Pequenas Empresas, trabalha desde 1972 pelo desenvolvimento sustentável das empresas de pequeno porte. Para isso, a entidade promove cursos de capacitação, facilita o acesso a serviços financeiros, estimula a cooperação entre as empresas, organiza feiras e rodadas de negócios e incentiva o desenvolvimento de atividades que contribuem para a geração de emprego e renda. São centenas de projetos gerenciados pelas Unidades de Negócios e de Gestão do Sebrae”.

11 http://www.inpi.gov.br

Portal do Instituto Nacional de Propriedade Intelectual, um órgão do Ministério do Desenvolvimento, Indústria e Comércio Exterior, criado em 1970. Sua principal finalidade é "executar, no âmbito nacional, as normas que regulam a propriedade industrial, tendo em vista a sua função social, econômica, jurídica e técnica. É também sua atribuição 
pronunciar-se quanto à conveniência de assinatura, ratificação e denúncia de convenções, tratados, convênios e acordos sobre propriedade industrial”.

12 http://www.inovar.org.br

Portal do projeto Mobilizar para Inovar, "um programa de mobilização para utilização dos instrumentos de apoio à inovação como ferramenta de competitividade”. Está inserido no contexto do 'Movimento Brasil Competitivo', disponível em http://www.mbc.org.br. Conta com o apoio do MCT e da Finep. Tem como parceiro a FNQ, o Programa de Gestão Pública, entre outros.

13 http://www.pdp.org.br

Portal da Comunidade de Prática sobre desenvolvimento de produto do NUMA - Núcleo de Manufatura Avançada do Departamento de Engenharia de Produção da Escola de Engenharia, da USP - São Carlos. Atualmente em processo de migração do conteúdo para um portal de conhecimentos (http://www.portaldeconhecimentos.org.br);

14 http://www.abdi.com.br

Portal da Agência Brasileira de Desenvolvimento Industrial - ABDI, tem como missão promover o desenvolvimento industrial e tecnológico brasileiro por meio do aumento da competitividade e da inovação. O principal enfoque está nos programas e projetos estabelecidos pela Política Industrial, Tecnológica e de Comércio Exterior (PITCE), da qual é coordenadora, articuladora e promotora. Funciona como elo de ligação entre as diretrizes estratégicas discutidas em várias instâncias governamentais e na sociedade civil e os executores de políticas públicas;

15 http://www.desenvolvimento.gov.br

Portal do Ministério do Desenvolvimento, Indústria e Comércio Exterior, do Governo Federal. Disponibiliza informações gerais que servem de apoio às empresas.

16 http://www.terraforum.com.br

A TerraForum é uma empresa de consultoria e treinamento que tem como clientes empresas dos setores público, privado e terceiro setor. Atua principalmente nas áreas de gestão do conhecimento, gestão da inovação, portais corporativos e inteligência 
empresarial. Lançou em julho de 2007 o Innovation Center, um portal totalmente dedicado à inovação. Traz notícias, artigos, glossário com termos relacionados e links para textos interessantes;

17 http://www.designbrasil.org.br

Portal que visa integrar a comunidade do design brasileiro. Além de criar uma grande comunidade de interessados no tema, abre espaço para a interação e a troca de informações. O Design Brasil é uma porta de entrada para ações institucionais de incentivo ao design: Programa Brasileiro de Design, Via Design, Marca Brasil, PSGD (Programa SENAI de Gestão da Inovação e do Design), dentre outros. Lançado em dezembro de 2004, é resultado de uma iniciativa conjunta de três instituições: MDIC (Ministério do Desenvolvimento, Indústria e Comércio Exterior), através do PBD (Programa Brasileiro de Design); Senai e Sebrae Nacional. A coordenação é do Centro de Design Paraná;

18 http://www.portalinovacao.info ou http://www.portalinovacao.mct.gov.br

É um portal do MCT - Ministério da Ciência e Tecnologia, que tem como objetivo “aproximar e promover a interação entre Empresas, Comunidade Técnico-Científica, Instituições de Ciência, Tecnologia e Inovação (ICTIs) e Organizações de Apoio visando à cooperação e à inovação nos diversos setores sócio-econômicos em todas as áreas do conhecimento";

19 http://www.cdt.unb.br

Portal do Centro de Desenvolvimento Tecnológico, da Universidade de Brasília, "responsável pela transferência de tecnologia, prestação de serviços especializados e interação da Universidade com os empresários, empreendedores e com a sociedade em geral". Dentre os programas disponíveis, está o "Disque Tecnologia", que trata de novos produtos, mas não há informação sobre o assunto e sim o oferecimento de serviços;

20 http://www.kmol.online.pt

O portal KMOL tem como princípio ser uma publicação periódica dedicada à Gestão de Conhecimento e à Aprendizagem Organizacional. Idealizada para atender especialmente a comunidade lusófona, sua estrutura e conteúdo estão em Português. Disponibiliza alguns conteúdos em inglês com o intuito de conquistar colaboradores externos. O principal 
objetivo do portal é reunir uma comunidade de pessoas interessadas no assunto, para leitura, comentários e publicação de conteúdos;

21 http://www.nit.ufscar.br

Portal do Núcleo de Informação Tecnológica em Materiais, da Universidade Federal de São Carlos, que tem como missão "atuar como centro indutor de desenvolvimento tecnológico e de aprimoramento empresarial, voltado para o aumento da competitividade brasileira, pelo desenvolvimento e execução de serviços de informação que proporcionem vantagens estratégicas aos clientes, com foco no diagnóstico de necessidades e disseminação de conhecimentos para a tomada de decisão”. Possui uma Comunidade de Prática denominada SisInfo/TSM (Sistema de Informações em Tratamento de Superfícies Metálicas). Seu ideal é "garantir à comunidade envolvida com a Pesquisa e o Desenvolvimento em Tratamento de Superfícies Metálicas, uma forma eficiente, barata e dinâmica de integração e cooperação".

22 http://ocw.mit.edu

Portal do MIT (Massachusetts Institute of Technology) que disponibiliza programas de cursos, em várias áreas do conhecimento. Trata-se de um recurso educacional aberto e gratuito para educadores, estudantes e auto-aprendizes (self-learness) ao redor do mundo. Não se trata de oferecimento de cursos on-line pelo MIT e sim de disponibilização de conteúdos de curso. Não fornece certificado de participação / conclusão;

23 http://www.patentnet.com.br

O portal é uma ferramenta de trabalho para auxiliar na tomada de decisão nas áreas da propriedade intelectual. Disponibiliza informações essenciais às pessoas comprometidas com a atividade inventiva nos meios acadêmico e empresarial.

24 http://portal.crie.coppe.ufrj.br

Portal do Centro de Referência em Inteligência Empresarial (CRIE), um "laboratório de pesquisa e desenvolvimento em inteligência empresarial do Programa de Engenharia de Produção da COPPE / UFRJ. Tem como missão criar e desenvolver produtos e serviços na área de inteligência empresarial - com ênfase na Gestão do Conhecimento - de forma a contribuir para a inserção competitiva do Brasil na sociedade do conhecimento"; 
25 http://www.prossiga.br

Portal do Programa de Informação para Gestão de Ciência, Tecnologia e Inovação do Instituto Brasileiro de Informação em Ciência e Tecnologia, criado em 1995, "tem por objetivo promover a criação e o uso de serviços de informação na Internet voltados para as áreas prioritárias do Governo Federal, assim como estimular o uso de veículos eletrônicos de comunicação pelas comunidades dessas áreas". Disponibiliza metodologias consolidadas de organização e tratamento da informação em ambiente web, através de acordos de interesse formais com instituições que queiram organizar e difundir seus conteúdos temáticos;

26 http://www.prossiga.br/finep

Portal da Biblioteca Virtual de Inovação Tecnológica, desenvolvida pela FINEP em conjunto com o Programa Prossiga/CNPq. "Reúne de forma estruturada e seletiva, sites brasileiros e estrangeiros contendo informações relevantes sobre inovação tecnológica, em seus múltiplos aspectos";

27 http://sbrt.ibict.br

O Serviço Brasileiro de Respostas Técnicas (SBRT), instituído em 2002, visa facilitar o rápido acesso das empresas a soluções tecnológicas em áreas específicas, promover a difusão do conhecimento e contribuir para o processo de transferência de tecnologia com foco, especialmente, nas micro e pequenas empresas;

$28 \mathrm{http}: / / \mathrm{www} \cdot$ sitedoempreendedor.com.br

Surgiu através da "Empresa Cria", desenvolvida no Programa Empretec, um workshop da Organização das Nações Unidas - ONU, que tem como parceiro no Brasil a Agência Brasileira de Cooperação do Ministério das Relações Exteriores e como executor o Serviço Brasileiro de Apoio as Micros e Pequenas Empresas - Sebrae.

Tem como propósito estimular, incentivar e motivar os "visitantes a tornarem-se vencedores ou aguçarem suas qualidades empreendedoras. Acima de tudo incitando todos a sonharem, a buscarem melhoria de vida, a darem passos para realizarem seus sonhos e fazerem com que suas visões de futuro se transformem em realidade”. Isso é feito através 
da disponibilização de informações que podem levar ao crescimento empreendedor e ao desenvolvimento profissional ou pessoal;

29 http://www.fundacaofia.com.br/pgtusp

Portal do "Núcleo de Política e Gestão Tecnológica (PGT/USP), vinculado à Pró-Reitoria de Pesquisa da Universidade de São Paulo, agrega as competências disponíveis nos Departamentos de Administração, Economia, Engenharia de Produção e, mais recentemente, do Departamento de Patologia e do Núcleo de Manufatura Avançada da Universidade de São Paulo (NUMA). O conjunto dessas iniciativas gera um capital intelectual que permite ao PGT/USP deter competências diferenciadas na área de gestão da inovação tecnológica". Tem como missão "produzir conhecimento, formar competências e prover soluções requeridas para o desenvolvimento dos Sistemas Locais, Regionais e Nacionais de Inovação";

30 http://www.stoa.usp.br

Portal de relacionamento acadêmico da Universidade de São Paulo. Trata-se de uma rede social dos estudantes, professores e funcionários da USP. Tem como prinicipais objetivos: a) "promover uma maior interação entre os membros da comunidade USP; b) criar um espaço onde cada pessoa dentro da Universidade tenha uma identidade digital de fácil acesso, tanto para quem está dentro da USP, quanto para a comunidade externa; c) fornecer um sistema de softwares que facilite aos professores a administração de seus cursos para os estudantes".

$31 \mathrm{http}: / /$ baru.ibict.br/openaccess

Espaço de disponibilização de conteúdo e de discussão sobre acesso aberto no Brasil e países lusófonos.

32 http://www.universia.com.br/mit

Versão brasileira da iniciativa do MIT de apoio à sua missão fundamental, que é promover o conhecimento e a educação para melhor servir à nação e ao mundo. Oferece acesso gratuito a cursos on-line, preparados pelo MIT e traduzidos para o português. Há portais em outras línguas, como a espanhola e a chinesa (Obs.: página brasileira do http://ocw.mit.edu); 
33 http://www.portaldeconhecimentos.org.br

"O Portal de conhecimentos tem o objetivo de registrar e organizar conhecimentos sobre o processo de desenvolvimento de produtos de forma que esses conhecimentos sejam compartilhados pela comunidade interessada no assunto";

34 http://numa.sc.usp.br/forum

Portal da comunidade do livro Gestão do desenvolvimento de produtos, "um local para a troca de informações entre os leitores e autores do livro, assim como compartilhamento de conhecimento relacionado com o livro";

35 http://www.irs.gov/businesses/small

Um dos portais do Departamento de Tesouraria do governo americano, responsável pelo recolhimento de imposto. Tem como missão assegurar o recebimento dos impostos conforme a legislação e também aplicação dos recursos. Tem uma área especifica voltada para o apoio às pequenas empresas.

36 http://www.ibge.gov.br

Portal do Instituto Brasileiro de Geografia e Estatística que, dentre muitas outras atividades de pesquisa, é responsável pela pesquisa sobre inovação tecnológica no Brasil. O último relatório, com dados da pesquisa de 2005, foi disponibilizado para consulta em agosto de 2007(http://www.ibge.gov.br/home/estatistica/economia/industria/pintec/2005/pintec2005.pdf);

37 http://portal.stela.org.br/

Portal do Instituto Stela, uma organização privada, sem fins lucrativos, criada em 2002, dedicada à pesquisa, ao desenvolvimento e à inovação em engenharia e gestão do conhecimento. Tem como missão “conjugar a pesquisa científica com a inovação tecnológica na geração de conhecimento para o desenvolvimento das organizações e da sociedade". Busca inserir o País na era da informação e do conhecimento. Tem como visão "ser referência internacional em inovação científica e tecnológica, elo entre academia e mercado, promotor de spin-offs empresariais e gerador de soluções de impacto socioeconômico". 
$38 \mathrm{http}: / /$ acessolivre.capes.gov.br/

Portal de acesso livre da CAPES que tem por objetivo disponibilizar periódicos com textos completos, bases de dados referenciais com resumos, patentes, teses e dissertações, estatísticas e outras publicações de acesso gratuito na Internet. Os documentos provenientes de instituições científicas, profissionais, órgãos governamentais, em nível nacional e internacional, são selecionados pelo nível acadêmico;

39 http://www.scienti.net/

Portal da ScienTi (Rede Internacional de Fontes de Informação e Conhecimento para a Gestão de Ciência, Tecnologia e Inovação), uma rede pública que tem como objetivo contribuir para a gestão da atividade científica, tecnológica e de inovação. Promove um espaço público e cooperativo de interação entre os paises membros. Disponibiliza currículos, grupos de pesquisa, instituições e projetos, padronizados com referenciais internacionais para assegurar a interoperabilidade na Internet. Também se propõe a identificar recursos humanos qualificados, instituições e projetos de pesquisa para o desenvolvimento e avaliação de políticas e capacidades nacionais em CT\&I, assim como promover programas de cooperação internacional. Possui uma comunidade de prática para compartilhar e gerar informação entre os membros da rede.

Obs.1: Não há data de atualização. Última notícia de julho de 2006. Não consegui me inscrever na comunidade de prática.

Obs.2: A busca é direcionada para fontes de acesso livre como SciELO, CV Lattes etc. e estão devidamente atualizados.

$40 \mathrm{http}: / /$ www.protec.org.br/

Portal da Sociedade Brasileira Pró-inovação Tecnológica (Protec), fundada em fevereiro de 2002, com a missão de "conscientizar e mobilizar representantes institucionais do setor produtivo e as empresas para atuar no constante aperfeiçoamento de políticas públicas de fomento às inovações tecnológicas, elevando a competitividade dos produtos, processos e serviços, gerando empregos, distribuindo renda, e propiciando o crescimento sustentado do país e a sua inserção ativa no comércio internacional". 
Para cumprir com esta missão a Protec, "uma associação civil em prol da inovação tecnológica nacional, tem como objetivo estimular, fomentar e mobilizar os diversos segmentos da sociedade e do poder público em toda e qualquer atividade que promova a pesquisa e o desenvolvimento de inovações tecnológicas realizadas no País, procurando elevar a competitividade e a eficiência das empresas em geral na produção de bens, processos e serviços". 


\section{APÊNDICE B - Formulário para coleta de dados}

http://

- Identificação / breve descrição do portal

\begin{tabular}{|c|c|c|c|c|}
\hline Dimensão & Característica & Atributo & Pontuação & Observações \\
\hline \multirow{27}{*}{$\begin{array}{l}\mathrm{C} \\
\mathrm{O} \\
\mathrm{N} \\
\mathrm{T} \\
\mathrm{E} \\
U^{\prime} \\
\mathrm{D} \\
\mathrm{O}\end{array}$} & \multirow{4}{*}{ Propósito (Vilella) } & Visão geral & & \\
\hline & & Escopo & & \\
\hline & & Serviços & & \\
\hline & & Complementação & & \\
\hline & \multirow{4}{*}{$\begin{array}{l}\text { Abrangência / cobertura (Vilella - } \\
\text { junto com propósito) }\end{array}$} & Tipo de conteúdo & & \\
\hline & & Tipo de assunto & & \\
\hline & & Outros idiomas & & \\
\hline & & Versões & & \\
\hline & $\begin{array}{l}\text { Padrão de publicação de conteúdo } \\
\text { (Almeida e Bax, Breitman, Terra e } \\
\text { Gordon) }\end{array}$ & $\begin{array}{l}\text { Taxonomia/onto/ } \\
\text { classificação/nada }\end{array}$ & & \\
\hline & \multirow{2}{*}{$\begin{array}{l}\text { Atualidade (Vilella, Chou et al. - } \\
\text { timeless) }\end{array}$} & Atualização & & \\
\hline & & Data - conteúdo sig & & \\
\hline & \multirow{3}{*}{ Correção (Vilella) } & Precisão & & \\
\hline & & Referência correta & & \\
\hline & & Inconsistências & & \\
\hline & \multirow{4}{*}{$\begin{array}{l}\text { Autoridade / copirraite (Vilella), } \\
\text { believability e reputation (Chou et } \\
\text { al.) }\end{array}$} & Copirraite & & \\
\hline & & Menção a fontes & & \\
\hline & & Responsabilidade & & \\
\hline & & Legitimidade & & \\
\hline & \multirow{5}{*}{ Objetividade (Vilella, Chou e al.) } & Conteúdo - inicial & & \\
\hline & & Conteúdo adequado & & \\
\hline & & Forma de escrita & & \\
\hline & & Publicidade & & \\
\hline & & Utilidade & & \\
\hline & \multirow{4}{*}{$\begin{array}{l}\text { Regras de publicação e acesso } \\
\text { (Moretti et al.) ou acessibilidade } \\
\text { (Coelho, 2007) }\end{array}$} & Regras de publ & & \\
\hline & & Acesso livre & & \\
\hline & & Acesso condi & & \\
\hline & & Acesso restrito & & \\
\hline \multirow{20}{*}{$\begin{array}{l}\text { U } \\
\text { S } \\
\text { A } \\
\text { B } \\
\text { I } \\
\text { L } \\
\text { I } \\
\text { D } \\
\text { A } \\
\text { D } \\
\text { E }\end{array}$} & \multirow{3}{*}{$\begin{array}{l}\text { Inteligibilidade (Chou et al., ISO, } \\
\text { Nielsen, Vilella) - easy to } \\
\text { understand, interpretability }\end{array}$} & Fontes e atributos & & \\
\hline & & Links claros & & \\
\hline & & Interface & & \\
\hline & \multirow{4}{*}{$\begin{array}{l}\text { Apreensibilidade (ISO, Nielsen, } \\
\text { Vilella) }\end{array}$} & Navegação & & \\
\hline & & Apreensão & & \\
\hline & & Instruções de uso & & \\
\hline & & Interface humana & & \\
\hline & \multirow{8}{*}{$\begin{array}{l}\text { Operacionalidade (ISO, Chou et al., } \\
\text { Nielsen, Vilella) }\end{array}$} & Rolagem & & \\
\hline & & Ajuste de leiaute & & \\
\hline & & Agrupamento & & \\
\hline & & Tarefas prioritárias & & \\
\hline & & Clareza da URL & & \\
\hline & & Disponibilidade & & \\
\hline & & Outras mídias & & \\
\hline & & Acessibilidade & & \\
\hline & \multirow{5}{*}{$\begin{array}{l}\text { Adequação (Vilella, ISO, Moretti } \\
\text { et al.) }\end{array}$} & Diálogo real & & \\
\hline & & Cooperação & & \\
\hline & & Criação de CoP & & \\
\hline & & Ferramentas de CoP & & \\
\hline & & Versão personal & & \\
\hline
\end{tabular}




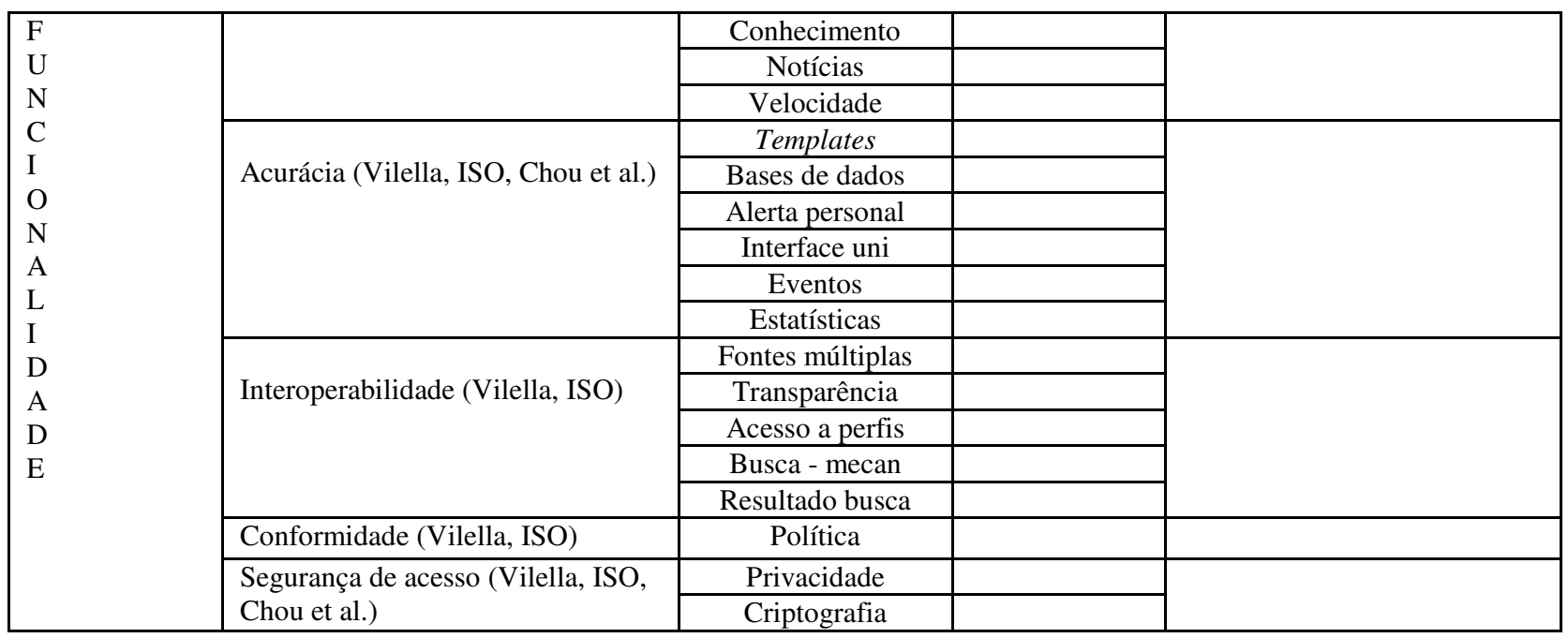




\section{APÊNDICE C - Lista dos sites que constituem a Amostra}

Foi atribuida uma "sigla" a cada site, indicada entre parênteses após o endereço eletrônico. O intuito é facilitar a identificação dos sites nos gráficos e no texto.

1. http://www.abdi.com.br (abdi)

2. http://ccs.mit.edu/oph (ccs)

3. http://portal.crie.coppe.ufrj.br (crie)

4. http://designbrasil.org.br (design)

5. http://www.inovar.org.br (inovar)

6. http://www.inpi.gov.br (inpi)

7. http://www.kmol.online.pt (kmol)

8. htttp://www.terraforum.com.br (terraforum)

9. htttp://numa.sc.usp.br/forum (numaforum)

10. http://ocw.mit.edu (ocw)

11. http://www.patentenet.com.br (patentenet)

12. http://portaldeconhecimentos.org.br (conhece)

13. http://www.portalinovacao.info ou http://www.portalinovacao.mct.gov.br (inovação)

14. http://www.prossiga.br/finep (bvinova)

15. http://sbrt.ibict.br (sbrt)

16. http://www.score.org (score)

17. http://www.sebrae.com.br (sebrae)

18. http://www.sitedoempreendedor.com.br (empreende)

19. http://www.scienti.net (scienti)

20. http://www.universia.com.br/mit (universia) 


\section{APÊNDICE D - Pontuação}

\begin{tabular}{|c|c|c|c|c|c|c|}
\hline Dimensão & Característica & Atributo & Peso & Nota & $\begin{array}{c}\text { Pontuação } \\
\text { (peso x nota) }\end{array}$ & Observação \\
\hline \multirow{27}{*}{$\begin{array}{l}\mathrm{C} \\
\mathrm{O} \\
\mathrm{N} \\
\mathrm{T} \\
\mathrm{E} \\
\mathrm{U} \\
\mathrm{D} \\
\mathrm{O}\end{array}$} & \multirow{4}{*}{ Propósito } & Visão geral & 1 & Zero ou 10 & & \multirow{52}{*}{$\begin{array}{l}\text { Pontuação } \\
\text { (peso x nota) } \\
\text { significa o } \\
\text { valor obtido, } \\
\text { por critério. }\end{array}$} \\
\hline & & Escopo & 1 & Zero ou 10 & & \\
\hline & & Serviços & 1 & Zero ou 10 & & \\
\hline & & Complementação & 1 & Zero ou 10 & & \\
\hline & \multirow{4}{*}{$\begin{array}{l}\text { Abrangência / } \\
\text { cobertura }\end{array}$} & Tipo de conteúdo & 2 & Zero/3/6/10 & & \\
\hline & & Tipo de assunto & 3 & Zero/3/6/10 & & \\
\hline & & Outros idiomas & 1 & Zero ou 10 & & \\
\hline & & Versões & 1 & Zero ou 10 & & \\
\hline & $\begin{array}{l}\text { Padrão de publicação } \\
\text { de conteúdo }\end{array}$ & $\begin{array}{l}\text { Taxonomia/onto/ } \\
\text { classificação/nada }\end{array}$ & 1 & Zero/3/6/10 & & \\
\hline & Atualidade & Atualização & 1 & Zero ou 10 & & \\
\hline & & Data - conteúdo sig & 1 & Zero ou 10 & & \\
\hline & & Precisão & 1 & Zero ou 10 & & \\
\hline & Correção & Referência correta & 1 & Zero ou 10 & & \\
\hline & & Inconsistências & 1 & Zero ou 10 & & \\
\hline & & Copirraite & 1 & Zero ou 10 & & \\
\hline & Autoridade / copirraite & Menção a fontes & 1 & Zero ou 10 & & \\
\hline & & Responsabilidade & 1 & Zero ou 10 & & \\
\hline & & Legitimidade & 1 & Zero ou 10 & & \\
\hline & & Conteúdo - inicial & 1 & Zero ou 10 & & \\
\hline & Objetividade & Conteúdo adequado & 1 & Zero ou 10 & & \\
\hline & & Forma de escrita & 1 & Zero ou 10 & & \\
\hline & & Publicidade & 1 & Zero ou 10 & & \\
\hline & & Utilidade & 1 & Zero ou 10 & & \\
\hline & & Regras de publ & 1 & Zero ou 10 & & \\
\hline & Regras de publicação & Acesso livre & 3 & Zero ou 10 & & \\
\hline & & Acesso condi & 1 & Zero ou 10 & & \\
\hline & & Acesso restrito & 1 & Zero ou 10 & & \\
\hline \multirow{15}{*}{$\begin{array}{l}\text { U } \\
\text { S } \\
\text { A } \\
\text { B } \\
\text { I } \\
\text { L } \\
\text { I } \\
\text { D } \\
\text { A } \\
\text { D } \\
\text { E }\end{array}$} & \multirow[t]{3}{*}{ Inteligibilidade } & Fontes e atributos & 1 & Zero ou 10 & & \\
\hline & & Links claros & 1 & Zero ou 10 & & \\
\hline & & Interface & 1 & Zero ou 10 & & \\
\hline & \multirow{4}{*}{ Apreensibilidade } & Navegação & 1 & Zero ou 10 & & \\
\hline & & Apreensão & 1 & Zero ou 10 & & \\
\hline & & Instruções de uso & 1 & Zero ou 10 & & \\
\hline & & Interface humana & 1 & Zero ou 10 & & \\
\hline & \multirow{8}{*}{ Operacionalidade } & Rolagem & 1 & Zero ou 10 & & \\
\hline & & Ajuste de leiaute & 1 & Zero ou 10 & & \\
\hline & & Agrupamento & 1 & Zero ou 10 & & \\
\hline & & Tarefas prioritárias & 1 & Zero ou 10 & & \\
\hline & & Clareza da URL & 1 & Zero ou 10 & & \\
\hline & & Disponibilidade & 1 & Zero ou 10 & & \\
\hline & & Outras mídias & 1 & Zero ou 10 & & \\
\hline & & Acessibilidade & 2 & Zero ou 10 & & \\
\hline \multirow{10}{*}{$\begin{array}{l}\mathrm{F} \\
\mathrm{U} \\
\mathrm{N} \\
\mathrm{C} \\
\mathrm{I}\end{array}$} & \multirow{8}{*}{ Adequação } & Diálogo real & 1 & Zero ou 10 & & \\
\hline & & Cooperação & 1 & Zero ou 10 & & \\
\hline & & Criação de CoP & 3 & Zero ou 10 & & \\
\hline & & Ferramentas de CoP & 2 & Zero ou 10 & & \\
\hline & & Versão personal & 1 & Zero ou 10 & & \\
\hline & & Conhecimento & 1 & Zero ou 10 & & \\
\hline & & Notícias & 1 & Zero ou 10 & & \\
\hline & & Velocidade & 1 & Zero ou 10 & & \\
\hline & \multirow[b]{2}{*}{ Acurácia } & Templates & 1 & Zero ou 10 & & \\
\hline & & Bases de dados & 1 & Zero ou 10 & & \\
\hline
\end{tabular}




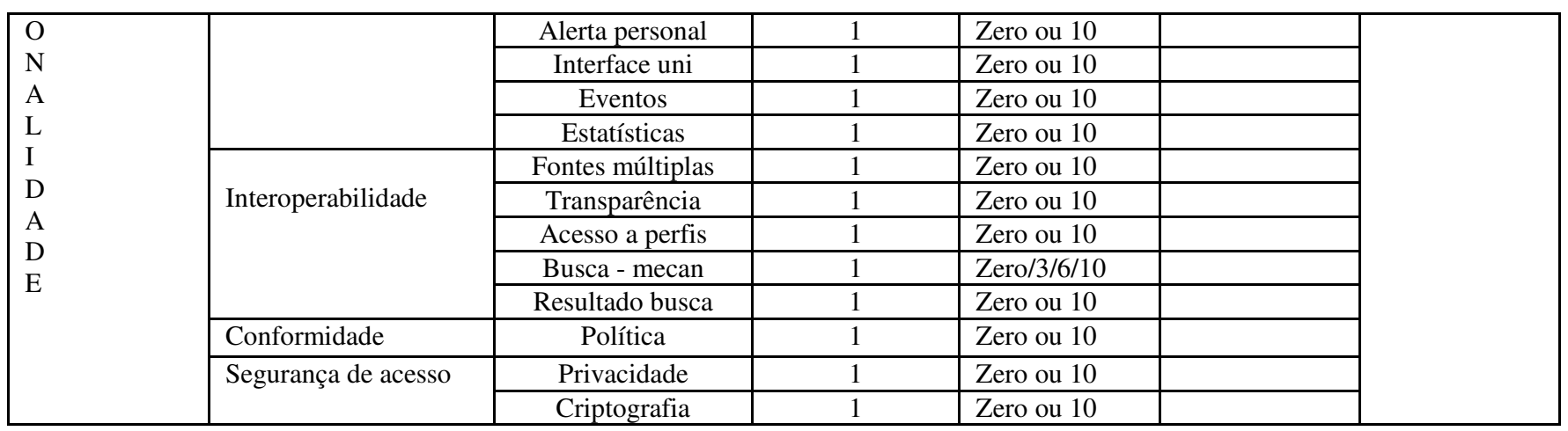




\section{APÊNDICE E - Amostra - formulário de análise com a pontuação de cada site}

\section{http://www.abdi.com.br}

Portal da Agência Brasileira de Desenvolvimento Industrial - ABDI tem como missão "promover o desenvolvimento industrial e tecnológico brasileiro por meio do aumento da competitividade e da inovação. O principal enfoque está nos programas e projetos estabelecidos pela Política Industrial, Tecnológica e de Comércio Exterior (PITCE), da qual é coordenadora, articuladora e promotora, funcionando como ligação entre as diretrizes estratégicas discutidas em várias instâncias governamentais e na sociedade civil e os executores de políticas públicas”.

\begin{tabular}{|c|c|c|c|c|}
\hline Dimensão & Característica & Atributo & Pontuação & Observações \\
\hline \multirow{27}{*}{$\begin{array}{l}\mathrm{C} \\
\mathrm{O} \\
\mathrm{N} \\
\mathrm{T} \\
\mathrm{E} \\
\mathrm{U} \\
\mathrm{D} \\
\mathrm{O}\end{array}$} & \multirow{4}{*}{ Propósito (Vilella) } & Visão geral & 10 & \\
\hline & & Escopo & 10 & \\
\hline & & Serviços & 10 & \\
\hline & & Complementação & 10 & \\
\hline & \multirow{4}{*}{$\begin{array}{l}\text { Abrangência / cobertura (Vilella - } \\
\text { junto com propósito) }\end{array}$} & Tipo de conteúdo & 6 & \multirow{4}{*}{$\begin{array}{l}\text { 1.artigos nac. e int., sites, } \\
\text { legislação, relatórios, } \\
\text { depoimentos, boletim } \\
\text { (Conjuntura Industrial } \\
\text { 2. Inovação, conjuntura, des. } \\
\text { e política industrial }\end{array}$} \\
\hline & & Tipo de assunto & 18 & \\
\hline & & Outros idiomas & 0 & \\
\hline & & Versões & 0 & \\
\hline & $\begin{array}{l}\text { Padrão de publicação de conteúdo } \\
\text { (Almeida e Bax, Breitman, Terra e } \\
\text { Gordon) }\end{array}$ & $\begin{array}{l}\text { Taxonomia/onto/ } \\
\text { classificação/nada }\end{array}$ & 3 & $\begin{array}{l}\text { Apresenta uma relação de } \\
\text { temas e remete a uma listagem } \\
\text { de docs (arquivos pdf) }\end{array}$ \\
\hline & \multirow{2}{*}{$\begin{array}{l}\text { Atualidade (Vilella, Chou et al. - } \\
\text { timeless) }\end{array}$} & Atualização & 0 & \multirow{2}{*}{$\begin{array}{l}\text { Mas o conteúdo está } \\
\text { atualizado }\end{array}$} \\
\hline & & Data - conteúdo sig & 0 & \\
\hline & \multirow{3}{*}{ Correção (Vilella) } & Precisão & 10 & \\
\hline & & Referência correta & 10 & \\
\hline & & Inconsistências & 10 & \\
\hline & \multirow{4}{*}{$\begin{array}{l}\text { Autoridade / copirraite (Vilella), } \\
\text { believability e reputation (Chou et } \\
\text { al.) }\end{array}$} & Copirraite & 0 & \\
\hline & & Menção a fontes & 10 & \\
\hline & & Responsabilidade & 10 & \\
\hline & & Legitimidade & 10 & \\
\hline & \multirow{5}{*}{ Objetividade (Vilella, Chou e al.) } & Conteúdo - inicial & 10 & \multirow{5}{*}{$\begin{array}{l}\text { A Biblioteca Virtual precisa } \\
\text { ser ampliada - poucos docs. }\end{array}$} \\
\hline & & Conteúdo adequado & 10 & \\
\hline & & Forma de escrita & 10 & \\
\hline & & Publicidade & 10 & \\
\hline & & Utilidade & 10 & \\
\hline & \multirow{4}{*}{$\begin{array}{l}\text { Regras de publicação e acesso } \\
\text { (Moretti et al.) ou acessibilidade } \\
\text { (Coelho, 2007) }\end{array}$} & Regras de publ & 0 & \multirow{4}{*}{$\begin{array}{l}1 \text { e } 2 . \text { Possibilidade de } \\
\text { cadastro. }\end{array}$} \\
\hline & & Acesso livre & 30 & \\
\hline & & Acesso condi & 10 & \\
\hline & & Acesso restrito & 10 & \\
\hline \multirow{10}{*}{$\begin{array}{l}\text { U } \\
\text { S } \\
\text { A } \\
\text { B } \\
\text { I } \\
\text { L } \\
\text { I } \\
\text { D } \\
\text { A }\end{array}$} & \multirow{3}{*}{$\begin{array}{l}\text { Inteligibilidade (Chou et al., ISO, } \\
\text { Nielsen, Vilella) - easy to } \\
\text { understand, interpretability }\end{array}$} & Fontes e atributos & 10 & \\
\hline & & Links claros & 10 & \\
\hline & & Interface & 10 & \\
\hline & \multirow{4}{*}{$\begin{array}{l}\text { Apreensibilidade (ISO, Nielsen, } \\
\text { Vilella) }\end{array}$} & Navegação & 10 & \multirow{4}{*}{$\begin{array}{l}\text { 4. Existe uma ajuda dinâmica, } \\
\text { mas não funciona (três } \\
\text { tentativas de acesso em dois } \\
\text { meses diferentes) }\end{array}$} \\
\hline & & Apreensão & 10 & \\
\hline & & Instruções de uso & 0 & \\
\hline & & Interface humana & 0 & \\
\hline & \multirow[b]{3}{*}{ Operacionalidade (ISO, Chou et al., } & Rolagem & 10 & \\
\hline & & Ajuste de leiaute & 0 & \\
\hline & & Agrupamento & 10 & \\
\hline
\end{tabular}




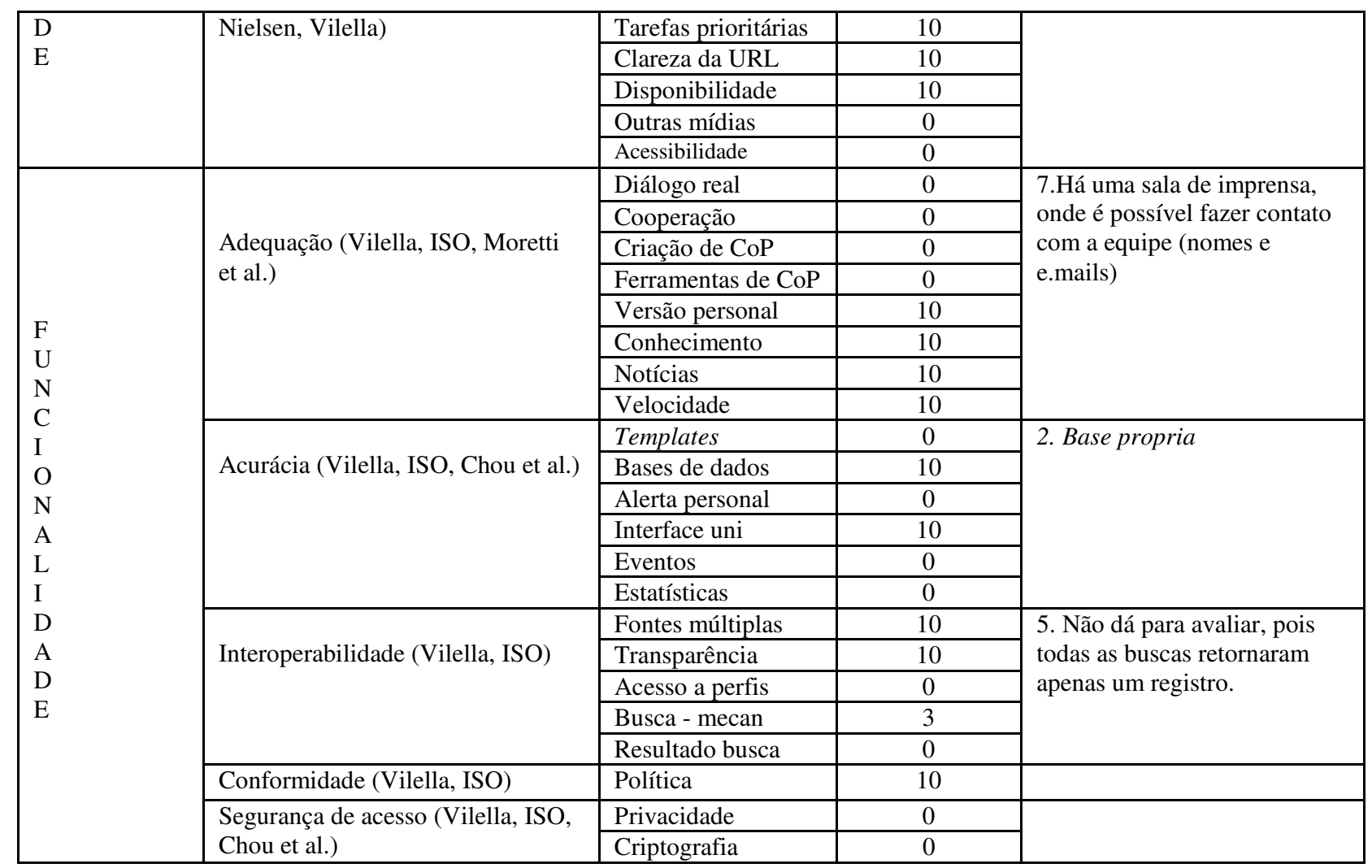

Obs.1: "Existem no Brasil vários instrumentos de apoio à inovação de responsabilidade de diferentes órgãos. Mas não há uma consolidação, obrigando que o interessado faça um périplo para poder ter acesso à informação - acessar programas nos portais de ministérios e agências pode ser bastante difícil, pois a informação não está consolidada sob a ótica do usuário e sim sob a ótica do órgão. Assim, o desafio também é consolidar um sistema simples, acessível e ágil, que propicie simultaneamente a divulgação integrada e o maior acesso à informação sobre os diversos instrumentos, leis, programas etc. relativos à inovação e ao desenvolvimento produtivo, considerando a necessidade do usuário" (Planejamento Estratégico, Desafio 5: Desenvolver cultura e ambiente inovador";

Obs.2: Um dos focos de atuação é através do Programa de Desenvolvimento Setorial PDS, que tem como objetivos "atuar setorialmente com ênfase regional buscando: fortalecer e modernizar o parque industrial brasileiro, estimular a tecnologia industrial básica, aumentar o porte das empresas nacionais, estimular as atividades de engenharia de concepção e projeto de produto, estimular o investimento em geral e prover financiamento para a expansão da capacidade instalada e para o desenvolvimento de produtos. O plano se articula em 4 eixos:1.Financiamento; 2.Tecnologia e inovação; 3.Gestão e capacitação; 4.Ações especiais (Áreas: biotecnoloiga, frutas processadas, confecções, produtos médicos, cosméticos, calçados, semicondutores e nanotecnologia).

(Análise elaborada e revista no período de 01.09 a 30.10.2007). 


\section{http://ccs.mit.edu/oph}

Portal do Projeto que tem como meta o desenvolvimento de uma rica biblioteca on-line para compartilhamento e gestão de vários tipos de conhecimento sobre negócios. O trabalho, em desenvolvimento há mais de 15 anos, é uma iniciativa de pesquisadores da MIT Sloan School of Mangement, denominada "The Open Process Handbook Initiative (OPHI). A idéia central é a disponibilidade livre para o público geral, com o uso de licença "open source".

Parte da documentação está disponível numa pública, mas o resultado principal do projeto, o livro "MIT Process Handbook" está à venda no site do MIT e pela Amazon. Na versão pública estão disponíveis somente o sumário, a introdução, os capítulos 1 e 8, e o índice.

\begin{tabular}{|c|c|c|c|c|}
\hline Dimensão & Característica & Atributo & Pontuação & Observações \\
\hline \multirow{27}{*}{$\begin{array}{l}\mathrm{C} \\
\mathrm{O} \\
\mathrm{N} \\
\mathrm{T} \\
\mathrm{E} \\
\dot{U} \\
\mathrm{D} \\
\mathrm{O}\end{array}$} & \multirow{4}{*}{ Propósito (Vilella) } & Visão geral & 10 & \\
\hline & & Escopo & 10 & \\
\hline & & Serviços & 10 & \\
\hline & & Complementação & 10 & \\
\hline & \multirow{4}{*}{$\begin{array}{l}\text { Abrangência / cobertura (Vilella } \\
\text { - junto com propósito) }\end{array}$} & Tipo de conteúdo & 6 & \multirow{4}{*}{$\begin{array}{l}\text { 1. sites, textos, exemplos de casos, } \\
\text { guia para navegar pelo repositório, } \\
\text { cap. livro } \\
\text { 2. processos de negócio em } \\
\text { compras, gestão da cadeia de } \\
\text { suprimentos, marketing, vendas, } \\
\text { sistemas de informação, } \\
\text { planejamento estratégico, finanças } \\
\text { e contabilidade, manufatura e } \\
\text { logística, engenharia, RH }\end{array}$} \\
\hline & & Tipo de assunto & 9 & \\
\hline & & Outros idiomas & 0 & \\
\hline & & Versões & 0 & \\
\hline & $\begin{array}{l}\text { Padrão de publicação de } \\
\text { conteúdo (Almeida e Bax, } \\
\text { Breitman, Terra e Gordon) }\end{array}$ & $\begin{array}{l}\text { Taxonomia/onto/ } \\
\text { classificação/nada }\end{array}$ & 3 & \\
\hline & \multirow{2}{*}{$\begin{array}{l}\text { Atualidade (Vilella, Chou et al. - } \\
\text { timeless) }\end{array}$} & Atualização & 0 & \multirow{2}{*}{$\begin{array}{l}\text { P. inicial não informa data de } \\
\text { atualização. Somente nos } \\
\text { conteúdos específicos. }\end{array}$} \\
\hline & & Data - conteúdo sig & 10 & \\
\hline & \multirow{3}{*}{ Correção (Vilella) } & Precisão & 10 & \\
\hline & & Referência correta & 10 & \\
\hline & & Inconsistências & 10 & \\
\hline & \multirow{4}{*}{$\begin{array}{l}\text { Autoridade / copirraite (Vilella), } \\
\text { believability e reputation (Chou } \\
\text { et al.) }\end{array}$} & Copirraite & 10 & \\
\hline & & Menção a fontes & 10 & \\
\hline & & Responsabilidade & 10 & \\
\hline & & Legitimidade & 10 & \\
\hline & \multirow{5}{*}{$\begin{array}{l}\text { Objetividade (Vilella, Chou e } \\
\text { al.) }\end{array}$} & Conteúdo - inicial & 10 & \\
\hline & & Conteúdo adequado & 10 & \\
\hline & & Forma de escrita & 10 & \\
\hline & & Publicidade & 10 & \\
\hline & & Utilidade & 10 & \\
\hline & \multirow{4}{*}{$\begin{array}{l}\text { Regras de publicação e acesso } \\
\text { (Moretti et al.) ou acessibilidade } \\
\text { (Coelho, 2007) }\end{array}$} & Regras de publ & 10 & \multirow{4}{*}{$\begin{array}{l}\text { Para acesso ao repositório de textos } \\
\text { específicos é necessário concordar } \\
\text { com a política de acesso / } \\
\text { privacidade }\end{array}$} \\
\hline & & Acesso livre & 30 & \\
\hline & & Acesso condi & 0 & \\
\hline & & Acesso restrito & 10 & \\
\hline \multirow{4}{*}{$\begin{array}{l}\mathrm{U} \\
\mathrm{S} \\
\mathrm{A}\end{array}$} & \multirow{4}{*}{$\begin{array}{l}\text { Inteligibilidade (Chou et al., } \\
\text { ISO, Nielsen, Vilella) - easy to } \\
\text { understand, interpretability }\end{array}$} & Fontes e atributos & 10 & \\
\hline & & Links claros & 10 & \\
\hline & & Interface & 0 & \\
\hline & & Navegação & 0 & 1 e 2. Disponíveis mas de difícil \\
\hline
\end{tabular}




\begin{tabular}{|c|c|c|c|c|}
\hline \multirow{11}{*}{$\begin{array}{l}\text { B } \\
\text { I } \\
\text { L } \\
\text { I } \\
\text { D } \\
\text { A } \\
\text { D } \\
\text { E }\end{array}$} & \multirow{3}{*}{$\begin{array}{l}\text { Apreensibilidade (ISO, Nielsen, } \\
\text { Vilella) }\end{array}$} & Apreensão & 0 & \multirow[t]{3}{*}{ identificação /localização } \\
\hline & & Instruções de uso & 0 & \\
\hline & & Interface humana & 0 & \\
\hline & \multirow{8}{*}{$\begin{array}{l}\text { Operacionalidade (ISO, Chou et } \\
\text { al., Nielsen, Vilella) }\end{array}$} & Rolagem & 0 & \\
\hline & & Ajuste de leiaute & 0 & \\
\hline & & Agrupamento & 0 & \\
\hline & & Tarefas prioritárias & 0 & \\
\hline & & Clareza da URL & 0 & \\
\hline & & Disponibilidade & 10 & \\
\hline & & Outras mídias & 0 & \\
\hline & & Acessibilidade & 0 & \\
\hline \multirow{22}{*}{$\begin{array}{l}\mathrm{F} \\
\mathrm{U} \\
\mathrm{N} \\
\mathrm{C} \\
\mathrm{I} \\
\mathrm{O} \\
\mathrm{N} \\
\mathrm{A} \\
\mathrm{L} \\
\mathrm{I} \\
\mathrm{D} \\
\mathrm{A} \\
\mathrm{D} \\
\mathrm{E}\end{array}$} & \multirow{8}{*}{$\begin{array}{l}\text { Adequação (Vilella, ISO, } \\
\text { Moretti et al.) }\end{array}$} & Diálogo real & 0 & \\
\hline & & Cooperação & 10 & \\
\hline & & Criação de CoP & 0 & \\
\hline & & Ferramentas de CoP & 0 & \\
\hline & & Versão personal & 0 & \\
\hline & & Conhecimento & 10 & \\
\hline & & Notícias & 0 & \\
\hline & & Velocidade & 10 & \\
\hline & \multirow{6}{*}{$\begin{array}{l}\text { Acurácia (Vilella, ISO, Chou et } \\
\text { al.) }\end{array}$} & Templates & 0 & \multirow[t]{6}{*}{ 2. Local e externa } \\
\hline & & Bases de dados & 10 & \\
\hline & & Alerta personal & 0 & \\
\hline & & Interface uni & 0 & \\
\hline & & Eventos & 0 & \\
\hline & & Estatísticas & 0 & \\
\hline & \multirow{5}{*}{ Interoperabilidade (Vilella, ISO) } & Fontes múltiplas & 10 & \multirow{5}{*}{$\begin{array}{l}\text { 5. O resultado de busca é } \\
\text { apresentado em lista única } \\
\text { proveniente das diferentes bases, } \\
\text { em ordem alfabética de título e } \\
\text { dentro de cada título, há uma } \\
\text { descrição em formato padrão. }\end{array}$} \\
\hline & & Transparência & 10 & \\
\hline & & Acesso a perfis & 0 & \\
\hline & & Busca - mecan & 10 & \\
\hline & & Resultado busca & 10 & \\
\hline & Conformidade (Vilella, ISO) & Política & 10 & \\
\hline & \multirow{2}{*}{$\begin{array}{l}\text { Segurança de acesso (Vilella, } \\
\text { ISO, Chou et al.) }\end{array}$} & Privacidade & 10 & \\
\hline & & Criptografia & 0 & \\
\hline
\end{tabular}

(Análise elaborada e revista no período de 01.09 a 30.10.2007). 


\section{http://portal.crie.coppe.ufrj.br}

"O Centro de Referência em Inteligência Empresarial (CRIE) é um laboratório de pesquisa e desenvolvimento em inteligência empresarial do Programa de Engenharia de Produção da COPPE / UFRJ. Tem como missão criar e desenvolver produtos e serviços na área de inteligência empresarial - com ênfase na Gestão do Conhecimento - de forma a contribuir para a inserção competitiva do Brasil na sociedade do conhecimento".

\begin{tabular}{|c|c|c|c|c|}
\hline Dimensão & Característica & Atributo & Pontuação & Observações \\
\hline \multirow{27}{*}{$\begin{array}{l}\mathrm{C} \\
\mathrm{O} \\
\mathrm{N} \\
\mathrm{T} \\
\mathrm{E} \\
\mathrm{U} \\
\mathrm{D} \\
\mathrm{O}\end{array}$} & \multirow{4}{*}{ Propósito (Vilella) } & Visão geral & 10 & \\
\hline & & Escopo & 10 & \\
\hline & & Serviços & 10 & \\
\hline & & Complementação & 10 & \\
\hline & \multirow{4}{*}{$\begin{array}{l}\text { Abrangência / cobertura (Vilella - } \\
\text { junto com propósito) }\end{array}$} & Tipo de conteúdo & 6 & \multirow{4}{*}{$\begin{array}{l}\text { 1. sites, artigos, noticias de } \\
\text { jornais, apresentações, casos } \\
\text { (projetos), dissertações e teses } \\
\text { em texto completo, resumo de } \\
\text { livros. } \\
\text { 2. inteligência competitiva, } \\
\text { política industrial, gestão da } \\
\text { comunicação, gestão do } \\
\text { conhecimento, inovação, } \\
\text { desenvolvimento de produto, } \\
\text { comunidades de prática }\end{array}$} \\
\hline & & Tipo de assunto & 18 & \\
\hline & & Outros idiomas & 0 & \\
\hline & & Versões & 0 & \\
\hline & $\begin{array}{l}\text { Padrão de publicação de conteúdo } \\
\text { (Almeida e Bax, Breitman, Terra e } \\
\text { Gordon) }\end{array}$ & $\begin{array}{l}\text { Taxonomia/onto/ } \\
\text { classificação/nada }\end{array}$ & 3 & Por tipo de Documento \\
\hline & \multirow{2}{*}{$\begin{array}{l}\text { Atualidade (Vilella, Chou et al. - } \\
\text { timeless) }\end{array}$} & Atualização & 10 & \multirow{2}{*}{$\begin{array}{l}\text { 1. Não há indicação da última } \\
\text { atualização, mas na p. inicial tem } \\
\text { o "Crie Informa", com notícias } \\
\text { bem recentes }\end{array}$} \\
\hline & & Data - conteúdo sig & 0 & \\
\hline & \multirow{3}{*}{ Correção (Vilella) } & Precisão & 10 & \\
\hline & & Referência correta & 10 & \\
\hline & & Inconsistências & 10 & \\
\hline & \multirow{4}{*}{$\begin{array}{l}\text { Autoridade / copirraite (Vilella), } \\
\text { believability e reputation (Chou et } \\
\text { al.) }\end{array}$} & Copirraite & 0 & \\
\hline & & Menção a fontes & 10 & \\
\hline & & Responsabilidade & 10 & \\
\hline & & Legitimidade & 10 & \\
\hline & \multirow{5}{*}{ Objetividade (Vilella, Chou e al.) } & Conteúdo - inicial & 10 & \\
\hline & & Conteúdo adequado & 10 & \\
\hline & & Forma de escrita & 10 & \\
\hline & & Publicidade & 10 & \\
\hline & & Utilidade & 10 & \\
\hline & \multirow{4}{*}{$\begin{array}{l}\text { Regras de publicação e acesso } \\
\text { (Moretti et al.) ou acessibilidade } \\
\text { (Coelho, 2007) }\end{array}$} & Regras de publ & 10 & \multirow{4}{*}{$\begin{array}{l}\text { 3. O acesso é restrito ao texto } \\
\text { completo dos artigos publicados } \\
\text { na Revista Inteligência } \\
\text { Empresarial - acesso mediante } \\
\text { assinatura. }\end{array}$} \\
\hline & & Acesso livre & 30 & \\
\hline & & Acesso condi & 0 & \\
\hline & & Acesso restrito & 10 & \\
\hline \multirow{7}{*}{$\begin{array}{l}\text { U } \\
\text { S } \\
\text { A } \\
\text { B } \\
\text { I } \\
\text { L }\end{array}$} & \multirow{3}{*}{$\begin{array}{l}\text { Inteligibilidade (Chou et al., ISO, } \\
\text { Nielsen, Vilella) - easy to } \\
\text { understand, interpretability }\end{array}$} & Fontes e atributos & 10 & \\
\hline & & Links claros & 10 & \\
\hline & & Interface & 10 & \\
\hline & \multirow{4}{*}{$\begin{array}{l}\text { Apreensibilidade (ISO, Nielsen, } \\
\text { Vilella) }\end{array}$} & Navegação & 10 & \\
\hline & & Apreensão & 0 & \\
\hline & & Instruções de uso & 0 & \\
\hline & & Interface humana & 10 & \\
\hline
\end{tabular}




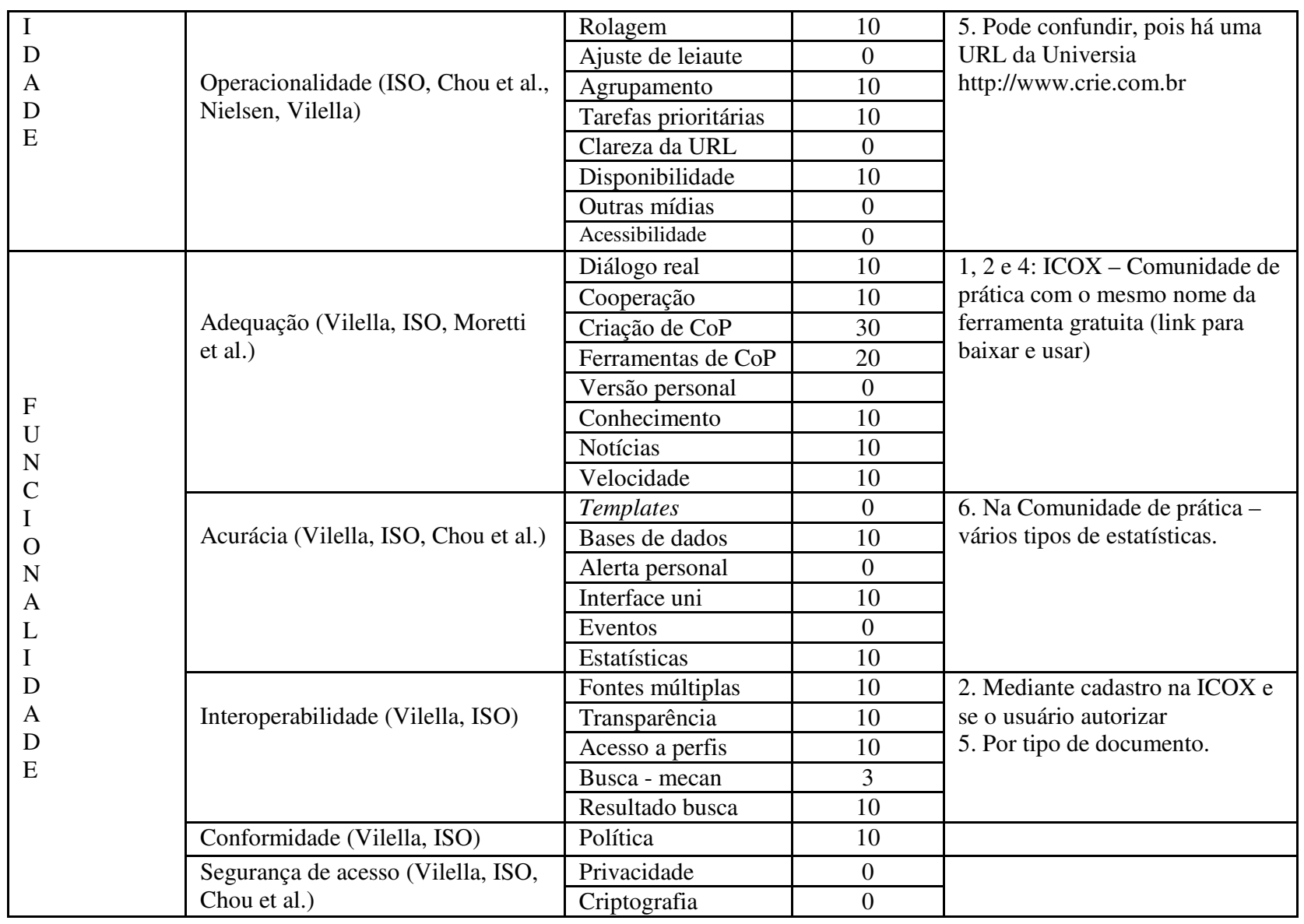

(Análise elaborada e revista no período de 01.09 a 30.10.2007). 


\section{http://www.designbrasil.org.br}

Portal que visa integrar a comunidade do design brasileiro. Além de criar uma grande comunidade de interessados no tema, abre espaço para a interação e a troca de informações. O Design Brasil é uma porta de entrada para ações institucionais de incentivo ao design: Programa Brasileiro de Design, Via Design, Marca Brasil, PSGD (Programa SENAI de Gestão da Inovação e do Design), dentre outros.

Lançado em dezembro de 2004, o Design Brasil é resultado de uma iniciativa conjunta de três instituições: MDIC, através do PBD; Senai e do Sebrae Nacional. A coordenação é do Centro de Design Paraná.

Possui uma comunidade denominada "Comunidade design Brasil", com mais de 7.500 pessoas cadastradas (21.08.2007).

\begin{tabular}{|c|c|c|c|c|}
\hline Dimensão & Característica & Atributo & Pontuação & Observações \\
\hline \multirow{27}{*}{$\begin{array}{l}\mathrm{C} \\
\mathrm{O} \\
\mathrm{N} \\
\mathrm{T} \\
\mathrm{E} \\
\mathrm{U}^{\mathrm{U}} \\
\mathrm{D} \\
\mathrm{O}\end{array}$} & \multirow{4}{*}{ Propósito (Vilella) } & Visão geral & 10 & \\
\hline & & Escopo & 10 & \\
\hline & & Serviços & 10 & \\
\hline & & Complementação & 10 & \\
\hline & \multirow{4}{*}{$\begin{array}{l}\text { Abrangência / cobertura (Vilella - } \\
\text { junto com propósito) }\end{array}$} & Tipo de conteúdo & 6 & \multirow{4}{*}{$\begin{array}{l}\text { 1. textos, sites, dissertações e } \\
\text { teses, artigos de divulgação e } \\
\text { científicos, depoimentos, } \\
\text { entrevistas, bibliografia } \\
\text { comentada, imagens, lista de } \\
\text { boletins e revistas } \\
\text { 2. design (ensino, gestão, } \\
\text { políticas), eco design, inovação, } \\
\text { desenvolvimento de produtos, } \\
\text { marcas e patentes. } \\
\text { 3. Em espanhol e inglês }\end{array}$} \\
\hline & & Tipo de assunto & 18 & \\
\hline & & Outros idiomas & 10 & \\
\hline & & Versões & 0 & \\
\hline & $\begin{array}{l}\text { Padrão de publicação de conteúdo } \\
\text { (Almeida e Bax, Breitman, Terra e } \\
\text { Gordon) }\end{array}$ & $\begin{array}{l}\text { Taxonomia/onto/ } \\
\text { classificação/nada }\end{array}$ & 3 & \\
\hline & \multirow{2}{*}{$\begin{array}{l}\text { Atualidade (Vilella, Chou et al. - } \\
\text { timeless) }\end{array}$} & Atualização & 10 & \multirow{2}{*}{$\begin{array}{l}\text { 1. pela recuperação da } \\
\text { informação. Não há indicação de } \\
\text { atualização da página. } \\
\text { 2. Mas de difícil identificação }\end{array}$} \\
\hline & & Data - conteúdo sig & 10 & \\
\hline & \multirow{3}{*}{ Correção (Vilella) } & Precisão & 10 & \multirow{3}{*}{$\begin{array}{l}\text { Possui um Manual de Redação } \\
\text { on-line da Comunidade }\end{array}$} \\
\hline & & Referência correta & 10 & \\
\hline & & Inconsistências & 10 & \\
\hline & \multirow{4}{*}{$\begin{array}{l}\text { Autoridade / copirraite (Vilella), } \\
\text { believability e reputation (Chou et } \\
\text { al.) }\end{array}$} & Copirraite & 10 & \\
\hline & & Menção a fontes & 10 & \\
\hline & & Responsabilidade & 10 & \\
\hline & & Legitimidade & 10 & \\
\hline & \multirow{5}{*}{ Objetividade (Vilella, Chou e al.) } & Conteúdo - inicial & 10 & \\
\hline & & Conteúdo adequado & 10 & \\
\hline & & Forma de escrita & 10 & \\
\hline & & Publicidade & 10 & \\
\hline & & Utilidade & 10 & \\
\hline & \multirow{4}{*}{$\begin{array}{l}\text { Regras de publicação e acesso } \\
\text { (Moretti et al.) ou acessibilidade } \\
\text { (Coelho, 2007) }\end{array}$} & Regras de publ & 10 & \multirow{4}{*}{$\begin{array}{l}\text { Há restrições de acessos, por ex. } \\
\text { para estudante, para empresas } \\
\text { (focos específicos) }\end{array}$} \\
\hline & & Acesso livre & 30 & \\
\hline & & Acesso condi & 0 & \\
\hline & & Acesso restrito & 0 & \\
\hline
\end{tabular}




\begin{tabular}{|c|c|c|c|c|}
\hline \multirow{15}{*}{$\begin{array}{l}\text { U } \\
\text { S } \\
\text { A } \\
\text { B } \\
\text { I } \\
\text { L } \\
\text { I } \\
\text { D } \\
\text { A } \\
\text { D } \\
\text { E }\end{array}$} & \multirow{3}{*}{$\begin{array}{l}\text { Inteligibilidade (Chou et al., ISO, } \\
\text { Nielsen, Vilella) - easy to } \\
\text { understand, interpretability }\end{array}$} & Fontes e atributos & 10 & \\
\hline & & Links claros & 10 & \\
\hline & & Interface & 10 & \\
\hline & \multirow{4}{*}{$\begin{array}{l}\text { Apreensibilidade (ISO, Nielsen, } \\
\text { Vilella) }\end{array}$} & Navegação & 10 & \\
\hline & & Apreensão & 0 & \\
\hline & & Instruções de uso & 0 & \\
\hline & & Interface humana & 0 & \\
\hline & \multirow{8}{*}{$\begin{array}{l}\text { Operacionalidade (ISO, Chou et al., } \\
\text { Nielsen, Vilella) }\end{array}$} & Rolagem & 10 & \\
\hline & & Ajuste de leiaute & 0 & \\
\hline & & Agrupamento & 10 & \\
\hline & & Tarefas prioritárias & 10 & \\
\hline & & Clareza da URL & 10 & \\
\hline & & Disponibilidade & 10 & \\
\hline & & Outras mídias & 0 & \\
\hline & & Acessibilidade & 0 & \\
\hline \multirow{22}{*}{$\begin{array}{l}\mathrm{F} \\
\mathrm{U} \\
\mathrm{N} \\
\mathrm{C} \\
\mathrm{I} \\
\mathrm{O} \\
\mathrm{N} \\
\mathrm{A} \\
\mathrm{L} \\
\mathrm{I} \\
\mathrm{D} \\
\mathrm{A} \\
\mathrm{D} \\
\mathrm{E}\end{array}$} & \multirow{8}{*}{$\begin{array}{l}\text { Adequação (Vilella, ISO, Moretti } \\
\text { et al.) }\end{array}$} & Diálogo real & 0 & \multirow{8}{*}{$\begin{array}{l}\text { 3. Mas tem uma comunidade. } \\
\text { 8. Lento em vários momentos. }\end{array}$} \\
\hline & & Cooperação & 0 & \\
\hline & & Criação de CoP & 0 & \\
\hline & & Ferramentas de CoP & 0 & \\
\hline & & Versão personal & 0 & \\
\hline & & Conhecimento & 10 & \\
\hline & & Notícias & 10 & \\
\hline & & Velocidade & 0 & \\
\hline & \multirow{6}{*}{ Acurácia (Vilella, ISO, Chou et al.) } & Templates & 10 & \\
\hline & & Bases de dados & 10 & \\
\hline & & Alerta personal & 0 & \\
\hline & & Interface uni & 10 & \\
\hline & & Eventos & 0 & \\
\hline & & Estatísticas & 0 & \\
\hline & \multirow{5}{*}{ Interoperabilidade (Vilella, ISO) } & Fontes múltiplas & 10 & \multirow[t]{5}{*}{ 5. Por categoria de assunto } \\
\hline & & Transparência & 10 & \\
\hline & & Acesso a perfis & 0 & \\
\hline & & Busca - mecan & 3 & \\
\hline & & Resultado busca & 10 & \\
\hline & Conformidade (Vilella, ISO) & Política & 10 & \\
\hline & \multirow{2}{*}{$\begin{array}{l}\text { Segurança de acesso (Vilella, ISO, } \\
\text { Chou et al.) }\end{array}$} & Privacidade & 10 & \\
\hline & & Criptografia & 10 & \\
\hline
\end{tabular}

(Análise elaborada e revista no período de 01.09 a 30.10.2007). 


\section{http://www.inovar.org.br}

Portal do projeto Mobilizar para Inovar, "um programa de mobilização para utilização dos instrumentos de apoio à inovação como ferramenta de competitividade". É um programa brasileiro, inserido no contexto do 'Movimento Brasil Competitivo' (http://www.mbc.org.br). Conta com o apoio do MCT e da Finep. Tem como parceiro a FNQ, o Programa de Gestão Pública, entre outros.

\begin{tabular}{|c|c|c|c|c|}
\hline Dimensão & Característica & Atributo & Pontuação & Observações \\
\hline \multirow{27}{*}{$\begin{array}{l}\mathrm{C} \\
\mathrm{O} \\
\mathrm{N} \\
\mathrm{T} \\
\mathrm{E} \\
\mathrm{U} \\
\mathrm{D} \\
\mathrm{O}\end{array}$} & \multirow{4}{*}{ Propósito (Vilella) } & Visão geral & 10 & \\
\hline & & Escopo & 0 & \\
\hline & & Serviços & 10 & \\
\hline & & Complementação & 10 & \\
\hline & \multirow{4}{*}{$\begin{array}{l}\text { Abrangência / cobertura (Vilella - } \\
\text { junto com propósito) }\end{array}$} & Tipo de conteúdo & 6 & \multirow{4}{*}{$\begin{array}{l}\text { 1. casos, artigos, entrevistas, } \\
\text { apresentações, depoimentos, } \\
\text { textos, releases, relatórios, } \\
\text { apostilas, sites, imagens, vídeo, } \\
\text { glossário. } \\
\text { 2. inovação, processo, liderança, } \\
\text { sociedade e meio ambiente, } \\
\text { educação, qualidade. }\end{array}$} \\
\hline & & Tipo de assunto & 18 & \\
\hline & & Outros idiomas & 0 & \\
\hline & & Versões & 0 & \\
\hline & $\begin{array}{l}\text { Padrão de publicação de conteúdo } \\
\text { (Almeida e Bax, Breitman, Terra e } \\
\text { Gordon) }\end{array}$ & $\begin{array}{l}\text { Taxonomia/onto/ } \\
\text { classificação/nada }\end{array}$ & 6 & $\begin{array}{l}\text { 2. Possui um glossário dos } \\
\text { termos utilizados. }\end{array}$ \\
\hline & \multirow{2}{*}{$\begin{array}{l}\text { Atualidade (Vilella, Chou et al. - } \\
\text { timeless) }\end{array}$} & Atualização & 10 & \\
\hline & & Data - conteúdo sig & $\mathbf{1 0}$ & \\
\hline & \multirow{3}{*}{ Correção (Vilella) } & Precisão & 10 & \\
\hline & & Referência correta & 10 & \\
\hline & & Inconsistências & 10 & \\
\hline & \multirow{4}{*}{$\begin{array}{l}\text { Autoridade / copirraite (Vilella), } \\
\text { believability e reputation (Chou et } \\
\text { al.) }\end{array}$} & Copirraite & 0 & \\
\hline & & Menção a fontes & 10 & \\
\hline & & Responsabilidade & 10 & \\
\hline & & Legitimidade & 10 & \\
\hline & \multirow{5}{*}{ Objetividade (Vilella, Chou e al.) } & Conteúdo - inicial & 10 & \\
\hline & & Conteúdo adequado & 10 & \\
\hline & & Forma de escrita & 10 & \\
\hline & & Publicidade & 10 & \\
\hline & & Utilidade & 10 & \\
\hline & \multirow{4}{*}{$\begin{array}{l}\text { Regras de publicação e acesso } \\
\text { (Moretti et al.) ou acessibilidade } \\
\text { (Coelho, 2007) }\end{array}$} & Regras de publ & 10 & \multirow{4}{*}{$\begin{array}{l}\text { 2. O acesso a alguns conteúdos é } \\
\text { possível mediante cadastro. }\end{array}$} \\
\hline & & Acesso livre & 30 & \\
\hline & & Acesso condi & 10 & \\
\hline & & Acesso restrito & 10 & \\
\hline \multirow{12}{*}{$\begin{array}{l}\text { U } \\
\text { S } \\
\text { A } \\
\text { B } \\
\text { I } \\
\text { L } \\
\text { I } \\
\text { D } \\
\text { A } \\
\text { D } \\
\text { E }\end{array}$} & \multirow{3}{*}{$\begin{array}{l}\text { Inteligibilidade (Chou et al., ISO, } \\
\text { Nielsen, Vilella) - easy to } \\
\text { understand, interpretability }\end{array}$} & Fontes e atributos & 10 & \\
\hline & & Links claros & 10 & \\
\hline & & Interface & 10 & \\
\hline & \multirow{4}{*}{$\begin{array}{l}\text { Apreensibilidade (ISO, Nielsen, } \\
\text { Vilella) }\end{array}$} & Navegação & 10 & \\
\hline & & Apreensão & 10 & \\
\hline & & Instruções de uso & 0 & \\
\hline & & Interface humana & 0 & \\
\hline & \multirow{5}{*}{$\begin{array}{l}\text { Operacionalidade (ISO, Chou et al., } \\
\text { Nielsen, Vilella) }\end{array}$} & Rolagem & 10 & \multirow{5}{*}{$\begin{array}{l}\text { 6. Mas durante a navegação, é } \\
\text { recorrente a indicação de "erro } \\
\text { de página" mesmo quando o } \\
\text { acesso é feito; }\end{array}$} \\
\hline & & Ajuste de leiaute & 0 & \\
\hline & & Agrupamento & 10 & \\
\hline & & Tarefas prioritárias & 10 & \\
\hline & & Clareza da URL & 10 & \\
\hline
\end{tabular}




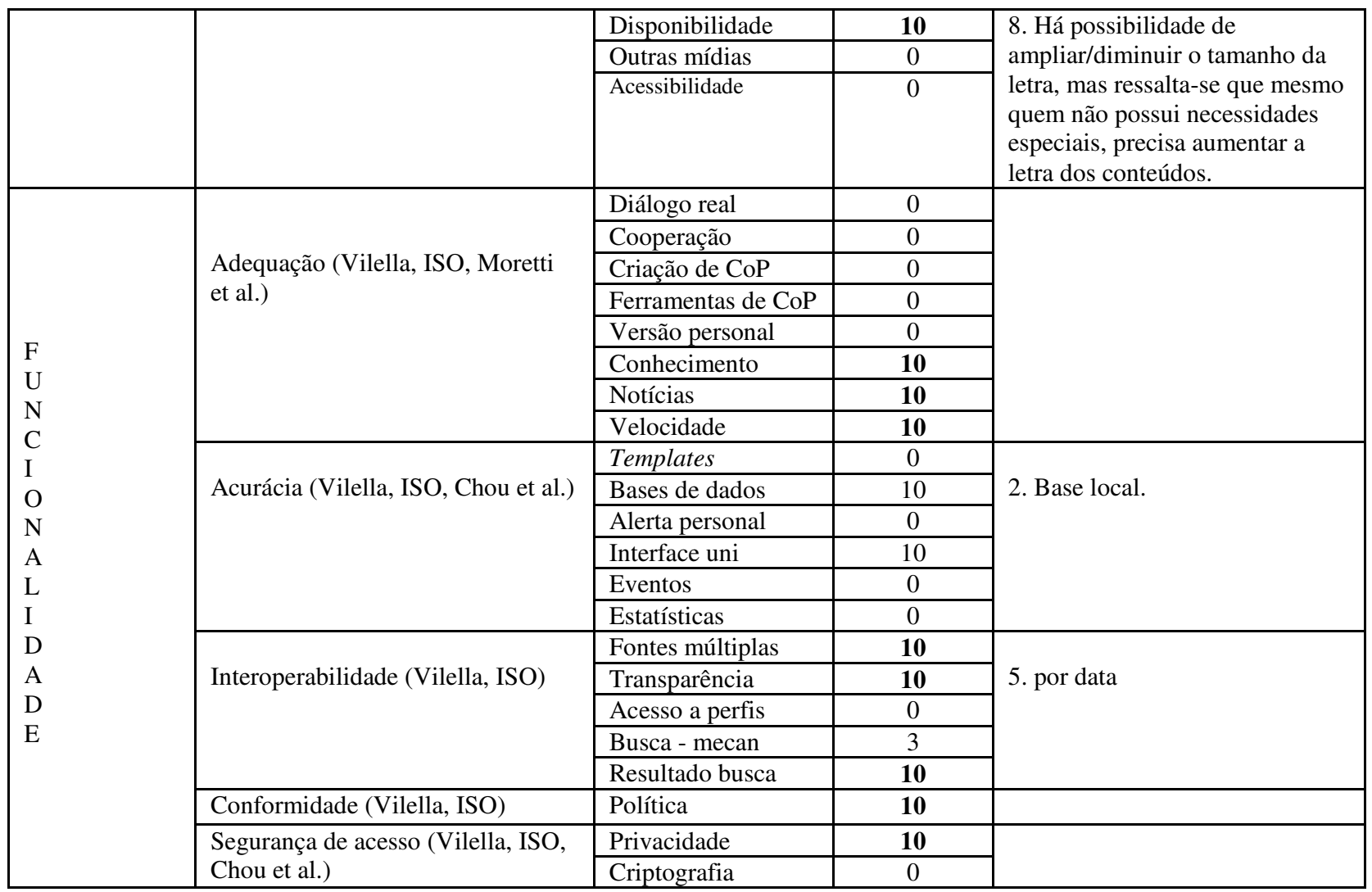

(Análise elaborada e revista no período de 01.09 a 30.10.2007). 


\section{http://www.inpi.gov.br/}

Portal do Instituto Nacional de Propriedade Industrial, um órgão do Ministério do Desenvolvimento, Indústria e Comércio Exterior, foi criado em 1970. Sua principal finalidade é "executar, no âmbito nacional, as normas que regulam a propriedade industrial, tendo em vista a sua função social, econômica, jurídica e técnica. É também sua atribuição pronunciar-se quanto à conveniência de assinatura, ratificação e denúncia de convenções, tratados, convênios e acordos sobre propriedade industrial".

Nesse contexto, são de sua responsabilidade os seguintes serviços:

1. Publicar a Revista de Propriedade Industrial - RPI;

2. Fornecer orientação e encaminhar os processos de Marcas, Patentes e Desenhos Industriais;

3. Acompanhar os processos de Transferência de Tecnologia.

Atua em consonância com a Lei 9.279/96 (Lei da Propriedade Industrial).

\begin{tabular}{|c|c|c|c|c|}
\hline Dimensão & Característica & Atributo & Pontuação & Observações \\
\hline \multirow{25}{*}{$\begin{array}{l}\mathrm{C} \\
\mathrm{O} \\
\mathrm{N} \\
\mathrm{T} \\
\mathrm{E} \\
\mathrm{U} \\
\mathrm{D} \\
\mathrm{O}\end{array}$} & \multirow{4}{*}{ Propósito (Vilella) } & Visão geral & 10 & \\
\hline & & Escopo & 10 & \\
\hline & & Serviços & 10 & \\
\hline & & Complementação & 10 & \\
\hline & \multirow{4}{*}{$\begin{array}{l}\text { Abrangência / cobertura (Vilella - } \\
\text { junto com propósito) }\end{array}$} & Tipo de conteúdo & 6 & \multirow{4}{*}{$\begin{array}{l}\text { 1. textos, sites, legislação, } \\
\text { relatórios, manuais, bases de } \\
\text { dados, estatísticas, templates, } \\
\text { cursos, boletins, revistas. } \\
\text { 2. marcas, patentes, propriedade } \\
\text { intelectual, transferência de } \\
\text { tecnologia, informação } \\
\text { tecnológica } \\
\text { 4. Especialmente legislação. }\end{array}$} \\
\hline & & Tipo de assunto & 18 & \\
\hline & & Outros idiomas & 0 & \\
\hline & & Versões & 10 & \\
\hline & $\begin{array}{l}\text { Padrão de publicação de conteúdo } \\
\text { (Almeida e Bax, Breitman, Terra e } \\
\text { Gordon) }\end{array}$ & $\begin{array}{l}\text { Taxonomia/onto/ } \\
\text { classificação/nada }\end{array}$ & 6 & $\begin{array}{l}\text { 2. Utiliza codificação própria e } \\
\text { classificações internacionais } \\
\text { específicas para a área. }\end{array}$ \\
\hline & \multirow{2}{*}{$\begin{array}{l}\text { Atualidade (Vilella, Chou et al. - } \\
\text { timeless) }\end{array}$} & Atualização & 10 & \multirow{2}{*}{$\begin{array}{l}\text { Não há indicação da última data } \\
\text { de atualização das páginas, mas } \\
\text { há data nos documentos, notícias } \\
\text { etc. nas diferentes páginas. }\end{array}$} \\
\hline & & Data - conteúdo sig & 10 & \\
\hline & \multirow{3}{*}{ Correção (Vilella) } & Precisão & 10 & \\
\hline & & Referência correta & 10 & \\
\hline & & Inconsistências & 10 & \\
\hline & \multirow{4}{*}{$\begin{array}{l}\text { Autoridade / copirraite (Vilella), } \\
\text { believability e reputation (Chou et } \\
\text { al.) }\end{array}$} & Copirraite & 0 & \\
\hline & & Menção a fontes & 10 & \\
\hline & & Responsabilidade & 10 & \\
\hline & & Legitimidade & 10 & \\
\hline & \multirow{5}{*}{ Objetividade (Vilella, Chou e al.) } & Conteúdo - inicial & 10 & \\
\hline & & Conteúdo adequado & 10 & \\
\hline & & Forma de escrita & 10 & \\
\hline & & Publicidade & 10 & \\
\hline & & Utilidade & 10 & \\
\hline & \multirow[b]{2}{*}{ Regras de publicação e acesso } & Regras de publ & 0 & \multirow[b]{2}{*}{ 2. Para obtenção de "guia } \\
\hline & & Acesso livre & 30 & \\
\hline
\end{tabular}




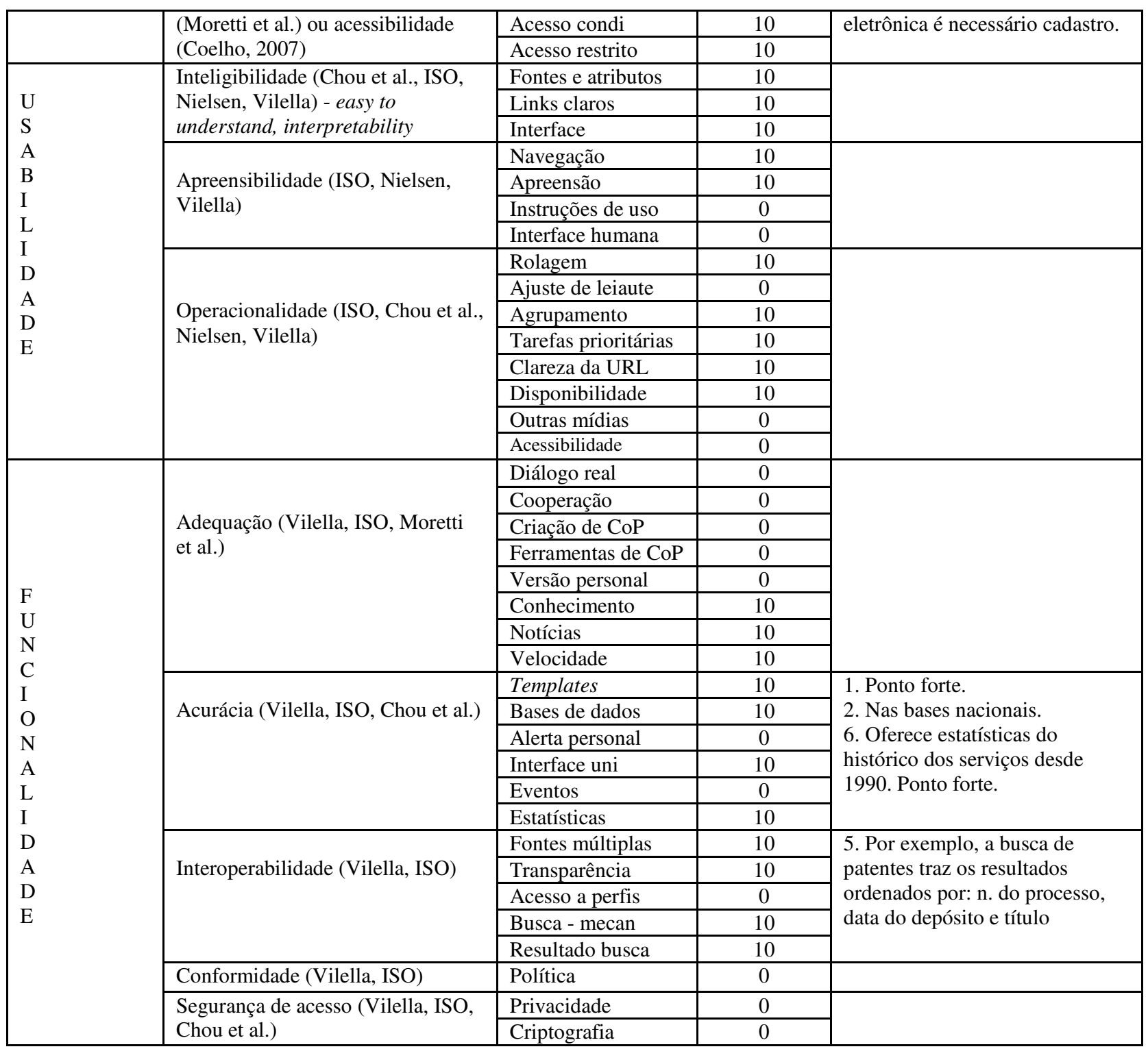

(Análise elaborada e revista no período de 01.09 a 30.10.2007). 


\section{http://www.kmol.online.pt/}

O portal KMOL que tem como princípio ser uma publicação periódica dedicada à Gestão de Conhecimento e à Aprendizagem Organizacional. Idealizada para atender especialmente a comunidade lusófona, sua estrutura e conteúdo estão em Português. Disponibiliza alguns conteúdos em inglês com o intuito de conquistar colaboradores externos. O principal objetivo do portal é reunir uma comunidade de pessoas interessadas no assunto, para leitura, comentários e publicação de conteúdos.

\begin{tabular}{|c|c|c|c|c|}
\hline Dimensão & Característica & Atributo & Pontuação & Observações \\
\hline \multirow{26}{*}{$\begin{array}{l}\mathrm{C} \\
\mathrm{O} \\
\mathrm{N} \\
\mathrm{T} \\
\mathrm{E} \\
\mathrm{U} \\
\mathrm{D} \\
\mathrm{O}\end{array}$} & \multirow{4}{*}{ Propósito (Vilella) } & Visão geral & 10 & \multirow[t]{4}{*}{ 4. Ponto forte } \\
\hline & & Escopo & 10 & \\
\hline & & Serviços & $\mathbf{1 0}$ & \\
\hline & & Complementação & 10 & \\
\hline & \multirow{4}{*}{$\begin{array}{l}\text { Abrangência / cobertura (Vilella - } \\
\text { junto com propósito) }\end{array}$} & Tipo de conteúdo & 6 & \multirow[b]{4}{*}{$\begin{array}{l}\text { 1. artigos, pessoas, software, } \\
\text { glossário, casos, sites } \\
\text { (apontador), entrevistas, } \\
\text { resumos, textos. } \\
\text { Em pessoas traz biografia, } \\
\text { entrevistas, resumos e artigos } \\
\text { dos membros especialistas da } \\
\text { comunidade. Em mercados traz } \\
\text { empresas e softwares para a } \\
\text { gestão do conhecimento. } \\
\text { 2. gestão do conhecimento, } \\
\text { portal corporativo, CoP, gestão } \\
\text { social, organizações de } \\
\text { aprendizagem, cultura } \\
\text { corporativa, legislação. } \\
\text { 3. Há indicação de textos em } \\
\text { inglês para ampliar o espectro de } \\
\text { usuários além da comunidade } \\
\text { lusófona. }\end{array}$} \\
\hline & & Tipo de assunto & 9 & \\
\hline & & Outros idiomas & 0 & \\
\hline & & Versões & 0 & \\
\hline & $\begin{array}{l}\text { Padrão de publicação de conteúdo } \\
\text { (Almeida e Bax, Breitman, Terra e } \\
\text { Gordon) }\end{array}$ & $\begin{array}{l}\text { Taxonomia/onto/ } \\
\text { classificação/nada }\end{array}$ & 0 & $\begin{array}{l}\text { 3. Artigos e resumos estão } \\
\text { apresentados por ordem de } \\
\text { inclusão (mais recentes). }\end{array}$ \\
\hline & \multirow{2}{*}{$\begin{array}{l}\text { Atualidade (Vilella, Chou et al. - } \\
\text { timeless) }\end{array}$} & Atualização & 10 & \\
\hline & & Data - conteúdo sig & $\mathbf{1 0}$ & \\
\hline & \multirow{3}{*}{ Correção (Vilella) } & Precisão & 10 & \\
\hline & & Referência correta & 10 & \\
\hline & & Inconsistências & 0 & \\
\hline & \multirow{4}{*}{$\begin{array}{l}\text { Autoridade / copirraite (Vilella), } \\
\text { believability e reputation (Chou et } \\
\text { al.) }\end{array}$} & Copirraite & 0 & \multirow{4}{*}{ 4. Nome da empresa e endereço. } \\
\hline & & Menção a fontes & 10 & \\
\hline & & Responsabilidade & $\mathbf{1 0}$ & \\
\hline & & Legitimidade & 10 & \\
\hline & \multirow{5}{*}{ Objetividade (Vilella, Chou e al.) } & Conteúdo - inicial & 10 & \\
\hline & & Conteúdo adequado & $\mathbf{1 0}$ & \\
\hline & & Forma de escrita & 10 & \\
\hline & & Publicidade & 10 & \\
\hline & & Utilidade & 10 & \\
\hline & \multirow{3}{*}{$\begin{array}{l}\text { Regras de publicação e acesso } \\
\text { (Moretti et al.) ou acessibilidade }\end{array}$} & Regras de publ & 0 & \\
\hline & & Acesso livre & 30 & \\
\hline & & Acesso condi & 10 & \\
\hline
\end{tabular}




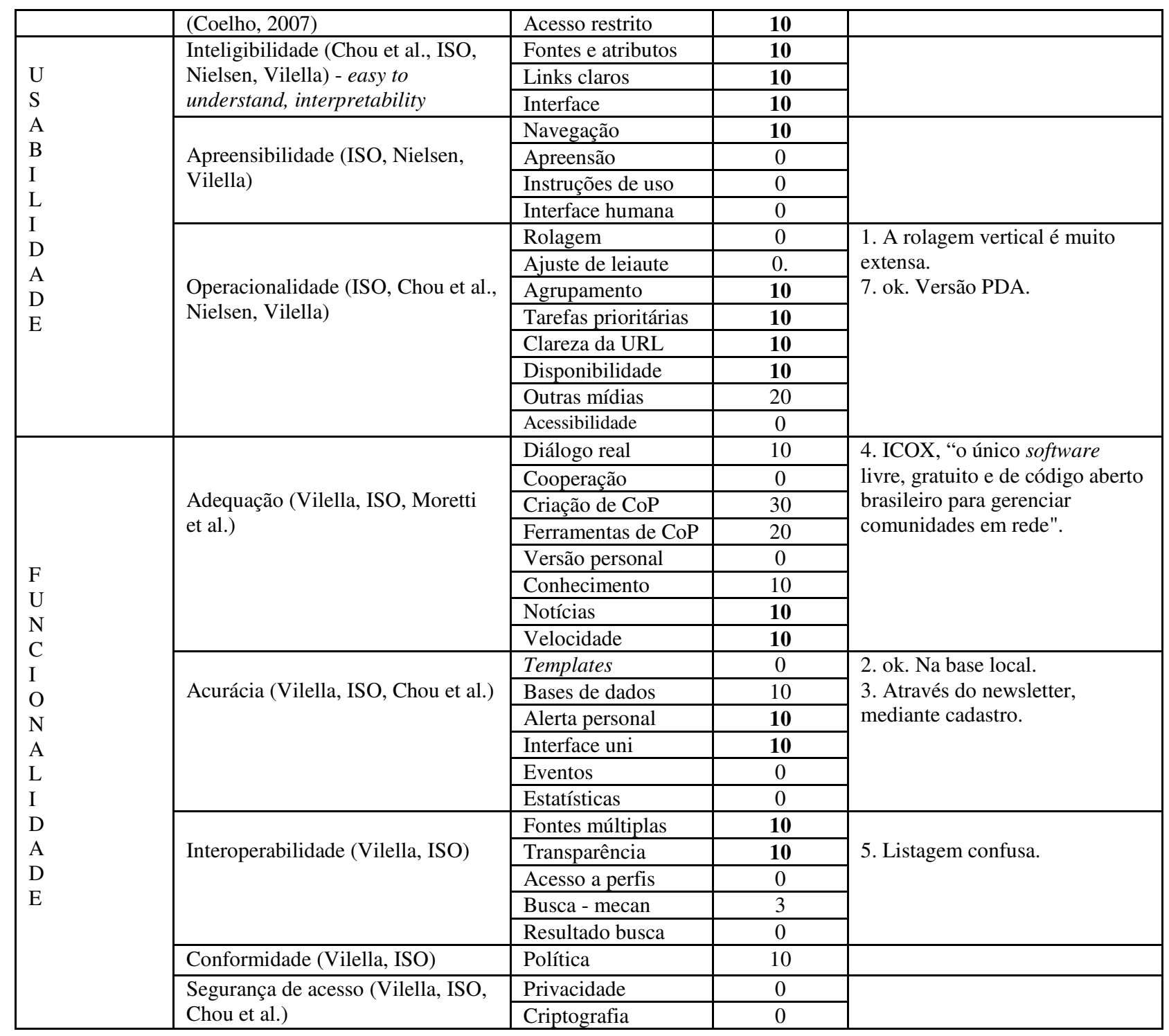

(Análise elaborada e revista no período de 01.09 a 30.10.2007). 


\section{http://www.terraforum.com.br}

A TerraForum é uma empresa de consultoria e treinamento que tem como clientes empresas dos setores público, privado e terceiro setor. Atua principalmente nas áreas de gestão do conhecimento, gestão da inovação, portais corporativos e inteligência empresarial.

\section{Segundo a TerraForum "é o maior portal com conteúdo sobre inovação do país".}

Obs. Lançado em julho de 2007 o Innovation Center, um portal totalmente dedicado à inovação. Traz notícias, artigos, glossário com termos relacionados e links para textos.

\begin{tabular}{|c|c|c|c|c|}
\hline Dimensão & Característica & Atributo & Pontuação & Observações \\
\hline \multirow{27}{*}{$\begin{array}{l}\mathrm{C} \\
\mathrm{O} \\
\mathrm{N} \\
\mathrm{T} \\
\mathrm{E} \\
\mathrm{U} \\
\mathrm{D} \\
\mathrm{O}\end{array}$} & \multirow{4}{*}{ Propósito (Vilella) } & Visão geral & 10 & \\
\hline & & Escopo & 10 & \\
\hline & & Serviços & 10 & \\
\hline & & Complementação & 10 & \\
\hline & \multirow{4}{*}{$\begin{array}{l}\text { Abrangência / cobertura (Vilella - } \\
\text { junto com propósito) }\end{array}$} & Tipo de conteúdo & 6 & \multirow{4}{*}{$\begin{array}{l}\text { 1. apresentações, sites, textos, } \\
\text { artigos de revistas científicas } \\
\text { nac. e int., teses, resenhas de } \\
\text { livros para divulgação e venda, } \\
\text { serviços, depoimentos, } \\
\text { treinamentos, pessoas. } \\
\text { 2. gestão do conhecimento, } \\
\text { portais corporativos, qualidade, } \\
\text { inovação, Balanced scorecard, } \\
\text { inteligência empresarial, } \\
\text { comunidades de prática }\end{array}$} \\
\hline & & Tipo de assunto & 18 & \\
\hline & & Outros idiomas & 0 & \\
\hline & & Versões & 0 & \\
\hline & $\begin{array}{l}\text { Padrão de publicação de conteúdo } \\
\text { (Almeida e Bax, Breitman, Terra e } \\
\text { Gordon) }\end{array}$ & $\begin{array}{l}\text { Taxonomia/onto/ } \\
\text { classificação/nada }\end{array}$ & 6 & \\
\hline & \multirow{2}{*}{$\begin{array}{l}\text { Atualidade (Vilella, Chou et al. - } \\
\text { timeless) }\end{array}$} & Atualização & 10 & \multirow{2}{*}{$\begin{array}{l}\text { 2. Há indicação da data de } \\
\text { criação de cada conteúdo. }\end{array}$} \\
\hline & & Data - conteúdo sig & $\mathbf{1 0}$ & \\
\hline & \multirow{3}{*}{ Correção (Vilella) } & Precisão & 10 & \\
\hline & & Referência correta & 10 & \\
\hline & & Inconsistências & 10 & \\
\hline & \multirow{4}{*}{$\begin{array}{l}\text { Autoridade / copirraite (Vilella), } \\
\text { believability e reputation (Chou et } \\
\text { al.) }\end{array}$} & Copirraite & 10 & \\
\hline & & Menção a fontes & 10 & \\
\hline & & Responsabilidade & 10 & \\
\hline & & Legitimidade & 10 & \\
\hline & \multirow{5}{*}{ Objetividade (Vilella, Chou e al.) } & Conteúdo - inicial & 10 & \multirow{5}{*}{$\begin{array}{l}\text { 4. Apresenta os clientes, mas } \\
\text { sem comprometer a usabilidade. }\end{array}$} \\
\hline & & Conteúdo adequado & 10 & \\
\hline & & Forma de escrita & 10 & \\
\hline & & Publicidade & 0 & \\
\hline & & Utilidade & 10 & \\
\hline & \multirow{4}{*}{$\begin{array}{l}\text { Regras de publicação e acesso } \\
\text { (Moretti et al.) ou acessibilidade } \\
\text { (Coelho, 2007) }\end{array}$} & Regras de publ & 10 & \\
\hline & & Acesso livre & 30 & \\
\hline & & Acesso condi & 0 & \\
\hline & & Acesso restrito & 10 & \\
\hline \multirow{6}{*}{$\begin{array}{l}\mathrm{U} \\
\mathrm{S} \\
\mathrm{A} \\
\mathrm{B} \\
\mathrm{I}\end{array}$} & \multirow{3}{*}{$\begin{array}{l}\text { Inteligibilidade (Chou et al., ISO, } \\
\text { Nielsen, Vilella) - easy to } \\
\text { understand, interpretability }\end{array}$} & Fontes e atributos & 10 & \\
\hline & & Links claros & 10 & \\
\hline & & Interface & 10 & \\
\hline & \multirow{3}{*}{$\begin{array}{l}\text { Apreensibilidade (ISO, Nielsen, } \\
\text { Vilella) }\end{array}$} & Navegação & 0 & \\
\hline & & Apreensão & 0 & \\
\hline & & Instruções de uso & 0 & \\
\hline
\end{tabular}




\begin{tabular}{|c|c|c|c|c|}
\hline \multirow{9}{*}{$\begin{array}{l}\mathrm{L} \\
\mathrm{I} \\
\mathrm{D} \\
\mathrm{A} \\
\mathrm{D} \\
\mathrm{E}\end{array}$} & & Interface humana & 0 & \\
\hline & \multirow{8}{*}{$\begin{array}{l}\text { Operacionalidade (ISO, Chou et al., } \\
\text { Nielsen, Vilella) }\end{array}$} & Rolagem & 0 & \\
\hline & & Ajuste de leiaute & 0 & \\
\hline & & Agrupamento & 10 & \\
\hline & & Tarefas prioritárias & 10 & \\
\hline & & Clareza da URL & 10 & \\
\hline & & Disponibilidade & 10 & \\
\hline & & Outras mídias & 0 & \\
\hline & & Acessibilidade & 0 & \\
\hline \multirow{22}{*}{$\begin{array}{l}\mathrm{F} \\
\mathrm{U} \\
\mathrm{N} \\
\mathrm{C} \\
\mathrm{I} \\
\mathrm{O} \\
\mathrm{N} \\
\mathrm{A} \\
\mathrm{L} \\
\mathrm{I} \\
\mathrm{D} \\
\mathrm{A} \\
\mathrm{D} \\
\mathrm{E}\end{array}$} & \multirow{8}{*}{$\begin{array}{l}\text { Adequação (Vilella, ISO, Moretti } \\
\text { et al.) }\end{array}$} & Diálogo real & 0 & \multirow{8}{*}{ 4. Solicita que entre em contato. } \\
\hline & & Cooperação & 0 & \\
\hline & & Criação de CoP & 30 & \\
\hline & & Ferramentas de CoP & 0 & \\
\hline & & Versão personal & 0 & \\
\hline & & Conhecimento & 10 & \\
\hline & & Notícias & 0 & \\
\hline & & Velocidade & 10 & \\
\hline & \multirow{6}{*}{ Acurácia (Vilella, ISO, Chou et al.) } & Templates & 0 & \\
\hline & & Bases de dados & 0 & \\
\hline & & Alerta personal & 0 & \\
\hline & & Interface uni & 10 & \\
\hline & & Eventos & 0 & \\
\hline & & Estatísticas & 0 & \\
\hline & \multirow{5}{*}{ Interoperabilidade (Vilella, ISO) } & Fontes múltiplas & 10 & \\
\hline & & Transparência & 10 & \\
\hline & & Acesso a perfis & 0 & \\
\hline & & Busca - mecan & 0 & \\
\hline & & Resultado busca & 0 & \\
\hline & Conformidade (Vilella, ISO) & Política & 10 & \\
\hline & \multirow{2}{*}{$\begin{array}{l}\text { Segurança de acesso (Vilella, ISO, } \\
\text { Chou et al.) }\end{array}$} & Privacidade & 10 & \\
\hline & & Criptografia & 0 & \\
\hline
\end{tabular}

(Análise elaborada e revista no período de 01.09 a 30.10.2007). 


\section{http://numa.sc.usp.br/forum}

\section{'comunidade do livro'}

Portal da comunidade do livro Gestão do desenvolvimento de produtos, "um local para a troca de informações entre os leitores e autores do livro, assim como compartilhamento de conhecimento relacionado com o livro".

\begin{tabular}{|c|c|c|c|c|}
\hline Dimensão & Característica & Atributo & Pontuaçãa & Observações \\
\hline \multirow{27}{*}{$\begin{array}{l}\mathrm{C} \\
\mathrm{O} \\
\mathrm{N} \\
\mathrm{T} \\
\mathrm{E} \\
\text { Ú } \\
\mathrm{D} \\
\mathrm{O}\end{array}$} & \multirow{4}{*}{ Propósito (Vilella) } & Visão geral & 10 & \\
\hline & & Escopo & 10 & \\
\hline & & Serviços & 10 & \\
\hline & & Complementação & 0 & \\
\hline & \multirow{4}{*}{$\begin{array}{l}\text { Abrangência / cobertura (Vilella - } \\
\text { junto com propósito) }\end{array}$} & Tipo de conteúdo & 0 & \multirow{4}{*}{$\begin{array}{l}\text { 1. discussão, texto } \\
\text { 2. PDP } \\
\text { 4. Discussão do livro. Indica } \\
\text { atualizações, prevê ajustes, } \\
\text { oferece explicações. }\end{array}$} \\
\hline & & Tipo de assunto & 18 & \\
\hline & & Outros idiomas & 0 & \\
\hline & & Versões & 10 & \\
\hline & $\begin{array}{l}\text { Padrão de publicação de conteúdo } \\
\text { (Almeida e Bax, Breitman, Terra e } \\
\text { Gordon) }\end{array}$ & $\begin{array}{l}\text { Taxonomia/onto/ } \\
\text { classificação/nada }\end{array}$ & 0 & \\
\hline & \multirow{2}{*}{$\begin{array}{l}\text { Atualidade (Vilella, Chou et al. - } \\
\text { timeless) }\end{array}$} & Atualização & 10 & \\
\hline & & Data - conteúdo sig & 10 & \\
\hline & \multirow{3}{*}{ Correção (Vilella) } & Precisão & 10 & \\
\hline & & Referência correta & 10 & \\
\hline & & Inconsistências & 10 & \\
\hline & \multirow{4}{*}{$\begin{array}{l}\text { Autoridade / copirraite (Vilella), } \\
\text { believability e reputation (Chou et } \\
\text { al.) }\end{array}$} & Copirraite & 0 & \\
\hline & & Menção a fontes & 0 & \\
\hline & & Responsabilidade & 10 & \\
\hline & & Legitimidade & 10 & \\
\hline & \multirow{5}{*}{ Objetividade (Vilella, Chou e al.) } & Conteúdo - inicial & 10 & \\
\hline & & Conteúdo adequado & 10 & \\
\hline & & Forma de escrita & 10 & \\
\hline & & Publicidade & 10 & \\
\hline & & Utilidade & 10 & \\
\hline & \multirow{4}{*}{$\begin{array}{l}\text { Regras de publicação e acesso } \\
\text { (Moretti et al.) ou acessibilidade } \\
\text { (Coelho, 2007) }\end{array}$} & Regras de publ & 10 & \multirow{4}{*}{ 2. mediante cadastro } \\
\hline & & Acesso livre & 30 & \\
\hline & & Acesso condi & 10 & \\
\hline & & Acesso restrito & 10 & \\
\hline \multirow{16}{*}{$\begin{array}{l}\mathrm{U} \\
\mathrm{S} \\
\mathrm{A} \\
\mathrm{B} \\
\mathrm{I} \\
\mathrm{L} \\
\mathrm{I} \\
\mathrm{D} \\
\mathrm{A} \\
\mathrm{D} \\
\mathrm{E}\end{array}$} & \multirow{3}{*}{$\begin{array}{l}\text { Inteligibilidade (Chou et al., ISO, } \\
\text { Nielsen, Vilella) - easy to } \\
\text { understand, interpretability }\end{array}$} & Fontes e atributos & 10 & \\
\hline & & Links claros & 10 & \\
\hline & & Interface & 10 & \\
\hline & \multirow{4}{*}{$\begin{array}{l}\text { Apreensibilidade (ISO, Nielsen, } \\
\text { Vilella) }\end{array}$} & Navegação & 10 & \\
\hline & & Apreensão & 10 & \\
\hline & & Instruções de uso & 10 & \\
\hline & & Interface humana & 0 & \\
\hline & \multirow{8}{*}{$\begin{array}{l}\text { Operacionalidade (ISO, Chou et al., } \\
\text { Nielsen, Vilella) }\end{array}$} & Rolagem & 10 & \\
\hline & & Ajuste de leiaute & 0 & \\
\hline & & Agrupamento & 10 & \\
\hline & & Tarefas prioritárias & 10 & \\
\hline & & Clareza da URL & 10 & \\
\hline & & Disponibilidade & 10 & \\
\hline & & Outras mídias & 0 & \\
\hline & & Acessibilidade & 0 & \\
\hline & & Diálogo real & 10 & \\
\hline
\end{tabular}




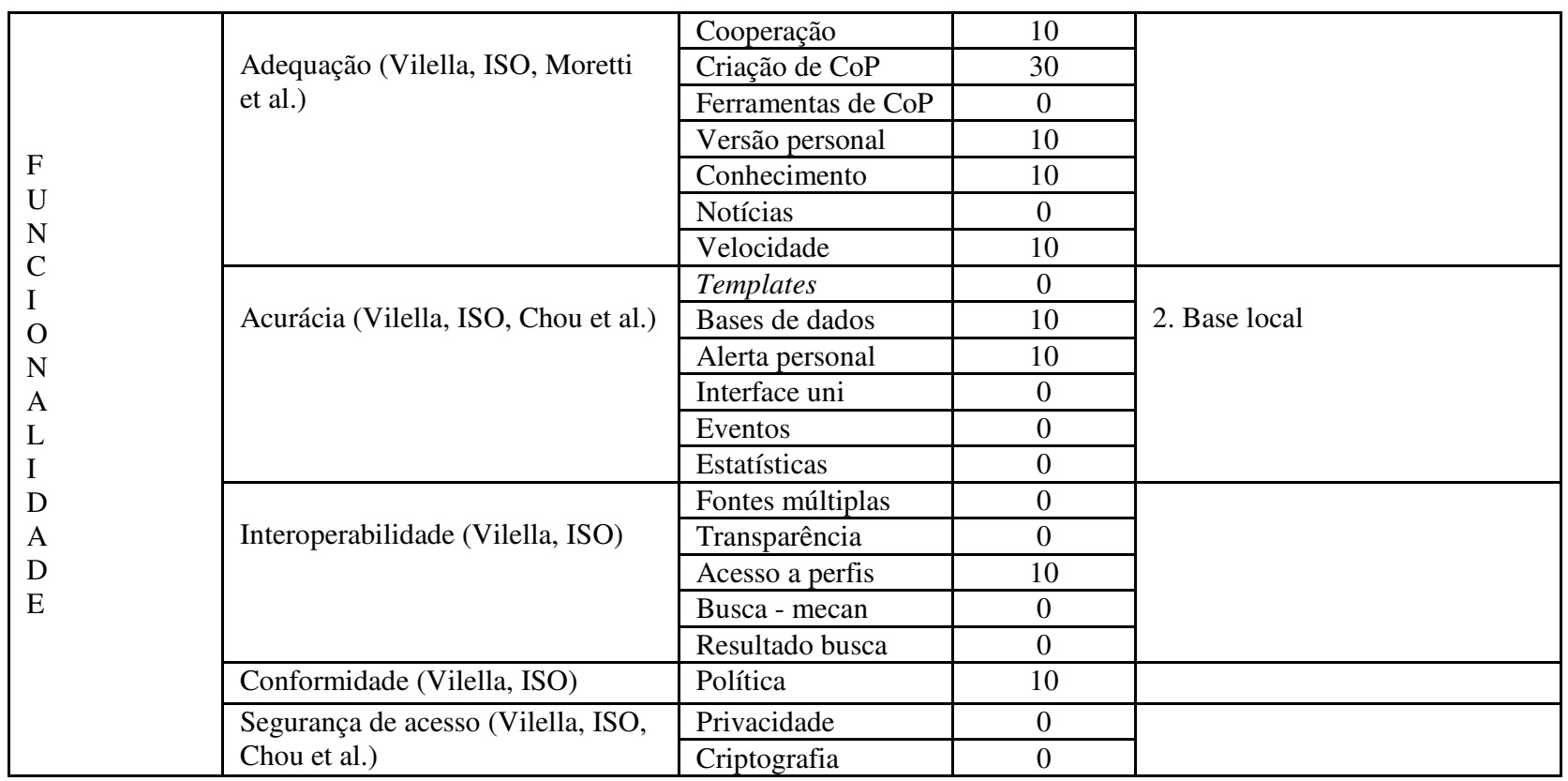

(Análise elaborada e revista no período de 01.09 a 30.10.2007). 


\title{
http://ocw.mit.edu
}

\author{
'mit ocw'
}

Portal do MIT que disponibiliza programas de cursos, em várias áreas do conhecimento. Trata-se de um recurso educacional aberto e gratuito para educadores, estudantes e autoaprendizes (self-learness) ao redor do mundo. Ressalta-se que não se trata de oferecimento de cursos on-line pelo MIT e não são fornecidos certificados de participação / conclusão.

Obs.1: no Brasil o endereço é http://www.universia.com.br/mit.

Obs.2: solicitam doação para o projeto, mas o uso do material não está condicionado a isso.

\begin{tabular}{|c|c|c|c|c|}
\hline Dimensão & Característica & Atributo & Pontuação & Observações \\
\hline \multirow{27}{*}{$\begin{array}{l}\mathrm{C} \\
\mathrm{O} \\
\mathrm{N} \\
\mathrm{T} \\
\mathrm{E} \\
U^{\prime} \\
\mathrm{D} \\
\mathrm{O}\end{array}$} & \multirow{4}{*}{ Propósito (Vilella) } & Visão geral & 10 & \\
\hline & & Escopo & 10 & \\
\hline & & Serviços & 10 & \\
\hline & & Complementação & 10 & \\
\hline & \multirow{4}{*}{$\begin{array}{l}\text { Abrangência / cobertura (Vilella - } \\
\text { junto com propósito) }\end{array}$} & Tipo de conteúdo & 6 & \multirow[b]{4}{*}{$\begin{array}{l}\text { 1. } 1.700 \text { cursos em } 09.09 .2007 \\
\text { (programa e todo o material } \\
\text { instrucional - slides, textos, } \\
\text { vídeos, softwares para } \\
\text { instalação, tutoriais, referências, } \\
\text { bibliog. Comentada, modelos de } \\
\text { avaliação, casos). São cursos on- } \\
\text { line, em várias áreas do } \\
\text { conhecimento. Há um curso } \\
\text { específico em DP denominado } \\
\text { "product design and } \\
\text { development", de } 2006 \text {. } \\
\text { 3. Através de parceria com a } \\
\text { Universia, os cursos são } \\
\text { traduzidos para várias línguas: } \\
\text { português, francês, espanhol e } \\
\text { chinês. }\end{array}$} \\
\hline & & Tipo de assunto & 0 & \\
\hline & & Outros idiomas & 10 & \\
\hline & & Versões & 0 & \\
\hline & $\begin{array}{l}\text { Padrão de publicação de conteúdo } \\
\text { (Almeida e Bax, Breitman, Terra e } \\
\text { Gordon) }\end{array}$ & $\begin{array}{l}\text { Taxonomia/onto/ } \\
\text { classificação/nada }\end{array}$ & 3 & \\
\hline & \multirow{2}{*}{$\begin{array}{l}\text { Atualidade (Vilella, Chou et al. - } \\
\text { timeless) }\end{array}$} & Atualização & 10 & \\
\hline & & Data - conteúdo sig & 10 & \\
\hline & \multirow{3}{*}{ Correção (Vilella) } & Precisão & 10 & \\
\hline & & Referência correta & 10 & \\
\hline & & Inconsistências & 10 & \\
\hline & \multirow{4}{*}{$\begin{array}{l}\text { Autoridade / copirraite (Vilella), } \\
\text { believability e reputation (Chou et } \\
\text { al.) }\end{array}$} & Copirraite & 10 & \\
\hline & & Menção a fontes & 10 & \\
\hline & & Responsabilidade & 10 & \\
\hline & & Legitimidade & 10 & \\
\hline & \multirow{5}{*}{ Objetividade (Vilella, Chou e al.) } & Conteúdo - inicial & 10 & \\
\hline & & Conteúdo adequado & 10 & \\
\hline & & Forma de escrita & 10 & \\
\hline & & Publicidade & 10 & \\
\hline & & Utilidade & 10 & \\
\hline & \multirow{4}{*}{$\begin{array}{l}\text { Regras de publicação e acesso } \\
\text { (Moretti et al.) ou acessibilidade } \\
\text { (Coelho, 2007) }\end{array}$} & Regras de publ & 10 & \\
\hline & & Acesso livre & 30 & \\
\hline & & Acesso condi & 10 & \\
\hline & & Acesso restrito & 10 & \\
\hline
\end{tabular}




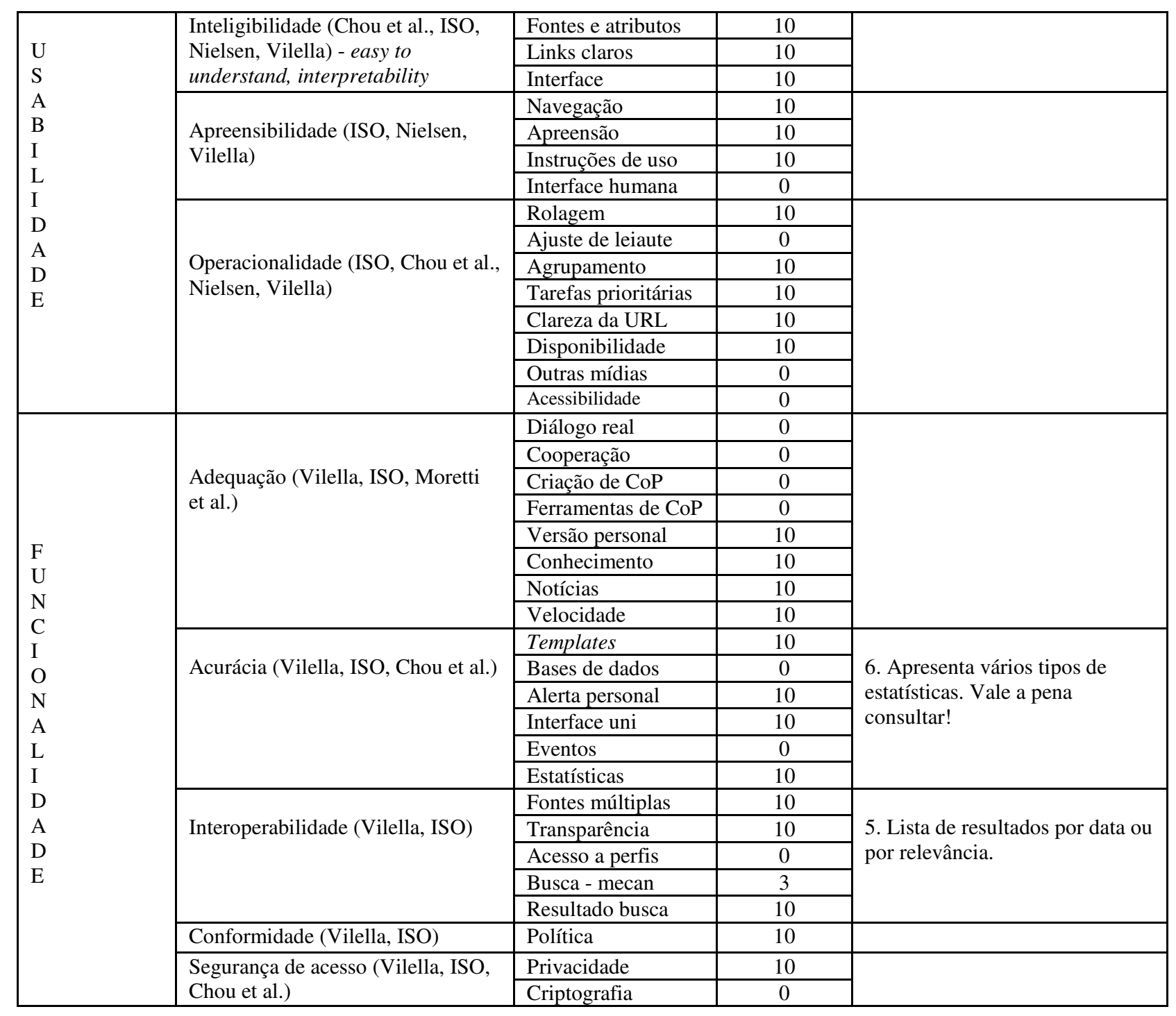

Cursos de interesse identificados:

- Design of medical devices and implants - em inglês;

- Mechanical assembly and its role in product development - em inglês com tradução para o chinês;

- MADM with applications in material selection and optimal design - em inglês;

- Introduction to design - em inglês;

- Proseminar in manufacturing - em espanhol e português;

- Managing in innovation process;

- Innovation in military organization.

(Análise elaborada e revista no período de 01.09 a 30.10.2007). 


\section{http://www.patentnet.com.br}

O portal é uma ferramenta de trabalhão para auxiliar na tomada de decisão nas áreas da propriedade intelectual. Disponibiliza informações essenciais às pessoas comprometidas com a atividade inventiva nos meios acadêmico e empresarial.

\begin{tabular}{|c|c|c|c|c|}
\hline Dimensão & Característica & Atributo & Pontuação & Observações \\
\hline \multirow{27}{*}{$\begin{array}{l}\mathrm{C} \\
\mathrm{O} \\
\mathrm{N} \\
\mathrm{T} \\
\mathrm{E} \\
\mathrm{U} \\
\mathrm{D} \\
\mathrm{O}\end{array}$} & \multirow{4}{*}{ Propósito (Vilella) } & Visão geral & 10 & \\
\hline & & Escopo & 10 & \\
\hline & & Serviços & 10 & \\
\hline & & Complementação & 10 & \\
\hline & \multirow{4}{*}{$\begin{array}{l}\text { Abrangência / cobertura (Vilella - } \\
\text { junto com propósito) }\end{array}$} & Tipo de conteúdo & 6 & \multirow{4}{*}{$\begin{array}{l}\text { 1. referências de publicações de } \\
\text { interesse, textos, sites, glossário, } \\
\text { serviços, procedimentos } \\
\text { 2. marcas, patentes, direitos } \\
\text { autorais voltados para o } \\
\text { desenvolvimento de produtos }\end{array}$} \\
\hline & & Tipo de assunto & 9 & \\
\hline & & Outros idiomas & 0 & \\
\hline & & Versões & 0 & \\
\hline & $\begin{array}{l}\text { Padrão de publicação de conteúdo } \\
\text { (Almeida e Bax, Breitman, Terra e } \\
\text { Gordon) }\end{array}$ & $\begin{array}{l}\text { Taxonomia/onto/ } \\
\text { classificação/nada }\end{array}$ & 0 & \\
\hline & \multirow{2}{*}{$\begin{array}{l}\text { Atualidade (Vilella, Chou et al. - } \\
\text { timeless) }\end{array}$} & Atualização & 0 & \multirow[b]{2}{*}{$\begin{array}{l}\text { Somente em atualidades } \\
\text { aparecem as datas das notícias } \\
\text { desatualizadas (2001 e 2002) } \\
\text { 3. Há erros de grafia e de } \\
\text { digitação. }\end{array}$} \\
\hline & & Data - conteúdo sig & 0 & \\
\hline & \multirow{3}{*}{ Correção (Vilella) } & Precisão & 10 & \\
\hline & & Referência correta & 0 & \\
\hline & & Inconsistências & 0 & \\
\hline & \multirow{4}{*}{$\begin{array}{l}\text { Autoridade / copirraite (Vilella), } \\
\text { believability e reputation (Chou et } \\
\text { al.) }\end{array}$} & Copirraite & 0 & \multirow{4}{*}{$\begin{array}{l}\text { 3. De difícil identificação: em } \\
\text { serviços, no link apoio, há } \\
\text { indicação da cidade, caixa postal } \\
\text { e telefone. }\end{array}$} \\
\hline & & Menção a fontes & 0 & \\
\hline & & Responsabilidade & 0 & \\
\hline & & Legitimidade & 10 & \\
\hline & \multirow{5}{*}{ Objetividade (Vilella, Chou e al.) } & Conteúdo - inicial & 10 & \multirow{5}{*}{$\begin{array}{l}\text { 3. Parte do conteúdo apresenta } \\
\text { problemas de grafia e digitação. }\end{array}$} \\
\hline & & Conteúdo adequado & 10 & \\
\hline & & Forma de escrita & 0. & \\
\hline & & Publicidade & 10 & \\
\hline & & Utilidade & 10 & \\
\hline & \multirow{4}{*}{$\begin{array}{l}\text { Regras de publicação e acesso } \\
\text { (Moretti et al.) ou acessibilidade } \\
\text { (Coelho, 2007) }\end{array}$} & Regras de publ & 10 & \multirow{4}{*}{$\begin{array}{l}2 \text { e } 3 . \text { O acesso às informações } \\
\text { gerais é livre. Os serviços são } \\
\text { pagos. }\end{array}$} \\
\hline & & Acesso livre & 30 & \\
\hline & & Acesso condi & 0 & \\
\hline & & Acesso restrito & 10 & \\
\hline \multirow{13}{*}{$\begin{array}{l}\text { U } \\
\text { S } \\
\text { A } \\
\text { B } \\
\text { I } \\
\text { L } \\
\text { I } \\
\text { D } \\
\text { A } \\
\text { D } \\
\text { E }\end{array}$} & \multirow{3}{*}{$\begin{array}{l}\text { Inteligibilidade (Chou et al., ISO, } \\
\text { Nielsen, Vilella) - easy to } \\
\text { understand, interpretability }\end{array}$} & Fontes e atributos & 10 & \\
\hline & & Links claros & 10 & \\
\hline & & Interface & 10 & \\
\hline & \multirow{4}{*}{$\begin{array}{l}\text { Apreensibilidade (ISO, Nielsen, } \\
\text { Vilella) }\end{array}$} & Navegação & 0 & \multirow{4}{*}{$\begin{array}{l}\text { 2. Mas os menus são fartos e } \\
\text { bem explicativos. }\end{array}$} \\
\hline & & Apreensão & 0 & \\
\hline & & Instruções de uso & 0 & \\
\hline & & Interface humana & 0 & \\
\hline & \multirow{6}{*}{$\begin{array}{l}\text { Operacionalidade (ISO, Chou et al., } \\
\text { Nielsen, Vilella) }\end{array}$} & Rolagem & 10 & \\
\hline & & Ajuste de leiaute & 0 & \\
\hline & & Agrupamento & 10 & \\
\hline & & Tarefas prioritárias & 10 & \\
\hline & & Clareza da URL & 10 & \\
\hline & & Disponibilidade & 10 & \\
\hline
\end{tabular}




\begin{tabular}{|c|c|c|c|c|}
\hline & & Outras mídias & 0 & \\
\hline & & Acessibilidade & 0 & \\
\hline & & Diálogo real & 0 & \\
\hline & & Cooperação & 0 & 7. Tem espaço para atualidades, \\
\hline & Adequação (Vilella, ISO, Moretti & Criação de CoP & 0 & mas está desatualizado (notícias \\
\hline & et al.) & Ferramentas de CoP & 0 & \\
\hline & & Versão personal & 0 & \\
\hline F & & Conhecimento & 10 & \\
\hline $\mathrm{U}$ & & Notícias & 10 & \\
\hline $\begin{array}{l}\mathrm{N} \\
\mathrm{C}\end{array}$ & & Velocidade & 10 & \\
\hline I & & Templates & 10 & 3. Mediante cadastro. \\
\hline $\mathrm{O}$ & Acurácia (Vilella, ISO, Chou et al.) & Bases de dados & 10 & \\
\hline $\mathrm{N}$ & & Alerta personal & 10 & \\
\hline A & & Interface uni & 10 & \\
\hline $\mathrm{L}$ & & Eventos & 0 & \\
\hline I & & Estatísticas & 0 & \\
\hline D & & Fontes múltiplas & 10 & 1. mas poucos links. \\
\hline A & Interoperabilidade (Vilella, ISO) & Transparência & 10 & \\
\hline D & & Acesso a perfis & 0 & \\
\hline E & & Busca - mecan & 0 & \\
\hline & & Resultado busca & 0 & \\
\hline & Conformidade (Vilella, ISO) & Política & 10 & \\
\hline & Segurança de acesso (Vilella, ISO, & Privacidade & 0 & \\
\hline & Chou et al.) & Criptografia & 0 & \\
\hline
\end{tabular}

(Análise elaborada e revista no período de 01.09 a 30.10.2007). 


\section{http://www.portaldeconhecimentos.org.br}

"O Portal de conhecimentos tem o objetivo de registrar e organizar conhecimentos sobre o processo de desenvolvimento de produtos de forma que esses conhecimentos sejam compartilhados pela comunidade interessada no assunto".

Obs.: Os dados da PDPNet - Comunidade de prática em desenvolvimento de produtos estão sendo transferidos para este Portal. Alguns links ainda estão vazios como, por exemplo, o 'histórico'.

\begin{tabular}{|c|c|c|c|c|}
\hline Dimensão & Característica & Atributo & Pontuação & Observações \\
\hline \multirow{27}{*}{$\begin{array}{l}\mathrm{C} \\
\mathrm{O} \\
\mathrm{N} \\
\mathrm{T} \\
\mathrm{E} \\
\dot{U} \\
\mathrm{D} \\
\mathrm{O}\end{array}$} & \multirow{4}{*}{ Propósito (Vilella) } & Visão geral & 10 & \multirow[t]{4}{*}{ 2. Falta período de cobertura. } \\
\hline & & Escopo & 10 & \\
\hline & & Serviços & 10 & \\
\hline & & Complementação & 10 & \\
\hline & \multirow{4}{*}{$\begin{array}{l}\text { Abrangência / cobertura (Vilella - } \\
\text { junto com propósito) }\end{array}$} & Tipo de conteúdo & 12 & \multirow[b]{4}{*}{$\begin{array}{l}\text { 1. apresentação, artigos, cap. de } \\
\text { livros, melhores práticas, } \\
\text { procedimentos, projetos, } \\
\text { revistas, sites, trabalho } \\
\text { acadêmico, casos, pessoas } \\
\text { 2. Inovação, desenvolvimento de } \\
\text { produto, gestão do ciclo de vida } \\
\text { e sustentabilidade. } \\
\text { Destaca-se a disponibilidade de } \\
\text { "Melhores Práticas", } \\
\text { consideradas aqui como } \\
\text { informações que "tratam de } \\
\text { métodos, ferramentas, conceitos } \\
\text { e sistemas que podem ser } \\
\text { utilizados para apoiar as } \\
\text { atividades do processo de } \\
\text { desenvolvimento de produtos". }\end{array}$} \\
\hline & & Tipo de assunto & 30 & \\
\hline & & Outros idiomas & 0 & \\
\hline & & Versões & 10 & \\
\hline & $\begin{array}{l}\text { Padrão de publicação de conteúdo } \\
\text { (Almeida e Bax, Breitman, Terra e } \\
\text { Gordon) }\end{array}$ & $\begin{array}{l}\text { Taxonomia/onto/ } \\
\text { classificação/nada }\end{array}$ & 6 & \\
\hline & \multirow{2}{*}{$\begin{array}{l}\text { Atualidade (Vilella, Chou et al. - } \\
\text { timeless) }\end{array}$} & Atualização & 10 & \multirow{2}{*}{$\begin{array}{l}\text { 1. Mas na página inicial não há } \\
\text { indicação de data de atualização. } \\
\text { 2. Há data de inclusão de cada } \\
\text { conteúdo. }\end{array}$} \\
\hline & & Data - conteúdo sig & 10 & \\
\hline & \multirow{3}{*}{ Correção (Vilella) } & Precisão & 10 & \\
\hline & & Referência correta & 10 & \\
\hline & & Inconsistências & 10 & \\
\hline & \multirow{4}{*}{$\begin{array}{l}\text { Autoridade / copirraite (Vilella), } \\
\text { believability e reputation (Chou et } \\
\text { al.) }\end{array}$} & Copirraite & 0 & \\
\hline & & Menção a fontes & 10 & \\
\hline & & Responsabilidade & 10 & \\
\hline & & Legitimidade & 0 & \\
\hline & \multirow{5}{*}{ Objetividade (Vilella, Chou e al.) } & Conteúdo - inicial & 10 & \\
\hline & & Conteúdo adequado & 10 & \\
\hline & & Forma de escrita & 10 & \\
\hline & & Publicidade & 10 & \\
\hline & & Utilidade & 10 & \\
\hline & \multirow{4}{*}{$\begin{array}{l}\text { Regras de publicação e acesso } \\
\text { (Moretti et al.) ou acessibilidade } \\
\text { (Coelho, 2007) }\end{array}$} & Regras de publ & 10 & \multirow{4}{*}{ 2. Mediante cadastro. } \\
\hline & & Acesso livre & 30 & \\
\hline & & Acesso condi & 10 & \\
\hline & & Acesso restrito & 10 & \\
\hline
\end{tabular}




\begin{tabular}{|c|c|c|c|c|}
\hline \multirow{15}{*}{$\begin{array}{l}\text { U } \\
\text { S } \\
\text { A } \\
\text { B } \\
\text { I } \\
\text { L } \\
\text { I } \\
\text { D } \\
\text { A } \\
\text { D } \\
\text { E }\end{array}$} & \multirow{3}{*}{$\begin{array}{l}\text { Inteligibilidade (Chou et al., ISO, } \\
\text { Nielsen, Vilella) - easy to } \\
\text { understand, interpretability }\end{array}$} & Fontes e atributos & 10 & \\
\hline & & Links claros & 10 & \\
\hline & & Interface & 10 & \\
\hline & \multirow{4}{*}{$\begin{array}{l}\text { Apreensibilidade (ISO, Nielsen, } \\
\text { Vilella) }\end{array}$} & Navegação & 10 & \multirow{4}{*}{ 2. Ajuda - forte. } \\
\hline & & Apreensão & 10 & \\
\hline & & Instruções de uso & 0 & \\
\hline & & Interface humana & 10 & \\
\hline & \multirow{8}{*}{$\begin{array}{l}\text { Operacionalidade (ISO, Chou et al., } \\
\text { Nielsen, Vilella) }\end{array}$} & Rolagem & 10 & \\
\hline & & Ajuste de leiaute & 0 & \\
\hline & & Agrupamento & 10 & \\
\hline & & Tarefas prioritárias & 10 & \\
\hline & & Clareza da URL & 10 & \\
\hline & & Disponibilidade & 10 & \\
\hline & & Outras mídias & 0 & \\
\hline & & Acessibilidade & 0 & \\
\hline \multirow{22}{*}{$\begin{array}{l}\mathrm{F} \\
\mathrm{U} \\
\mathrm{N} \\
\mathrm{C} \\
\mathrm{I} \\
\mathrm{O} \\
\mathrm{N} \\
\mathrm{A} \\
\mathrm{L} \\
\mathrm{I} \\
\mathrm{D} \\
\mathrm{A} \\
\mathrm{D} \\
\mathrm{E}\end{array}$} & \multirow{8}{*}{$\begin{array}{l}\text { Adequação (Vilella, ISO, Moretti } \\
\text { et al.) }\end{array}$} & Diálogo real & 0 & \\
\hline & & Cooperação & 0 & \\
\hline & & Criação de $\mathrm{CoP}$ & 30 & \\
\hline & & Ferramentas de $\mathrm{CoP}$ & 0 & \\
\hline & & Versão personal & 0 & \\
\hline & & Conhecimento & 10 & \\
\hline & & Notícias & 10 & \\
\hline & & Velocidade & 10 & \\
\hline & \multirow{6}{*}{ Acurácia (Vilella, ISO, Chou et al.) } & Templates & 10 & \multirow{6}{*}{ 2. Base local. } \\
\hline & & Bases de dados & 10 & \\
\hline & & Alerta personal & 0 & \\
\hline & & Interface uni & 10 & \\
\hline & & Eventos & 0 & \\
\hline & & Estatísticas & 10 & \\
\hline & \multirow{5}{*}{ Interoperabilidade (Vilella, ISO) } & Fontes múltiplas & 10 & \multirow{5}{*}{$\begin{array}{l}\text { 3. Só especifica os tipos de } \\
\text { perfis. } \\
\text { 5. Listagem de títulos por tipo de } \\
\text { conteúdo. }\end{array}$} \\
\hline & & Transparência & 10 & \\
\hline & & Acesso a perfis & 0 & \\
\hline & & Busca - mecan & 6 & \\
\hline & & Resultado busca & 10 & \\
\hline & Conformidade (Vilella, ISO) & Política & 10 & \\
\hline & \multirow{2}{*}{$\begin{array}{l}\text { Segurança de acesso (Vilella, ISO, } \\
\text { Chou et al.) }\end{array}$} & Privacidade & 0 & \\
\hline & & Criptografia & 0 & \\
\hline
\end{tabular}

(Análise elaborada e revista no período de 01.09 a 30.10.2007). 


\title{
http://www.portalinovacao.info ou http://www.portalinovacao.mct.gov.br
}

\author{
"inovação MINC"
}

É um portal do MCT - Ministério da Ciência e Tecnologia, que tem como objetivo "aproximar e promover a interação entre Empresas, Comunidade Técnico-Científica, Instituições de Ciência, Tecnologia e Inovação (ICTIs) e Organizações de Apoio visando à cooperação e à inovação nos diversos setores sócio-econômicos em todas as áreas do conhecimento".

\begin{tabular}{|c|c|c|c|c|}
\hline Dimensão & Característica & Atributo & Pontuação & Observações \\
\hline \multirow{22}{*}{$\begin{array}{l}\mathrm{C} \\
\mathrm{O} \\
\mathrm{N} \\
\mathrm{T} \\
\mathrm{E} \\
\mathrm{U} \\
\mathrm{D} \\
\mathrm{O}\end{array}$} & \multirow{4}{*}{ Propósito (Vilella) } & Visão geral & 10 & \\
\hline & & Escopo & 10 & \\
\hline & & Serviços & 10 & \\
\hline & & Complementação & 10 & \\
\hline & \multirow{4}{*}{$\begin{array}{l}\text { Abrangência / cobertura (Vilella - } \\
\text { junto com propósito) }\end{array}$} & Tipo de conteúdo & 12 & \multirow[b]{4}{*}{$\begin{array}{l}\text { 1. Arquivos de texto e modelos } \\
\text { de convênios e acordos para } \\
\text { download, artigos de científicos } \\
\text { e de divulgação nacional e } \\
\text { internacional, bibliotecas digitais } \\
\text { de acesso livre (Scielo) e } \\
\text { restritos (Science Direct, Portal } \\
\text { CAPES), bibliotecas virtuais e } \\
\text { portais de interesse, livros, } \\
\text { manuais, revistas, agências de } \\
\text { fomento e fontes de } \\
\text { financiamento de negócios no } \\
\text { Brasil, incubadoras de empresas, } \\
\text { legislação (cópia na íntegra), } \\
\text { bases de patentes, programas de } \\
\text { governo ligados à inovação, } \\
\text { indicadores, produtos, software } \\
\text { Lattes } \\
\text { 2. Inovação, interação empresa } \\
\text { comunidade de CT\&I, } \\
\text { propriedade intelectual }\end{array}$} \\
\hline & & Tipo de assunto & 18 & \\
\hline & & Outros idiomas & 0 & \\
\hline & & Versões & 0 & \\
\hline & $\begin{array}{l}\text { Padrão de publicação de conteúdo } \\
\text { (Almeida e Bax, Breitman, Terra e } \\
\text { Gordon) }\end{array}$ & $\begin{array}{l}\text { Taxonomia/onto/ } \\
\text { classificação/nada }\end{array}$ & 3 & \\
\hline & \multirow{2}{*}{$\begin{array}{l}\text { Atualidade (Vilella, Chou et al. - } \\
\text { timeless) }\end{array}$} & Atualização & 0 & \multirow[b]{2}{*}{$\begin{array}{l}\text { 1. Não indicação de atualização. } \\
\text { Somente pela recuperação é } \\
\text { possível verificar que o conteúdo } \\
\text { é atualizado. Mas a base de } \\
\text { eventos, por exemplo, está } \\
\text { desatualizada. } \\
\text { 2. Na maioria dos documentos, é } \\
\text { difícil identificar a data. }\end{array}$} \\
\hline & & Data - conteúdo sig & 0 & \\
\hline & \multirow{3}{*}{ Correção (Vilella) } & Precisão & 0 & \\
\hline & & Referência correta & 10 & \\
\hline & & Inconsistências & 10 & \\
\hline & \multirow{4}{*}{$\begin{array}{l}\text { Autoridade / copirraite (Vilella), } \\
\text { believability e reputation (Chou et } \\
\text { al.) }\end{array}$} & Copirraite & 10 & \\
\hline & & Menção a fontes & 10 & \\
\hline & & Responsabilidade & 10 & \\
\hline & & Legitimidade & 10 & \\
\hline & \multirow{4}{*}{ Objetividade (Vilella, Chou e al.) } & Conteúdo - inicial & 10 & \\
\hline & & Conteúdo adequado & 10 & \\
\hline & & Forma de escrita & 10 & \\
\hline & & Publicidade & 10 & \\
\hline
\end{tabular}




\begin{tabular}{|c|c|c|c|c|}
\hline & & Utilidade & 10 & \\
\hline & \multirow{4}{*}{$\begin{array}{l}\text { Regras de publicação e acesso } \\
\text { (Moretti et al.) ou acessibilidade } \\
\text { (Coelho, 2007) }\end{array}$} & Regras de publ & 0 & \\
\hline & & Acesso livre & 30 & \\
\hline & & Acesso condi & 10 & \\
\hline & & Acesso restrito & 10 & \\
\hline \multirow{15}{*}{$\begin{array}{l}\text { U } \\
\text { S } \\
\text { A } \\
\text { B } \\
\text { I } \\
\text { L } \\
\text { I } \\
\text { D } \\
\text { A } \\
\text { D } \\
\text { E }\end{array}$} & \multirow{3}{*}{$\begin{array}{l}\text { Inteligibilidade (Chou et al., ISO, } \\
\text { Nielsen, Vilella) - easy to } \\
\text { understand, interpretability }\end{array}$} & Fontes e atributos & 10 & \\
\hline & & Links claros & 10 & \\
\hline & & Interface & 10 & \\
\hline & \multirow{4}{*}{$\begin{array}{l}\text { Apreensibilidade (ISO, Nielsen, } \\
\text { Vilella) }\end{array}$} & Navegação & 10 & \\
\hline & & Apreensão & 10 & \\
\hline & & Instruções de uso & 0 & \\
\hline & & Interface humana & 0 & \\
\hline & \multirow{8}{*}{$\begin{array}{l}\text { Operacionalidade (ISO, Chou et al., } \\
\text { Nielsen, Vilella) }\end{array}$} & Rolagem & 10 & \\
\hline & & Ajuste de leiaute & 0 & \\
\hline & & Agrupamento & 10 & \\
\hline & & Tarefas prioritárias & 10 & \\
\hline & & Clareza da URL & 10 & \\
\hline & & Disponibilidade & 10 & \\
\hline & & Outras mídias & 0 & \\
\hline & & Acessibilidade & 0 & \\
\hline \multirow{22}{*}{$\begin{array}{l}\mathrm{F} \\
\mathrm{U} \\
\mathrm{N} \\
\mathrm{C} \\
\mathrm{I} \\
\mathrm{O} \\
\mathrm{N} \\
\mathrm{A} \\
\mathrm{L} \\
\mathrm{I} \\
\mathrm{D} \\
\mathrm{A} \\
\mathrm{D} \\
\mathrm{E}\end{array}$} & \multirow{8}{*}{$\begin{array}{l}\text { Adequação (Vilella, ISO, Moretti } \\
\text { et al.) }\end{array}$} & Diálogo real & 10 & \multirow{8}{*}{$\begin{array}{l}\text { 1. Mas só para usuários } \\
\text { cadastrados no "Ambiente } \\
\text { especialista". } \\
\text { 7. Em "novidades" e } \\
\text { "destaques". }\end{array}$} \\
\hline & & Cooperação & 10 & \\
\hline & & Criação de CoP & 0 & \\
\hline & & Ferramentas de CoP & 0 & \\
\hline & & Versão personal & 0 & \\
\hline & & Conhecimento & 10 & \\
\hline & & Notícias & 10 & \\
\hline & & Velocidade & 10 & \\
\hline & \multirow{6}{*}{ Acurácia (Vilella, ISO, Chou et al.) } & Templates & 10 & \multirow{6}{*}{$\begin{array}{l}\text { 6. Em “indicadores" estão as } \\
\text { interações feitas mediante } \\
\text { acessos e consultas. Como } \\
\text { 'anônimo' são mais de } 360 \text { mil } \\
\text { acessos e mais de } 330 \text { mil } \\
\text { consultas. Identificados = } 39 \\
\text { envios, } 13 \text { respostas, } 03 \\
\text { interações bem sucedidas } \\
(09.06 .2007)\end{array}$} \\
\hline & & Bases de dados & 10 & \\
\hline & & Alerta personal & 0 & \\
\hline & & Interface uni & 10 & \\
\hline & & Eventos & 0 & \\
\hline & & Estatísticas & 10 & \\
\hline & \multirow{5}{*}{ Interoperabilidade (Vilella, ISO) } & Fontes múltiplas & 10 & \multirow{5}{*}{$\begin{array}{l}\text { 3. Política de privacidade. } \\
\text { 5. A busca geral resulta em uma } \\
\text { lista, separada por: especialistas, } \\
\text { grupos e empresas. Em } \\
\text { 'especialistas', os registros são } \\
\text { apresentados por ordem de } \\
\text { incidência no currículo Lattes. }\end{array}$} \\
\hline & & Transparência & 10 & \\
\hline & & Acesso a perfis & 0 & \\
\hline & & Busca - mecan & 3 & \\
\hline & & Resultado busca & 10 & \\
\hline & Conformidade (Vilella, ISO) & Política & 10 & \\
\hline & \multirow{2}{*}{$\begin{array}{l}\text { Segurança de acesso (Vilella, ISO, } \\
\text { Chou et al.) }\end{array}$} & Privacidade & 10 & \\
\hline & & Criptografia & 0 & \\
\hline
\end{tabular}

Missão: "promover o encontro de competências e de oportunidades e estabelecer um espaço para cooperação entre os diversos atores envolvidos com a cadeia de inovação";

Visão: "se constituir no principal espaço virtual de divulgação de competências, de encontro de oportunidades e de promoção de interação e cooperação para o desenvolvimento e a inovação no País".

(Análise elaborada e revista no período de 01.09 a 30.10.2007). 


\section{http://www.prossiga.br/finep}

\section{Biblioteca Virtual de Inovação Tecnológica (bv inovação)}

Portal da Biblioteca Virtual de Inovação Tecnológica, que "é resultado de uma ação conjunta envolvendo a FINEP e o Programa Prossiga/CNPq. Reúne de forma estruturada e seletiva, sites brasileiros e estrangeiros contendo informações relevantes sobre inovação tecnológica, em seus múltiplos aspectos".

\begin{tabular}{|c|c|c|c|c|}
\hline Dimensão & Característica & Atributo & Pontuação & Observações \\
\hline \multirow{26}{*}{$\begin{array}{l}\mathrm{C} \\
\mathrm{O} \\
\mathrm{N} \\
\mathrm{T} \\
\mathrm{E} \\
\mathrm{U} \\
\mathrm{D} \\
\mathrm{O}\end{array}$} & \multirow{4}{*}{ Propósito (Vilella) } & Visão geral & 10 & \\
\hline & & Escopo & 10 & \\
\hline & & Serviços & 10 & \\
\hline & & Complementação & 10 & \\
\hline & \multirow{4}{*}{$\begin{array}{l}\text { Abrangência / cobertura (Vilella - } \\
\text { junto com propósito) }\end{array}$} & Tipo de conteúdo & 6 & \multirow{4}{*}{$\begin{array}{l}\text { 1. sites, textos, legislação, } \\
\text { artigos de jornais e artigos } \\
\text { científicos, diretórios de } \\
\text { pesquisa, teses e dissertações, } \\
\text { estatísticas e indicadores, } \\
\text { patentes e marcas, estudos e } \\
\text { diagnósticos, pesquisas, Revista } \\
\text { Brasileira de Inovação. } \\
\text { 2. inovação, marcas e patentes, } \\
\text { fontes de informação, políticas } \\
\text { públicas, inf. tecnológica, } \\
\text { recursos humanos, política } \\
\text { industrial, parcerias, APLs, } \\
\text { competitividade, cadeias } \\
\text { produtivas, aprendizagem org. }\end{array}$} \\
\hline & & Tipo de assunto & 18 & \\
\hline & & Outros idiomas & 0 & \\
\hline & & Versões & 0 & \\
\hline & $\begin{array}{l}\text { Padrão de publicação de conteúdo } \\
\text { (Almeida e Bax, Breitman, Terra e } \\
\text { Gordon) }\end{array}$ & $\begin{array}{l}\text { Taxonomia/onto/ } \\
\text { classificação/nada }\end{array}$ & 3 & \\
\hline & \multirow{2}{*}{$\begin{array}{l}\text { Atualidade (Vilella, Chou et al. - } \\
\text { timeless) }\end{array}$} & Atualização & 0 & \multirow[b]{2}{*}{$\begin{array}{l}\text { 1. Alguns conteúdos estão } \\
\text { desatualizados. Ex.: a pesquisa } \\
\text { Pintec } 2005 \text { foi publicada em } \\
31.07 \text {, mas o site ainda indica a } \\
\text { de } 2003 \text {. Ressalta-se que há } \\
\text { indicação da última atualização } \\
\text { do site em } 07.09 \text {. } \\
\text { 2. Algumas páginas não indicam } \\
\text { a data de atualização. }\end{array}$} \\
\hline & & Data - conteúdo sig & 0 & \\
\hline & \multirow{3}{*}{ Correção (Vilella) } & Precisão & 10 & \\
\hline & & Referência correta & 10 & \\
\hline & & Inconsistências & 10 & \\
\hline & \multirow{4}{*}{$\begin{array}{l}\text { Autoridade / copirraite (Vilella), } \\
\text { believability e reputation (Chou et } \\
\text { al.) }\end{array}$} & Copirraite & 10 & \\
\hline & & Menção a fontes & 10 & \\
\hline & & Responsabilidade & 10 & \\
\hline & & Legitimidade & 10 & \\
\hline & \multirow{5}{*}{ Objetividade (Vilella, Chou e al.) } & Conteúdo - inicial & 10 & \\
\hline & & Conteúdo adequado & 10 & \\
\hline & & Forma de escrita & 10 & \\
\hline & & Publicidade & 10 & \\
\hline & & Utilidade & 10 & \\
\hline & \multirow{3}{*}{$\begin{array}{l}\text { Regras de publicação e acesso } \\
\text { (Moretti et al.) ou acessibilidade }\end{array}$} & Regras de publ & 0 & \\
\hline & & Acesso livre & 30 & \\
\hline & & Acesso condi & 10 & \\
\hline
\end{tabular}




\begin{tabular}{|c|c|c|c|c|}
\hline & (Coelho, 2007) & Acesso restrito & 10 & \\
\hline \multirow{15}{*}{$\begin{array}{l}\text { U } \\
\text { S } \\
\text { A } \\
\text { B } \\
\text { I } \\
\text { L } \\
\text { I } \\
\text { D } \\
\text { A } \\
\text { D } \\
\text { E }\end{array}$} & \multirow{3}{*}{$\begin{array}{l}\text { Inteligibilidade (Chou et al., ISO, } \\
\text { Nielsen, Vilella) - easy to } \\
\text { understand, interpretability }\end{array}$} & Fontes e atributos & 10 & \multirow[t]{3}{*}{ 1. Mas deve melhorar. } \\
\hline & & Links claros & 10 & \\
\hline & & Interface & 0 & \\
\hline & \multirow{4}{*}{$\begin{array}{l}\text { Apreensibilidade (ISO, Nielsen, } \\
\text { Vilella) }\end{array}$} & Navegação & 10 & \\
\hline & & Apreensão & 0 & \\
\hline & & Instruções de uso & 0 & \\
\hline & & Interface humana & 0 & \\
\hline & \multirow{8}{*}{$\begin{array}{l}\text { Operacionalidade (ISO, Chou et al., } \\
\text { Nielsen, Vilella) }\end{array}$} & Rolagem & 0 & \multirow[t]{8}{*}{ 3. confuso. } \\
\hline & & Ajuste de leiaute & 0 & \\
\hline & & Agrupamento & 0 & \\
\hline & & Tarefas prioritárias & 10 & \\
\hline & & Clareza da URL & 10 & \\
\hline & & Disponibilidade & 10 & \\
\hline & & Outras mídias & 0 & \\
\hline & & Acessibilidade & 0 & \\
\hline \multirow{22}{*}{$\begin{array}{l}\mathrm{F} \\
\mathrm{U} \\
\mathrm{N} \\
\mathrm{C} \\
\mathrm{I} \\
\mathrm{O} \\
\mathrm{N} \\
\mathrm{A} \\
\mathrm{L} \\
\mathrm{I} \\
\mathrm{D} \\
\mathrm{A} \\
\mathrm{D} \\
\mathrm{E}\end{array}$} & \multirow{8}{*}{$\begin{array}{l}\text { Adequação (Vilella, ISO, Moretti } \\
\text { et al.) }\end{array}$} & Diálogo real & 0 & \multirow{8}{*}{$\begin{array}{l}\text { 7. A partir de: } \\
\text { - ‘clipping Finep': possibilita } \\
\text { visualizar as noticias sobre } \\
\text { inovação tecnológica nos } \\
\text { principais jornais, revistas e } \\
\text { mídias eletrônicas nacionais; } \\
\text { - 'Folha Inovação': um boletim } \\
\text { informativo publicado até } \\
\text { fev./06; } \\
\text { - Sala de imprensa: noticias } \\
\text { atualizadas. }\end{array}$} \\
\hline & & Cooperação & 0 & \\
\hline & & Criação de CoP & 0 & \\
\hline & & Ferramentas de CoP & 0 & \\
\hline & & Versão personal & 0 & \\
\hline & & Conhecimento & 10 & \\
\hline & & Notícias & 10 & \\
\hline & & Velocidade & 10 & \\
\hline & \multirow{6}{*}{ Acurácia (Vilella, ISO, Chou et al.) } & Templates & 10 & \\
\hline & & Bases de dados & 10 & \\
\hline & & Alerta personal & 0 & \\
\hline & & Interface uni & 10 & \\
\hline & & Eventos & 0 & \\
\hline & & Estatísticas & 0 & \\
\hline & \multirow{5}{*}{ Interoperabilidade (Vilella, ISO) } & Fontes múltiplas & 0 & \multirow{5}{*}{$\begin{array}{l}\text { 1. É um catálogo de links, com } \\
\text { dados complementares. } \\
5 \text {. Por categorias, conforme } \\
\text { apresentadas na página inicial. } \\
\text { Confuso. }\end{array}$} \\
\hline & & Transparência & 10 & \\
\hline & & Acesso a perfis & 0 & \\
\hline & & Busca - mecan & 3 & \\
\hline & & Resultado busca & 10 & \\
\hline & Conformidade (Vilella, ISO) & Política & 10 & \\
\hline & \multirow{2}{*}{$\begin{array}{l}\text { Segurança de acesso (Vilella, ISO, } \\
\text { Chou et al.) }\end{array}$} & Privacidade & 0 & \\
\hline & & Criptografia & 0 & \\
\hline
\end{tabular}

(Análise elaborada e revista no período de 01.09 a 30.10.2007). 


\section{http://sbrt.ibict.br}

O Serviço Brasileiro de Respostas Técnicas (SBRT), instituído em 2002, "visa facilitar o rápido acesso das empresas a soluções tecnológicas em áreas específicas, promover a difusão do conhecimento e contribuir para o processo de transferência de tecnologia com foco, especialmente, nas micro e pequenas empresas".

\begin{tabular}{|c|c|c|c|c|}
\hline Dimensão & Característica & Atributo & Pontuação & Observações \\
\hline \multirow{27}{*}{$\begin{array}{l}\mathrm{C} \\
\mathrm{O} \\
\mathrm{N} \\
\mathrm{T} \\
\mathrm{E} \\
\mathrm{U} \\
\mathrm{D} \\
\mathrm{O}\end{array}$} & \multirow{4}{*}{ Propósito (Vilella) } & Visão geral & 10 & \multirow{4}{*}{$\begin{array}{l}\text { 2. Mas não há indicação de data } \\
\text { de cobertura }\end{array}$} \\
\hline & & Escopo & 10 & \\
\hline & & Serviços & 10 & \\
\hline & & Complementação & 0 & \\
\hline & \multirow{4}{*}{$\begin{array}{l}\text { Abrangência / cobertura (Vilella - } \\
\text { junto com propósito) }\end{array}$} & Tipo de conteúdo & 0 & \multirow{4}{*}{$\begin{array}{l}\text { 1. dossies, resposta técnica, } \\
\text { relatórios e links } \\
\text { 2. qualquer assunto sob demanda } \\
\text { (RT) ou por antecipação } \\
\text { (dossiês). Ex. dossiê: DP de } \\
\text { plástico biodegradável; ciclo de } \\
\text { vida do calçado; DP em calçado; } \\
\text { etapas do processo cerâmico e } \\
\text { outros }\end{array}$} \\
\hline & & Tipo de assunto & 0 & \\
\hline & & Outros idiomas & 0 & \\
\hline & & Versões & 0 & \\
\hline & $\begin{array}{l}\text { Padrão de publicação de conteúdo } \\
\text { (Almeida e Bax, Breitman, Terra e } \\
\text { Gordon) }\end{array}$ & $\begin{array}{l}\text { Taxonomia/onto/ } \\
\text { classificação/nada }\end{array}$ & 0 & $\begin{array}{l}\text { A publicação das respostas } \\
\text { técnicas é apresentada em forma } \\
\text { de listagem, onde está indicada a } \\
\text { pergunta recebida, as palavras- } \\
\text { chave, o assunto, a instituição } \\
\text { que respondeu e o arquivo do } \\
\text { texto. }\end{array}$ \\
\hline & \multirow{2}{*}{$\begin{array}{l}\text { Atualidade (Vilella, Chou et al. - } \\
\text { timeless) }\end{array}$} & Atualização & 0 & \multirow{2}{*}{$\begin{array}{l}\text { 1. não há data de atualização das } \\
\text { páginas } \\
\text { 2. ok. Cada conteúdo tem a data } \\
\text { de produção }\end{array}$} \\
\hline & & Data - conteúdo sig & 10 & \\
\hline & \multirow{3}{*}{ Correção (Vilella) } & Precisão & 10 & \\
\hline & & Referência correta & 10 & \\
\hline & & Inconsistências & 10 & \\
\hline & \multirow{4}{*}{$\begin{array}{l}\text { Autoridade / copirraite (Vilella), } \\
\text { believability e reputation (Chou et } \\
\text { al.) }\end{array}$} & Copirraite & 10 & \\
\hline & & Menção a fontes & 10 & \\
\hline & & Responsabilidade & 10 & \\
\hline & & Legitimidade & 0 & \\
\hline & \multirow{5}{*}{ Objetividade (Vilella, Chou e al.) } & Conteúdo - inicial & 10 & \\
\hline & & Conteúdo adequado & 10 & \\
\hline & & Forma de escrita & 10 & \\
\hline & & Publicidade & 10 & \\
\hline & & Utilidade & 10 & \\
\hline & \multirow{4}{*}{$\begin{array}{l}\text { Regras de publicação e acesso } \\
\text { (Moretti et al.) ou acessibilidade } \\
\text { (Coelho, 2007) }\end{array}$} & Regras de publ & 10 & \multirow{4}{*}{$\begin{array}{l}\text { 1. Existe um modelo padrão de } \\
\text { formato de resposta. }\end{array}$} \\
\hline & & Acesso livre & 30 & \\
\hline & & Acesso condi & 10 & \\
\hline & & Acesso restrito & 10 & \\
\hline \multirow{7}{*}{$\begin{array}{l}\text { U } \\
\text { S } \\
\text { A } \\
\text { B } \\
\text { I } \\
\text { L }\end{array}$} & \multirow{3}{*}{$\begin{array}{l}\text { Inteligibilidade (Chou et al., ISO, } \\
\text { Nielsen, Vilella) - easy to } \\
\text { understand, interpretability }\end{array}$} & Fontes e atributos & 10 & \\
\hline & & Links claros & 10 & \\
\hline & & Interface & 10 & \\
\hline & \multirow{4}{*}{$\begin{array}{l}\text { Apreensibilidade (ISO, Nielsen, } \\
\text { Vilella) }\end{array}$} & Navegação & 0 & \\
\hline & & Apreensão & 0 & \\
\hline & & Instruções de uso & 0 & \\
\hline & & Interface humana & 0 & \\
\hline
\end{tabular}




\begin{tabular}{|c|c|c|c|c|}
\hline \multirow{8}{*}{$\begin{array}{l}\mathrm{I} \\
\mathrm{D} \\
\mathrm{A} \\
\mathrm{D} \\
\mathrm{E}\end{array}$} & \multirow{8}{*}{$\begin{array}{l}\text { Operacionalidade (ISO, Chou et al., } \\
\text { Nielsen, Vilella) }\end{array}$} & Rolagem & 10 & \\
\hline & & Ajuste de leiaute & 0 & \\
\hline & & Agrupamento & 10 & \\
\hline & & Tarefas prioritárias & 10 & \\
\hline & & Clareza da URL & 10 & \\
\hline & & Disponibilidade & 10 & \\
\hline & & Outras mídias & 0 & \\
\hline & & Acessibilidade & 0 & \\
\hline \multirow{22}{*}{$\begin{array}{l}\mathrm{F} \\
\mathrm{U} \\
\mathrm{N} \\
\mathrm{C} \\
\mathrm{I} \\
\mathrm{O} \\
\mathrm{N} \\
\mathrm{A} \\
\mathrm{L} \\
\mathrm{I} \\
\mathrm{D} \\
\mathrm{A} \\
\mathrm{D} \\
\mathrm{E}\end{array}$} & \multirow{8}{*}{$\begin{array}{l}\text { Adequação (Vilella, ISO, Moretti } \\
\text { et al.) }\end{array}$} & Diálogo real & 0 & \multirow{8}{*}{ 7. Mas está desativado. } \\
\hline & & Cooperação & 0 & \\
\hline & & Criação de CoP & 0 & \\
\hline & & Ferramentas de CoP & 0 & \\
\hline & & Versão personal & 0 & \\
\hline & & Conhecimento & 10 & \\
\hline & & Notícias & 10 & \\
\hline & & Velocidade & 10 & \\
\hline & \multirow{6}{*}{ Acurácia (Vilella, ISO, Chou et al.) } & Templates & 10 & \multirow{6}{*}{$\begin{array}{l}\text { 1. Há somente um formulário } \\
\text { on-line para solicitação, mas } \\
\text { para o seu propósito, é suficiente } \\
2 \text {. na base local de RT. A base é } \\
\text { composta de } 15.500 \\
\text { atendimentos, } 6.145 \text { respostas } \\
\text { técnicas e } 115 \text { dossiês (agosto } \\
\text { 2007). }\end{array}$} \\
\hline & & Bases de dados & 10 & \\
\hline & & Alerta personal & 0 & \\
\hline & & Interface uni & 10 & \\
\hline & & Eventos & 0 & \\
\hline & & Estatísticas & 0 & \\
\hline & \multirow{5}{*}{ Interoperabilidade (Vilella, ISO) } & Fontes múltiplas & 0 & \multirow{5}{*}{$\begin{array}{l}\text { 5. em forma de quadro, por } \\
\text { ordem de pertinência }\end{array}$} \\
\hline & & Transparência & 0 & \\
\hline & & Acesso a perfis & 0 & \\
\hline & & Busca - mecan & 3 & \\
\hline & & Resultado busca & 10 & \\
\hline & Conformidade (Vilella, ISO) & Política & 10 & \\
\hline & \multirow{2}{*}{$\begin{array}{l}\text { Segurança de acesso (Vilella, ISO, } \\
\text { Chou et al.) }\end{array}$} & Privacidade & 0 & \\
\hline & & Criptografia & 0 & \\
\hline
\end{tabular}

\section{Objetivos do SBRT:}

- Buscar, por meio das instituições participantes, a solução para as questões apresentadas pelas empresas, em qualquer ponto do território nacional;

- Facilitar o rápido acesso das empresas a soluções de problemas tecnológicos de baixa complexidade, em áreas específicas, mediante o fornecimento de resposta técnica personalizada, elaborada sob medida e customizada;

- Promover a difusão do conhecimento;

- Contribuir para o processo de transferência de tecnologia, especialmente, para MPEs.

Ações - com uma estrutura descentralizada, cabe ao SBRT, entre outras ações:

- promover a cooperação entre instituições que ofertam serviços dessa natureza, por meio da integração de suas capacidades e competências, para buscar soluções apropriadas aos principais problemas das MPEs;

- possibilitar a otimização dos recursos de informação disponíveis e potencializar o seu tratamento e disseminação;

- permitir a realimentação de todo o processo de produção de conhecimento e informação.

(Análise elaborada e revista no período de 01.09 a 30.10.2007). 


\section{http://www.score.org}

Portal do Counselors to America's Small Business (SCORE), cuja proposta se assemelha ao SEBRAE, embora bem mais abrangente. É a primeira iniciativa americana voltada para o aconselhamento livre e confidencial à pequena empresa e ao empresário. É uma organização sem fins lucrativos dedicada à formação e desenvolvimento de pequenas empresas.

Instituído em 1964, o SCORE já apoiou mais de 7.5 milhões de pequenas empresas, através do atendimento on-line, por e.mail e através dos 389 escritórios nos diferentes Estados americanos. Para tanto conta com mais de 10,500 conselheiros voluntários, que atendem a mais de 600 habilidades empresariais. Esses conselheiros são executivos procedentes das 500 empresas top da Fortune.

\begin{tabular}{|c|c|c|c|c|}
\hline Dimensão & Característica & Atributo & Pontuação & Observações \\
\hline \multirow{27}{*}{$\begin{array}{l}\mathrm{C} \\
\mathrm{O} \\
\mathrm{N} \\
\mathrm{T} \\
\mathrm{E} \\
U^{\prime} \\
\mathrm{D} \\
\mathrm{O}\end{array}$} & \multirow{4}{*}{ Propósito (Vilella) } & Visão geral & 10 & \multirow[t]{4}{*}{ 2. Não há data de cobertura. } \\
\hline & & Escopo & 0 & \\
\hline & & Serviços & 10 & \\
\hline & & Complementação & 10 & \\
\hline & \multirow{4}{*}{$\begin{array}{l}\text { Abrangência / cobertura (Vilella - } \\
\text { junto com propósito) }\end{array}$} & Tipo de conteúdo & 12 & \multirow{4}{*}{$\begin{array}{l}\text { 1. textos, templates, modelos de } \\
\text { planos de negócios, casos de } \\
\text { sucesso, manuais, artigos, cursos } \\
\text { on-line (apres., vídeos, } \\
\text { referencias, programas de } \\
\text { ensino), sites, newsletter. Para os } \\
\text { cursos on-line, há também o } \\
\text { direcionamento para uma página } \\
\text { do Governo, com vários cursos } \\
\text { gratuitos } \\
\text { (http://www.irs.gov/business/small) } \\
\text { 2. gestão de pequenas empresas }\end{array}$} \\
\hline & & Tipo de assunto & 9 & \\
\hline & & Outros idiomas & 0 & \\
\hline & & Versões & 0 & \\
\hline & $\begin{array}{l}\text { Padrão de publicação de conteúdo } \\
\text { (Almeida e Bax, Breitman, Terra e } \\
\text { Gordon) }\end{array}$ & $\begin{array}{l}\text { Taxonomia/onto/ } \\
\text { classificação/nada }\end{array}$ & 6 & 2. Possui glossário. \\
\hline & \multirow{2}{*}{$\begin{array}{l}\text { Atualidade (Vilella, Chou et al. - } \\
\text { timeless) }\end{array}$} & Atualização & 10 & \multirow{2}{*}{$\begin{array}{l}\text { Não há indicação de data de } \\
\text { atualização. }\end{array}$} \\
\hline & & Data - conteúdo sig & 0 & \\
\hline & \multirow{3}{*}{ Correção (Vilella) } & Precisão & 10 & \\
\hline & & Referência correta & 10 & \\
\hline & & Inconsistências & 10 & \\
\hline & \multirow{4}{*}{$\begin{array}{l}\text { Autoridade / copirraite (Vilella), } \\
\text { believability e reputation (Chou et } \\
\text { al.) }\end{array}$} & Copirraite & 10 & \\
\hline & & Menção a fontes & 10 & \\
\hline & & Responsabilidade & 10 & \\
\hline & & Legitimidade & 10 & \\
\hline & \multirow{5}{*}{ Objetividade (Vilella, Chou e al.) } & Conteúdo - inicial & 10 & \multirow{5}{*}{$\begin{array}{l}\text { 4. A publicidade dos parceiros é } \\
\text { saudável. }\end{array}$} \\
\hline & & Conteúdo adequado & 10 & \\
\hline & & Forma de escrita & 10 & \\
\hline & & Publicidade & 0 & \\
\hline & & Utilidade & 10 & \\
\hline & \multirow{4}{*}{$\begin{array}{l}\text { Regras de publicação e acesso } \\
\text { (Moretti et al.) ou acessibilidade } \\
\text { (Coelho, 2007) }\end{array}$} & Regras de publ & 10 & \multirow{4}{*}{$\begin{array}{l}\text { 2. O acesso a alguns conteúdos é } \\
\text { feito mediante cadastro. } \\
\text { 3. Alguns conteúdos são pagos: } \\
\text { cursos, softwares, alguns planos } \\
\text { de negócio. }\end{array}$} \\
\hline & & Acesso livre & 30 & \\
\hline & & Acesso condi & 0 & \\
\hline & & Acesso restrito & 10 & \\
\hline & Inteligibilidade (Chou et al., ISO, & Fontes e atributos & 10 & \\
\hline
\end{tabular}




\begin{tabular}{|c|c|c|c|c|}
\hline \multirow{14}{*}{$\begin{array}{l}\text { U } \\
\text { S } \\
\text { A } \\
\text { B } \\
\text { I } \\
\text { L } \\
\text { I } \\
\text { D } \\
\text { A } \\
\text { D } \\
\text { E }\end{array}$} & \multirow{2}{*}{$\begin{array}{l}\text { Nielsen, Vilella) - easy to } \\
\text { understand, interpretability }\end{array}$} & Links claros & 10 & \\
\hline & & Interface & 10 & \\
\hline & \multirow{4}{*}{$\begin{array}{l}\text { Apreensibilidade (ISO, Nielsen, } \\
\text { Vilella) }\end{array}$} & Navegação & 10 & \multirow{4}{*}{$\begin{array}{l}\text { 4. Há indicação de um } \\
\text { especialista para quem a sua } \\
\text { consulta é direcionada. }\end{array}$} \\
\hline & & Apreensão & 10 & \\
\hline & & Instruções de uso & 10 & \\
\hline & & Interface humana & 10 & \\
\hline & \multirow{8}{*}{$\begin{array}{l}\text { Operacionalidade (ISO, Chou et al., } \\
\text { Nielsen, Vilella) }\end{array}$} & Rolagem & 10 & \\
\hline & & Ajuste de leiaute & 0 & \\
\hline & & Agrupamento & 10 & \\
\hline & & Tarefas prioritárias & 10 & \\
\hline & & Clareza da URL & 10 & \\
\hline & & Disponibilidade & 10 & \\
\hline & & Outras mídias & 0 & \\
\hline & & Acessibilidade & 20 & \\
\hline \multirow{22}{*}{$\begin{array}{l}\mathrm{F} \\
\mathrm{U} \\
\mathrm{N} \\
\mathrm{C} \\
\mathrm{I} \\
\mathrm{O} \\
\mathrm{N} \\
\mathrm{A} \\
\mathrm{L} \\
\mathrm{I} \\
\mathrm{D} \\
\mathrm{A} \\
\mathrm{D} \\
\mathrm{E}\end{array}$} & \multirow{8}{*}{$\begin{array}{l}\text { Adequação (Vilella, ISO, Moretti } \\
\text { et al.) }\end{array}$} & Diálogo real & 10 & \multirow{8}{*}{ 8. Braille e "talking forms". } \\
\hline & & Cooperação & 10 & \\
\hline & & Criação de CoP & 0 & \\
\hline & & Ferramentas de CoP & 0 & \\
\hline & & Versão personal & 0 & \\
\hline & & Conhecimento & 10 & \\
\hline & & Notícias & 0 & \\
\hline & & Velocidade & 10 & \\
\hline & \multirow{6}{*}{ Acurácia (Vilella, ISO, Chou et al.) } & Templates & 10 & \\
\hline & & Bases de dados & 10 & \\
\hline & & Alerta personal & 0 & \\
\hline & & Interface uni & 10 & \\
\hline & & Eventos & 0 & \\
\hline & & Estatísticas & 10 & \\
\hline & \multirow{5}{*}{ Interoperabilidade (Vilella, ISO) } & Fontes múltiplas & 10 & \multirow{5}{*}{$\begin{array}{l}\text { 5. Por título do documento, por } \\
\text { expertise, por respostas } \\
\text { anteriores, por localidade. }\end{array}$} \\
\hline & & Transparência & 10 & \\
\hline & & Acesso a perfis & 0 & \\
\hline & & Busca - mecan & 3 & \\
\hline & & Resultado busca & 10 & \\
\hline & Conformidade (Vilella, ISO) & Política & 10 & \\
\hline & \multirow{2}{*}{$\begin{array}{l}\text { Segurança de acesso (Vilella, ISO, } \\
\text { Chou et al.) }\end{array}$} & Privacidade & 10 & \\
\hline & & Criptografia & 10 & \\
\hline
\end{tabular}

(Análise elaborada e revista no período de 01.09 a 30.10.2007). 


\section{http://www.sebrae.com.br}

"O Sebrae, Serviço Brasileiro de Apoio às Micro e Pequenas Empresas, trabalha desde 1972 pelo desenvolvimento sustentável das empresas de pequeno porte. Para isso, a entidade promove cursos de capacitação, facilita o acesso a serviços financeiros, estimula a cooperação entre as empresas, organiza feiras e rodadas de negócios e incentiva o desenvolvimento de atividades que contribuem para a geração de emprego e renda. São centenas de projetos gerenciados pelas Unidades de Negócios e de Gestão do Sebrae".

Há unidades SEBRAE nos Estados brasileiros e cada um possui um site específico, que também deve ser consultado. No final desta análise são acrescentados alguns dados disponíveis no site do Sebrae São Paulo.

\begin{tabular}{|c|c|c|c|c|}
\hline Dimensão & Característica & Atributo & Pontuação & Observações \\
\hline \multirow{17}{*}{$\begin{array}{l}\mathrm{C} \\
\mathrm{O} \\
\mathrm{N} \\
\mathrm{T} \\
\mathrm{E} \\
\mathrm{U} \\
\mathrm{D} \\
\mathrm{O}\end{array}$} & \multirow{4}{*}{ Propósito (Vilella) } & Visão geral & 10 & \\
\hline & & Escopo & 0 & \\
\hline & & Serviços & 10 & \\
\hline & & Complementação & 10 & \\
\hline & \multirow{4}{*}{$\begin{array}{l}\text { Abrangência / cobertura (Vilella - } \\
\text { junto com propósito) }\end{array}$} & Tipo de conteúdo & 12 & \multirow[b]{4}{*}{$\begin{array}{l}\text { 1. sites, textos, melhores } \\
\text { práticas, cursos on-line } \\
\text { (programas, referências), } \\
\text { manuais, artigos, estudos e } \\
\text { pesquisas, serviços, casos, } \\
\text { empresas, revista, informativo } \\
\text { 2.. negócios em geral, APLs, } \\
\text { redes de empresas, parcerias, } \\
\text { empreendedorismo, legislação, } \\
\text { comunidades de prática, } \\
\text { treinamentos, cursos pela } \\
\text { Internet etc.. Em comunidades } \\
\text { de prática diz o que é e está } \\
\text { disponível toda a documentação } \\
\text { sobre comunidades constituídas } \\
\text { (melhores práticas), textos de } \\
\text { interesse, casos de sucesso } \\
\text { (inclusive referências } \\
\text { internacionais, com links para } \\
\text { org. que apóiam iniciativas dessa } \\
\text { natureza). Os documentos } \\
\text { (muitos) podem ser localizados } \\
\text { através da "Biblioteca on-line". }\end{array}$} \\
\hline & & Tipo de assunto & 9 & \\
\hline & & Outros idiomas & 0 & \\
\hline & & Versões & 0 & \\
\hline & $\begin{array}{l}\text { Padrão de publicação de conteúdo } \\
\text { (Almeida e Bax, Breitman, Terra e } \\
\text { Gordon) }\end{array}$ & $\begin{array}{l}\text { Taxonomia/onto/ } \\
\text { classificação/nada }\end{array}$ & 3 & \\
\hline & \multirow{2}{*}{$\begin{array}{l}\text { Atualidade (Vilella, Chou et al. - } \\
\text { timeless) }\end{array}$} & Atualização & 0 & \multirow[b]{2}{*}{$\begin{array}{l}\text { Não indicação de "última data de } \\
\text { atualização" nas diferentes } \\
\text { páginas. Mas em "noticias" e } \\
\text { também quando da recuperação } \\
\text { de dados de busca, há indicação } \\
\text { de datas. }\end{array}$} \\
\hline & & Data - conteúdo sig & 10 & \\
\hline & \multirow{3}{*}{ Correção (Vilella) } & Precisão & 10 & \\
\hline & & Referência correta & 10 & \\
\hline & & Inconsistências & 10 & \\
\hline & \multirow{3}{*}{$\begin{array}{l}\text { Autoridade / copirraite (Vilella), } \\
\text { believability e reputation (Chou et }\end{array}$} & Copirraite & 0 & \\
\hline & & Menção a fontes & 10 & \\
\hline & & Responsabilidade & 0 & \\
\hline
\end{tabular}




\begin{tabular}{|c|c|c|c|c|}
\hline & al.) & Legitimidade & 10 & \\
\hline & & Conteúdo - inicial & 10 & \\
\hline & Objetividade (Vilella, Chou e al.) & Conteúdo adequado & 10 & \\
\hline & & Forma de escrita & 10 & \\
\hline & & Publicidade & 10 & \\
\hline & & Utilidade & 10 & \\
\hline & & Regras de publ & 0 & \\
\hline & Regras de publicação e acesso & Acesso livre & 30 & \\
\hline & (Moretti et al.) ou acessibilidade & Acesso condi & 10 & \\
\hline & & Acesso restrito & 10 & \\
\hline & Inteligibilidade (Chou et al., ISO, & Fontes e atributos & 10 & \\
\hline $\mathrm{U}$ & Nielsen, Vilella) - easy to & Links claros & 10 & \\
\hline $\mathrm{S}$ & understand, interpretability & Interface & 0 & \\
\hline A & & Navegação & 10 & 4. Existe o auto atendimento (e- \\
\hline B & Apreensibilidade (ISO, Nielsen, & Apreensão & 10 & duardo) e dentro dele, a \\
\hline I & Vilella) & Instruções de uso & 10 & Consultoria on-line, que é um \\
\hline $\begin{array}{l}\text { L } \\
\text { I } \\
\text { D }\end{array}$ & & Interface humana & 0 & $\begin{array}{l}\text { chat onde você e mais quatro } \\
\text { participantes debatem um } \\
\text { assunto. Muito interessante. }\end{array}$ \\
\hline A & & Rolagem & 10 & \\
\hline D & & Ajuste de leiaute & 0 & \\
\hline $\mathrm{E}$ & Operacionalidade (ISO, Chou et al., & Agrupamento & 10 & \\
\hline & Nielsen, Vilella) & Tarefas prioritárias & 10 & \\
\hline & & Clareza da URL & 10 & \\
\hline & & Disponibilidade & 10 & \\
\hline & & Outras mídias & 0 & \\
\hline & & Acessibilidade & 0 & \\
\hline & & Diálogo real & 10 & \\
\hline & & Cooperação & 10 & 3. Oferece apoio forte para \\
\hline & Adequação (Vilella, ISO, Moretti & Criação de CoP & 30 & diferentes modalidades de \\
\hline & et al.) & Ferramentas de CoP & 0 & cooperação, mas não menciona \\
\hline & & Versão personal & 0 & \\
\hline F & & Conhecimento & 10 & \\
\hline $\mathrm{U}$ & & Notícias & 10 & \\
\hline $\begin{array}{l}\mathrm{N} \\
\mathrm{C}\end{array}$ & & Velocidade & 10 & \\
\hline I & & Templates & 0 & 2. ok. Na Biblioteca on-line. \\
\hline $\mathrm{O}$ & Acurácia (Vilella, ISO, Chou et al.) & Bases de dados & 10 & \\
\hline $\mathrm{N}$ & & Alerta personal & 0 & \\
\hline A & & Interface uni & 10 & \\
\hline $\mathrm{L}$ & & Eventos & 0 & \\
\hline I & & Estatísticas & 0 & \\
\hline $\mathrm{D}$ & & Fontes múltiplas & 10 & \\
\hline A & Interoperabilidade (Vilella, ISO) & Transparência & 10 & 5. Por áreas temáticas, por \\
\hline D & & Acesso a perfis & 0 & palavras-chave e por data \\
\hline E & & Busca - mecan & 3 & (recenticidade) \\
\hline & & Resultado busca & 10 & \\
\hline & Conformidade (Vilella, ISO) & Política & 10 & \\
\hline & Segurança de acesso (Vilella, ISO, & Privacidade & 0 & \\
\hline & Chou et al.) & Criptografia & 0 & \\
\hline
\end{tabular}

SEBRAE SP disponível em http://www.sebraesp.com.br, onde é possível identificar dados não disponíveis no site do SEBRAE Nacional, como: Política de privacidade; Ouvidoria; Enquete; Programa negócios \& soluções, em parceria com a TV Cultura.

(Análise elaborada e revista no período de 01.09 a 30.10.2007). 


\section{http://www.sitedoempreendedor.com.br}

Surgiu através da "Empresa Cria", desenvolvida no Programa Empretec, um "Workshops" da Organização das Nações Unidas - ONU, que tem como parceiro no Brasil a Agencia Brasileira de Cooperação do Ministério da Relações Exteriores e como executor o Serviço Brasileiro de Apoio as Micros e Pequenas Empresas - Sebrae.

Tem como propósito estimular, incentivar e motivar os "visitantes a tornarem-se vencedores ou aguçarem suas qualidades empreendedoras. Acima de tudo incitando todos a sonharem, a buscarem melhoria de vida, a darem passos para realizarem seus sonhos e fazerem com que suas visões de futuro se transformem em realidade". Isso é feito através da disponibilização de informações que podem levar ao crescimento empreendedor, ao desenvolvimento profissional ou pessoal.

Obs.: Parece pouco confiável.

\begin{tabular}{|c|c|c|c|c|}
\hline Dimensão & Característica & Atributo & Pontuação & Observações \\
\hline \multirow{27}{*}{$\begin{array}{l}\mathrm{C} \\
\mathrm{O} \\
\mathrm{N} \\
\mathrm{T} \\
\mathrm{E} \\
\mathrm{U}^{\prime} \\
\mathrm{D} \\
\mathrm{O}\end{array}$} & \multirow{4}{*}{ Propósito (Vilella) } & Visão geral & 10 & \multirow[t]{4}{*}{ 4. Poucos. } \\
\hline & & Escopo & 10 & \\
\hline & & Serviços & 10 & \\
\hline & & Complementação & 10 & \\
\hline & \multirow{4}{*}{$\begin{array}{l}\text { Abrangência / cobertura (Vilella - } \\
\text { junto com propósito) }\end{array}$} & Tipo de conteúdo & 0 & \multirow{4}{*}{$\begin{array}{l}\text { 1. reflexões, entrevistas, artigos, } \\
\text { histórias de sucesso, dicas, } \\
\text { curiosidades, sites, lições de } \\
\text { vida, newsletter } \\
\text { 2. empreendedorismo e negócios } \\
\text { em geral }\end{array}$} \\
\hline & & Tipo de assunto & 9 & \\
\hline & & Outros idiomas & 0 & \\
\hline & & Versões & 0 & \\
\hline & $\begin{array}{l}\text { Padrão de publicação de conteúdo } \\
\text { (Almeida e Bax, Breitman, Terra e } \\
\text { Gordon) }\end{array}$ & $\begin{array}{l}\text { Taxonomia/onto/ } \\
\text { classificação/nada }\end{array}$ & 3 & \\
\hline & \multirow{2}{*}{$\begin{array}{l}\text { Atualidade (Vilella, Chou et al. - } \\
\text { timeless) }\end{array}$} & Atualização & 10 & \\
\hline & & Data - conteúdo sig & 0 & \\
\hline & \multirow{3}{*}{ Correção (Vilella) } & Precisão & 10 & \multirow{3}{*}{$\begin{array}{l}\text { 3. Há erros de digitação, grafia e } \\
\text { gramática. }\end{array}$} \\
\hline & & Referência correta & 10 & \\
\hline & & Inconsistências & 0 & \\
\hline & \multirow{4}{*}{$\begin{array}{l}\text { Autoridade / copirraite (Vilella), } \\
\text { believability e reputation (Chou et } \\
\text { al.) }\end{array}$} & Copirraite & 0 & \\
\hline & & Menção a fontes & 0 & \\
\hline & & Responsabilidade & 0 & \\
\hline & & Legitimidade & 0 & \\
\hline & \multirow{5}{*}{ Objetividade (Vilella, Chou e al.) } & Conteúdo - inicial & 10 & \multirow{5}{*}{$\begin{array}{l}\text { 2. Superficial, estilo auto-ajuda, } \\
\text { "marketeiro". }\end{array}$} \\
\hline & & Conteúdo adequado & 0 & \\
\hline & & Forma de escrita & 0 & \\
\hline & & Publicidade & 0 & \\
\hline & & Utilidade & 0 & \\
\hline & \multirow{4}{*}{$\begin{array}{l}\text { Regras de publicação e acesso } \\
\text { (Moretti et al.) ou acessibilidade } \\
\text { (Coelho, 2007) }\end{array}$} & Regras de publ & 0 & \\
\hline & & Acesso livre & 30 & \\
\hline & & Acesso condi & 10 & \\
\hline & & Acesso restrito & 10 & \\
\hline \multirow{6}{*}{$\begin{array}{l}\text { U } \\
\text { S } \\
\text { A } \\
\text { B } \\
\text { I }\end{array}$} & \multirow{3}{*}{$\begin{array}{l}\text { Inteligibilidade (Chou et al., ISO, } \\
\text { Nielsen, Vilella) - easy to } \\
\text { understand, interpretability }\end{array}$} & Fontes e atributos & 10 & \\
\hline & & Links claros & 10 & \\
\hline & & Interface & 10 & \\
\hline & \multirow{3}{*}{$\begin{array}{l}\text { Apreensibilidade (ISO, Nielsen, } \\
\text { Vilella) }\end{array}$} & Navegação & 0 & \\
\hline & & Apreensão & 0 & \\
\hline & & Instruções de uso & 0 & \\
\hline
\end{tabular}




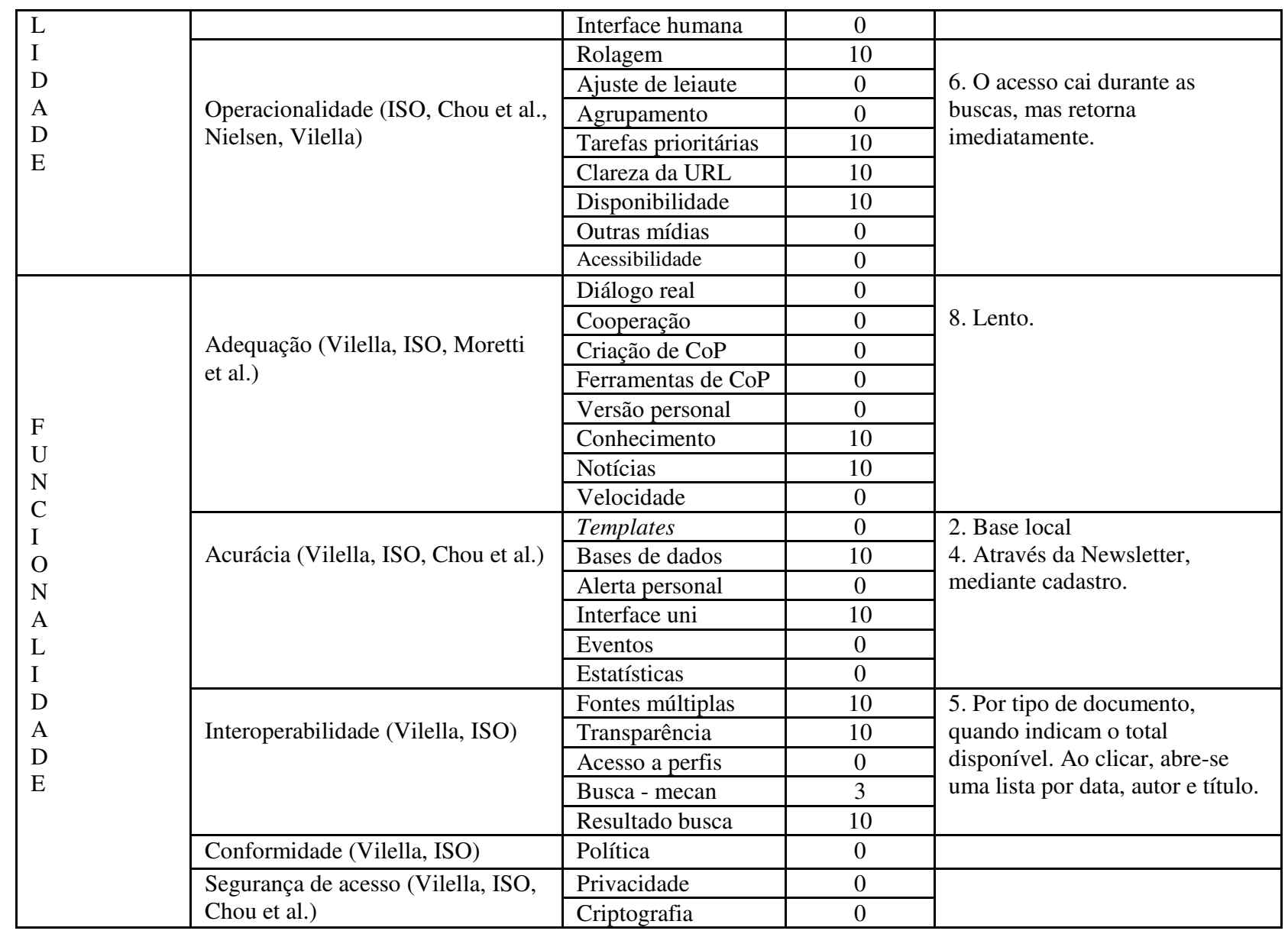

(Análise elaborada e revista no período de 01.09 a 30.10.2007). 


\section{http://www.scienti.net/}

ScienTI é uma rede pública de fontes de informação e conhecimento, com o objetivo de contribuir à gestão da atividade científica, tecnológica e de inovação. Promove um espaço público e cooperativo de interação sobre ciência, tecnologia e inovação entre os paises membros. Disponibiliza currículos, grupos de pesquisa, instituições e projetos, padronizados com referenciais internacionais para assegurar a interoperabilidade na Internet. Também se propõe a identificar recursos humanos qualificados, instituições e projetos de pesquisa para o desenvolvimento e avaliação de políticas e capacidades nacionais em CT\&I, assim como promover programas de cooperação internacional. Possui uma comunidade de prática para compartilhar e gerar informação entre os membros da rede.

\begin{tabular}{|c|c|c|c|c|}
\hline Dimensão & Característica & Atributo & Pontuação & Observações \\
\hline \multirow{27}{*}{$\begin{array}{l}\mathrm{C} \\
\mathrm{O} \\
\mathrm{N} \\
\mathrm{T} \\
\mathrm{E} \\
\dot{U} \\
\mathrm{D} \\
\mathrm{O}\end{array}$} & \multirow{4}{*}{ Propósito (Vilella) } & Visão geral & 10 & \\
\hline & & Escopo & 10 & \\
\hline & & Serviços & 10 & \\
\hline & & Complementação & 10 & \\
\hline & \multirow{4}{*}{$\begin{array}{l}\text { Abrangência / cobertura (Vilella - } \\
\text { junto com propósito) }\end{array}$} & Tipo de conteúdo & 0 & \multirow{4}{*}{$\begin{array}{l}\text { 1.cvs. diretórios de pesquisa, } \\
\text { artigos científicos e de } \\
\text { digulgação } \\
\text { 2. Ciência, tecnologia e inovação } \\
\text { para todas as áreas do } \\
\text { conhecimento }\end{array}$} \\
\hline & & Tipo de assunto & 0 & \\
\hline & & Outros idiomas & 10 & \\
\hline & & Versões & 0 & \\
\hline & $\begin{array}{l}\text { Padrão de publicação de conteúdo } \\
\text { (Almeida e Bax, Breitman, Terra e } \\
\text { Gordon) }\end{array}$ & $\begin{array}{l}\text { Taxonomia/onto/ } \\
\text { classificação/nada }\end{array}$ & 0 & \\
\hline & \multirow{2}{*}{$\begin{array}{l}\text { Atualidade (Vilella, Chou et al. - } \\
\text { timeless) }\end{array}$} & Atualização & 0 & \multirow{2}{*}{$\begin{array}{l}\text { Não há data de atualização. A } \\
\text { última notícia é de jul/06, exceto } \\
\text { na CoP, onde está atualizada. Os } \\
\text { cvs e os artigos tb estão } \\
\text { atualizados. }\end{array}$} \\
\hline & & Data - conteúdo sig & 10 & \\
\hline & \multirow{3}{*}{ Correção (Vilella) } & Precisão & 10 & \\
\hline & & Referência correta & 10 & \\
\hline & & Inconsistências & 10 & \\
\hline & \multirow{4}{*}{$\begin{array}{l}\text { Autoridade / copirraite (Vilella), } \\
\text { believability e reputation (Chou et } \\
\text { al.) }\end{array}$} & Copirraite & 0 & \\
\hline & & Menção a fontes & 10 & \\
\hline & & Responsabilidade & 10 & \\
\hline & & Legitimidade & 10 & \\
\hline & \multirow{5}{*}{ Objetividade (Vilella, Chou e al.) } & Conteúdo - inicial & 10 & \\
\hline & & Conteúdo adequado & 10 & \\
\hline & & Forma de escrita & 10 & \\
\hline & & Publicidade & 10 & \\
\hline & & Utilidade & 10 & \\
\hline & \multirow{4}{*}{$\begin{array}{l}\text { Regras de publicação e acesso } \\
\text { (Moretti et al.) ou acessibilidade } \\
\text { (Coelho, 2007) }\end{array}$} & Regras de publ & 0 & \\
\hline & & Acesso livre & 10 & \\
\hline & & Acesso condi & 10 & \\
\hline & & Acesso restrito & 10 & \\
\hline \multirow{6}{*}{$\begin{array}{l}\text { U } \\
\text { S } \\
\text { A } \\
\text { B } \\
\text { I }\end{array}$} & \multirow{3}{*}{$\begin{array}{l}\text { Inteligibilidade (Chou et al., ISO, } \\
\text { Nielsen, Vilella) - easy to } \\
\text { understand, interpretability }\end{array}$} & Fontes e atributos & 10 & \\
\hline & & Links claros & 0 & \\
\hline & & Interface & 0 & \\
\hline & \multirow{3}{*}{$\begin{array}{l}\text { Apreensibilidade (ISO, Nielsen, } \\
\text { Vilella) }\end{array}$} & Navegação & 0 & \\
\hline & & Apreensão & 0 & \\
\hline & & Instruções de uso & 0 & \\
\hline
\end{tabular}




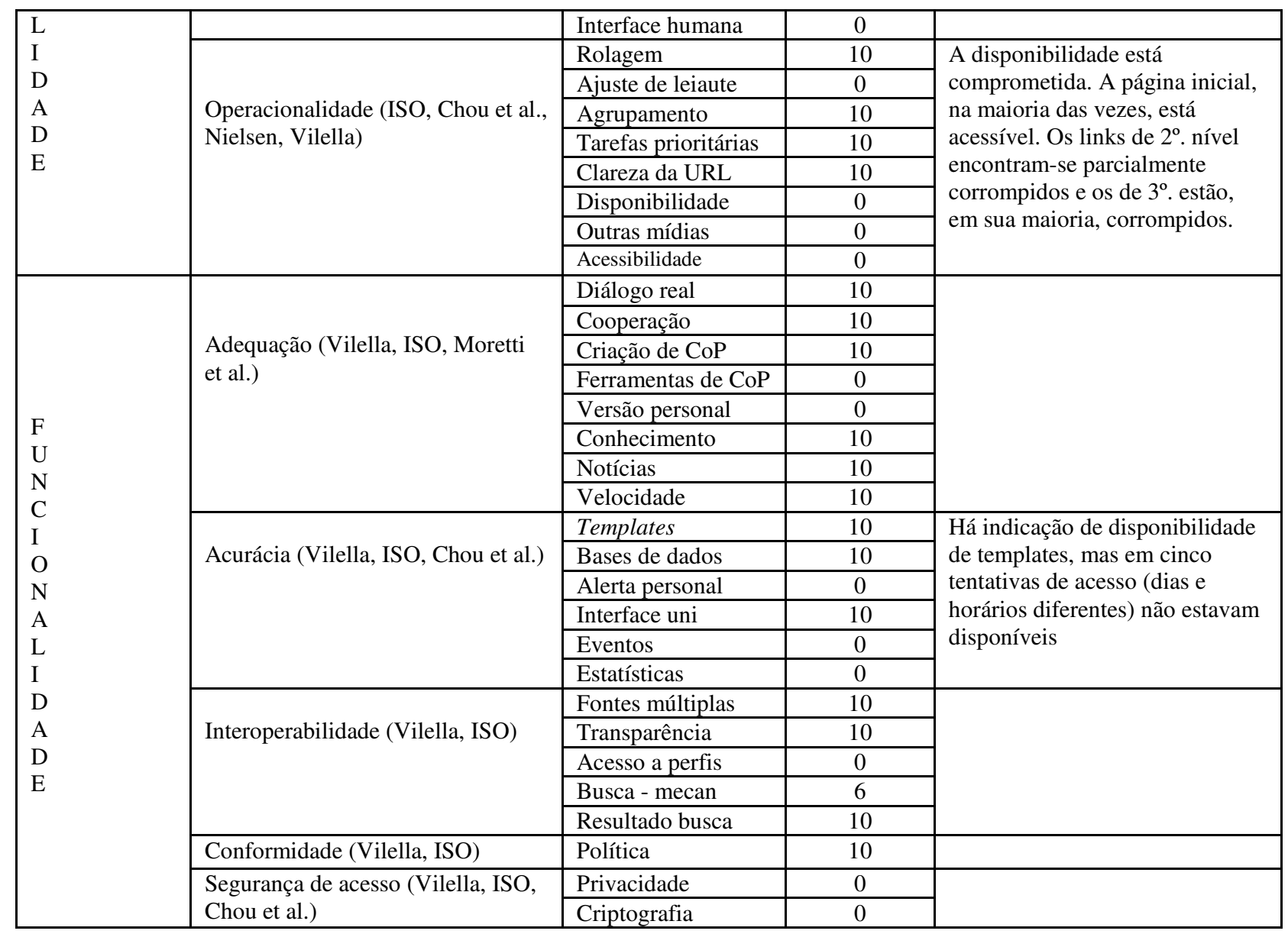

(Análise elaborada e revista no período de 01.09 a 30.10.2007). 


\section{http://www.unversia.com.br/mit}

Portal do MIT para iniciativa de apoio à sua missão fundamental, que é promover o conhecimento e a educação para melhor servir à nação e ao mundo. Oferece acesso gratuito a cursos on-line, preparados pelo MIT e traduzidos para o português. (Obs.: Página brasileira do http://ocw.mit.edu)

\begin{tabular}{|c|c|c|c|c|}
\hline Dimensão & Característica & Atributo & Pontuação & Observações \\
\hline \multirow{28}{*}{$\begin{array}{l}\mathrm{C} \\
\mathrm{O} \\
\mathrm{N} \\
\mathrm{T} \\
\mathrm{E} \\
\mathbf{U}^{\mathrm{U}} \\
\mathrm{D} \\
\mathrm{O}\end{array}$} & \multirow{4}{*}{ Propósito (Vilella) } & Visão geral & 10 & \multirow{4}{*}{$\begin{array}{l}\text { 4. Fantástico. Até os softwares } \\
\text { necessários para uso nos cursos } \\
\text { estão disponíveis gratuitamente. } \\
\text { Ex.: Mathematica. }\end{array}$} \\
\hline & & Escopo & 10 & \\
\hline & & Serviços & 10 & \\
\hline & & Complementação & 10 & \\
\hline & \multirow{4}{*}{$\begin{array}{l}\text { Abrangência / cobertura (Vilella - } \\
\text { junto com propósito) }\end{array}$} & Tipo de conteúdo & 12 & \multirow[b]{4}{*}{$\begin{array}{l}\text { 1. Os cursos disponibilizam } \\
\text { softwares, amostras de planos de } \\
\text { negócio, normas para projetos, } \\
\text { exemplos de projetos, } \\
\text { bibliografia, notas de aula, } \\
\text { tutoriais, casos, modelo de carta } \\
\text { de intenção e outros recursos } \\
\text { relacionados. } \\
\text { 2. Todas as áreas do } \\
\text { conhecimento. Ver obs.1, no } \\
\text { final do formulário. } \\
\text { 3. Nesse caso trata-se da versão } \\
\text { para a língua portuguesa do } \\
\text { original em inglês. } \\
\text { 4. O propósito do OWC é } \\
\text { publicar materiais de cursos do } \\
\text { MIT na Web, e não proporcionar } \\
\text { uma experiência interativa com o } \\
\text { corpo docente. }\end{array}$} \\
\hline & & Tipo de assunto & 0 & \\
\hline & & Outros idiomas & 0 & \\
\hline & & Versões & 0 & \\
\hline & $\begin{array}{l}\text { Padrão de publicação de conteúdo } \\
\text { (Almeida e Bax, Breitman, Terra e } \\
\text { Gordon) }\end{array}$ & $\begin{array}{l}\text { Taxonomia/onto/ } \\
\text { classificação/nada }\end{array}$ & 3 & \\
\hline & \multirow{2}{*}{$\begin{array}{l}\text { Atualidade (Vilella, Chou et al. - } \\
\text { timeless) }\end{array}$} & Atualização & 10 & \multirow[b]{2}{*}{$\begin{array}{l}\text { 1. Existem cursos produzidos a } \\
\text { partir de } 2000 \text {, antes mesmo do } \\
\text { projeto piloto de disposição on- } \\
\text { line gratuita, de } 2000 \text { e } \\
\text { oficialmente lançado em } 2002\end{array}$} \\
\hline & & Data - conteúdo sig & 10 & \\
\hline & \multirow{3}{*}{ Correção (Vilella) } & Precisão & 10 & \\
\hline & & Referência correta & 10 & \\
\hline & & Inconsistências & 10 & \\
\hline & \multirow{4}{*}{$\begin{array}{l}\text { Autoridade / copirraite (Vilella), } \\
\text { believability e reputation (Chou et } \\
\text { al.) }\end{array}$} & Copirraite & 10 & \multirow{4}{*}{$\begin{array}{l}\text { 1. Utiliza licença Creative } \\
\text { Commons } \\
\text { 4. Indica o endereço do MIT }\end{array}$} \\
\hline & & Menção a fontes & 10 & \\
\hline & & Responsabilidade & 10 & \\
\hline & & Legitimidade & 10 & \\
\hline & \multirow{5}{*}{ Objetividade (Vilella, Chou e al.) } & Conteúdo - inicial & 10 & \\
\hline & & Conteúdo adequado & 10 & \\
\hline & & Forma de escrita & 10 & \\
\hline & & Publicidade & 10 & \\
\hline & & Utilidade & 10 & \\
\hline & \multirow{4}{*}{$\begin{array}{l}\text { Regras de publicação e acesso } \\
\text { (Moretti et al.) ou acessibilidade } \\
\text { (Coelho, 2007) }\end{array}$} & Regras de publ & 10 & \\
\hline & & Acesso livre & 30 & \\
\hline & & Acesso condi & 10 & \\
\hline & & Acesso restrito & 10 & \\
\hline & \multirow{2}{*}{$\begin{array}{l}\text { Inteligibilidade (Chou et al., ISO, } \\
\text { Nielsen, Vilella) - easy to }\end{array}$} & Fontes e atributos & 10 & \\
\hline $\mathrm{U}$ & & Links claros & 10 & \\
\hline
\end{tabular}




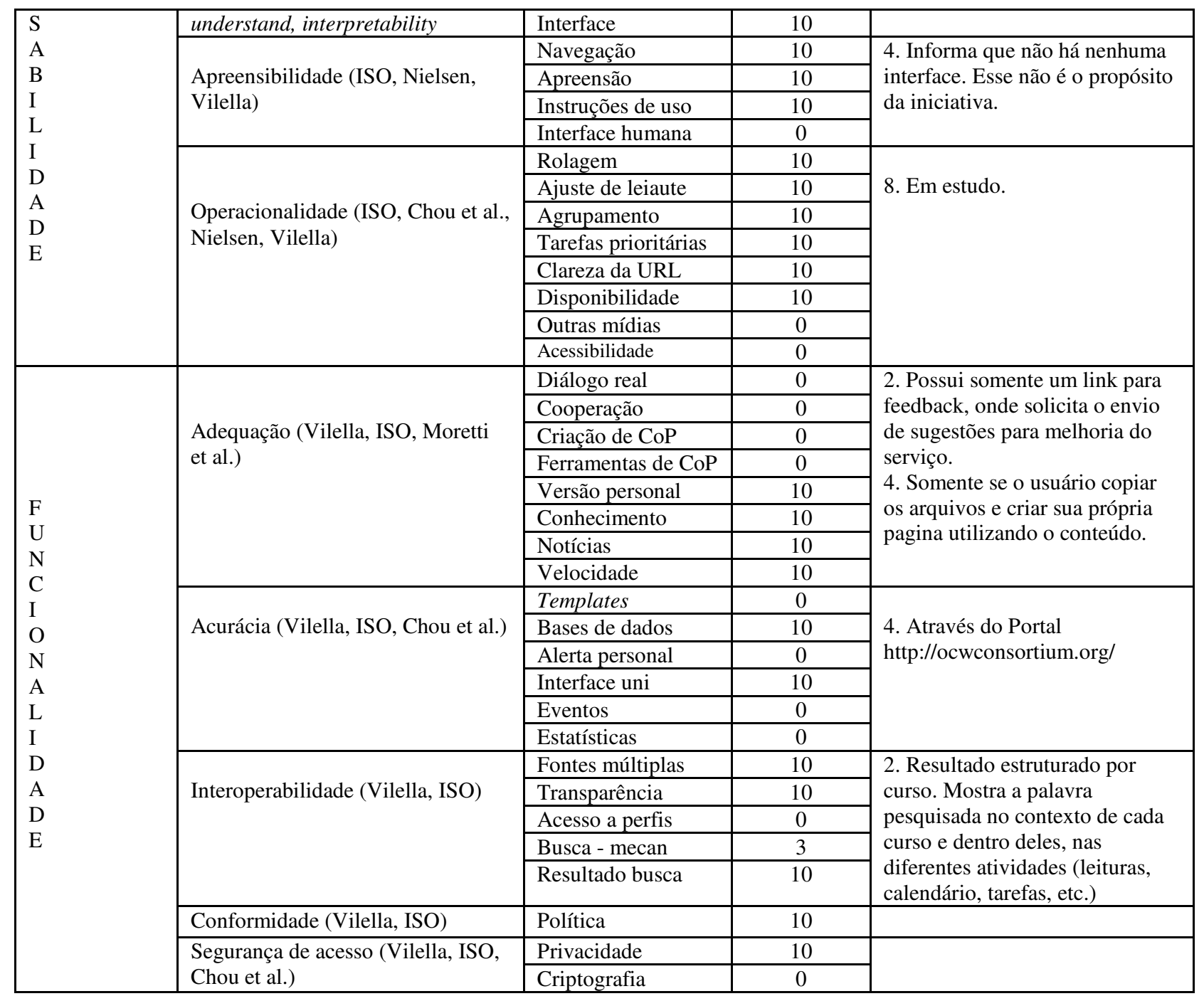

Obs. 1: Abrangência:

2. todas as áreas do conhecimento - Interesse para este estudo:

- Curso 1: Gerenciamento em Engenharia - Princípios financeiros, gerenciamento de inovação, planejamento e controle de projeto de engenharia, fatores humanos, planejamento de carreira, patentes e estratégia técnica

- Curso 2: Introdução à otimização - Modelos de otimização com aplicações de transporte, logística, fabricação, ciência da computação, E-business, gerência de projeto, finanças e etc. Traz, inclusive, link para recursos relacionados.

- Curso 3: Criação e Desenvolvimento de Produto - Ferramentas e métodos modernos para criar e desenvolver produtos, com elaboração de um projeto em grupo, onde criam e fazem um protótipo físico de um produto. Inclui identificação das necessidades dos consumidores, geração de idéia, arquitetura de produto, desenho industrial e projeto para fabricação. 
Curso 4: Projeto de Equipe - Busca desenvolver trabalhos em equipe e habilidades de liderança; e aprender com a análise de uma iniciativa de mudança em uma empresa verdadeira, usando os conceitos de outros cursos.

Curso 5: Mercados Internacionais, Política Interna e a Vantagem Competitiva Empresarial - Examina as oportunidades e os riscos que as empresas enfrentam no mundo global.

(Análise elaborada e revista no período de 01.09 a 30.10.2007). 